\title{
THE EFFECT OF STORMWATER DISCHARGE ON THE NEARSHORE BENTHIC ENVIRONMENT OF INNER WELLINGTON HARBOUR
}

by

Lesley Anne Bolton-Ritchie

\author{
A thesis \\ submitted to the Victoria University of Wellington \\ in fulfilment of the \\ requirements for the degree of \\ Doctor of Philosophy \\ in Marine Biology
}

Victoria University of Wellington

2003 


\begin{abstract}
To investigate the spatial and temporal effects of stormwater discharge on the nearshore benthic environment of inner Wellington Harbour, sediment grain size, organic matter content, concentrations of $\mathrm{As}, \mathrm{Cr}, \mathrm{Cu}, \mathrm{Ni}, \mathrm{Pb}$ and $\mathrm{Zn}$ and the presence and abundance of the benthic macrobiota were measured at a number of stations at both stormwater outlets and at control sites. Correlations between the biological and the sedimentological and chemical variables were also investigated.

In the vicinity of some outlets the sediment grain size distribution was altered and the sediment organic matter content was up to 5.5 times higher and metal concentrations were up to 11 times higher, than that at control sites. In general organic matter content and metal concentrations were highest close to an outlet and decreased with increasing distance seaward. With increasing distance from outlets the biological communities changed and there were significant differences in one or more of total, polychaete, arthropod and mollusc taxa, polychaete and mollusc individuals, diversity and the abundance of 12 taxa. The spatial extent of the impact of stormwater discharge on the benthic environment ranged from 10 to more than 45 metres from an outlet.
\end{abstract}

Over time the largest range in organic matter content at an outlet was $6.1-42.8 \%$ while at a control it was $4-9 \%$. For $\mathrm{As}, \mathrm{Cu}, \mathrm{Pb}$ and $\mathrm{Zn}$ the range in concentration over time was larger at stations closer to than those further from the outlet and larger at outlet than control site stations e.g. at $2 \mathrm{~m}$ in front of one outlet the $\mathrm{Pb}$ concentration range was $251-1367 \mathrm{ppm}$, at $20 \mathrm{~m}$ from the outlet it was $15-22 \mathrm{ppm}$ and at the associated control site $2 \mathrm{~m}$ station it was $15-20 \mathrm{ppm}$. Over time the direction of change in the biological community was different, and there were significant differences in the number of total, mollusc, polychaete and arthropod taxa and individuals and diversity, between that at the outlet and the associated control site. 27 taxa were more abundant at outlet than control sites and 45 taxa were more abundant at control than outlet sites over time. 
The biological community at outlet and control sites was best correlated to combinations of 2-5 of the sedimentological/chemical variables. Of these variables, organic matter content was the only commonly occurring variable at outlet sites and did not occur as one of the variables at the control sites. Where the organic matter content was $>22 \%$ there were a low number of taxa and individuals, and with an increase in organic matter content there was a significant decrease in the number of total and arthropod taxa. The abundance of two taxa was significantly correlated to organic matter content and the abundance of six taxa was significantly correlated to metal concentrations. 


\section{ACKNOWLEDGEMENTS}

This study came into being as a result of the Wellington City Stormdrain Outlet Survey Proposal, by Dr. J. Goff and Dr. J. Gardner being accepted and consequently funded by the Wellington City Council. This financial support as well as support in the form of the supply of relevant information and maps and discussion from notably Maria Archer and Sean Mallon, but also other council staff, is much appreciated.

I thank Dr J. Gardner and Dr. J. Goff for their offer of this study. Dr Jonathan Gardner, Dr. James Goff and Dr. Catherine Chagué-Goff supervised this study and have provided constructive advice and criticism, valued discussion, ideas, encouragement, references, tolerance and understanding. Through the duration of this study Catherine has provided much appreciated personal support in the form of e-mails, phone calls, cards and home made bread.

Joanne Long provided continued and invaluable assistance with all the practical work. This included help with the collection and processing of samples in the field and the laboratory processing of sediment and metal samples as well as data input. Thanks to the cheery, tolerant and ever willing Robert Williamson for running the boat the Raukawa Challenger and for assisting with the collection and sieving of samples. Graham Weakley skippered the Raukawa Challenger in Roberts' absence. Assistance with the field collection and processing of samples was also provided by Richard Moore, Paul McCarten, Sylvia Hill, Sue Keall, Dr. Jonathan Gardner and Kathryn Botherway. Special mention and thanks go to those who undertook the fieldwork shortly after the death of my husband Andy.

The following taxonomic specialists have provided assistance in the identification of the macrobenthos: Dr C. Glasby (Polychaetes), Dr G. Fenwick (Amphipoda), Dr. B. Marshall (Mollusca), Mr. S .Eagar (Ostracoda) and Dr. N. Bruce (Isopoda).

Thanks go to Dr John Patterson for the running of all the XRF analyses.

I am indebted to Dr. Elaine Wright (Department of Conservation) and Dr. P. Nilsson for their assistance with the most trying aspect of this study, the statistical analyses of the mountain of data. Statistical advice was also provided by Dr. J. Hewitt (NIWA) and Dr. R. Cole (NIWA). 
Thanks to my fellow students at the Island Bay Marine Laboratory for their continued support and encouragement. In particular thanks go to Kathryn Botherway and Kerstin Kröger for their helpful advice, information, sharing of ideas and references, support and friendship.

Special thanks to Gaye Robertson, Ally and Phil Gibbons, Sylvia Hill, Chris Currie, Ron Tester, Margaret Wise and the Rarangi community and my sister Jill and my mother and father who have been there for me and for all there support through all the emotional trauma and stress of, in particular, the last three years.

This thesis is dedicated to my late husband, Andy Ritchie. Andy's enthusiasm and encouragement at the start of this study helped make it all happen. In addition, Andy provided assistance with the diving and field work, valued practical ideas and discussion and continued love, support and tolerance through the highs and lows of the work. He is missed every hour of every day and it causes me great sadness that he did not get to see the completion of this thesis.

O Captain! My Captain! Our fearful trip is done,

The ship has weather'd every rack, the prize we sought is won,

The port is near, the bells I hear, the people all exulting,

While follow eyes the steady keel, the vessel grim and daring;

But O heart! Heart! Heart!

$O$ the bleeding drops of red,

Where on the deck my Captain lies,

Fallen cold and dead.

(Walt Whitman) 


\section{TABLE OF CONTENTS}

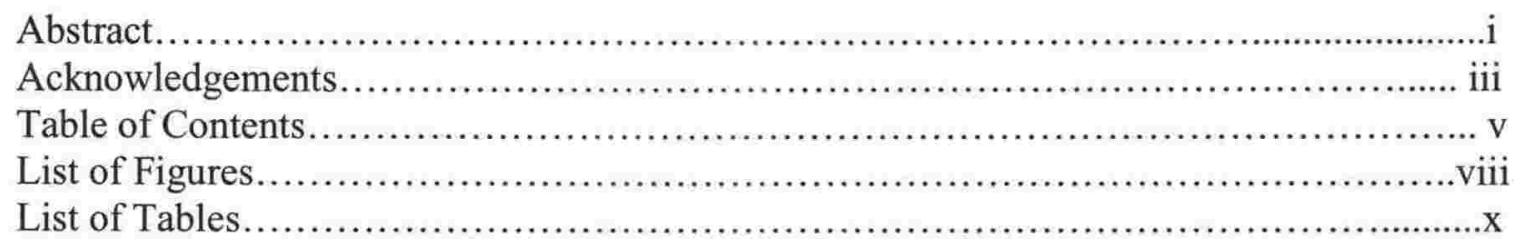

\section{Introduction}

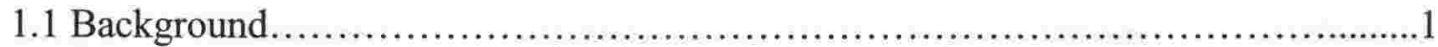

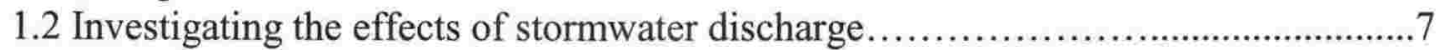

1.2.1 Considerations for the design of this study...................................... 8

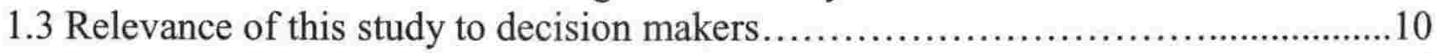

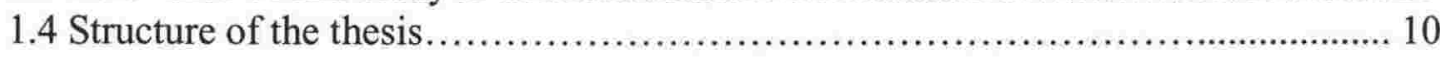

\section{Study sites and sampling methods}

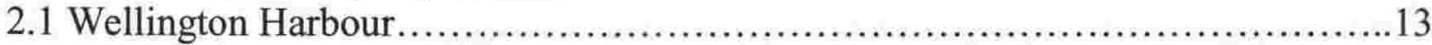

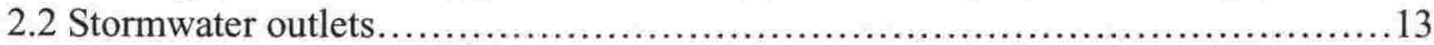

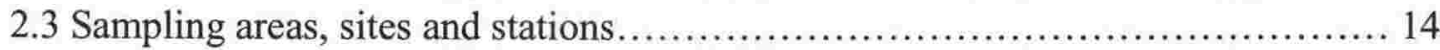

2.3.1 Background information on each sampling area...........................14

2.3.2 Sampling sites............................................................. 16

2.3.3 Location of the sampling stations at each site.............................18

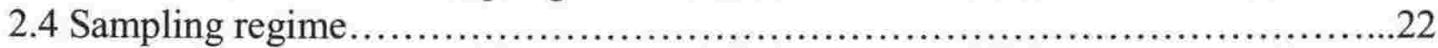

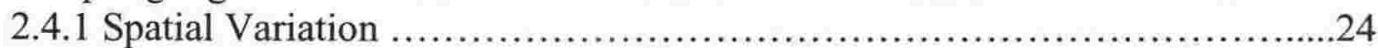

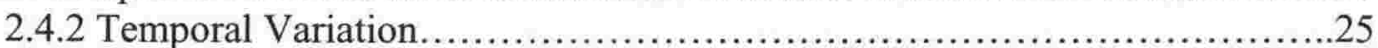

2.5 Methods used for the collection of the samples ..............................26

3. The effect of stormwater discharge on the sediment characteristics of inner Wellington Harbour

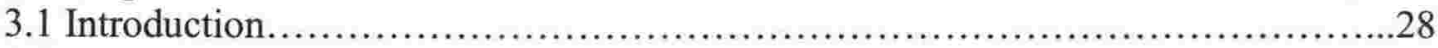

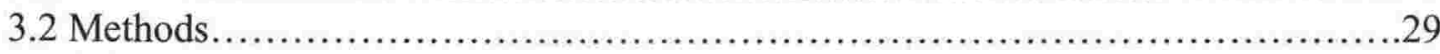

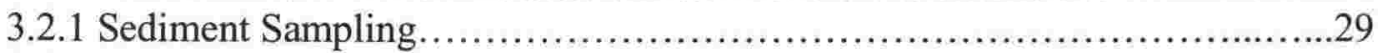

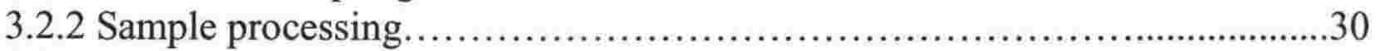

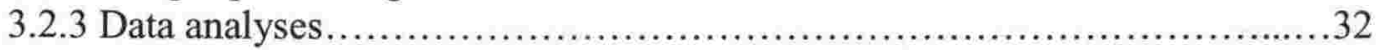

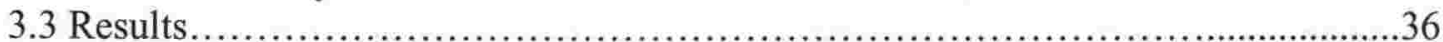

3.3.1 Organic Matter Content.................................................. 36

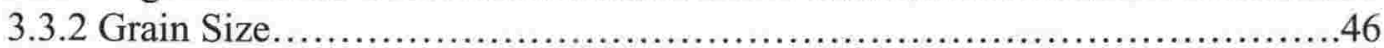

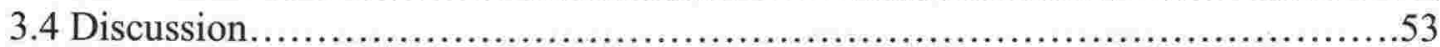

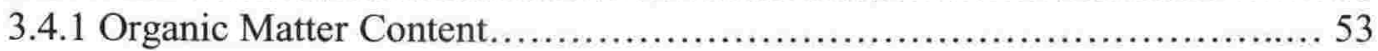

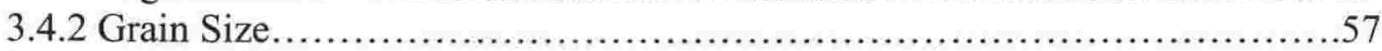

3.4.3 Seaward limit of impact of stormwater discharge on

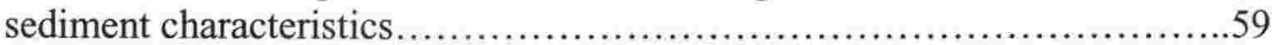

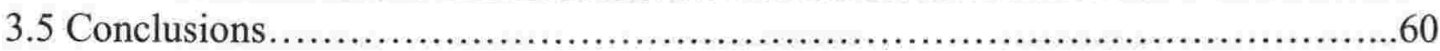


4. The effect of stormwater discharge on sediment metal concentrations

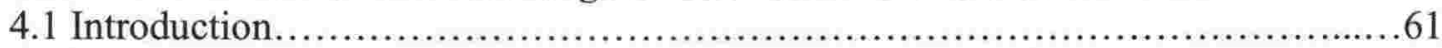

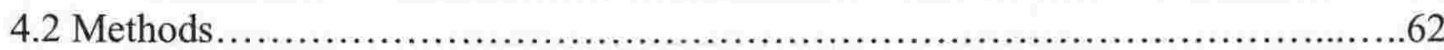

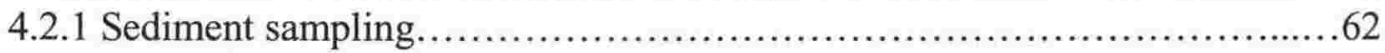

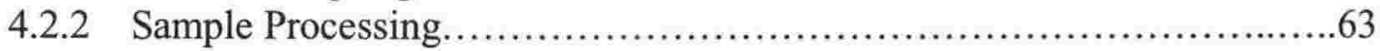

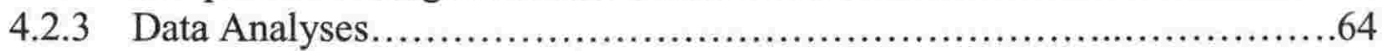

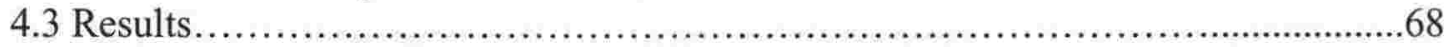

4.3.1 Assessment of anthropogenic input of metals.............................68

4.3.2 Spatial Variability of metal concentrations.............................. 70

4.3.3 Ranking of the outlets for metal enrichment..............................80

4.3.4 Temporal Variability of metal concentrations..............................82

4.3.5 Environmental Relationships............................................ 91

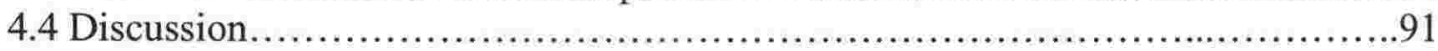

4.4.1 Metal concentration at control sites................................... 92

4.4.2 Spatial variability in metal concentrations..................................994

4.4.3 Temporal variability in metal concentrations..............................99

4.5 Conclusions ..................................................................

\section{Spatial Distribution of the benthic macrobiota}

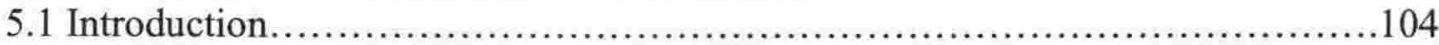

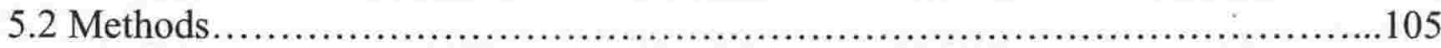

5.2.1 Sample Collection..............................................................

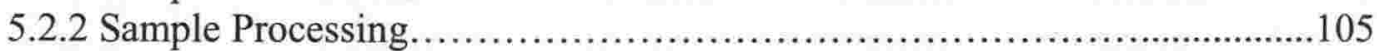

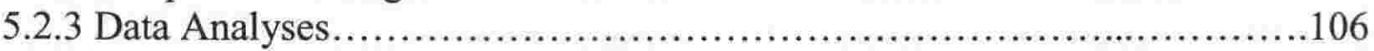

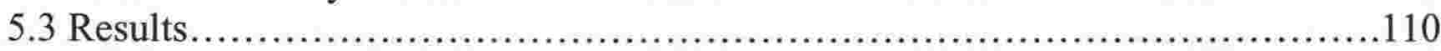

5.3.1 The biological community .............................................. 110

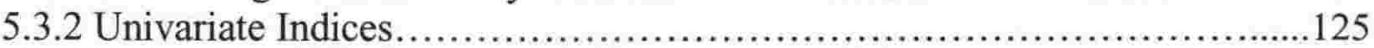

5.3.3 Patterns of Taxon Abundance............................................137

5.3.4 Summary of the macrobiota at each outlet.................................149

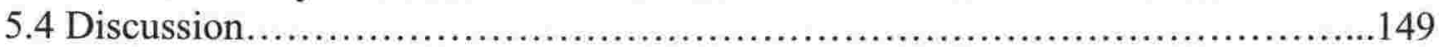

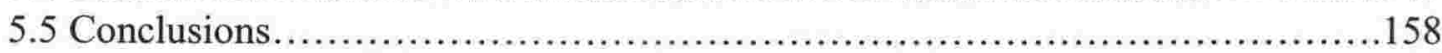

6. Temporal variability of the benthic macrobiota

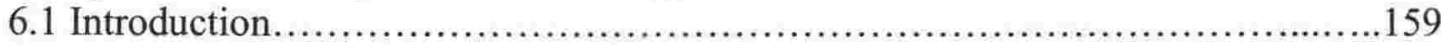

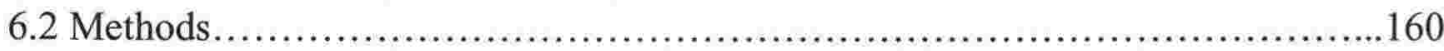

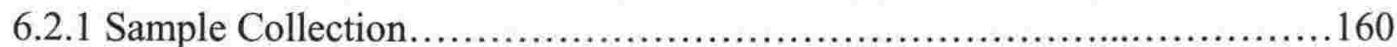

6.2.2 Sample Processing....................................................... 160

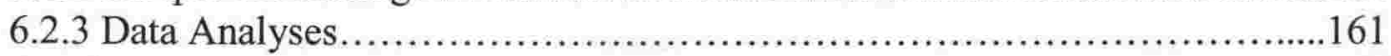

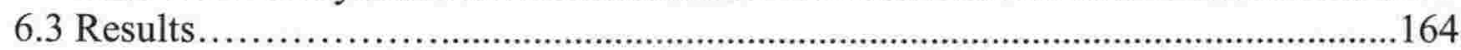

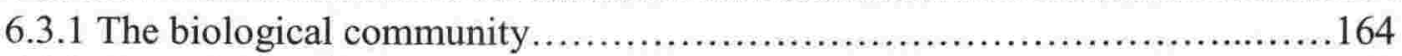

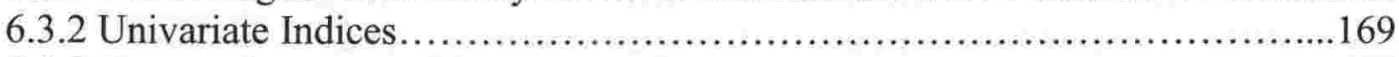

6.3.3 Temporal patterns of Taxon abundance................................... 178

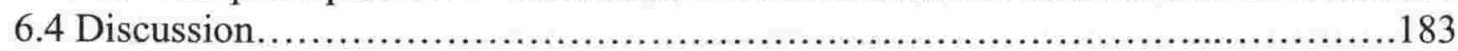

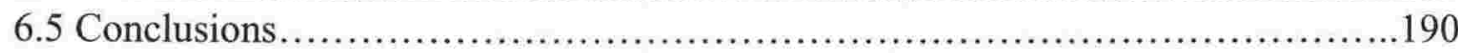




\section{Synthesis}

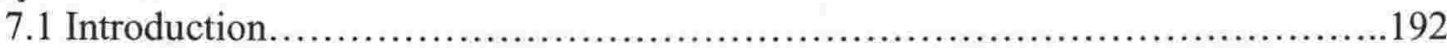

7.1.1 Sediment Characteristics..................................................... 194

7.1.2 Metal Concentrations...................................................... 194

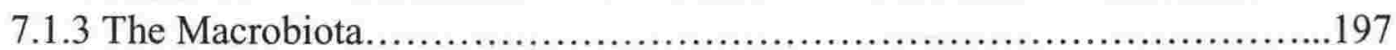

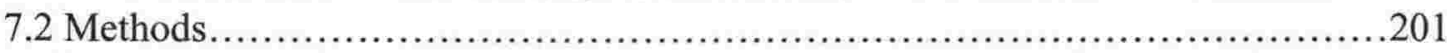

7.2.1 Sedimentological, chemical and biological variables used in the analyses.... 201

7.2.2 Linking the biological community to environmental and chemical

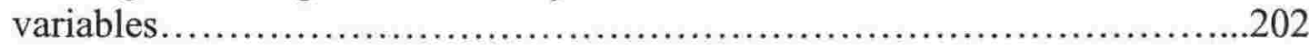

7.2.3 Linking univariate indices to sedimentological and chemical variables.......203

7.2.4 Linking taxa to sedimentological and chemical variables....................204

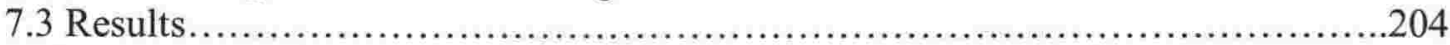

7.3.1 Linking the biological community to environmental and chemical

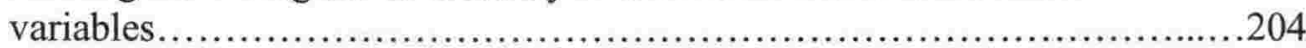

7.3.2 Linking univariate indices to sedimentological and chemical variables.......206

7.3.3 Linking taxon to sedimentological and chemical variables...................209

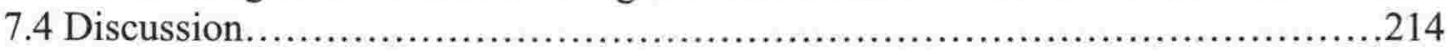

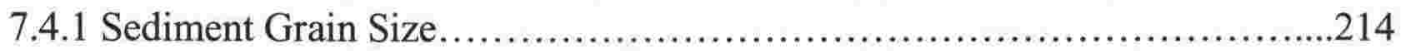

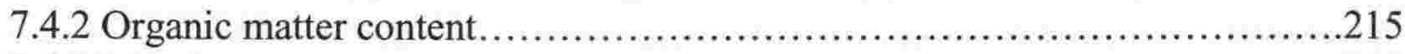

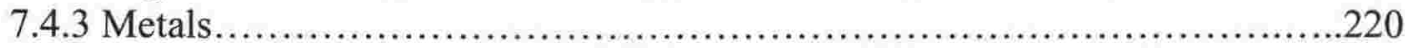

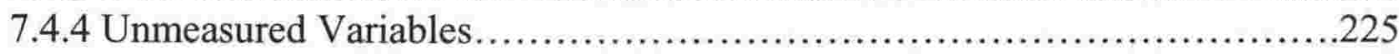

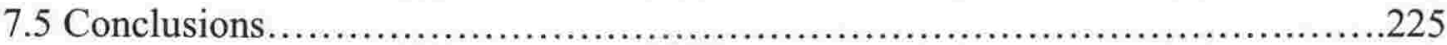

\section{Overview}

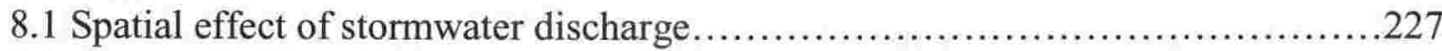

8.2 Temporal effect of stormwater discharge ..................................232

8.3 Links between the biological and the sedimentological and chemical variables....232

8.4 Information for decision makers .............................................. 234

8.4.1 Monitoring the 'health' of the nearshore benthic environment...............234

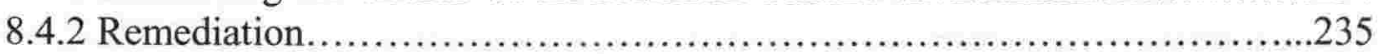

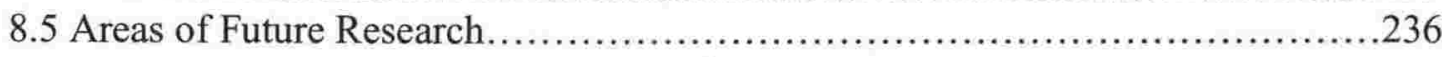

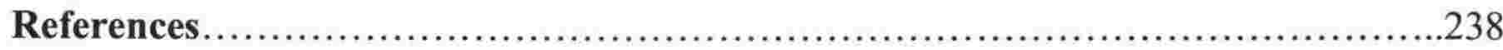

Appendix I - Pilot study on attached Compact Disc Appendix II - Sampling sites and sediment data. .on attached Compact Disc .on attached Compact Disc 


\section{LIST OF FIGURES}

Fig .1.1 Wellington Harbour.

Fig. 2.1 Inner Wellington Harbour with approximate location of Outlet and Control sites.

Fig. 2.2 Aotea Quay details......................................................... 19

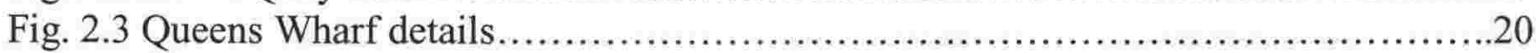

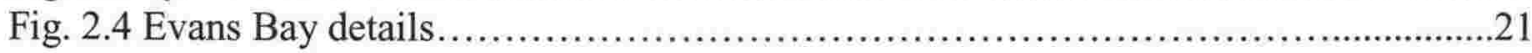

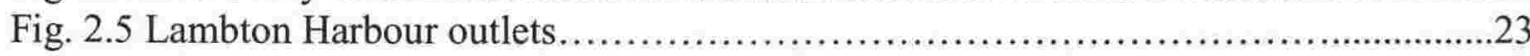

Fig. 2.6 Diagram of the plastic scoop with attached $20 \mu \mathrm{m}$ mesh bag.....................27

Fig. 3.1 Mean organic matter content (\%) at each station at Queens Wharf and Lambton Harbour.........................................................4 40

Fig. 3.2 Mean organic matter content (\%) at each station in Evans Bay.......................41

Fig. 3.3 Mean organic matter content (\%) at each station at Aotea Quay.....................42

Fig. 3.4 Organic matter content (\%) at station S24 at EB-2 and EB-C over time.............45

Fig. 3.5 Organic matter content (\%) at station S10 at AQ-2and AQ-C over time.............45

Fig. 3.6 Sediment grain size distribution, Evans Bay sites.............................47

Fig. 3.7 Relative Carbonate content of the sediment, Evans Bay sites.......................47

Fig. 3.8 Grain size distribution, Queens Wharf sites.........................................48

Fig. 3.9 Grain size distribution, Aotea Quay sites...................................... 48

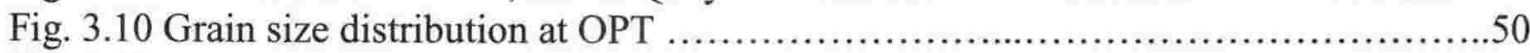

Fig. 3.11 Carbonate content at the Aotea Quay sites ....................................50

Fig. 3.12 Sediment grain size, Evans Bay sites over time ................................52

Fig. 3.13 Sediment grain size, Aotea Quay sites over time.............................52

Fig. 4.1 Spatial variability of sediment enrichment with arsenic at each outlet site...........71

Fig. 4.2 Spatial variability of sediment enrichment with chromium at each outlet site........72

Fig. 4.3 Spatial variability of sediment enrichment with copper at each outlet site............73

Fig. 4.4 Spatial variability of sediment enrichment with nickel at each outlet site...........74

Fig. 4.5 Spatial variability of sediment enrichment with lead at each outlet site..............75

Fig. 4.6 Spatial variability of sediment enrichment with zinc at each outlet site..............76

Fig. 4.7 Concentration of $\mathrm{As}, \mathrm{Cr}$ and $\mathrm{Cu}$ in the sediment at AQ-2 stations

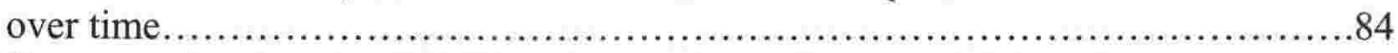

Fig. 4.8 Concentration (ppm) of $\mathrm{Ni}, \mathrm{Pb}$ and $\mathrm{Zn}$ in the sediment at $\mathrm{AQ}-2$ stations

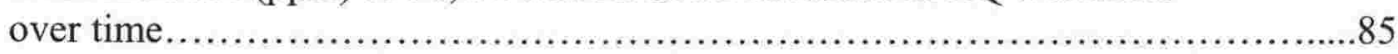

Fig. 4.9 Concentration (ppm) of As, $\mathrm{Cr}$ and $\mathrm{Cu}$ in the sediment at Q-2 stations

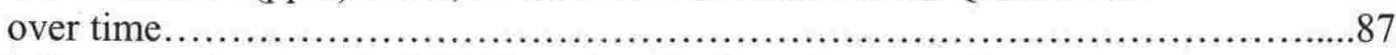

Fig. 4.10 Concentration (ppm) of $\mathrm{Ni}, \mathrm{Pb}$ and $\mathrm{Zn}$ in the sediment at Q-2 stations

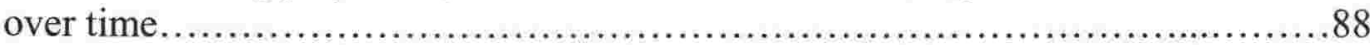

Fig. 4.11 Concentration (ppm) of As, $\mathrm{Cr}$ and $\mathrm{Cu}$ in the sediment at EB-2 stations over time

Fig. 4.12 Concentration (ppm) of $\mathrm{Ni}, \mathrm{Pb}$ and $\mathrm{Zn}$ in the sediment at $\mathrm{Q}-2$ stations over time. 
Fig. 5.1 Partial dominance plots of the biota at stations on the straight transect at Aotea Quay sites in November 1998.

Fig. 5.2 Partial dominance of the biota at stations on the straight transect at Queens Wharf sites in November 1998.

Fig. 5.3 Partial dominance plots of the biota at stations at OPT in November 1998.

Fig. 5.4 Partial dominance plots of the biota at stations on the straight transect at Aotea Quay sites in May 1999

Fig. 5.5 Partial dominance plots of the biota at stations on the straight transect at Evans Bay sites in November 1998.

Fig. 5.6 Partial dominance plots of the biota at stations on the straight transect at Evans Bay sites in May 1999

Fig. 5.7 MDS ordinations of the average faunal abundance of the biota at each station at each site.

Fig. 5.8 MDS ordination of the average faunal abundance of the biota at each station at each Evans Bay site.

Fig. 5.9 MDS ordination of the average faunal abundance of the biota at each station at each Queens Wharf site and at OPT.

Fig. 5.10 MDS ordination of the average faunal abundance of the biota at each station at each Aotea Quay site and at OPT.

Fig. 5.11 Mean $( \pm 95 \% \mathrm{CI})$ of the number of Total taxa and Total individuals

Fig. 5.12 Mean ( $\pm 95 \% \mathrm{CI})$ number of polychaete taxa, mollusc taxa and arthropod taxa.

Fig. 5.13 Mean $( \pm 95 \% \mathrm{CI})$ number of polychaete individuals, mollusc individuals, and arthropod individuals.

Fig. 6.1 Partial dominance plots at station S10 at Aotea Quay outlet and control sites on six sampling occasions.

Fig. 6.2 Partial dominance plots at station S24 at Evans Bay outlet and control sites on six sampling occasions.

Fig. 6.3 MDS of the biological community over time at outlet and control sites..............168

Fig. 6.4 Number of taxa at the Aotea Quay outlet and control sites over time.................171

Fig. 6.5 Number of individuals at the Aotea Quay outlet and control sites over time........172

Fig. 6.6 Number of arthropod individuals and diversity at the Aotea Quay outlet and control sites over time.

Fig. 6.7 Number of taxa at the Evans Bay outlet and control sites over time...............176

Fig. 6.8 Number of individuals at the Evans Bay outlet and control sites over time.........177

Fig. 6.9 Diversity at Evans Bay outlet and control sites over time.......................178

Fig. 7.1 Mean number of total taxa versus organic matter content..........................207

Fig. 7.2 Mean number of arthropod taxa versus organic matter content..................207

Fig. 8.1 Ranking of outlet sites from the most to least contaminated with organic matter...229

Fig. 8.2 Ranking of outlet sites from the most to least contaminated with metals.... 


\section{LIST OF TABLES}

Table 1.1 Range of concentration of copper, lead and zinc in harbour sediments in New Zealand.

Table 2.1 Outlet details.

Table 3.1 Classification of sediment by size.

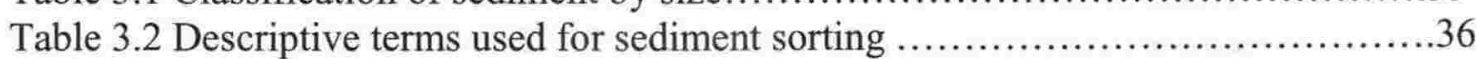

Table 3.3 Organic matter enrichment at each outlet.

Table 3.4 The effect of distance and direction on organic matter content at outlet and

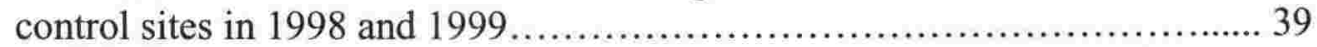

Table 3.5 The effect of direction on organic matter content at outlet and control sites....43

Table 4.1 Comparison of XRF analysis of PACS-2 with certified values (ppm).........63

Table 4.2 Descriptors for specific Enrichment Factor (EF) values......................65

Table 4.3 Geoaccumulation classes and descriptors ...............................66

Table 4.4 Total concentration (ppm) of metals from Wellington Argillite, harbour

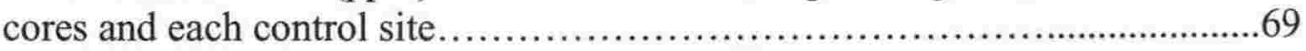

Table 4.5 Summary of metal enrichment (EF) at the outlet sites.......................77

Table 4.6 Summary of metal enrichment (IGEO) at the outlet sites....................78

Table 4.7 Distance of sediment enrichment with each metal at each outlet...............79

Table 4.8 Mean enrichment of each contaminant at each outlet.......................... 81

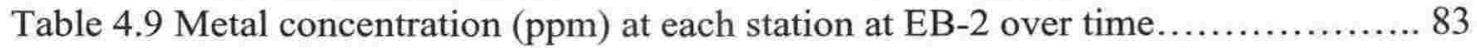

Table 5.1 The macrobiota at each site............................................111

Table 5.2 The biological community (ANOSIM analysis) at each site in Evans Bay....124

Table 5.3 The biological community (ANOSIM analysis) at each site at Aotea Quay..124

Table 5.4 Significant differences in each index between outlet and control

stations at each distance.............................................. 128

Table 5.5 Univariate indices with distance and direction at each outlet and control

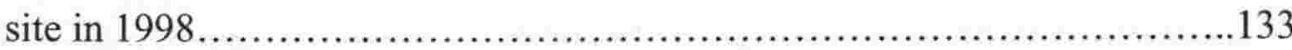

Table 5.6 Univariate indices with distance and direction at each outlet and control

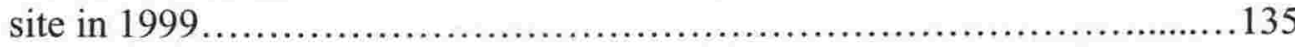

Table 5.7 Mean abundance of species contributing $\geq 2.5 \%$ to faunal dissimilarity between sites in Evans Bay..............................................138

Table 5.8 Taxa with a significant difference in abundance between outlet and control at each distance, Evans Bay sites, November 1998......................139

Table 5.9 Taxa with a significant difference in abundance between outlet and control at each distance, Evans Bay sites, May 1999 ...............................140

Table 5.10 Taxa abundance with distance and direction at each site in Evans Bay in 1998 and 1999.

Table 5.11 Mean abundance of species contributing $\geq 2.5 \%$ to faunal dissimilarity between sites at Queens Wharf. 
Table 5.12 Taxa with a significant difference in abundance between outlet and control at each distance, Queens Wharf sites, 1998.

Table 5.13 Taxa abundance with distance and direction at each site at Queens Wharf in 1998.

Table 5.14 Taxa abundance with distance and direction at OPT in November 1998.....145

Table 5.15 Mean abundance of species contributing $\geq 2.5 \%$ to faunal dissimilarity between sites at Aotea Quay

Table 5.16 Taxa with a significant difference in abundance between outlet and control at each distance, Aotea Quay sites, 1998 and 1999.

Table 5.17 Taxa abundance with distance and direction at each site at Aotea Quay in 1998 and 1999.

Table 5.18 Summary of impact of the biota at each outlet site in 1998

Table 5.19 Summary of impact of the biota at each outlet site in 1999

Table 6.1 The macrobiota present at each site over time.

Table 6.2 Summary of the significant temporal differences in each index at each site.

Table 6.3 Differences in the total abundance of taxa between the outlet and control site at Aotea Quay over time.

Table 6.4 Recruitment events of taxa at the Aotea Quay sites

Table 6.5 Differences in the total abundance of taxa between the outlet and control site in Evans Bay over time.

Table 6.6 Recruitment events of taxa at the Evans Bay sites.

Table 7.1 Sediment Quality Guideline Values (ppm) for six metals.

Table 7.2 Concentration ( $\mathrm{ppm}$ ) of six metals in sediment from harbour cores and from each control site.

Table 7.3 Stations at which the PEL and ISQG-High Sediment Quality Guideline values are exceeded

Table 7.4 Taxa with more than 10 individuals

Table 7.5 Linking biological and environmental/chemical variables.

Table 7.6 Relationship of univariate indices to sedimentological and chemical variables at outlet and control sites

Table 7.7 Relationship of taxa with sedimentological and chemical variables, Aotea Quay sites.

Table 7.8 The relationship between taxa and sedimentological and chemical variables at the Evans Bay sites. ...

Table 8.1 Extent of impact of stormwater discharge. 


\section{Chapter 1}

\section{INTRODUCTION}

\subsection{BACKGROUND}

In urbanised areas a considerable proportion of the land has been modified by humans and much now comprises impervious surfaces. Rainwater flows from all these surfaces into drains, through stormwater systems and ultimately into receiving water bodies such as streams, estuaries and coastal areas. When the water flows across impervious surfaces (e.g. roads, roofs, car parks, construction sites) it picks up and transports many potential contaminants such as organic matter (leaf litter, etc.), heavy metals, organic chemicals (polycyclic aromatic hydrocarbons (PAH's), organochlorines, dioxins), nutrients, pathogens and sediment (Vincent and Thomas, 1997). The amount and type of contaminants is dependent upon their 'availability' within a catchment (Williamson, 1986). The sources of these contaminants are catchment wide and, as such, their exact origins are difficult to trace (i.e. they are derived from non-point sources). However, as an input into a receiving water body, stormwater is a point source discharge.

Beyond the discharge outlet sediment, organic matter and other contaminants drop out of the water column and accumulate on the floor of the water body. For example analysis of material collected from subtidal sediment traps adjacent to stormwater outlets in Wellington Harbour revealed that gravel, sand and mud and high concentrations of copper (524 ppm), lead (2158 ppm) and zinc (1508 ppm) accumulated at some outlets (Pilotto et al., 1998, 1999). Thus, where stormwater is discharged into the marine environment, near-shore sediments become the recipients of nearly all of the introduced contaminants (Snelder and Williamson, 1997). Comparatively sheltered, low energy water bodies such as harbours and estuaries which typically have high levels of deposition, become 'accumulation zones' or 'sinks' for fine sediments and contaminants (Snelder and Williamson, 1997). 
Wellington Harbour (Te Whanga-nui A Tara or Port Nicholson) (Fig. 1.1a) is a sheltered coastal embayment with an urbanised coastline and regular shipping activity. Urbanisation of the Wellington region began with the arrival of European settlers in the 1840 's. Associated coastal developments since the 1840 's include reclamation (of the beach and shallow coastal area of Lambton Harbour - Fig. 1.1b), dredging, wharf construction and discharges. Initially, both stormwater and sewage were discharged into the harbour with Lambton Quay of the 1860's described as 'a muddy beach which received mud and filth from stormwater drains and sewers' (Johnson, 1990). Untreated sewage is now only discharged into the harbour as an emergency measure, but stormwater continues to be discharged.

Urbanisation of Wellington City and the greater Wellington region has resulted in (anthropogenic) enrichment of metals in harbour sediments. From the analysis of vertical cores sampled from six sites within the harbour, it has been ascertained that sediment enrichment with $\mathrm{Cu}, \mathrm{Pb}$ and $\mathrm{Zn}$ began to occur in the 1900's with significant quantities of all three metals recorded in sediments from the mid 1920's (Dickinson et al., 1996). Minimal metal contamination occurs in the surface sediments of the central basin of Wellington Harbour, with metal enrichment localised in inshore areas particularly Lambton Harbour, Evans Bay, Petone and Kaiwharawhara (Stoffers et al., 1986) (Fig. 1.1a). Within Lambton Harbour, higher concentrations of metals (Cu up to $2650 \mathrm{ppm}, \mathrm{Pb}$ up to $1066 \mathrm{ppm}, \mathrm{Zn}$ up to $889 \mathrm{ppm}$ ) have been recorded in the sediment of 'Lambton Harbour and Wharves' (Smith, 1986) than in the sediment of 'Lambton Harbour basin' (Cu up to113 ppm, Pb up to $447 \mathrm{ppm}, \mathrm{Zn}$ up to $444 \mathrm{ppm}$ ) (Stoffers et al., 1986), i.e. sediments in the wharf areas which are also the areas closest to the shore are the most contaminated. These metal enriched sediments have been attributed to an assortment of causes, including wharf activities, marina facilities, stormwater discharge and historic sewage discharge contaminated by industrial waste (Stoffers et al., 1986; Smith, 1986). The sediments in Wellington Harbour and, in particular, the inner harbour area, do contain higher concentrations of metals than those in many other Harbours in New Zealand (Table 1.1). 
A

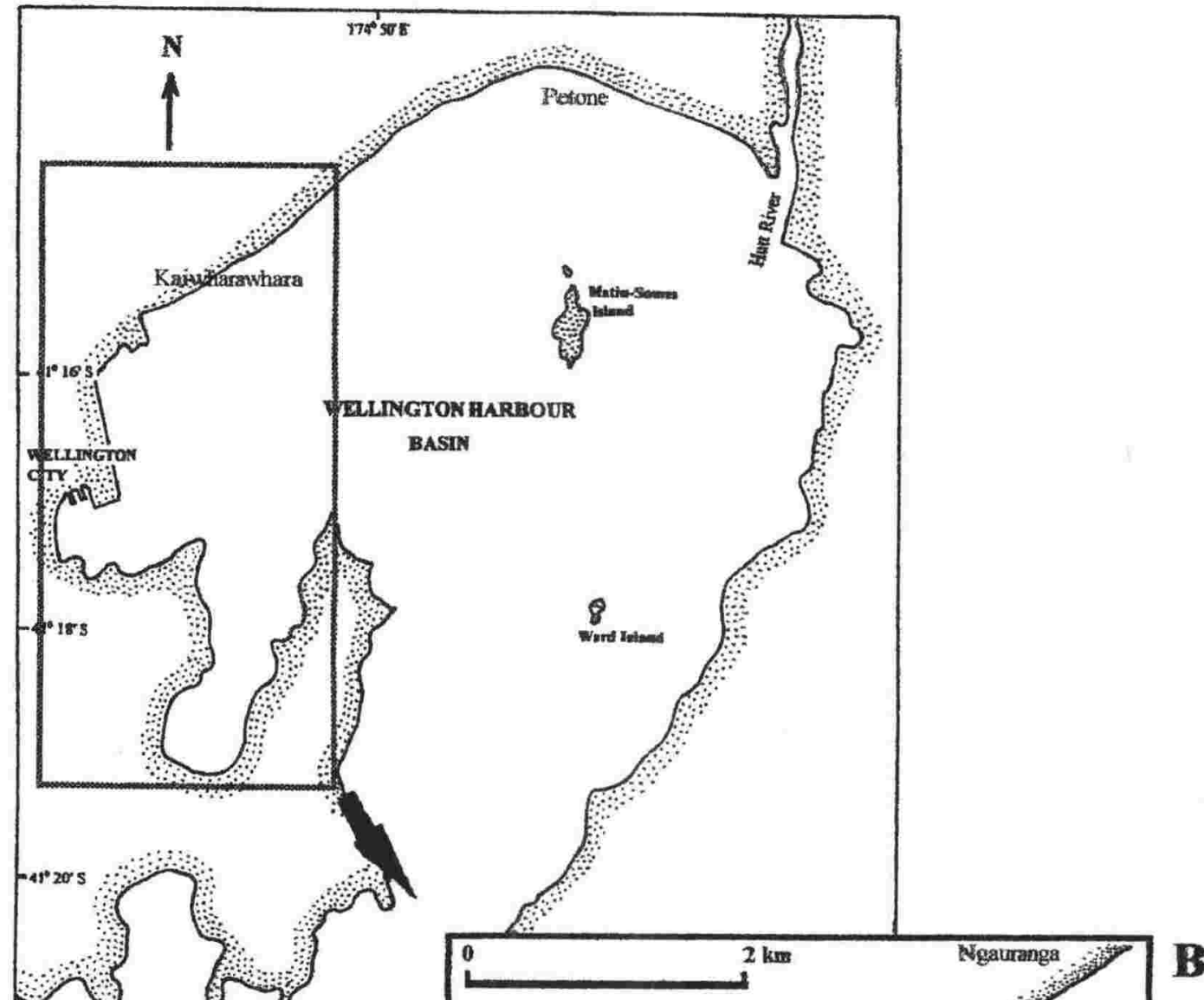

COOK STRATT
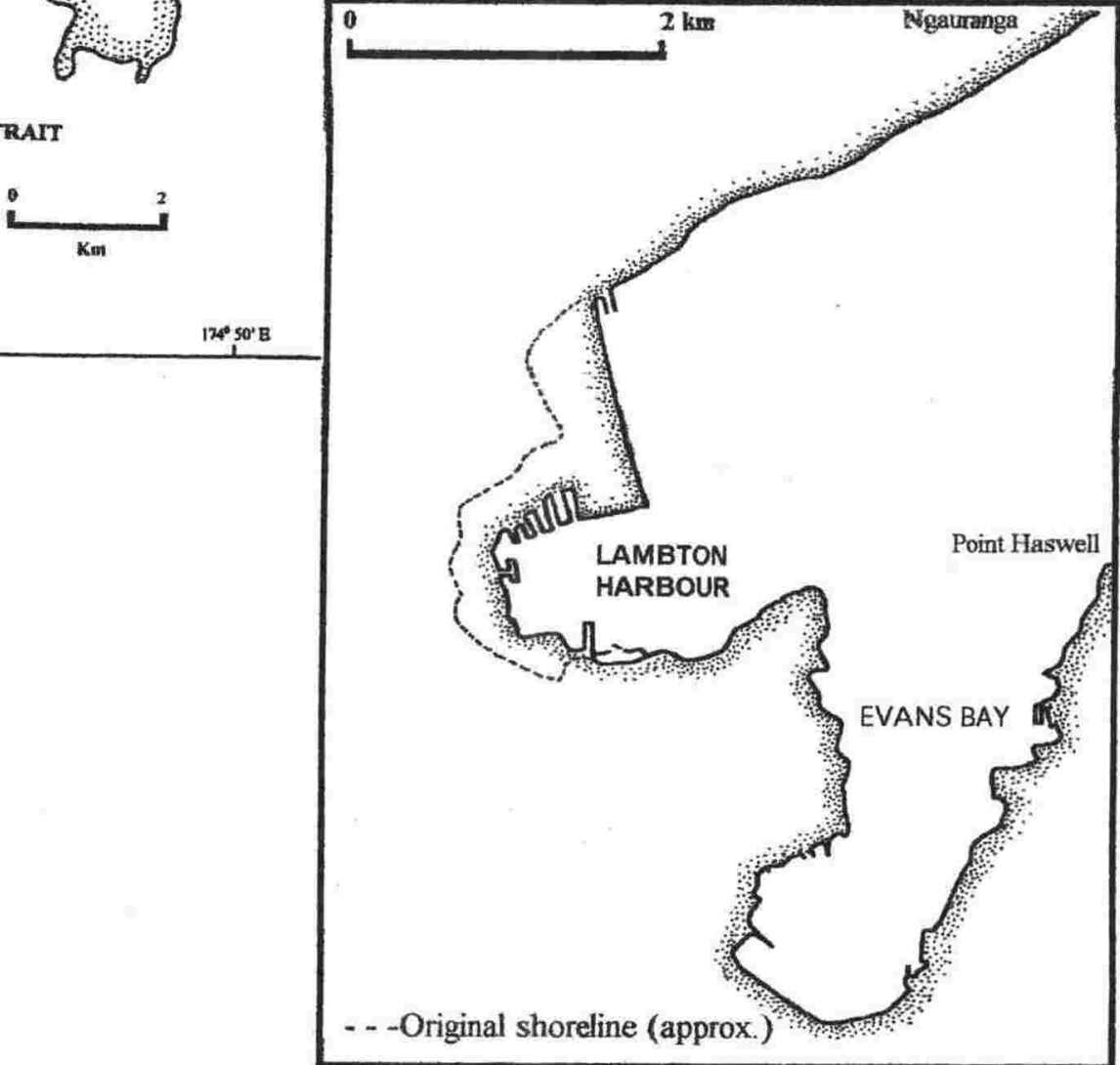

Figure 1.1 Wellington Harbour

a. Greater Harbour Area

b. Inner Wellington Harbour 
Table 1.1: Range of concentration (minimum-maximum) of copper, lead and zine in harbour sediments in New Zealand (from selected studies). All concentrations are $\mu \mathrm{g} \mathrm{g}^{-1}$.

Metal extraction (Except for Otago and Lyttleton); $\mathrm{HCl} / \mathrm{HNO}_{3}$ of $<20 \mu \mathrm{m}$ fraction. Unknown For Otago Harbour and the Port of Lyttelton

\begin{tabular}{|llll|}
\hline \multicolumn{1}{|c}{ Location } & Cu & Pb & Zn \\
\hline Wellington Harbour $^{\text {a }}$ & $15-113$ & $26-903$ & $55-440$ \\
Manakau Harbour $^{\mathrm{b}}$ & $13-67$ & $27-102$ & $80-258$ \\
Mangare Inlet $^{\mathrm{b}}$ & $13-453$ & $19-165$ & $52-309$ \\
Upper Waitemata Harbour $^{\mathrm{b}}$ & $21-42$ & $29-105$ & $83-183$ \\
Lower Waitemata Harbour $^{\mathrm{b}}$ & $13-104$ & $21-370$ & $42-879$ \\
Inner Otago Harbour $^{c}$ & $11-17$ & $15-24$ & $92-160$ \\
Port of Lyttelton $^{\mathrm{d}}$ & $16-31$ & $28-31$ & $98-110$ \\
\hline
\end{tabular}

Sources: ${ }^{a}$ Stoffers et al. 1986; ${ }^{\text {b }}$ Glasby et al. 1988; ${ }^{\text {c }}$ ORC, 1998, ${ }^{\mathrm{d}}$ ESR, 1997

The occurrence of contaminant-enriched sediments within other harbours and estuaries has also been attributed to stormwater discharge (Morrisey et al., 2000; Morrisey et al., 2003; Williamson et al., 1996), with sewage, industrial and agricultural discharges also implicated (Ansari et al., 1986; Dauer and Alden, 1995; Estacio et al., 1997; Grall and Glémarec, 1997; Raman and Ganapati, 1983). Within these environments, contaminant concentrations decrease with increasing distance from the urban area (Estacio et al., 1997; Morrisey et al., 2000). For sheltered New Zealand estuaries, a model predicting the distribution of sediment-associated metals $(\mathrm{Cu}, \mathrm{Pb}$ and $\mathrm{Zn})$ including higher concentrations within a defined settling zone at the upper end of an estuary has been developed and tested (Morrisey et al., 2000; Williamson and Morrisey, 2000). Such harbour and estuary-wide studies document the fate of contaminants derived from a variety of discharges. However, they cover extensive areas and provide no assessment of the levels of contamination in the immediate vicinity of specific discharge points. To date, there is little information on contaminant levels close to stormwater outlets and the spatial extent of elevated contaminant levels in the immediate vicinity of an outlet. Furthermore no documentation has been found with respect to sediment contaminant levels over time in the vicinity of stormwater outlets. 
Concern about the effects of stormwater discharge on the receiving environment relate not only to the actual process of concentration of contaminants, but also to the ecological consequences resulting from this. High concentrations of contaminants have the potential to cause adverse biological, effects. As high metal concentrations in marine sediments have the potential for biological effects Sediment Quality Guidelines (SQG's) have been developed for the protection of aquatic life and for the protection of consumers of aquatic life (Smith et al. 1996). These guidelines give two concentrations for each metal in the sediment - the lower concentration, below which adverse biological effects 'rarely' occur and the upper concentration, above which adverse biological effects are predicted to 'frequently' occur, while between the two concentrations adverse biological effects occur 'occasionally' (ANZECC Guidelines, 2000; Long et al., 1995: Smith et al., 1996).

Sediment quality guideline concentrations for metals are total metal concentrations in bulk sediment and are derived using the equilibrium-partitioning approach assuming a total organic carbon concentration of 1\% (Long et al., 1995). While total metal concentrations are used in sediment quality guidelines, the bioavailability, assimilation and toxicity of a metal is affected by:

- Mobilisation of metals to the interstitial water

- Transformation e.g. methylation of metals

- The concentration of sediments components which bind metals i.e. Fe and Mn, acid volatile sulphides, organic matter content

- Chemical speciation

- The influence of bioturbation, sediment stability, salinity, $\mathrm{pH}$ and redox conditions on the above processes

(e.g. Ankley, 1996; Ankley et al., 1996; Bryan and Langston, 1992; Berry et al., 1996; Gerringa and Cambon, 1991; Hansen et al., 1996; Luoma, 1989; Maloney, 1996; Mortimer and Rae, 2000; Tessier et al., 1984). Thus, for the same total metal concentration, but in different sediments, toxicity can differ by a factor of 10 or more (Adams et al., 1992). It has therefore been argued that no chemical measurement reliably predicts sediment toxicity, nonetheless at stations where the sediment metal 
content exceeds guideline concentrations there is potential for a biological effect (Long et al., 1995).

For organic matter, there is a well documented and consistent pattern of change in the biological community with increasing levels of organic matter in the sediment (Pearson and Rosenberg, 1978). From a discharge point the recognised spatial gradient (i.e. in response to the gradient from very high to background levels of organic matter) of macrobiota consists of the following zones:

1. An abiotic zone.

2. An opportunistic zone with a few species each occurring in high number.

3. An 'ecotone' point of overlap between opportunistic and 'normal' species, characterised by a low abundance of a low number of species.

4. A transition zone consisting of a large number of 'normal' species at 'nonnormal' densities.

5. Non-impacted macrobiota i.e. 'normal'.

There are currently no sediment quality values available for organic matter content.

The documented effects of organic matter on and the potential for high concentrations of metals to affect the biota highlight the need for a detailed assessment of the presence and abundance of macrobiota in the vicinity of stormwater outlets. In addition, by having detailed chemical, sedimentological (including organic matter content) and macrobiota data it is possible to investigate the correlation between factors i.e. are the measured chemical and sedimentological factors those likely to be responsible for any observed macrobiota effects as a result of stormwater discharge.

Few studies have been carried out on the link between stormwater discharge and biological effects. A number of investigations in the Auckland region have identified adverse effects on the marine biota in urbanised, contaminated estuaries (Nipper et al., 1998; Roper et al., 1995), and a study in Otago Harbour found that contaminants might be influencing benthic communities (ORC, 1998), but no direct links to stormwater discharge were established. A recent ecological study in the vicinity of a stormwater outlet in Porirua Inlet, north of Wellington, found that species diversity and the number of taxa were lowest close to the outlet and that there were significant 
differences in the composition of the biological community with increasing distance from the outlet. These biological changes corresponded with variations in sediment characteristics and heavy metal concentrations (Botherway and Gardner, 2002). Nevertheless more investigations of the link between stormwater contaminant discharge and benthic biota are needed before a comprehensive understanding of the effects of stormwater on the health of the environment is achieved.

\subsection{INVESTIGATING THE EFFECTS OF STORMWATER DISCHARGE}

\section{Aim: To investigate the spatial and temporal effect of stormwater discharge on} the nearshore benthic environment at sites in inner Wellington Harbour

To achieve this aim the spatial and temporal sedimentological (sediment structure i.e. grain size and organic matter content), chemical (As and the metals - $\mathrm{Cr}, \mathrm{Cu}, \mathrm{Ni}, \mathrm{Pb}$ and $\mathrm{Zn}$ ) and biological (macrobiota) characteristics of the nearshore benthic environment in the immediate vicinity of a number of inner Wellington Harbour stormwater outlets were investigated. As such this study aimed to determine:

- The effect and the spatial extent of the effect of stormwater discharge on sediment structure and the concentration of As and metals in the sediment in the vicinity of stormwater outlets

- The temporal effect of stormwater discharge on sediment structure and the concentration of As and metals in the sediment

- The effect and the spatial extent of the effect of stormwater discharge on the presence and abundance of the macrobiota in the vicinity of stormwater outlets

- The temporal effect of stormwater discharge on the presence and abundance of the macrobiota

A 'broad-scale' field based study at a number of outlets was used to achieve the overall aim. The advantage of field based studies over laboratory studies is that they can provide direct information on the state of the environment and the biotic communities of interest (Ankley, 1996). However they do have their limitations because in field based studies it can be difficult to discern between the biotic changes resulting from 
anthropogenic impact, and those due to natural spatial and temporal variability, particularly at low and moderate levels of contamination (Nipper et al., 1998; Chapman et al., 1998).

In addition to the study aspects outlined above, the relationship between the macrobiota and the sediment characteristics and As and metal concentrations will be investigated. This is to determine if biological effects attributed to stormwater discharge are correlated to the sedimentological and metal concentration conditions which result from stormwater discharge. As this is a field based study these relationships are correlations only, cause and effect links cannot be established (Chapman et al., 1998; Morrisey et al., 1996).

\subsubsection{Considerations for the design of this study}

An important consideration for this study was that of spatial scale. A pilot study was undertaken in order to obtain an idea of the spatial scale of sampling required and the nature of the stormwater outlets within the area of study. The results of this study are presented in Appendix I. From the experience gained during the pilot study, appropriate methodologies and sampling protocols were developed for use in the main project.

Stormwater discharge from outlets in inner Wellington Harbour has been taking place over a long period of time (i.e. up to 150 years) which raises two pertinent issues:

1. There are no pre-discharge data.

2. There is a high likelihood of historical environmental impact.

Since no pre-discharge data exist the detection of impact using the optimal designs of sampling prior to an impact occurring i.e. Before/After, Control/Impact (BACI) (Green, 1979) and 'beyond BACI' (Underwood, 1992, 1993) cannot be used. Therefore, the determination of the effects of stormwater discharge is based on a Control/Impact (CI) design using multiple impact (outlet) and multiple control sites. For sediment structure and metal concentrations the control site values are used as 'baseline values' against which sediment changes and metal enrichment in the vicinity of each outlet can be quantified. Differences between control and outlet sites in the 
spatial and temporal patterns of the macrobiota could be due to stormwater discharge, although it is recognised that at low to moderate levels of contamination it can be difficult to discern between the biotic effects resulting from anthropogenic impact, and those due to natural spatial and temporal variability.

As the coastal area of inner Wellington Harbour has been highly modified by human activities (reclamation, harbour development, marinas) over a long period of time, it is likely that the nearshore environment has been widely impacted. Nonetheless, the control sites reflect the present state of the nearshore environment not directly impacted by stormwater discharge and as such, are as close to genuine controls as it is possible to get.

Another concern was that of the possible impact of the freshwater discharged on the macrobiota in the vicinity of the stormwater outlets but not at the control sites. It was not possible to find control sites in the vicinity of freshwater stream discharges in inner Wellington Harbour because most of the city streams have, over time, been incorporated into the stormwater system. In inner Wellington Harbour the stormwater outlets are in the intertidal zone i.e. covered by water at high tide and exposed at low tide and consequently the freshwater discharges being less dense than seawater will likely form a plume on the surface at the point of discharge. It has been found that 2-10 m deep stormwater plumes form during heavy rainfall $(2-10 \mathrm{~cm})$ events in a catchment of approximately $600 \mathrm{~km}^{2}$ (60,000 ha) (Bay et al., 1999); the largest catchment in this study is 200 ha. Nothing is known about the depth of the freshwater plume in the vicinity of the Wellington Harbour stormwater outlets however based on the above information it is possible that in an extreme high rainfall event the benthic environment could be subjected to low salinity water. If such events were to occur they would be irregular and short term, nonetheless they could impact on the benthic macrobiota. The tolerance to changes in salinity is species specific (www.marlin.ac.uk) with numerous species able to withstand short term salinity fluctuations. Given that most stations sampled are deeper than $2 \mathrm{~m}$ and that the occurrence of lower salinity at any stations would be irregular and short term, salinity has not been included as a factor for investigation in this study. 


\subsection{RELEVANCE OF THIS STUDY TO DECISION MAKERS}

The information obtained in this study will increase the knowledge base of the effect of stormwater discharge on the nearshore marine benthic environment. This is of interest in its own right, but it is also of importance for Local Authorities who have a statutory obligation under the Resource Management Act (1991) with regard to discharges into receiving waters. Such authorities require 'the adoption of the best practicable option to prevent or minimise any actual or likely adverse effect on the environment of any discharge of a contaminant'. To date the authorities have had limited data on which to base their decision making with respect to the discharge of stormwater. To this end the Council funding this study were interested in the effects of stormwater discharge on the health of the nearshore environment and in particular the site specific effects of stormwater discharge.

By obtaining data on sedimentological, chemical and biological parameters it may also be possible to identify one or a small number of parameters that could be used as future 'cost-effective' measures to ascertain and monitor the 'health' of the nearshore environment of Wellington Harbour.

\subsection{STRUCTURE OF THE THESIS}

This study uses a multidisciplinary (sedimentological, chemical and biological) approach to investigate the spatial and temporal effects of stormwater discharge on the nearshore benthic environment. There is a chapter for each of the sedimentological and chemical investigations, two chapters for the biological investigations and a chapter in which the relationship of the macrobiota to the sedimentological and chemical parameters is investigated.

\section{Chapter 2: Study sites and sampling methods}

Details of the location of outlet and control sites, the position of the sampling stations at each site and the sampling regime, including the time frame of sampling, are presented. 


\section{Chapter 3: The effect of stormwater discharge on sediment characteristics}

The spatial and temporal patterns of sediment characteristics (grain size and organic matter content) at outlet and control sites are investigated. For organic matter, an enrichment index (as calculated with reference to control site values), is used to quantify the effect of stormwater discharge on this characteristic. Grain size at outlet sites is assessed against the grain size at control sites using ternary plots.

\section{Chapter 4: The effect of stormwater discharge on sediment metal concentrations}

The spatial and temporal patterns in the concentration of As and the metals $\mathrm{Cr}, \mathrm{Cu}, \mathrm{Ni}$, $\mathrm{Pb}$ and $\mathrm{Zn}$ at outlet and control sites are investigated. For As and each metal, enrichment and geoaccumulation values (Igeo), (as calculated with reference to control site values), are used to quantify the effect of stormwater discharge on concentration.

\section{Chapter 5: Spatial distribution of the benthic macrobiota}

The spatial patterns in the presence and abundance of the macrobiota at outlet and control sites are investigated. Multivariate and univariate analyses are used to determine the differences in the biological community, biological indices (including taxonomic groups) and individual taxa between outlet and control sites.

\section{Chapter 6: Temporal variability of the benthic macrobiota}

The temporal patterns in the presence and abundance of the macrobiota at outlet and control sites are investigated. Multivariate and univariate analyses are used to determine the differences in the biological community, biological indices (including taxonomic groups) and individual taxa between the outlet and control sites over time.

\section{Chapter 7: Synthesis}

A summary of the effect of stormwater discharge on sedimentological characteristics, As and metal concentrations and the macrobiota are presented and the potential for the sedimentological characteristics, As and metal concentrations which result from stormwater discharge to affect the presence and abundance of the macrobiota, is outlined. Multivariate and univariate techniques are then used to investigate the relationship of the macrobiota i.e. the biological community, biological indices and 
individual taxa, to sediment characteristics (grain size and organic matter content) and As and metal concentrations.

\section{Chapter 8: Overview}

The spatial extent of impact of stormwater discharge on sedimentological, As and metal concentrations and the macrobiota at each outlet is presented. Using both organic matter levels, As and metal concentrations the outlets are ranked from those with the most to those with the least contaminated sediment. The relevance of the results to decision makers is discussed and areas of future work outlined. 


\section{Chapter 2}

\section{STUDY SITES AND SAMPLING METHODS}

\subsection{WELLINGTON HARBOUR}

Wellington Harbour (latitude $41^{\circ} 16^{\prime} \mathrm{S}, 174^{\circ} 51^{\prime} \mathrm{E}$ ) is a roughly circular basin (Fig. 1.1a) situated on the southern tip of the North Island of New Zealand. It is approximately 85 $\mathrm{km}^{2}$ in surface area (Heath, 1977) with a single southern entrance into Cook Strait. The maximum depth of the harbour is $31 \mathrm{~m}$ (to the south east of Matiu-Somes Island) with a mean water depth of $14 \mathrm{~m}$ (Heath, 1977). The tides are semi-diurnal and of small amplitude (0.9-1.2 m), with a clockwise flood tidal flow and anticlockwise ebb flow. The tidal exchange of $4.5 \%$ of the total harbour volume gives a calculated water residence time of about 11 days (Maxwell, 1956).

The basement rock of the Wellington area is late Triassic (192-208 million years old) greywacke consisting of metamorphosed sandstones and argillites. Quaternary alluvial deposits in the Hutt River comprise well-rounded greywacke pebbles in a fine sand-silt matrix and are mineralogically identical to the basement rock (Roser, 1983).

The Hutt River is the major freshwater flow into the harbour, discharging between 2.6 and $180 \times 10^{6} \mathrm{~m}^{3} \mathrm{~d}^{-1}$ into the north-eastern corner (Fig. 1.1a) (Maxwell, 1956). Other streams such as the Korokoro stream, Ngauranga stream, Kaiwhararwhara stream and Horokiwi stream also flow into the harbour, however many smaller waterways within the Wellington metropolitan area have been channeled into the stormwater system over the last 150 years or so.

\subsection{STORMWATER OUTLETS}

Wellington City has approximately 50 large and numerous small outlets through which stormwater is discharged into the sea (Wellington Harbour and open coast). The largest outlets are either circular with an internal diameter of $1.2-1.8 \mathrm{~m}$ or rectangular and of variable size e.g. one Aotea Quay outlet measures 3.8 by $1.6 \mathrm{~m}$. Twenty-eight of the outlets are located in the inner harbour (bounded by Ngauranga $41^{\circ} 15^{\prime} \mathrm{S}, 174^{\circ} 48.85^{\prime} \mathrm{E}$ and Point Haswell $41^{\circ} 17.24^{\prime} \mathrm{S}, 174^{\circ} 49.55^{\prime}$ E) (Fig. 2.1). Eight of these large stormwater outlets, located in four areas, are the focus of this study (Fig. 2.1). 


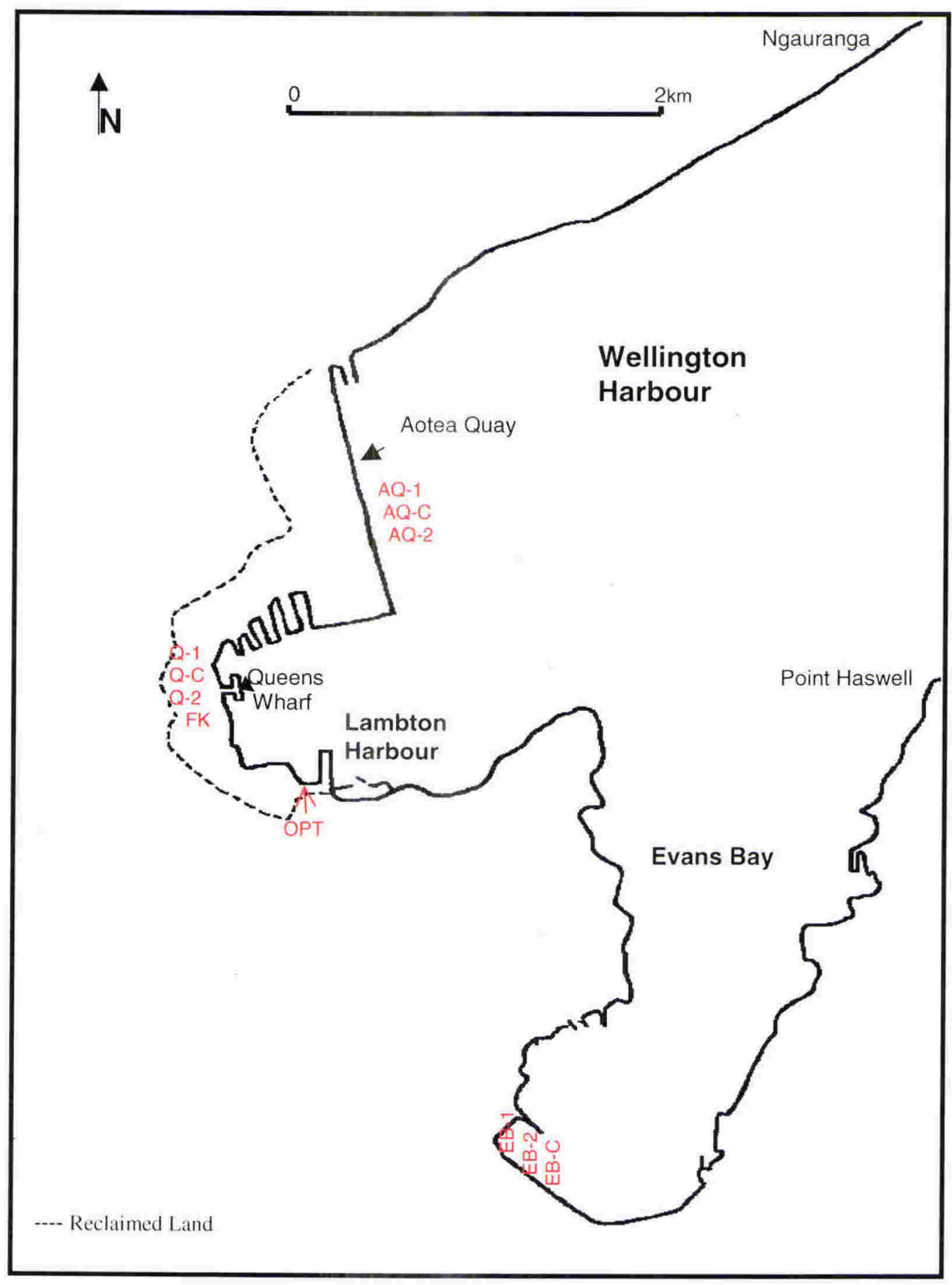

Figure 2.1: Inner Wellington Harbour with approximate location of Outlet (AQ-1, AQ-2, Q-1, Q-2, FK, OPT, EB-1 and EB-2) and Control sites (AQ-C, Q-C and EB-C).

\subsection{SAMPLING AREAS, SITES AND STATIONS}

\subsubsection{Background information on each sampling area}

The eight outlet sites (AQ-1, AQ-2, Q-1, Q-2, FK, OPT, EB-1 and EB-2) were located in four different areas of inner Wellington Harbour: Aotea Quay, Queens Wharf, Lambton 
Harbour and Evans Bay (Fig. 2.1). Control sites (AQ-C, Q-C and EB-2) were located in three of these areas.

\subsection{1.a Aotea Quay (study sites AQ-1, AQ-2, AQ-C)}

The land area behind Aotea Quay (Fig.1.1b) has been reclaimed from the sea with the land-sea margin being a concrete wall extending from approximately $1 \mathrm{~m}$ below the water line to the wharf above. The wharf, which extends $15 \mathrm{~m}$ from the wall, was constructed between 1920 and 1940. The wharf piles are made of concrete and Australian hardwoods with some of the earlier piles being sheathed in copper (D. Carter, CentrePort, Pers. Com., 2002). This wharf is the major berthing area for container, logging and cruise ships, Inter Island and overseas fishing vessels.

\subsection{1.b Queens Wharf (study sites Q-1, Q-2, Q-C)}

The land area behind Queens Wharf is reclaimed, with a sloping rock bank as the landsea margin. Sections of Queens Wharf are over 100 years old and the original structure was built in 1865. However, some areas have been reconstructed, the most recent being in 1964. Some of the piles are made of concrete, but most are made of Australian hardwoods, with some of the earlier piles being sheathed in copper (D. Carter, CentrePort, Pers. Com., 2002). Boating activities in the vicinity of the wharf include the East-West harbour ferry, berthing of charter vessels and a refueling area (at the time of sampling) for charter, commercial fishing and recreational vessels. In addition, public access to this wharf means it is widely used by the general public for recreational (fishing, sightseeing) activities.

\subsection{1.c Lambton Harbour (study sites FK, OPT)}

\section{Frank Kitts Park (FK)}

The land area behind Frank Kitts Park is reclaimed, with a sloping rock bank as the landsea margin. The 2 outlets sampled in this area drain the same catchment and because they are in close proximity to each other ( $22 \mathrm{~m}$ apart) they are referred to as FK throughout the body of this thesis.

\section{Overseas Passenger Terminal (OPT)}

The land area behind the Overseas Passenger Terminal is reclaimed (Fig. 1.1b) with the land-sea margin being a concrete wall extending from below the water line to the wharf 
above. The wharf extends some $250 \mathrm{~m}$ from this wall. The core of the wharf was constructed in 1907 as Clyde Quay Wharf with the outer section added in 1963. The original structure was made of concrete while the addition was constructed using Australian hardwood piles, some of which are sheathed in copper (D. Carter, CentrePort, Pers. Com., 2002). The recently constructed Chaffers Marina is to the west and the Clyde Quay Marina to the east of the wharf.

\subsection{1.d Evans Bay (study sites EB-1, EB-2, EB-C)}

The top of the shore has been modified with rock and concrete rubble while the low shore is base rock i.e. greywacke. The marina, located in the southwestern corner of Evans Bay, is adjacent to outlet EB-1. There are no man-made structures in the vicinity of outlet EB2 or the control site EB-C.

\subsubsection{Sampling sites}

As no pre-discharge data exist, the determination of the effects of stormwater discharge is based on a Control/Impact (CI) design involving comparison among multiple outlet and control sites.

\subsection{2.a Outlet sites}

The eight outlets included two at Aotea Quay (AQ-1 and AQ-2), two at Queens Wharf (Q-1 and Q-2), two in Lambton Harbour (Frank Kitts Park - FK (2 outlets but these drain the same catchment) and Overseas Passenger Terminal - OPT), and two in Evans Bay (EB-1 and EB-2) (Fig. 2.1). The size, catchment area and catchment details of each outlet are given in Table 2.1. The catchment area, 'green' area i.e. parks, school grounds, green belt and catchment details were determined from detailed GIS maps provided by Wellington City Council staff.

\subsection{2.b $\underline{\text { Control sites }}$}

Three control sites, Aotea Quay (AQ-C), Queens Wharf (Q-C) and Evans Bay (EB-C) were sampled (Fig. 2.1). The need for control sites was a major determinant of the outlets included in this study, as the control sites needed to be comparable with the outlets with regard to physical aspects (wind, tide, wave, substrate characteristics, depth), yet had to be unaffected by stormwater discharge. These control sites reflect the present 
Table 2.1: Outlet details. Size of each outlet and catchment information

\begin{tabular}{|c|c|c|c|c|}
\hline Outlet & Outlet Size & $\begin{array}{c}\text { Catchment area } \\
\text { (ha) }\end{array}$ & Green area (ha) & Other activities in Catchment \\
\hline AQ-1 & $2.7 \times 1.3 \mathrm{~m}$ & 99 & $\begin{array}{c}50 \\
\text { Town Belt }\end{array}$ & $\begin{array}{l}\text { Motorway } \\
\text { Rail yards } \\
\text { Wharves and Industrial } \\
\text { Residential }\end{array}$ \\
\hline AQ-2 & $3.8 \times 1.6 \mathrm{~m}$ & 175 & $\begin{array}{c}38 \\
\text { Town Belt } \\
\text { Botanic Gardens } \\
\text { School grounds }\end{array}$ & $\begin{array}{l}\text { Motorway } \\
\text { Colleges and grounds } \\
\text { Wharves, Stadium, Industrial } \\
\text { Residential }\end{array}$ \\
\hline Q-1 & $1.5 \mathrm{~m}$ diam. & 43 & $\begin{array}{c}9.5 \\
\text { Park } \\
\text { University }\end{array}$ & $\begin{array}{l}\text { Motorway } \\
\text { Central Business District (CBD) } \\
\text { Residential }\end{array}$ \\
\hline Q-2 & $1.0 \mathrm{~m}$ diam. & 4.7 & 0 & $\mathrm{CBD}$ \\
\hline $\begin{array}{c}\text { FK } \\
\text { (2 outlets) }\end{array}$ & $1.5 \mathrm{~m}$ diam. & 30 & 0 & CBD \\
\hline OPT & $2.3 \times 3.5 \mathrm{~m}$ & 500 & $\begin{array}{c}200 \\
\text { Zoo } \\
\text { Town Belt } \\
\text { Sports grounds } \\
\text { Parks } \\
\text { School grounds }\end{array}$ & $\begin{array}{l}\text { Hospital } \\
\text { Residential } \\
\text { Retail } \\
\text { Industrial }\end{array}$ \\
\hline EB-1 & $1.75 \mathrm{~m}$ diam. & 40 & $\begin{array}{c}10.5 \\
\text { Park } \\
\text { School grounds }\end{array}$ & $\begin{array}{l}\text { Residential } \\
\text { Retail } \\
\text { Light Industrial }\end{array}$ \\
\hline EB-2 & $1.75 \mathrm{~m}$ diam. & 75 & $\begin{array}{c}8.5 \\
\text { School grounds }\end{array}$ & $\begin{array}{l}\text { Residential } \\
\text { Retail } \\
\text { Light Industrial } \\
\text { Bus Depot }\end{array}$ \\
\hline
\end{tabular}

state of the nearshore environment, regardless of its modified status as a consequence of anthropogenic activity (reclamation, harbour developments, marinas) over a long period of time. As many of the harbour stormwater outlets are close together, areas had to be found where there was at least $100 \mathrm{~m}$ (as determined by on the ground measurement in 
combination with the GIS maps provided by Wellington City Council staff) between outlets for a control site to be located.

At Aotea Quay and Queens Wharf, the control site was about half way between the sampled outlets with approximately $500 \mathrm{~m}$ between each of the Aotea Quay outlets and $120 \mathrm{~m}$ between each of the Queens Wharf outlets (Figs. 2.1, 2.2A, 2.3B). In Evans Bay the control site was approximately $100 \mathrm{~m}$ alongshore from outlet EB-2; in this area the control site was not located between the two outlets because of the proximity of the marina (Fig. 2.4A). There was no suitable site within Lambton Harbour for a control.

\subsubsection{Location of the sampling stations at each site}

The results from the pilot study (Appendix I) indicated that the impact of stormwater discharge was in the order of tens of metres, hence a major consideration for the sampling regime was the distance of the sampling stations from each outlet, the distance between sampling stations and the outer extent of sampling. Because sampling stations were no more than 15 metres apart, the location of each station was precisely measured from the outlet and at the control sites from a point on the shore.

At each site, sampling was undertaken along three transect lines $\left(45^{\circ}\right.$ left (L), straight (S) and $45^{\circ}$ right $\left.(R)\right)$ measured from either the centre of each outlet or from a specific point on the shore. Three stations were positioned at set distances along each line ( 9 stations in total). Site-specific differences in the location of sampling stations along each transect were dictated by local topography. At EB-1, EB-2, EB-C and FK the stations were located at 24, 34 and 44 m, while at AQ-1, AQ-2, AQ-C, Q-1, Q-2 and Q-C the stations were located at 10,20 and $30 \mathrm{~m}$ and at OPT the stations were located at 15, 30 and $45 \mathrm{~m}$ along each transect line. Stations are named according to their direction and distance, for example L10 is the station at $10 \mathrm{~m}$ on the left transect.

At each Aotea Quay site, i.e. AQ-1, AQ-2 and AQ-C, the sampling stations were located under and beyond the wharf (Fig. 2.2B). In this area the seafloor slopes steeply to a depth of $11 \mathrm{~m}$, beyond which it levels out (Fig. 2.2C). 

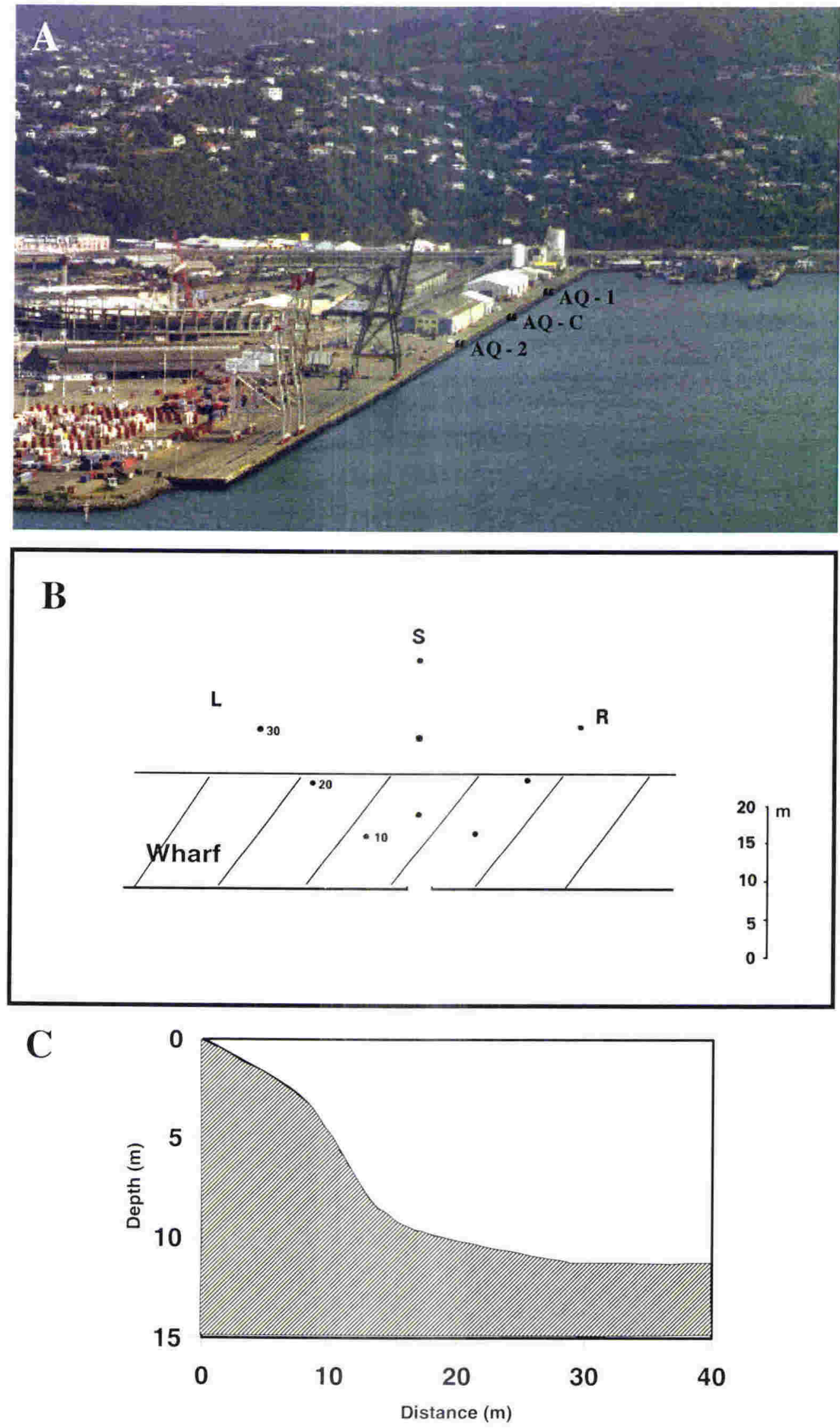

Figure 2,2: Aotea Quay Details

A: Position of each sampling site at Aotea Quay

B: Schematic position of sampling stations in relation to the wharf (for all sites) Transects: L - left, S - straight, R - right

Distance: 10,20,30 metres from the outlet or a point on the shore

C: General depth profile at Aotea Quay 

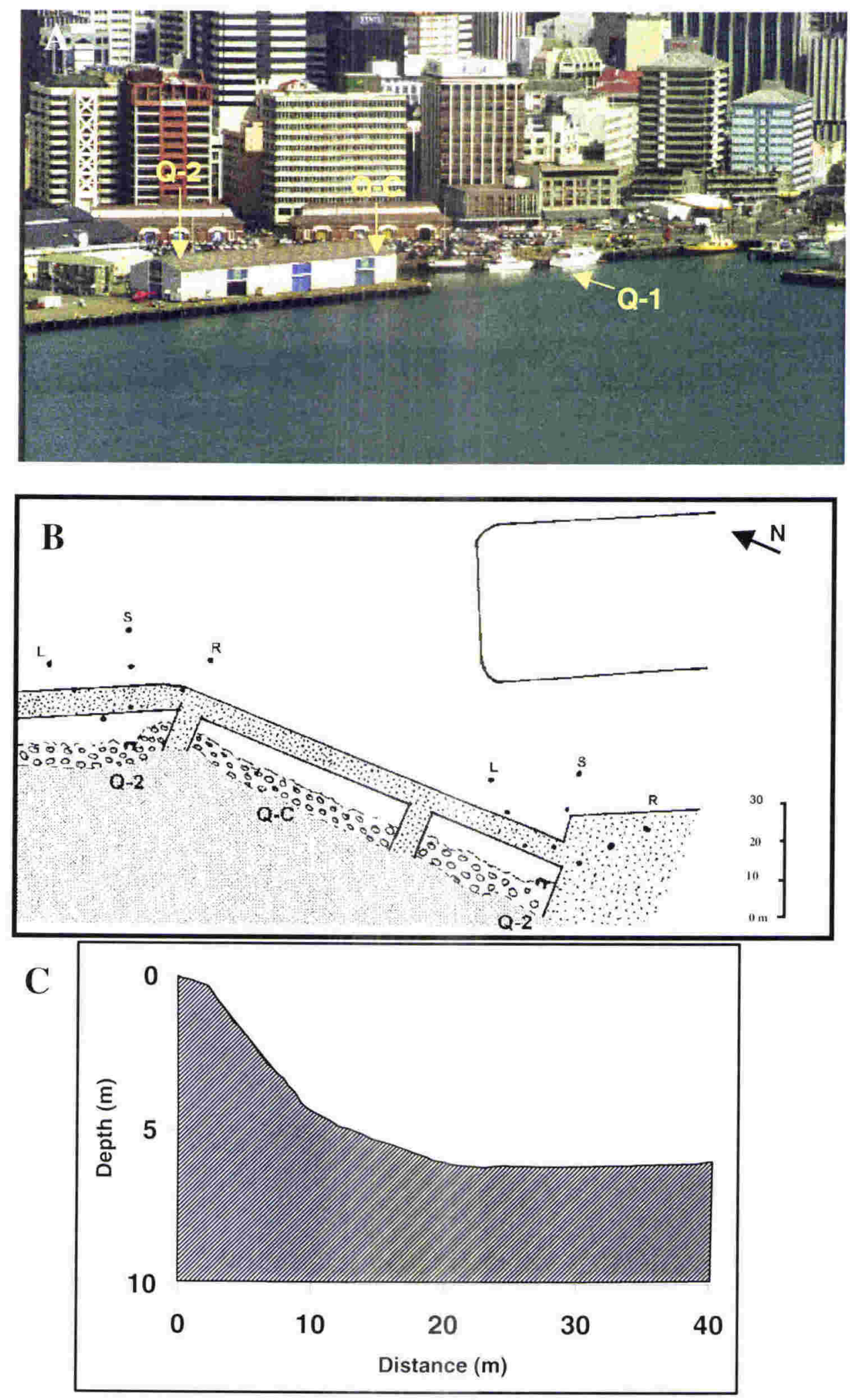

Figure 2.3: Queens Wharf Details

A: Position of each sampling site at Queens Wharf

B: Schematic position of sampling sites and sampling stations

Transects: L - left, S - straight, R - right

Distance: 10, 20, 30 metres

C: General depth profile at Queens Wharf 

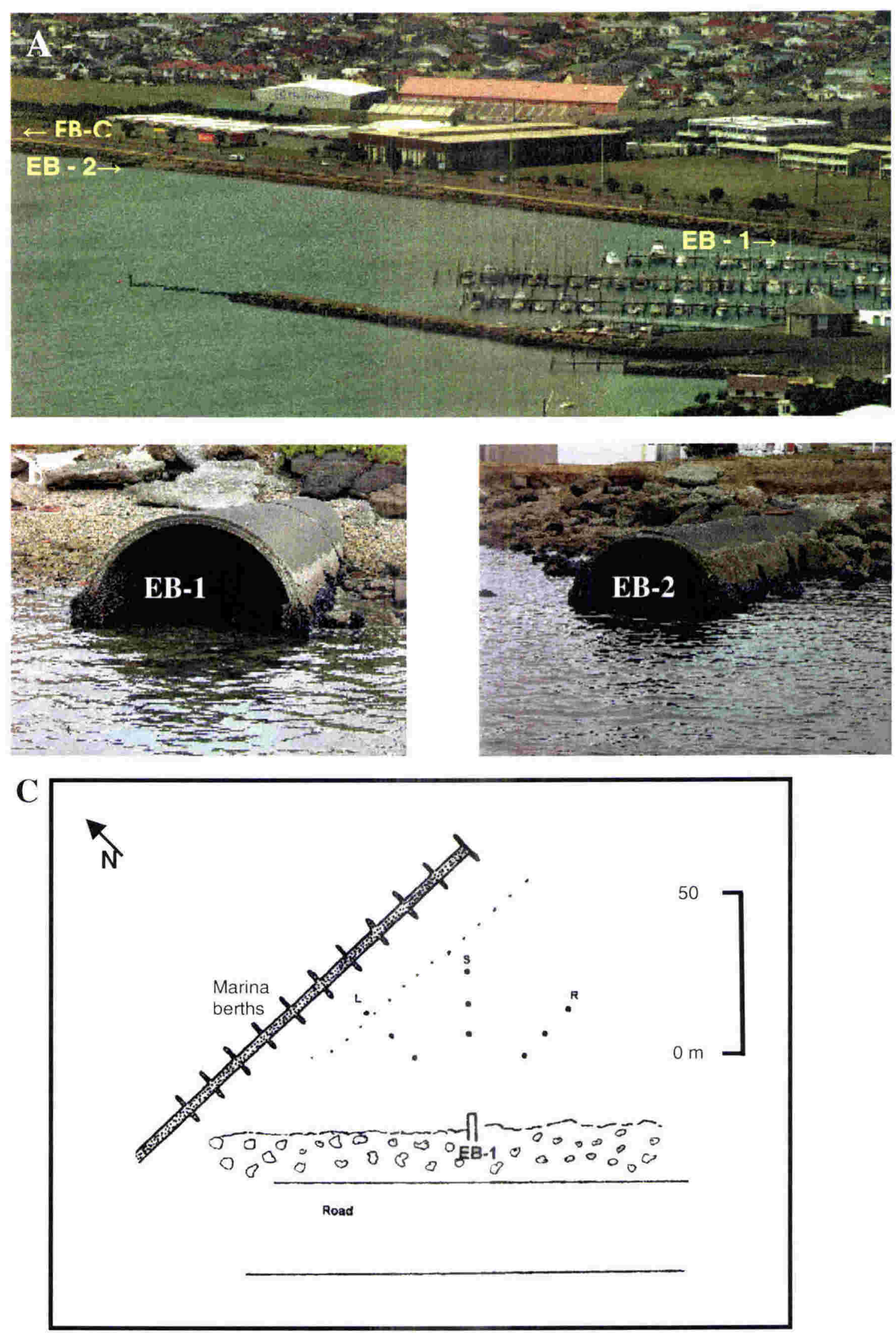

Figure 2.4: Evans Bay Details

A: Position of each sampling site in Evans Bay

B: Photo of each outlet

C: Schematic position of sampling stations at EB-1 in relation to the Marina Transects: L - left, S - straight, R - right 
At each Queens Wharf site, i.e. Q-1, Q-2 and Q-C, the sampling stations were located under and beyond the wharf (Fig. 2.3B). In this area the seafloor slopes to a depth of $6 \mathrm{~m}$ beyond which it levels out (Fig. 2.3C).

At FK the two outlets (draining the same catchment) are only $22 \mathrm{~m}$ apart so the left and straight transects in front of the left outlet and the straight and right transects of the right outlet were sampled (Fig. 2.5B). In this area the seafloor beyond the land-sea margin rock bank is rock rubble which grades into gently sloping soft sediment with increasing distance from shore.

At OPT the sampling stations were located under and beyond the wharf with some of the left stations being located within Chaffers Marina to the west (Figure 2.5C). In this area the seafloor is gently sloping.

In Evans Bay the sampling stations at EB-1 were located close to the Evans Bay marina (Fig. 2.4C), while stations at EB-2 and EB-C were unaffected by man-made structures. In this area the greywacke base rock of the intertidal area extends into the subtidal region, grading to gently sloping soft sediment some 11-16 m from MLWS.

\subsection{SAMPLING REGIME}

A general outline of all sampling methodology is provided here so that the context and contribution of each subsequent chapter (sediments, metals and macrobiota) can be understood. Specific details of the sampling methodology are developed in each chapter as appropriate.

Because sampling stations were no more than 15 metres apart at any one outlet or control site, sampling at each station was carried out within a $1.5 \mathrm{~m}$ radius of the marked location. As a consequence of the small size of the sample station in conjunction for the necessity for replicate sampling, small area $\left(0.011 \mathrm{~m}^{2}\right.$ ) (equivalent to a $12 \mathrm{~cm}$ diameter core) samples were collected for macrobiota analyses and small samples were collected for sediment and metal analyses. It is not uncommon for small area cores to be used for an assessment of the macrobiota, for example Morrisey et al., (1992) and Morrisey et al.,(1996) used $10 \mathrm{~cm}$ diameter cores (area $0.008 \mathrm{~m}^{2}$ ) in their study, and a national 


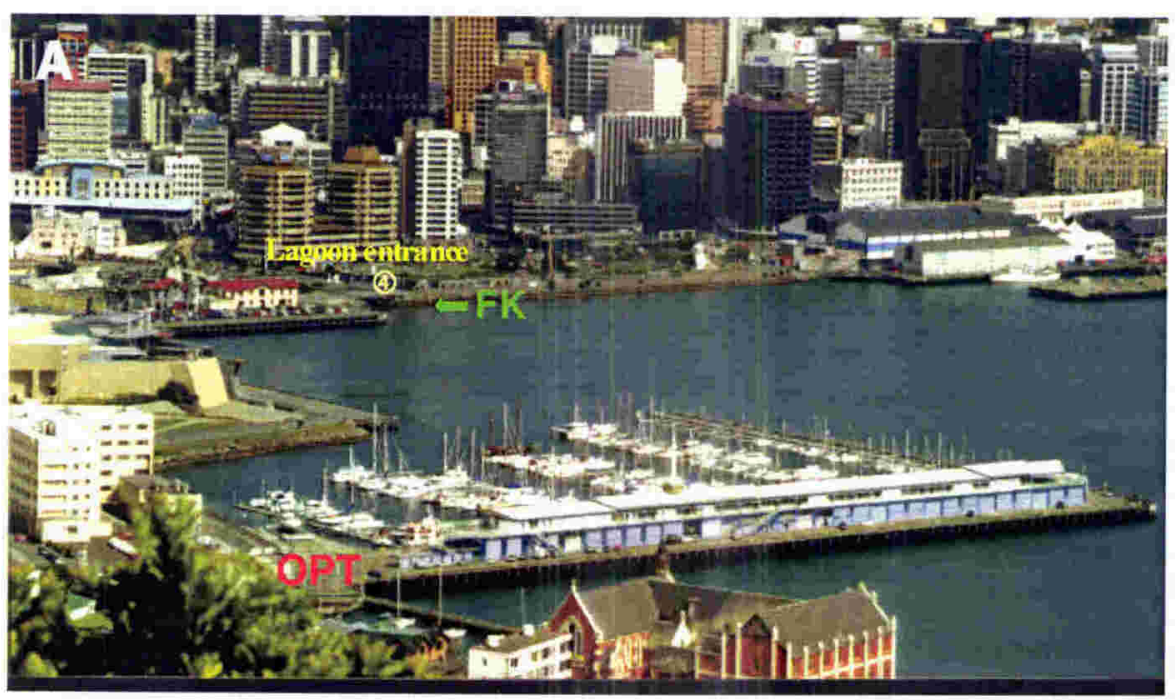

B

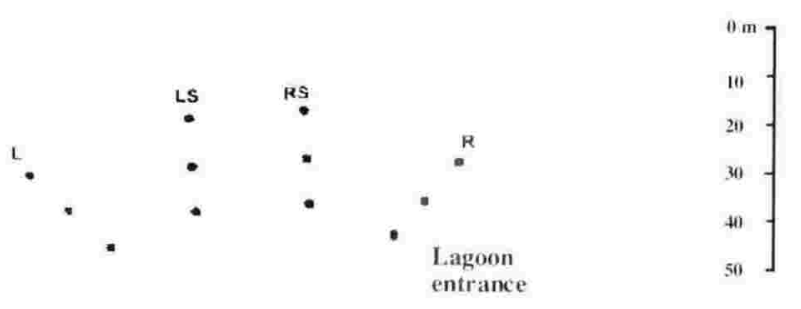

य5. (4)

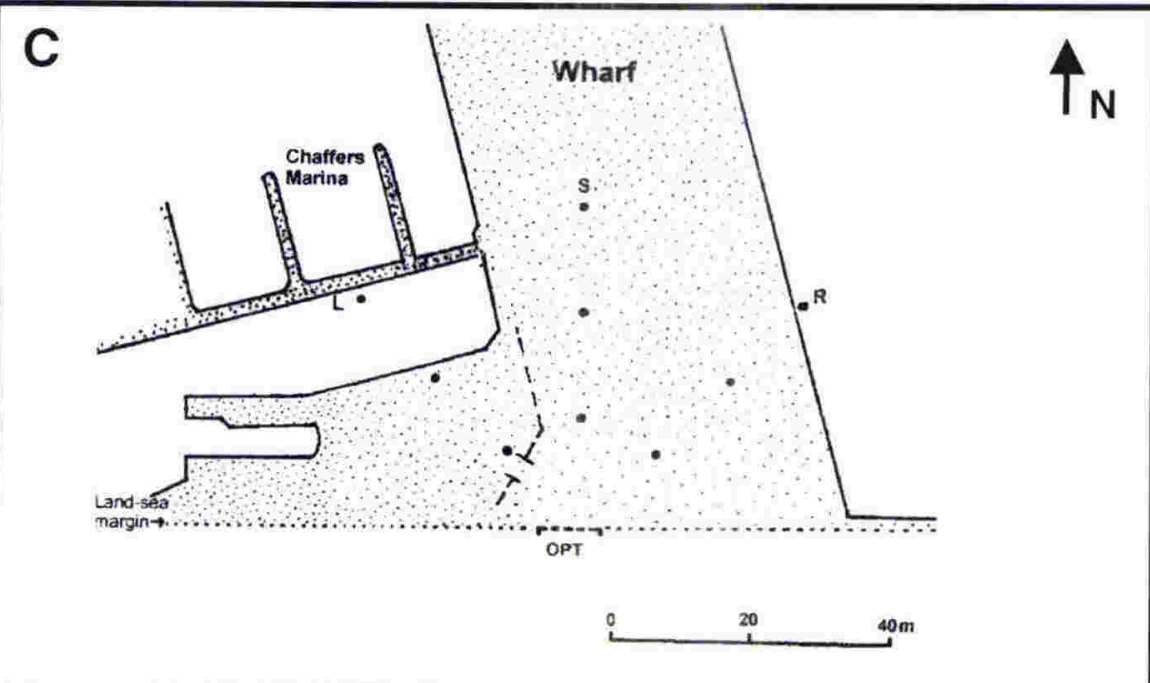

Figure 2.5: Lambton Harbour outlets

A: Position of each outlet sampled

B: Schematic position of sampling stations at the Frank Kitts outlets

C: Schematic position of sampling stations at the OPT outlet

Transects: L - left. LS - Left straight, RS - Right straight, S - Straight, R - Right 
Protocol for estuarine monitoring in New Zealand recommends the use $13 \mathrm{~cm}$ diameter cores (Robertson et al., 2002).

The routine temporal sampling i.e. repeated sampling, at a station was also carried out within the $1.5 \mathrm{~m}$ radius of the permanent station marker. Prior to the routine temporal sampling, random numbers were generated to determine the angle (relative to north) and the distance from the marker $(0-1.25 \mathrm{~m})$ at which the samples were to be collected. Because of the nature of this study, repeated sampling at the same stations could not be avoided, however, less that $2.5 \%$ of the total sample area at each station was sampled on each occasion, and the samples were not taken at the exact same location on each occasion (as a result of the random sampling method used). By sampling a small proportion relative to the total area of a plot from which the samples are to be collected, subsequent samples are presumed to be unaffected by the collection of samples from a previous time (Morrisey et al., 1996). At no time was there any evidence of previous sampling at a station, which, according to Don Morrisey (NIWA, pers.com.), is an indication that the sediment and biota had 'recovered'. In addition the routine sampling was carried out at both control and outlet stations and therefore any effects of repeated sampling are unlikely to account for the differences in the sediments, metals and macrobiota between outlet and control stations.

\subsubsection{Spatial Variation}

The aim of this part of the study was to investigate:

- The effect and the spatial extent of the effect of stormwater discharge on sediment structure and the concentration of As and metals in the sediment in the vicinity of stormwater outlets

- The effect and the spatial extent of the effect of stormwater discharge on the presence and abundance of the macrobiota in the vicinity of stormwater outlets

\subsection{1.a Sampling}

In November 1998 sampling was carried at the 9 stations of all the outlet and control sites (File: Sampling dates, Appendix II). In May 1999 stations at 3 of the outlet and 2 of the 
control sites (AQ-2, EB-1, EB-2, AQ-C and EB-C) were re-sampled (File: Sampling dates, Appendix II); an additional station at the outer end of each transect was also sampled i.e. 12 stations. The additional stations at AQ-2 and AQ-C were at $40 \mathrm{~m}$ and at EB-1, EB-2 and EB-C were at $54 \mathrm{~m}$ from the outlet or a fixed point on the shore. These additional stations were sampled in order to get a more accurate measure of the outer extent of effect of stormwater discharge because metal concentrations and organic matter levels at the outer stations at some outlets in November 1998 were above control site levels.

\subsection{1.b $\underline{\text { Samples collected at each station }}$}

At each station the following samples were collected:

- Three random sediment samples for analysis of organic matter content

- One random sediment sample for grain size analysis

- One random sediment sample for metal analysis

Four random samples were collected for macrobiota analysis at six of the stations in November 1998 and seven of the stations in May 1999. These stations were:

- All stations on the straight transect

- One station on the right transect: station R20 (Aotea Quay and Queens Wharf sites), R34 (Evans Bay sites), R30 (OPT)

- Two stations on the left transect : stations L10 and L30 (Aotea Quay and Queens Wharf sites), L24 and L44 (Evans Bay sites), L15 and L45 (OPT).

Three samples were processed, with the fourth available for use in case of accidental spillage or loss of a sample.

\subsubsection{Temporal Variation}

The aim of this part of the study was to investigate:

- The temporal effect of stormwater discharge on sediment structure and the concentration of As and metals in the sediment

- The temporal effect of stormwater discharge on the presence and abundance of the macrobiota 


\subsection{2.a Quarterly sampling}

\section{Sampling}

Quarterly sampling was carried out at seven stations at sites AQ-2, AQ-C, Q-2, EB-2 and EB-C from August 1998 to November 2000 (File: Sampling dates, Appendix II). At AQ2, AQ-C and Q-2 these stations were S2, S10, S20, L10, L20, R10 and R10 and at EB-2 and EB-C they were S24, S34, S44, L24, L34, R24 and R34. These stations were permanently marked with untreated wooden stakes.

\section{Samples collected at each station}

At each station the following samples were collected:

- Three random sediment samples for analysis of organic matter content

- One random sediment sample for metal analysis, except on the first sampling occasion when three random sediment samples were collected for metal analysis.

\subsection{2.b Monthly sampling for a year followed by quarterly sampling for 15 months}

\section{Sampling}

Sampling was carried out at station S10 at AQ-2, AQ-C and station S24 at EB-2 and EBC monthly for a year (from August 1998 to September 1999), and then quarterly for 15 months (from September 1999 to November 2000) (File: Sampling dates, Appendix II).

\section{Samples collected at each station}

On each sampling occasion the following samples were collected:

- 3 random sediment samples for analysis of organic matter content

- 1 random sediment sample for metal analysis

- 7 random samples for macrobiota analysis. Six of the samples were processed with the seventh available for use in case of accidental spillage or loss of a sample.

On 8 out of the 19 sampling occasions sediment was also collected for grain size analysis.

\subsection{Methods used for the collection of the samples}

All samples were collected by a SCUBA diver using purpose built samplers.

The organic matter, grain size and metal samples were collected using a plastic scoop with a $20 \mu \mathrm{m}$ mesh bag attached (Fig. 2.6) to retain the sediment. To ensure that the sediment analysed was representative of the actual sediment present i.e. there was not a 
loss of the $<20 \mu \mathrm{m}$ fraction, sufficient sediment was collected into the bag to ensure there was enough in the middle of the bag. Sediment from the middle of the mesh bag was used for the analyses. Macrobiota were collected using custom-made stainless steel samplers. Each macrobiota sample was $0.011 \mathrm{~m}^{2}$ in area and $15 \mathrm{~cm}$ deep.

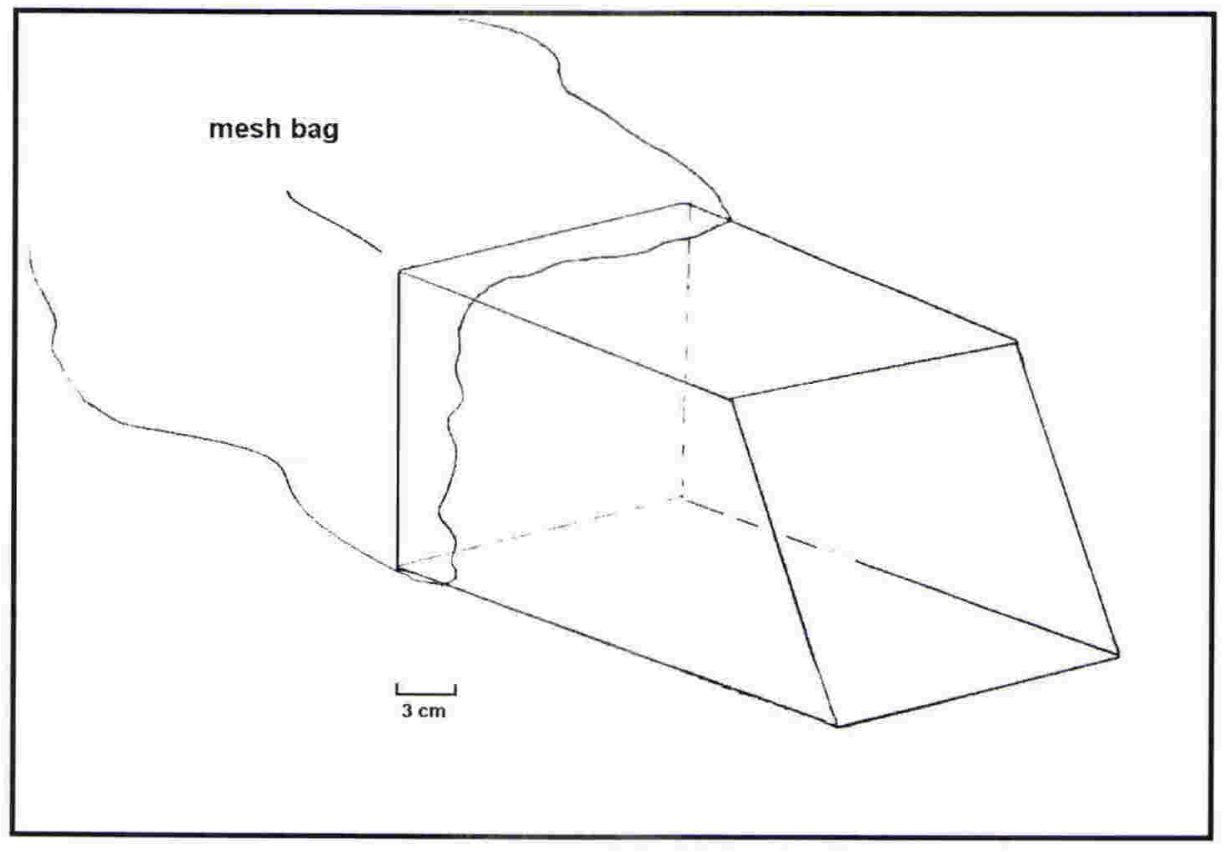

Figure 2.6: Diagram of the plastic scoop with attached $20 \mu \mathrm{m}$ mesh bag used to collect the sediment. 


\section{Chapter 3}

\section{THE EFFECT OF STORMWATER DISCHARGE ON SEDIMENT CHARACTERISTICS}

\subsection{INTRODUCTION}

Marine soft sediments are a complex semi-solid mixture comprised of different sized mineral particles, particulate organic matter, interstitial water, microbes and flocculated chemicals (Burton and MacPherson, 1995). The exact composition of the sediment at any given location depends on the proximity of the site to sources of these materials, the water chemistry, and the local hydrological conditions.

Shallow nearshore sediments can be extremely dynamic with continuous deposition of terrigenous and/or marine material from the water column, resuspension of particles at the sediment-water interface and reworking of the sediment through bioturbation. Such sediments in the vicinity of stormwater outlets are, in addition, subject to irregular flows of freshwater that can carry a wide range of inorganic and organic particles. The inorganic particles in stormwater can include a range of anthropogenic materials such as brick, glass, concrete, dust, paint chips, ash, plastics, litter and roading materials, and soil (inorganic fraction). The organic fraction can include soil (organic fraction), plant and animal debris, faecal matter and food wastes (Williamson, 1993; Ellis, 1976; Vincent and Thomas, 1997). The type and amount of these particles in stormwater is extremely variable and dependent upon the characteristics of, and land use in, the catchment and its water flow (Williamson, 1993; Mosley et al., 1997). For example, in residential and commercial urban catchments the suspended solid loading of stormwater has been calculated as being $0.44 \mathrm{t} \mathrm{ha}^{-1} \mathrm{yr}^{-1}$ in Sydney, Australia (Cordery, 1976 cited in Kennedy, 1981), $0.39 \mathrm{t} \mathrm{ha}^{-1} \mathrm{yr}^{-1}$ in Christchurch, New Zealand (Meyer, 1978), and 0.052 $\mathrm{t} \mathrm{ha}^{-1} \mathrm{yr}^{-1}$ in Dunedin, New Zealand (Mosley et al., 1997).

The deposition of this wide range of inorganic and organic particles beyond an outlet has the potential to change the composition of the nearshore soft sediments. Detailed data on the effect of stormwater discharge on the composition of soft sediments is however lacking for inner Wellington Harbour, the Wellington region, and New Zealand in general. Analyses of sediment composition in the vicinity of stormwater outlets will therefore increase the 
knowledge base of the effect of stormwater discharge on the nearshore environment and, in addition, will provide data with which the Local Authorities in Wellington will be able to make informed decisions with regard to regulating discharges into receiving waters under the Resource Management Act (1991). Sediment composition also has the potential to affect the biota as it is an important determinant of the composition of infaunal (living in the sediment), communities (Sanders, 1958; Gray, 1974) and there is also a well recognised biotic response to organic matter enriched sediment (Pearson and Rosenberg, 1978).

The overall aim of this section of the study is to investigate the effect of stormwater discharge on the spatial and temporal variability of the composition of the nearshore sediments in the vicinity of selected stormwater outlets in inner Wellington Harbour. Organic matter content and grain size were the characteristics used for this purpose. In addition, to determine if the temporal variability of organic matter content is linked to meteorological conditions, relationships between organic matter content and meteorological conditions were also investigated.

\subsection{METHODS}

\subsubsection{Sediment Sampling}

\subsection{1. a Sample Collection}

To assess the effect of stormwater discharge on sediment composition the top $2-3 \mathrm{~cm}$ of the sediment was sampled. The mean sediment accumulation rate in Wellington Harbour is about $37 \mathrm{~mm} \mathrm{yr}^{-1}$ (Goff et al., 1998) meaning that the most recently deposited, rather than historically deposited, sediment was collected. Each sample was scooped from the seafloor by a SCUBA diver using a purpose built plastic sampler with a $20 \mu \mathrm{m}$ mesh bag attached at the rear of it. Scooped sediment collected in the mesh bag. These samples were collected from stations at outlet and control sites (Section 2.3).

\subsection{1.b Spatial Variation sampling}

At each station sampled in November 1998 (Section 2.4.1.a) 4 random sediment samples were collected, 3 for the analysis of organic matter content and 1 for the analysis of grain size.

At each station sampled in May 1999 (Section 2.4.1.a) 3 random sediment samples were collected for the analysis of organic matter content. In addition, 1 sample was collected from the extra station at the outer end of each transect for grain size analysis (Section 2.4.1a). 


\subsection{1.c Temporal Variation sampling}

\section{Quarterly sampling}

At each station sampled quarterly (Section 2.4.2.a) from August 1998 to November 2000 (File: Sampling dates, Appendix II) 3 random sediment samples were collected for the analysis of organic matter content.

\section{Monthly sampling for a year followed by quarterly sampling for 15 months}

At each station sampled monthly for a year (from August 1998 to September 1999) then quarterly for 15 months (from September 1999 to November 2000) (File: Sampling dates, Appendix II) (Section 2.4.2.b) 3 random sediment samples were collected for the analysis of organic matter content. On 8 of the 19 sampling occasions samples were also collected for grain size analysis, with 3 random samples collected on 3 of the 8 occasions and one collected on each of the other 5 occasions.

Note: Samples collected as EB-2 station S24 in May 2000 were discarded because the station marker was not found due to low water visibility.

\subsubsection{Sample Processing}

Each sediment sample was homogenised and a representative sub-sample taken for analysis.

\subsection{2.a Determination of organic matter content}

Approx. $30 \mathrm{~g}$ of the homogenised sediment were dried at $40^{\circ} \mathrm{C}$ and then weighed at room temperature. The dried sediment was heated to $450^{\circ} \mathrm{C}$ in a muffle furnace for $24 \mathrm{~h}$ and then re-weighed after cooling to room temperature. The weight difference (weight loss on ignition) defined the organic matter content of each sediment sample. Determination of organic matter content of sediments using this method has been found to correlate well with total organic carbon values in sediments (Dahlbäck and Gunnarsson 1981). This method is widely used and is relatively quick and easy to carry out.

\subsection{2.b Determination of grain size}

Stormwater can carry a wide range of inorganic particles and therefore the focus of this part of the overall study is the composition of the grain size of the inorganic fraction, excluding particles of biological origin, of the nearshore sediments. The sediment samples were therefore processed using a methodology in which the organic matter and carbonate was removed before the grain size of the inorganic fraction was determined (Barrett and Brooker, 1989). 
Approx. $150 \mathrm{~g}$ of the homogenised sediment were dried at $40^{\circ} \mathrm{C}$ and then weighed at room temperature. $30 \%$ hydrogen peroxide $\left(\mathrm{H}_{2} \mathrm{O}_{2}\right)$ solution was added to oxidise the organic matter present. To aid in this process the samples were maintained in a water bath at $30^{\circ} \mathrm{C}$ and more $\mathrm{H}_{2} \mathrm{O}_{2}$ added as required until organic matter oxidation was complete i.e. no production of bubbles on addition of more $\mathrm{H}_{2} \mathrm{O}_{2}$ (this took up to three weeks for some samples because of their high organic matter content). Samples were rinsed with distilled water and centrifuged at $5000 \mathrm{rpm}$ for $10 \mathrm{~min}, 3$ times, before being dried at $40^{\circ} \mathrm{C}$ and reweighed at room temperature.

$10 \%$ hydrochloric acid $(\mathrm{HCl})$ was then added to remove the carbonate. Samples were rinsed with distilled water and centrifuged at $5000 \mathrm{rpm}$ for $10 \mathrm{~min}, 3$ times, before being dried at $40^{\circ} \mathrm{C}$ and reweighed at room temperature. Carbonate content was determined as the weight loss due to treatment with $\mathrm{HCl}$.

Each sample was then thoroughly mixed with the dispersant Calgon $\left(2.55 \mathrm{~g} \mathrm{l}^{-1}\right.$ sodium hexametaphosphate) before being wet sieved through a $0.63 \mu \mathrm{m}$ mesh to separate the sediment into coarse $(>0.63 \mu \mathrm{m})$ and fine $(<0.63 \mu \mathrm{m})$ grained fractions. Each fraction was rinsed with distilled water and centrifuged at $5000 \mathrm{rpm}$ for $10 \mathrm{~min}, 3$ times, before being dried at $40^{\circ} \mathrm{C}$ and reweighed at room temperature. The dry coarse-grained fraction was processed through a half-phi interval sieve series $(-3.5$ to 5 phi) on a Fritsch shaker for 6 min on intermittent mode, $6 \mathrm{~min}$ on micro mode and $6 \mathrm{~min}$ on intermittent mode. After sieving, each size fraction was weighed. The particle size analysis of the fine-grained fraction (4 to 10 phi) was carried out using a sedigraph. A sedigraph is a scientific instrument which uses soft XRays to determine the relative particle concentrations of particles $<0.63 \mu \mathrm{m}$. From the relative particle concentrations of a known weight of the $<0.63 \mu \mathrm{m}$, the weight of each fraction from 4 to 10 phi can be calculated.

The resulting data from the coarse and fine-grained analyses were combined and entered into the Grain size 1-2 software programme (P. Barrett and J. Adams, School of Earth Sciences, Victoria University, Wellington) for analysis. 


\subsubsection{Data Analyses}

\subsection{3.a Organic Matter Content}

\subsection{3.a.1 Spatial Variability}

Assessment of anthropogenic input of organic matter

The null hypothesis to be tested is:

The organic matter content of the sediment in the vicinity of stormwater outlets is the same as the organic matter content of the sediment at the control sites

Organic matter enrichment (OME) was used to determine if, and by how much, stormwater discharge affected the organic matter content in the vicinity of each outlet. OME was calculated for the sediment from each station at each outlet by dividing the mean organic matter percentage (from 3 samples) at the station, by a control site value.

The control site values used in the calculation of OME were the mean organic matter percentage over all samples at all stations (except at AQ-C) and were: AQ-C -- "under-wharf" stations - 6.5\% in $1998(\mathrm{n}=15)$ and 6\% in $1999(\mathrm{n}=15)$

-- "beyond-the-wharf" stations - $2.9 \%$ in $1998(\mathrm{n}=12)$ and $3.1 \%$ in $1999(\mathrm{n}=21)$

EB-C -- 2.1\% in $1998(\mathrm{n}=27)$ and $2 \%$ in $1999(\mathrm{n}=36)$

Q-C -- $7.8 \%$ in $1998(\mathrm{n}=27)$

OME at OPT stations was calculated using the AQ-C "under-wharf" value.

OME was not calculated for the sediment at the FK stations (see Section 3.2.3.a.1) as no control site values were suitable for determining OME at these stations; all the control site values (from AQ-C, Q-C and EB-C) were either too high or too low compared to the values at the stations furthest from the FK outlets.

An OME of $>1.0$ indicates the organic matter content at the outlet station is greater than at the control site and an $\mathrm{OME}<1.0$ indicates that the organic matter content at the outlet station is less than at the control site.

Organic matter content with distance and direction from an outlet or the shore The null hypotheses to be tested are:

There is no significant difference in sediment organic matter content with distance from an outlet 
There is no significant difference in sediment organic matter content with direction from an outlet

To determine if there was a significant difference in the organic matter content with distance and direction from an outlet or a point on the shore, a nested [distance and direction (nested in distance)] Analysis of Variance (ANOVA) was used (STATISTICA version 5.5). Where a significant distance and/or direction effect occurred, a posteriori multiple comparisons were performed using the Student-Newmans-Keuls test. The data (percent) were converted to a proportion for statistical analyses. Heteroscedastic raw data (Cochran's $C, p=0.05$ ) were transformed ( $\log$ or square root) to achieve homogeneity of variances (Cochran's $C, p<0.05$ ). Where the data remained heteroscedastic after transformation, non-parametric Kruskal-Wallis ANOVA was performed on the raw data (SYSTAT version 6.1). Using the non-parametric ANOVA it was not possible to nest direction in distance.

In addition, ANOVA was used to determine if there was a significant difference in the sediment organic matter content with direction i.e. L, S or R, from an outlet or a point on the shore. All 9 samples collected at the stations on each transect were used in the statistical analysis. As the data remained heteroscedastic after transformation, non-parametric KruskalWallis ANOVA was performed on the raw data (SYSTAT version 6.1).

\subsection{3.a.2 Temporal Variability}

Organic matter content at each station over time

The null hypothesis to be tested is:

The sediment organic matter content at outlet and control stations does not change significantly over time

ANOVA was used to determine if there was a significant difference in the organic matter content over time (28 months) at each station at each outlet and control site. The data (percent), which were converted to a proportion for statistical analysis, remained heteroscedastic (Cochran's $\mathrm{C}, \mathrm{p}=0.05$ ) after transformation. The raw data were therefore analysed using non-parametric Kruskal-Wallis ANOVA (SYSTAT version 6.1). 
Comparison of organic matter content between outlet and control stations

The null hypothesis to be tested is:

There is no significant difference in sediment organic matter content between an outlet station and the associated control station over time

ANOVA was used to determine if there was a significant difference over time between the organic matter content at each outlet station and the associated control site station. The data (percent), which were converted to a proportion for statistical analysis, remained heteroscedastic (Cochran's $\mathrm{C}, \mathrm{p}=0.05$ ) after transformation. The raw data were therefore analysed using non-parametric Kruskal-Wallis ANOVA.

\subsection{3.b Relationship of organic matter content over time to meteorological parameters}

The null hypothesis to be tested is:

There is no significant relationship of sediment organic matter content over time to each of the meteorological parameters

Changes in the organic matter content in the vicinity of the outlets over time could result from the rainfall and wind conditions prior to sampling, hence the relationships between organic matter and meteorological conditions are investigated. The temporal data (monthly sampling for a year, followed by quarterly sampling for 15 months) were used to calculate OME for each sampling time for stations S10 at AQ-2, and S24 at EB-2 while the data from quarterly sampling were used to calculate the OME for station S20 at AQ-2. OME was calculated by dividing the mean organic matter percentage (from 3 samples) at a station by the mean percentage from the associated control site station. The correlation of the OME from each station to each of the rainfall and wind parameters listed below was initially investigated by the generation of a Pearson correlation matrix. All correlations with a Pearson correlation coefficient value of $\geq 0.65$ or $\leq-0.65$ were assessed by linear regression (GLM: Estimate model). The simple linear regression significance level was $\alpha=0.05$, with corrections made to $\alpha$ when multiple tests were performed (Rice, 1989). Rainfall data (daily total) for Evans Bay (Hataitai) and Aotea Quay (Kelburn) (i.e. different sets of rainfall data) were provided by the Wellington City Council and the wind data (daily mean wind speed) were provided by NIWA Wellington. 


\section{Rainfall parameters used:}

a. number of days $>1 \mathrm{~mm}$ of rain

b. number of days $>10 \mathrm{~mm}$ of rain

c. highest daily rainfall

d. Number of days of antecedent dry period (plant material e.g. leaves and twigs, has time to accumulate) before the highest daily rainfall

in either the month prior to sampling (quarterly sampling) or the period between sampling (monthly sampling).

\section{Wind parameters used:}

a. number of days $>3.4 \mathrm{~ms}^{-1}$ (leaves and twigs in motion (Beatson, 1985)) mean wind speed

b. number of days $>8 \mathrm{~ms}^{-1}$ (small trees begin to sway) mean wind speed

c. highest mean wind speed

in either the month prior to sampling (quarterly sampling) or the period between sampling (monthly sampling).

\subsection{3.c Grain size}

Mean grain size $(\phi)$ (size classification is given in Table 3.1), the sediment sorting coefficient (Folk) (a measure of the uniformity of the sediment) (classification is given in Table 3.2), \%gravel $(\geq 2 \mathrm{~mm}), \%$ sand $(63 \mu \mathrm{m}-2 \mathrm{~mm}), \%$ silt $(4-63 \mu \mathrm{m})$ and \%clay $(<4 \mu \mathrm{m})$ were calculated for each sample using the Grain Size 1-2 software programme (School of Earth Sciences, Victoria University, Wellington) using indices developed by Folk and Ward (1957).

Table 3.1: Classification of sediment by size (from Folk, 1980)

\begin{tabular}{|cccl|}
\hline Phi $(\phi)$ & mm limits & $\mu$ m limits & $\begin{array}{l}\text { Particle } \\
\text { classification }\end{array}$ \\
-4 & 16 & 16000 & large pebble \\
-3 & 8 & 8000 & medium pebble \\
-2 & 4 & 4000 & small pebble \\
-1 & 2 & 2000 & granule \\
0 & 1 & 1000 & very coarse sand \\
1 & 0.5 & 500 & coarse sand \\
2 & 0.25 & 250 & medium sand \\
3 & 0.125 & 125 & fine sand \\
4 & 0.063 & 62.5 & very fine sand \\
5 & 0.032 & 32 & coarse silt \\
6 & 0.015 & 15 & medium silt \\
7 & 0.008 & 8 & fine silt \\
8 & 0.004 & 4 & very fine silt \\
9 & 0.002 & 2 & coarse clay \\
10 & 0.001 & 1 & medium clay \\
\hline
\end{tabular}


Table 3.2: Descriptive terms used for sediment sorting (Dispersion)

Calculated using the formula of Folk (Graphic Standard Deviation)

$\sigma_{1}=\frac{\phi_{84}-\phi_{16}}{4}+\frac{\phi_{95}-\phi_{5}}{6.6}$

(from Folk, 1980)

\begin{tabular}{|lc|}
\hline Description & Value $\left(\sigma_{1}\right)$ \\
\hline Very well sorted & $<0.35$ \\
Well sorted & $0.35-0.50$ \\
Moderately well sorted & $0.50-0.70$ \\
Moderately sorted & $0.70-1.00$ \\
Poorly sorted & $1.00-2.00$ \\
Very poorly sorted & $2.00-4.00$ \\
Extremely poorly sorted & $>4.00$ \\
\hline
\end{tabular}

Decreasing uniformity of sediment grain size

Ternary scatterplots of $\%$ gravel, $\%$ sand and $\%$ mud ( where $\%$ mud $=\%$ silt $+\%$ clay) (van der Linden, 1967; Folk, 1980) and \%sand, \%mud and \%carbonate (van der Linden, 1967) graphically present the spatial and temporal grain size data. No statistical analyses were performed on data because of the non-replication of samples from a station.

\subsection{RESULTS}

\subsubsection{Organic Matter Content}

\subsection{1.a Spatial Variability}

Organic matter content ranged from 1\% (EB-1, station L44) to 43.7\% (OPT, station S30) in the 303 samples collected in November 1998, and from 1.1\% (EB-1, station S54) to $16.2 \%$ (AQ-1, station L20) in the 180 samples collected in May 1999 (File: Sediment Organic Matter, Appendix II).

\subsection{1.a.1 Assessment of anthropogenic input of organic matter}

Stormwater discharge has resulted in organic matter enrichment of sediments in the vicinity of all outlets (excluding FK) (Table 3.3). Enrichment typically decreased with increasing distance from an outlet and changed through time. The highest enrichment at Q-2, EB-1 and EB-2 was at stations close to the outlet while at Q-1, AQ-1 and AQ-2 it was at $20 \mathrm{~m}$ stations. The outward extent of organically enriched sediment at AQ-1, AQ-2 and OPT was not determined because it extended beyond the outer limit of sampling ( $30 \mathrm{~m}$ at AQ-1, $40 \mathrm{~m}$ at AQ-2 and $45 \mathrm{~m}$ at OPT). 
The null hypothesis that the organic matter content of the sediment in the vicinity of stormwater outlets is the same as the organic matter content of the sediment at the control sites is rejected. Organic matter enrichment of sediment occurs in the vicinity of stormwater outlets.

At each outlet an average OME was calculated (using the OME values for all stations sampled, Table 3.3) and then used to rank the outlets from the most to least organically enriched sediment. The ranking of outlets was:

\section{8: $\mathbf{A Q - 2}>$ OPT $>$ AQ-1 $>$ EB-1 $>$ Q-1 $>$ Q-2 $>$ EB-2 \\ 1999: $\mathbf{A Q - 2}>$ EB-1 $>$ Q-2 $>$ EB-2}

\subsection{1.a.2 Organic matter content with distance}

\section{Control sites}

At Q-C and EB-C there was no significant difference in organic matter content with distance from shore (Table 3.4, Figs. 3.1, 3.2). At AQ-C in both 1998 and 1999 there was a significant decrease in the percent organic matter with increasing distance from the shore (Table 3.4, Fig. 3.3), and in general, higher percentages of organic matter occurred at stations under the wharf (R10, R20, S10, L10, L20) than at those beyond it (Fig. 3.3).

\section{Outlet sites}

At Q-2, EB-1, EB-2, AQ-1 and AQ-2 (1998) organic matter content was significantly higher closer to than further from the outlet (Table 3.4, Figs. 3.1, 3.2, 3.3). Organic matter content was significantly higher $20 \mathrm{~m}$ away from Q-1 and AQ-2 (1999), than at stations closer to and further away from these outlets and at FK and OPT there was no significant difference in organic matter content with distance from the outlet (Table 3.4, Figs. 3.1). At Q-2 (1998 and 1999) higher percentages extended to at least $10 \mathrm{~m}$ but not out to $20 \mathrm{~m}$ from the outlet (Tables 3.3, 3.4; Fig. 3.1A). At EB-1 higher percentages of organic matter extended to at least $24 \mathrm{~m}$ but not out to $34 \mathrm{~m}$ in 1998, and to $34 \mathrm{~m}$ but not out to $44 \mathrm{~m}$ in 1999 (Tables 3.3, 3.4; Fig. 3.2). At EB-2 in both 1998 and 1999 the organic matter content was significantly higher at the station closest to the outlet i.e. $24 \mathrm{~m}$, than at the stations further away. It was not possible to interpret distance effects at AQ-1 and AQ-2 because significant distance effects occurred at AQ-C. 
Table 3.3: Organic matter enrichment (OME) at each outlet as a function of distance, direction and time

$\mathrm{OME}>1.0$ indicates the $\% \mathrm{OM}$ at the outlet is greater than the $\% \mathrm{OM}$ at the control $\mathrm{OME}<1.0$ indicates the $\% \mathrm{OM}$ at the outlet is less than the $\% \mathrm{OM}$ at the control

\begin{tabular}{|c|c|c|c|c|}
\hline Outlet/Time & Distance (m) & Left & Straight & Right \\
\hline \multirow[t]{3}{*}{ EB-1/1998 } & 24 & 3.01 & 2.36 & 1.7 \\
\hline & 34 & 1.68 & 1.26 & 1.05 \\
\hline & 44 & 1.76 & 1.15 & 0.57 \\
\hline \multirow[t]{4}{*}{ EB-1/1999 } & 24 & 1.76 & 1.89 & 1.11 \\
\hline & 34 & 1.95 & 1.39 & 1.19 \\
\hline & 44 & 1.24 & 1.24 & 1.11 \\
\hline & 54 & 1.02 & 1 & 0.94 \\
\hline \multirow[t]{3}{*}{ EB-2/1998 } & 24 & 0.87 & 0.86 & 0.95 \\
\hline & 34 & 0.6 & 0.84 & 0.75 \\
\hline & 44 & 0.54 & 0.76 & 0.71 \\
\hline \multirow[t]{4}{*}{ EB-2/1999 } & 24 & 0.98 & 1.41 & 0.93 \\
\hline & 34 & 0.72 & 0.88 & 0.8 \\
\hline & 44 & 0.69 & 0.74 & 0.69 \\
\hline & 54 & 0.73 & 0.69 & 0.77 \\
\hline \multirow[t]{3}{*}{ OPT/1998 } & 15 & 3.6 & 0.39 & 2.72 \\
\hline & 30 & 1.82 & 5.57 & 0.92 \\
\hline & 45 & 1.63 & 1.65 & 2.37 \\
\hline \multirow[t]{3}{*}{ Q-1/1998 } & 10 & 1.53 & 0.67 & - \\
\hline & 20 & 1.42 & 1.57 & 1.32 \\
\hline & 30 & 0.92 & 0.95 & 0.67 \\
\hline \multirow[t]{3}{*}{ Q-2/1998 } & 10 & 1.26 & 1.24 & 1.24 \\
\hline & 20 & 1.24 & 0.96 & 0.82 \\
\hline & 30 & 0.87 & 0.98 & 1.07 \\
\hline \multirow[t]{4}{*}{ Q-2/1999 } & 10 & 1.24 & 1.27 & 1.21 \\
\hline & 20 & 1.07 & 0.77 & 0.78 \\
\hline & 30 & 0.88 & 0.77 & 1.12 \\
\hline & 40 & 0.86 & 0.68 & 1.04 \\
\hline \multirow[t]{3}{*}{ AQ-1/1998 } & 10 & 1.85 & 2.22 & 1.41 \\
\hline & 20 & 1.11 & 2.45 & 2.14 \\
\hline & 30 & 2.13 & 1.58 & 1.2 \\
\hline \multirow[t]{3}{*}{ AQ-2/1998 } & 10 & 2.4 & 3.29 & 1.49 \\
\hline & 20 & 1.65 & 3.34 & 1.57 \\
\hline & 30 & 2.5 & 1.88 & 2.73 \\
\hline \multirow[t]{4}{*}{ AQ-2/1999 } & 10 & 1.21 & 1.45 & 1.36 \\
\hline & 20 & 1.99 & 3.14 & 1.91 \\
\hline & 30 & 1.79 & 1.17 & 2.47 \\
\hline & 40 & 1.48 & 1.6 & 1.83 \\
\hline
\end{tabular}


Table 3.4: The effect of distance and direction (nested in distance) on organic matter content at outlet and control sites in 1998 and 1999.

\begin{tabular}{|c|c|c|c|c|c|}
\hline \multirow{2}{*}{ Year } & \multirow{2}{*}{ Site } & \multicolumn{2}{|r|}{ Distance } & \multicolumn{2}{|c|}{ Direction(distance) } \\
\hline & & $\mathrm{p}$ & Sign.diff. & $\mathrm{p}$ & Sign.diff. \\
\hline \multirow[t]{11}{*}{1998} & AQ-C & $<0.0001$ & $10>20>30$ & $<0.0001$ & $\mathrm{~L} 20>\mathrm{S} 20$ \\
\hline & AQ-1 & 0.0005 & $10 \& 20>30$ & 0.977 & \\
\hline & AQ-2 & $<0.0001$ & $10>20>30$ & 0.092 & \\
\hline & Q-C & 0.0586 & & 0.898 & \\
\hline & Q-1 & 0.004 & $20>10 \& 30$ & 0.4822 & \\
\hline & Q-2 & $<0.0001$ & $10>20 \& 30$ & 0.002 & $\mathrm{~L} 20>\mathrm{S} 20 \& \mathrm{R} 20$ \\
\hline & FK & 0.065 & & 0.002 & $S>L \& R$ \\
\hline & OPT & 0.9638 & & 0.9468 & \\
\hline & EB-C & 0.778 & & 0.003 & $\mathrm{~S} 34>\mathrm{L} 34$ \\
\hline & EB-1 & 0.001 & $24>34 \& 44$ & 0.059 & \\
\hline & EB-2 & 0.002 & $24>34 \& 44$ & 0.084 & \\
\hline \multirow[t]{6}{*}{1999} & AQ-C & $<0.0001$ & $10>20>30>40$ & $<0.0001$ & $\begin{array}{l}\mathrm{L} 10>\mathrm{R} 10, \mathrm{~L} 20>\mathrm{S} 20, \\
\mathrm{~L} 30>\mathrm{S} 30 \& \mathrm{R} 30, \\
\mathrm{~L} 40>\mathrm{R} 40\end{array}$ \\
\hline & AQ-2 & $<0.0001$ & $20>10>30 \& 40$ & 0.028 & $\mathrm{R} 30>\mathrm{S} 30$ \\
\hline & Q-2 & 0.002 & $10>20 \& 30 \& 40$ & 0.069 & \\
\hline & EB-C & 0.128 & & 0.005 & S44> L44 \\
\hline & EB-1 & 0.01 & $24 \& 34>44$ & 0.003 & $\mathrm{~L} 34>\mathrm{R} 34$ \\
\hline & EB-2 & $<0.0001$ & $24>34 \& 44$ & 0.002 & $\mathrm{~S} 24>\mathrm{L} 24 \&$ R24 \\
\hline
\end{tabular}

The null hypothesis that there is no significant difference in sediment organic matter content with distance from an outlet is rejected. Organic matter content does change significantly with increasing distance from some outlets but the response was outlet-specific.

\subsection{1.a.3 Organic matter content with direction}

\section{Control sites}

At Q-C there was no significant difference in the percent organic matter with direction from shore (Tables 3.4, 3.5, Figs. 3.1, 3.2). At EB-C there was a statistically significant difference in organic matter with direction from the shore (Tables 3.4, 3.5). In 1998 organic matter content with significantly higher at stations on the straight transect than at those on the left and right transects while in 1999 it was significantly higher at stations on the right and straight transects than at those on the left transect. At EB-C in 1999 organic matter content was significantly higher at S44 m than L44 (Table 3.4, Fig. 3.2). At AQ-C sediments at many stations along the left transect had a higher organic matter content than the sediment at stations on other transects (Tables 3.4, 3.5). 

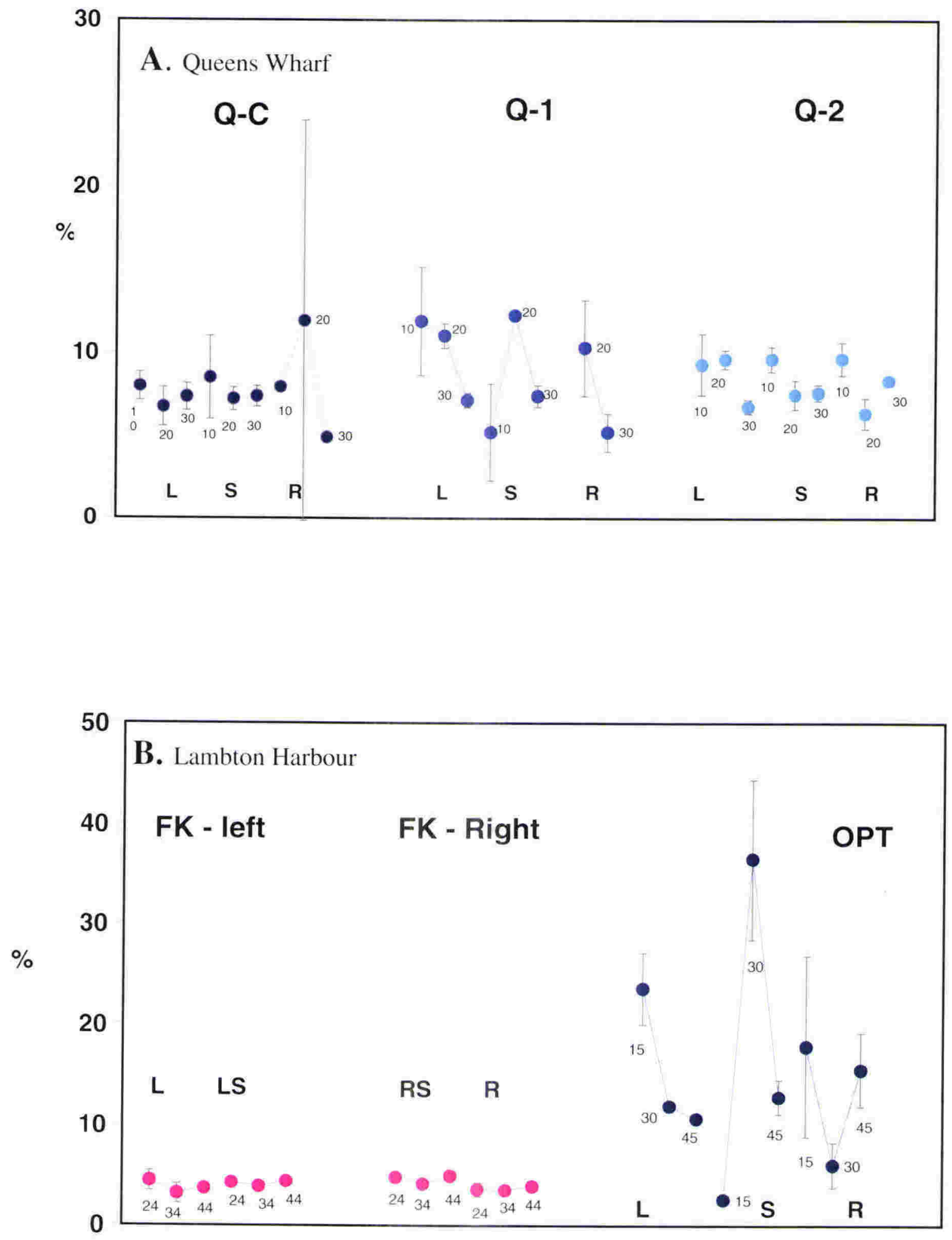

Figure 3.1: Mean ( $\pm 95 \% \mathrm{CI})$ organic matter content $(\%)$ at each station at Queens Wharf and Lambton Harbour.

$10,20,24,34 \mathrm{etc}$ - Distance $(\mathrm{m})$ from the outlet or a point on the shore L - Left Transect, S-Straight Transect, R-Right Transect 

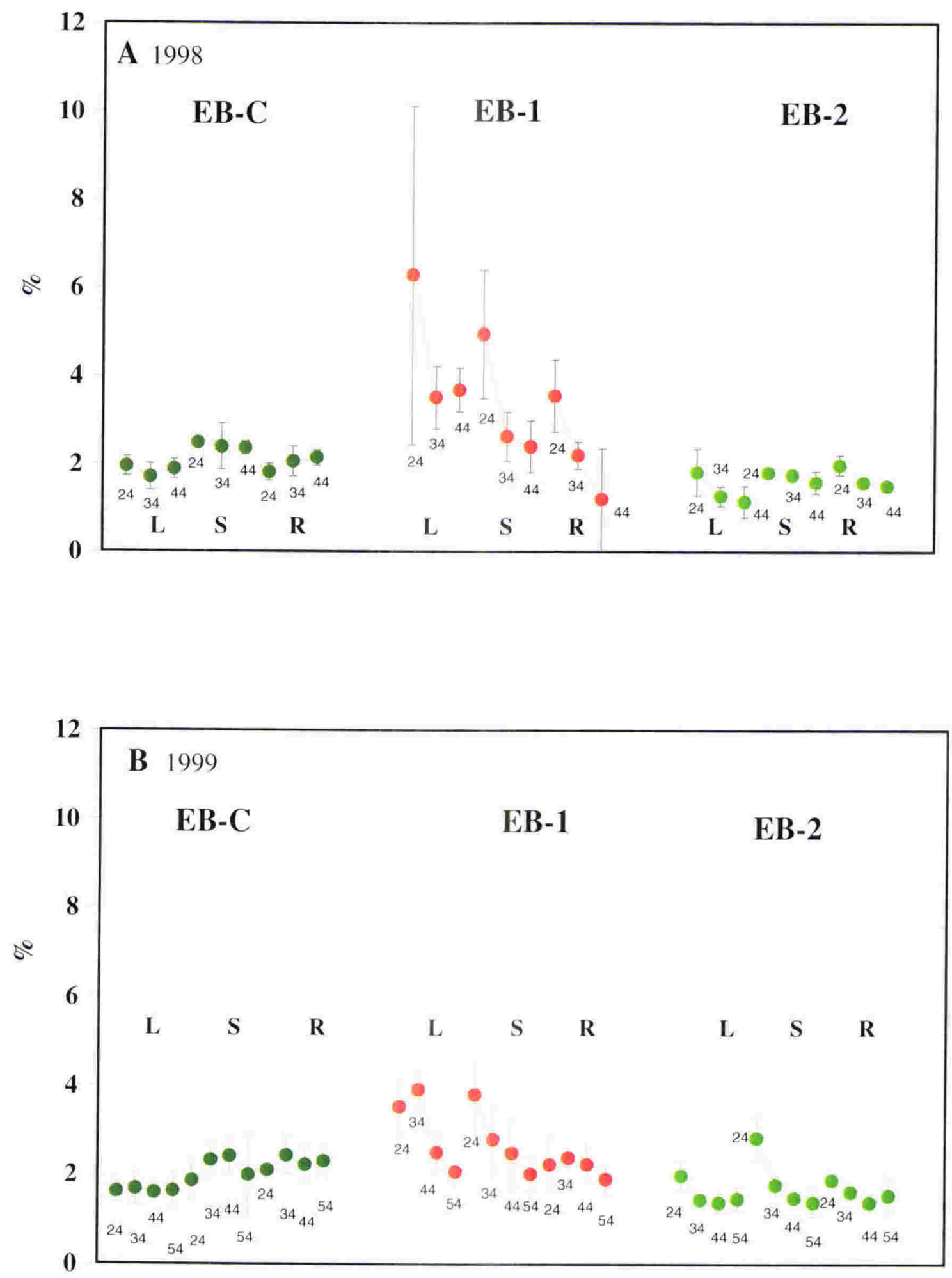

Figure 3.2 : Mean $( \pm 95 \% \mathrm{CI})$ organic matter (\%) at each station at each site in Evans Bay. $24,34,44,54$ - Distance $(\mathrm{m})$ from the outlet or a point on the shore

L - Left Transect, S - Straight Transect, R - Right Transect 

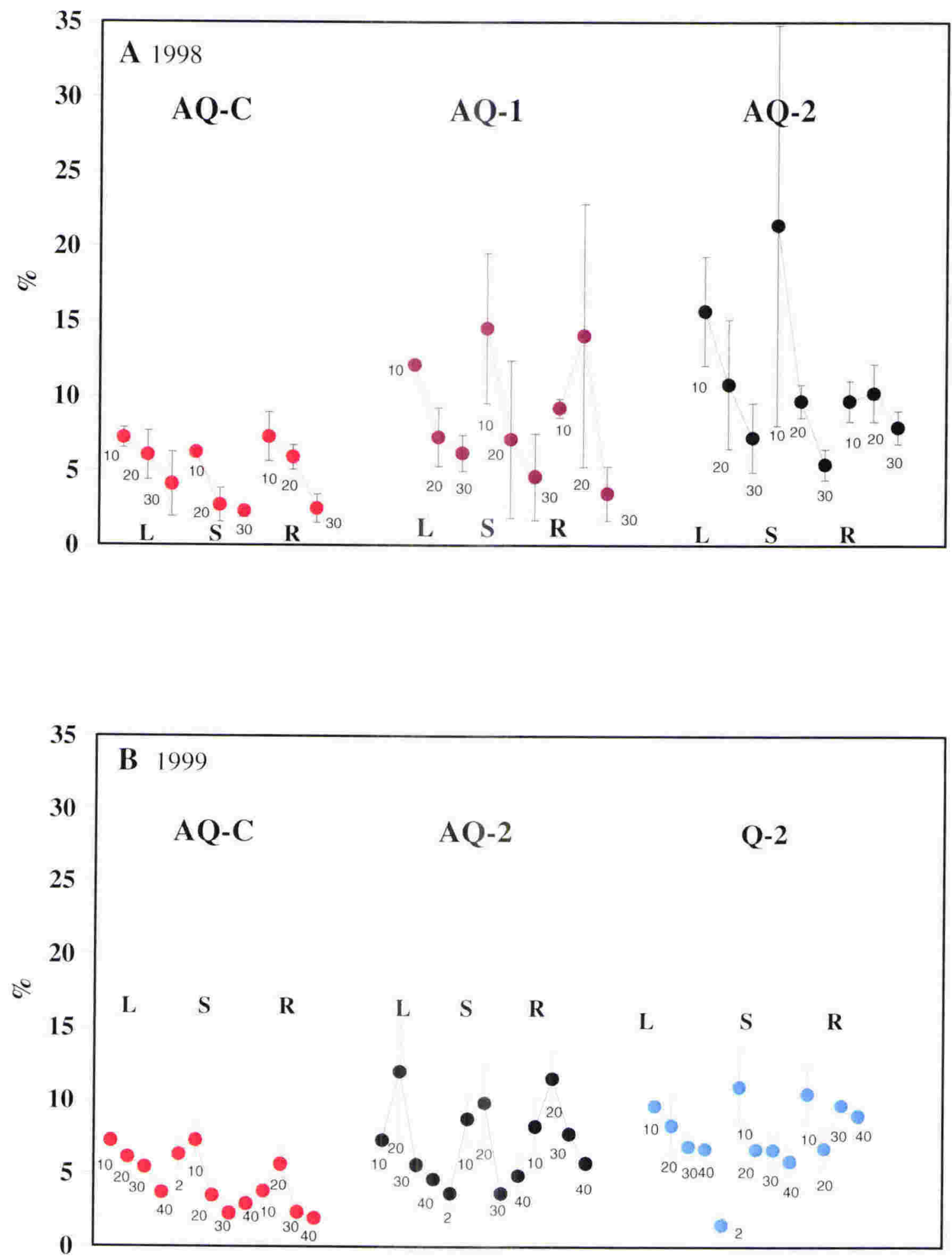

Figure 3.3: Mean ( $\pm 95 \%$ CI) organic matter (\%) at each station at the Aotea Quay sites in 1998, and the Aotea Quay and Queens Wharf sites in 1999

10, 20, 30 - Distance $(\mathrm{m})$ from the outlet or a point on the shore L - Left Transect, S - Straight Transect, R - Right Transect 


\section{Outlet sites}

At OPT, AQ-2 (1998) and EB-2 (1999) the organic matter content was higher at stations straight $(\mathrm{S})$ in front of the outlet than at stations on the left (L) and right (R) transects (Table 3.3, Figs. 3.1-3.3). At EB-1 (1998 and 1999) the sediment at stations on the L and S transects was organically enriched (Table 3.3, Fig. 3.2), while at AQ-1, AQ-2 (1999) and Q-1 sediments on all transects were enriched above control site levels (Table 3.3, Figs. 3.1, 3.3).

The organic matter content at EB-1 was significantly higher to the left than the right of the outlet and at FK it was significantly higher on the straight than the left and right transects (Table 3.5). There was significantly higher sediment organic matter content at S24 than at L24 and R24 at EB-2 in 1999, L24 than R24 at EB-1 in 1999 and L20 than S20 and R20 at Q2 in 1998 (Table 3.4). It was not possible to interpret direction (nested in distance) effects at AQ-2 in 1999 because significant direction (nested in distance) effects also occurred at AQ-C in 1999 (Table 3.4).

Table 3.5: The effect of direction on organic matter content at outlet and control sites in 1998 and 1999. Results from Kruskal-Wallis ANOVA.

\begin{tabular}{|c|c|c|c|c|c|}
\hline \multicolumn{3}{|c|}{1998} & \multicolumn{2}{|c|}{1999} & \\
\hline Site & $\mathrm{p}$ & sign. diff. & Site & $\mathrm{p}$ & sign. diff. \\
\hline$\overline{\mathrm{AQ}-1}$ & 0.98 & & $\mathrm{AQ}-2$ & 0.24 & \\
\hline AQ-2 & 0.75 & & AQ-C & 0.011 & $L>S \& R$ \\
\hline AQ-C & 0.21 & & Q-2 & 0.07 & \\
\hline Q-1 & 0.48 & & EB-1 & 0.026 & $L>R$ \\
\hline Q-2 & 0.90 & & EB-2 & 0.23 & \\
\hline Q-C & 0.90 & & EB-C & 0.001 & $S \& R>L$ \\
\hline FK & 0.002 & $S>L \& R$ & & & \\
\hline OPT & 0.96 & & & & \\
\hline EB-1 & 0.028 & $L>R$ & & & \\
\hline EB-2 & 0.065 & & & & \\
\hline EB-C & 0.001 & $S>L \& R$ & & & \\
\hline
\end{tabular}

The null hypothesis that there is no significant difference in sediment organic matter content with direction from an outlet is rejected. Organic matter content is significantly different with direction from some outlets but the response is outlet-specific.

\subsection{1.b Temporal Variablility}

3.3.1.b.1 Temporal variability in organic matter at the control sites

The organic matter content changed significantly over time at EB-C stations S44 $(\mathrm{p}<0.012)$ (range in mean value: $1.8-2.4 \%$ ) and L24 ( $<<0.013$ ) (range in mean value: 1.6-2.2\%) (Files: 
EB Organic Time Graphs1 and Graphs2, Appendix II) and at AQ-C stations R10 ( $<<0.016)$ (range in mean value: 3.8-9.3\%), R20 ( $<<0.013$ ) (range in mean value: 4.6-9.4\%) and S20 $(\mathrm{p}<0.009)$ (range in mean value: 2.7-6.7\%) (Files: AQ Organic Time Graphs1 and Graphs2, Appendix II). At EB-C stations S24, S34, L34, R24 and R34 and AQ-C stations S2, S10, L10 and L20 organic matter did not change significantly over time.

\subsection{1.b.2 Temporal variability in organic matter at outlet sites}

Over time organic matter content changed significantly at EB-2 station S24 time $(\mathrm{p}<0.003)$ (range in mean value: 1.8-3.1\%) (Fig.3.4), at Q-2 stations S2 ( $<<0.011)$ (range in mean value: $1.1-2.2 \%$ ) and R20 ( $<<0.015$ ) (range in mean value: 4.8-8.6\%) (Files: AQ Organic Time Graphs1 and Graphs2, Appendix II) and at AQ-2 stations S10 (p<0.002) (range in mean value: $6.1-42.8 \%$ ) (Fig. 3.5) and S20 ( $<<0.026)$ (range in mean value: $6.0-18.5 \%$ ). There was no significant difference in the percent organic matter over time at EB-2 stations S34, S44, L24, L34, R24 and R34, Q-2 stations S10, S20, L10, L20 and R10 and AQ-2 stations S2, L10, L20, R10 and R20.

The null hypothesis that the sediment organic matter content at outlet and control stations does not change significantly over time is rejected. The percent organic matter changed significantly over time at some stations at both outlet and control sites.

\subsection{1.b.3 Comparison of organic matter between outlet and control stations}

In Evans Bay, there was no significant difference in organic matter content between outlet (EB-2) and control stations S24, R24 and L24 over time. On the other hand, organic matter content at EB-2 stations R34 ( $<<0.001)$, L34 ( $<<0.001)$, S34 $(\mathrm{p}<0.005)$ and S44 $(\mathrm{p}<0.001)$ was significantly lower than at the comparable control site stations, as a function of time (Files: EB Organic Time Graphs1 and Graphs2, Appendix II).

At Aotea Quay, the organic matter content at AQ-2 station S2 $(\mathrm{p}<0.000)$ was significantly lower, and at stations S10 (p<0.001), S20 (p<0.001), L10 (p<0.036), L20 $(p<0.001)$, R10 $(p<0.001)$ and R20 $(p<0.001)$ significantly higher than at the comparable control site stations as a function of time (Files: AQ Organic Time Graphs1 and Graphs2, Appendix II). 


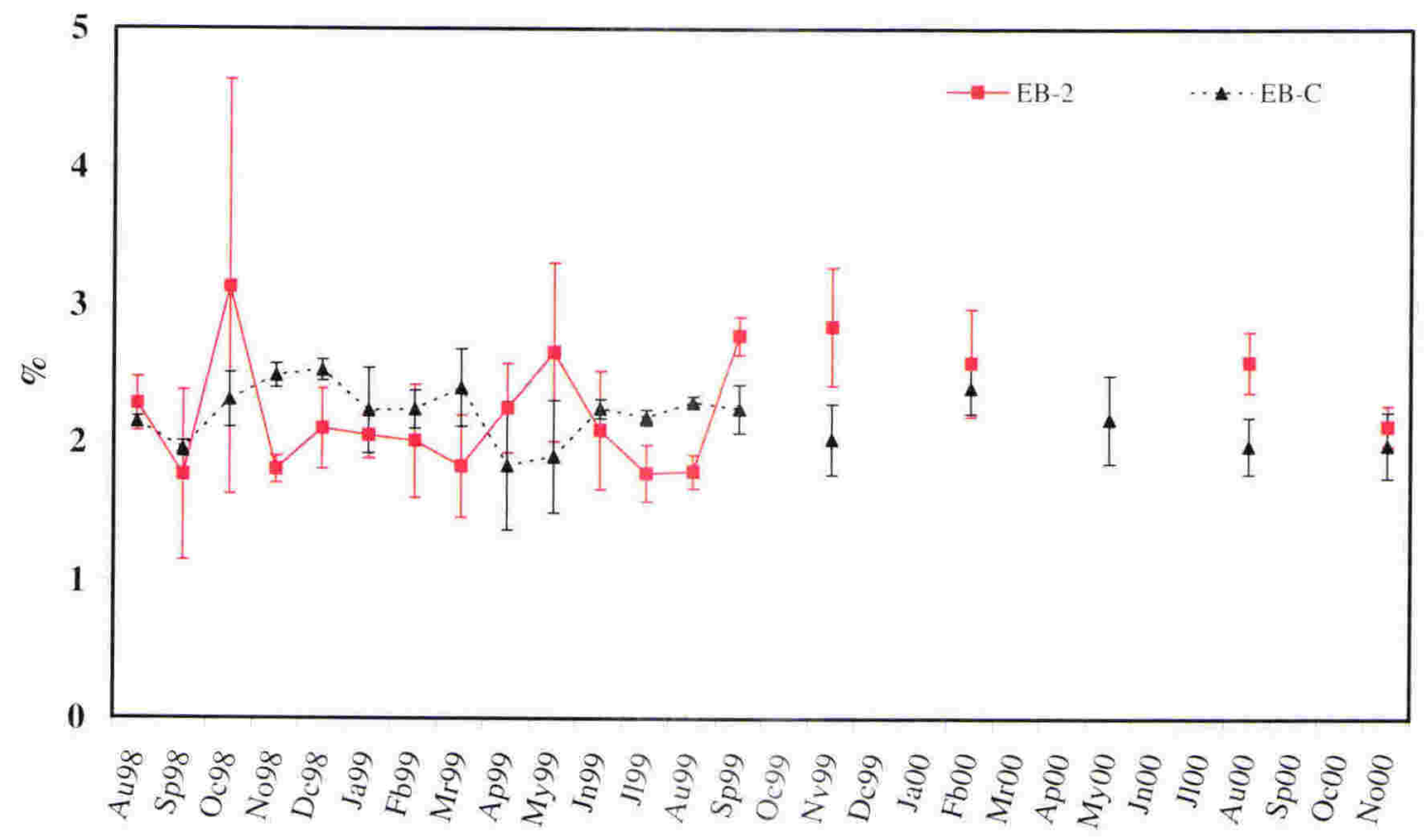

Time

Figure 3.4: Organic matter content $(\%)($ mean $\pm 95 \% \mathrm{CI})$ at station $\mathrm{S} 24$ at EB-2 and EB-C over time.

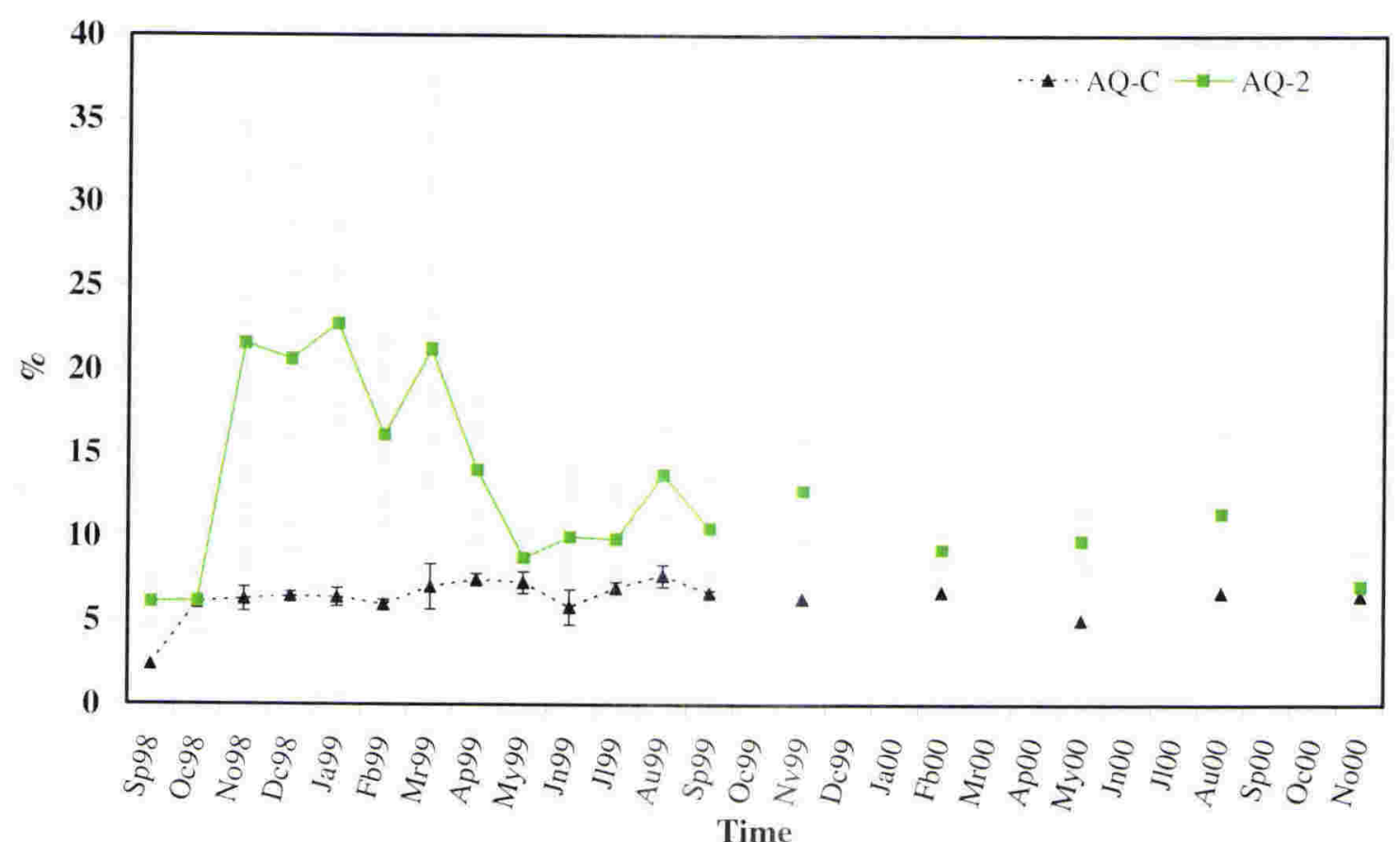

Figure 3.5: Organic matter content $(\%)($ mean $\pm 95 \% \mathrm{CI})$ at station $\mathrm{S} 10$ at $\mathrm{AQ}-2$ and $\mathrm{AQ}-\mathrm{C}$ over time. 
The null hypothesis that there is no significant difference in organic matter content between an outlet station and the associated control station over time is rejected. There are significant differences in organic matter content between some outlet and associated control stations as a function of time.

\subsection{1.c.4 Relationship of organic matter to meteorological parameters}

There was no significant association between organic matter over time and any of the hydrological and meteorological conditions at either outlet (File: Meteorological in Appendix II). This result is supported by the finding of no significant difference in organic matter content before (4.11.99) and after (18.11.99) a significant rainfall event (67 $\mathrm{mm}$ on 12.11.1999).

The null hypothesis that there is no significant relationship of organic matter content to each of the meteorological parameters is accepted.

\subsubsection{Grain Size Analysis}

\subsection{2.a Spatial Variability}

\subsection{2.a.1 Spatial variability of grain size at control sites}

At EB-C the sediment was sand/gravelly sand with the mean phi value ranging from -0.1 to 2.1 (grain size classification in Table 3.1). Variable amounts of gravel (0.5 to $31 \%)$ occurred along the straight and right transects (group A, Fig. 3.6). Sediments were poorly sorted along the left transect, while along the straight and right transects, they were very poorly to extremely poorly sorted (Sorting classification in Table 3.2). The carbonate content of the sediment ranged between 12-30\% (Fig. 3.7) (File: Sediment Grain Size in Appendix II).

At Q-C the sediment was a slightly gravelly/sandy/mud with the mean phi value ranging from 4.1-7.5 except at station S10 where it was a muddy/sandy/gravel with a mean phi of -1.1 (Fig. 3.8). In general, there was more gravel at the $20 \mathrm{~m}$ and $30 \mathrm{~m}$ than at the $10 \mathrm{~m}$ stations. The sediment was very poorly to extremely poorly sorted. The carbonate content at S10 was $11.6 \%$, while at all other stations it ranged from $4.8-8.3 \%$ (File: Sediment Grain Size, Appendix II).

At AQ-C the sediment was a sandy mud at 'under wharf' stations (group A, Fig. 3.9) and muddy/sandy/gravel (group B, Fig. 3.9) at 'beyond the wharf' stations. The sediments were 


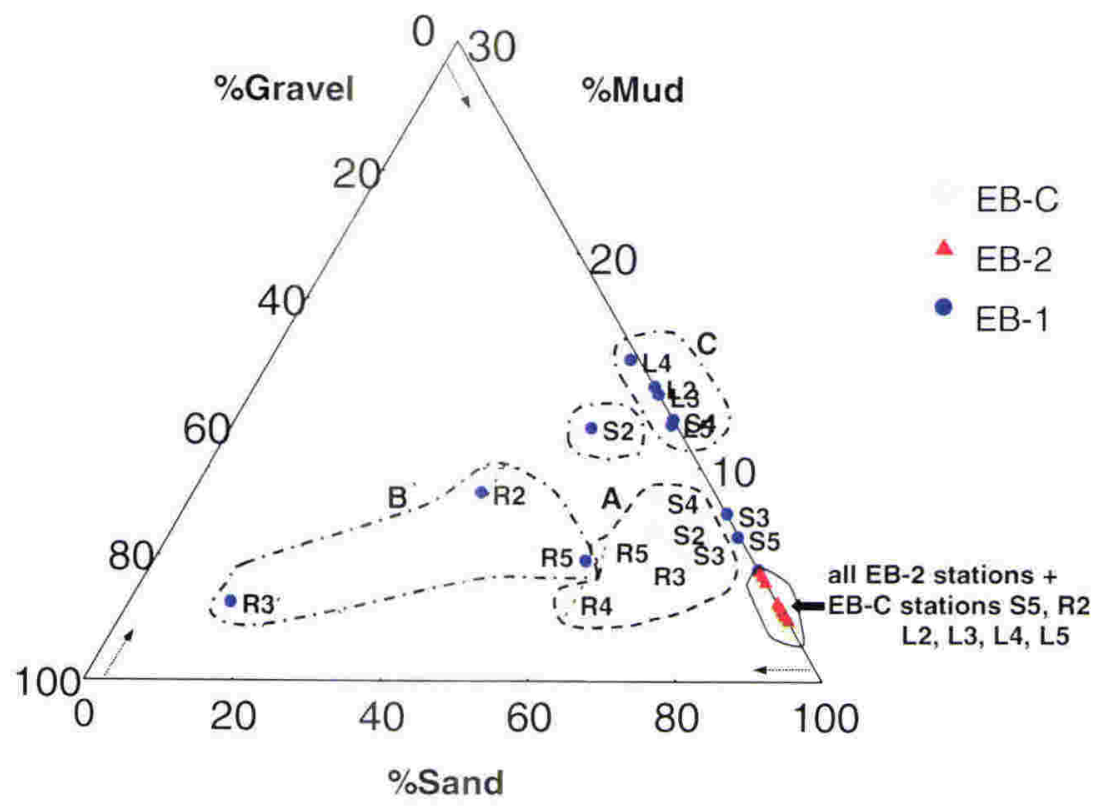

Figure 3.6: Sediment Grain Size Distribution, Evans Bay sites.

L-Left transect, S-Straight transect, R-Right transect

$2=24 \mathrm{~m}, 3=34 \mathrm{~m}, 4=44 \mathrm{~m}, 5=54 \mathrm{~m}$

Grouping of stations as determined by grain size - See text

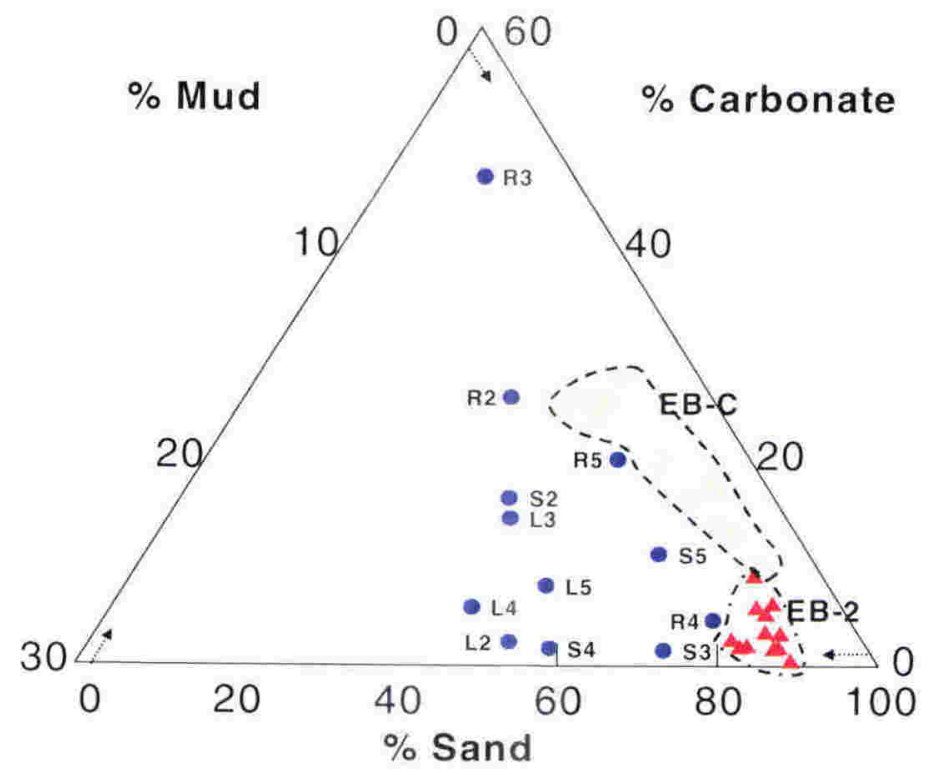

EB-C

- EB-2

- EB-1

Figure 3.7: Relative Carbonate content of the sediment at the Evans Bay sites.

L - left transect, $S$ - Straight transect, R - Right transect

$2=24 \mathrm{~m}, 3=34 \mathrm{~m}, 4=44 \mathrm{~m}, 5=54 \mathrm{~m}$

-..-- Grouping of stations as determined by site 


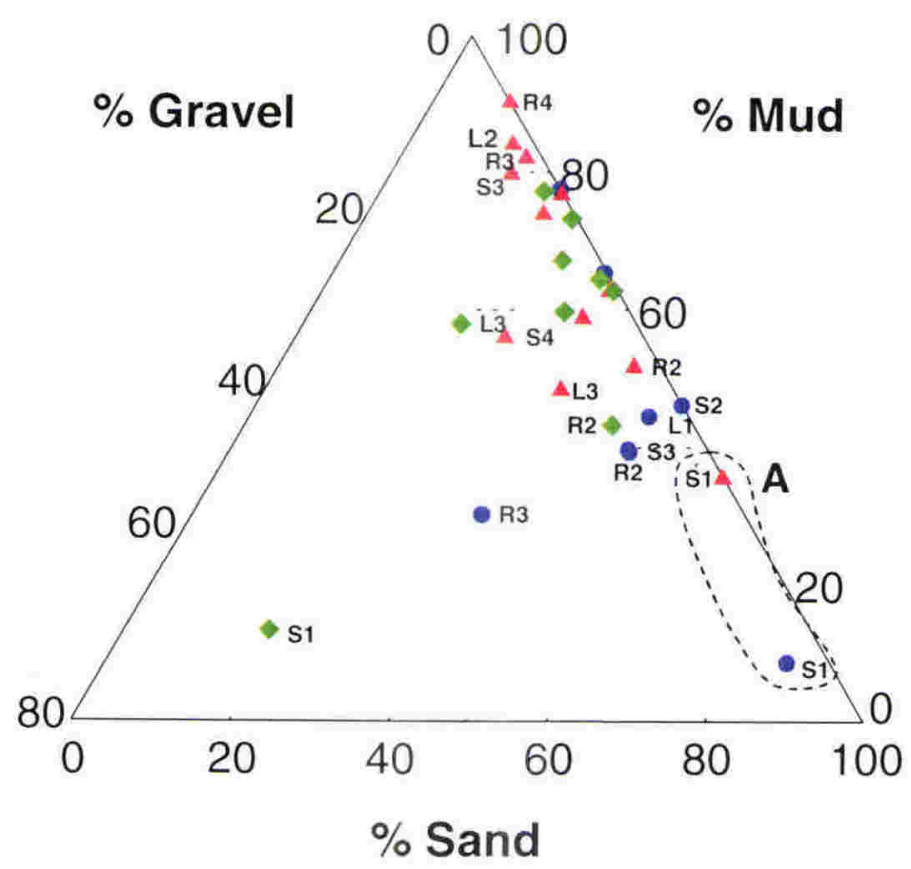

Figure 3.8: Sediment Grain Size Distribution; Queens Wharf sites

L-Left transect, S-Straight transect, R-Right transect

$1=10 \mathrm{~m}, 2=20 \mathrm{~m}, 3=30 \mathrm{~m}, 4=40 \mathrm{~m}$

----- grouping of stations

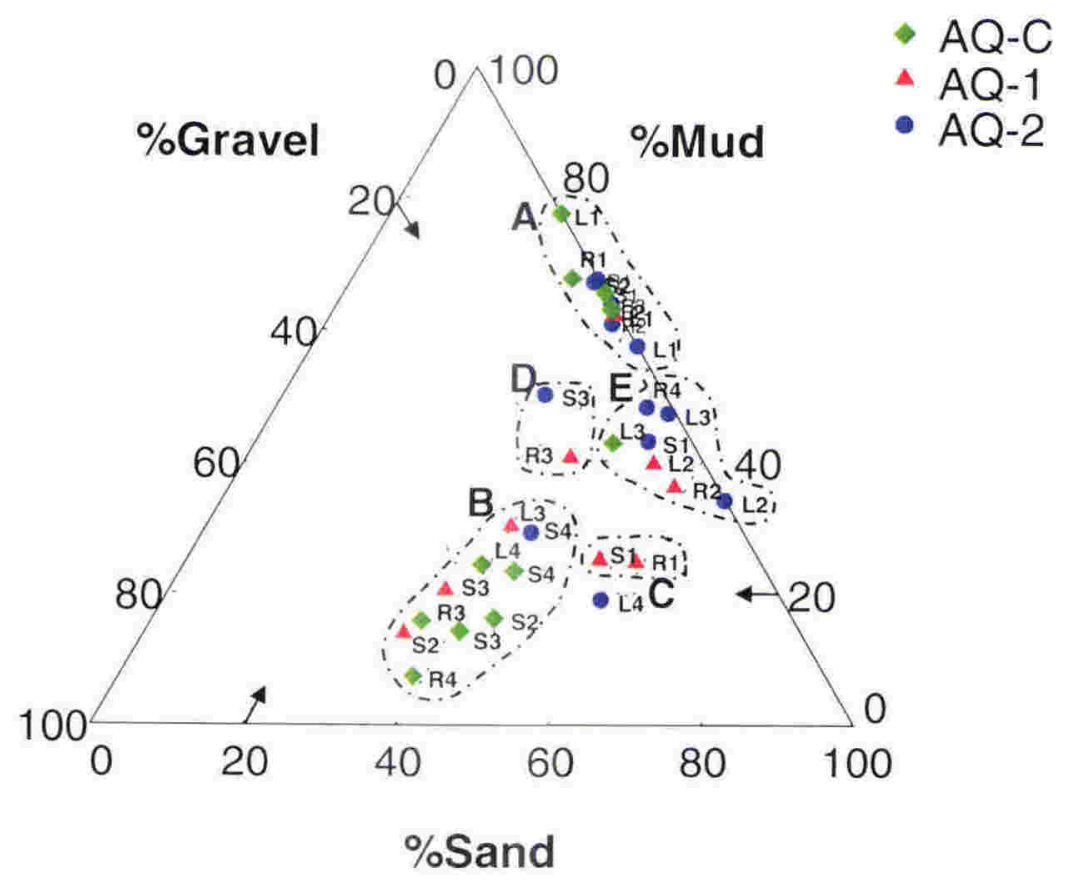

Figure 3.9: Sediment Grain Size Distribution; Aotea Quay sites.

L-Left transect, S-Straight transect, R-Right transect

$1=10 \mathrm{~m}, 2=20 \mathrm{~m}, 3=30 \mathrm{~m}, 4=40 \mathrm{~m}$

-.-.- grouping of stations 
very poorly to extremely poorly sorted. At 'under wharf' stations on the left and straight transect the carbonate content (primarily mussel shell and barnacle exoskeleton) ranged from $30-40 \%$ while on the right transect it was $10 \%$. At all 'beyond the wharf' stations the sediment carbonate content ranged from 2-4\% (Fig. 3.11).

\subsection{2.a.2 Spatial variability of grain size at outlet sites}

\section{Gravel, Sand and Mud}

Elevated levels of gravel occurred at S10 and R10 at AQ-1 (group C, Fig. 3.9), S10 at AQ-2 (Fig. 3.9) and S15 at OPT (Fig. 3.10) as compared to the grain size at the associated control stations (group A, Fig 3.9). Elevated levels of gravel/rock occurred at all right transect stations of EB-1 (group B, Fig. 3.6), with the clasts being rounded and variable in size.

Elevated levels of sand (above that at the associated control stations) were found at S10 and R10 at AQ-1 (group C, Fig. 3.9) and at S10 at AQ-2 (group E, Fig. 3.9), Q-1 and Q-2 (group A, Fig. 3.8). These elevated levels extended out as far as $20 \mathrm{~m}$ on the left and right transects at AQ-1 and $20 \mathrm{~m}$ on the left transect at AQ-2 (group E, Fig. 3.9). Sediment sand content at R15 and R30 at OPT was notably higher than at the other OPT stations (Fig.3.10).

Mud content was elevated (above that at the associated control site stations) at S30 at AQ-2 (group D, Fig. 3.9), at L20, R30, R40 and S30 at Q-2 (Fig. 3.9) and at S44 and all left stations at EB-1 (group C, Fig. 3.6). High mud content sediment occurred at OPT stations L15, S30, L30, L45, S45 and R45 (Fig. 3.10).

\section{Carbonate Content}

There were differences in carbonate content between control and outlet sites, at Aotea Quay and in Evans Bay. Carbonate levels at 'under wharf' AQ-2 stations were much lower than at 'under wharf' AQ-C stations (Fig. 3.11). At all AQ-1 'under wharf' stations the carbonate levels were higher than at AQ-2, but at some of these stations levels were below that at the associated AQ-C station (Fig 3.11). At EB-2 carbonate levels at all stations except R20 were lower than at the control site (Fig. 3.7), while at EB-1 levels were extremely variable ranging from $1.8-56.1 \%$ (Fig. 3.7). There was no apparent trend in carbonate content with distance or direction from any outlet. 


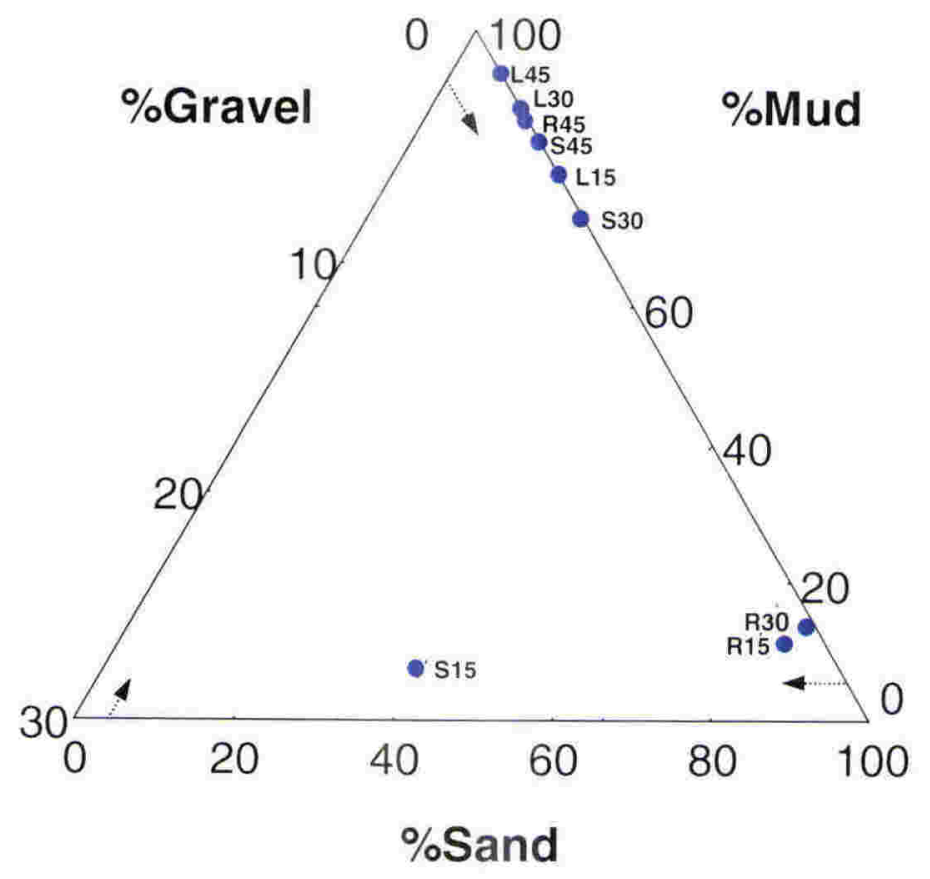

Figure 3.10: Grain size distribution at OPT,

L - Left transect, S - Straight transect, R - Right transect

$15,30,45$ - distance in $\mathrm{m}$ from the outlet

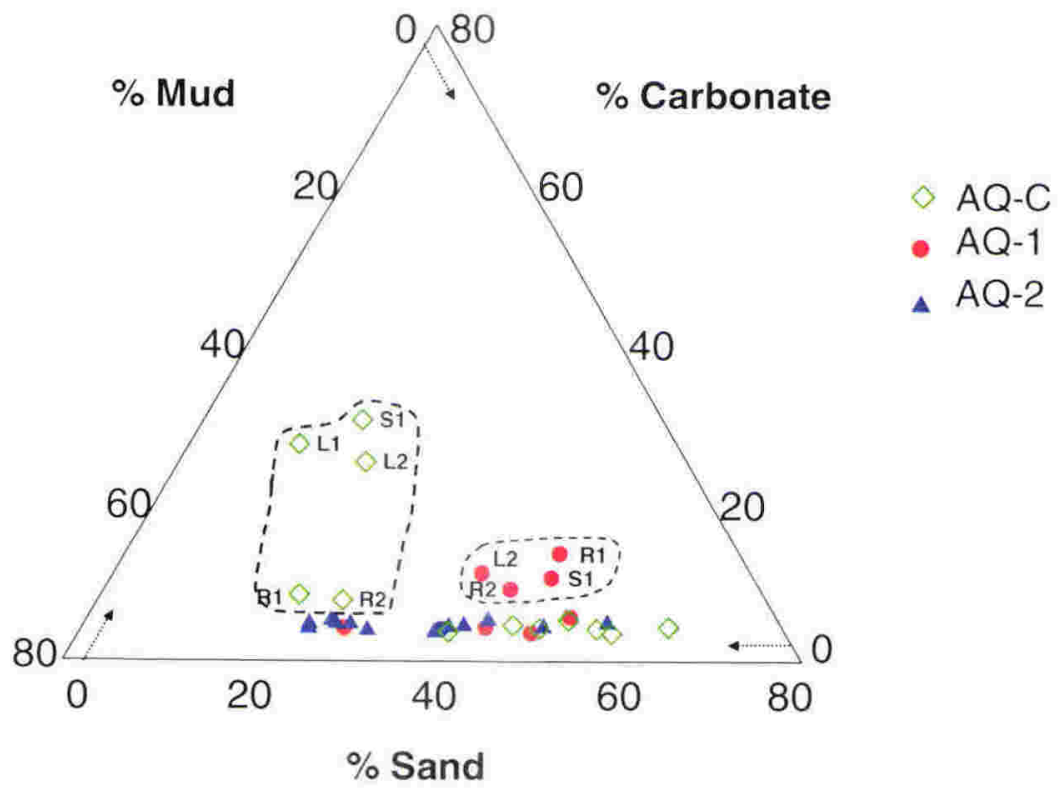

Figure 3.11: Carbonate content at the Aotea Quay sites.

L - Left transect, S - Straight transect, R - Right transect

$1=10 \mathrm{~m}, 2=20 \mathrm{~m}$ from the outlet or a point on the shore

-.---grouping of stations as determined by carbonate level - see text for details 


\section{Sediment Sorting}

Sediments near Aotea Quay, Queens Wharf and OPT outlets were very poorly to extremely poorly sorted, except at S10 of Q-1 where it was poorly sorted (Sorting classification - Table 3.2) (File: Sediment Grain Size, Appendix II). The coarser grained sediments in the vicinity of FK and EB-1 were poorly to very poorly sorted, while those in the vicinity of EB-2 were all moderately well to moderately sorted. There was no apparent trend in the sorting of the sediment with either distance or direction from any outlet.

\subsection{2.b Temporal Variability}

3.3.2.b.1 Temporal variability of grain size at the control sites

At EB-C station S24 the mean grain size ranged from 1.1-1.5 $\phi$ (Fig. 3.12) over time with a maximum variability at any one time of $0.35 \phi$. The sediment was poorly to very poorly sorted and the percent carbonate ranged from 33-48\% (File: Sediment Grain Size, Appendix II).

At AQ-C station S10 the mean grain size ranged from 4.1-8.4申 (Fig. 3.13) over time, with a maximum variability at any one time of $2.7 \phi$. The sediment was very poorly to extremely poorly sorted and the percent carbonate ranged from 7.4-61\%, with a maximum variability at any one time of $21 \%$ (File: Sediment Grain Size, Appendix II).

\subsection{2.b.2 Temporal variability of grain size at the outlet sites}

At EB-2 station S24 mean grain size ranged from 2.2-2.8 $\phi$ over time (Fig. 3.12). The sediment was typically moderately well sorted. Carbonate content was generally in the range $2.6-4 \%$, however elevated levels occurred in two samples giving a variability range of up to $6.5 \%$ and a maximum of $12.3 \%$ carbonate (File: Sediment Grain Size, Appendix II).

At AQ-2 station S10 the mean grain size ranged from 0.6-5.4申 over time (Fig. 3.13), with maximum variability at any one time being $3.5 \phi$. The sediment was very poorly to extremely poorly sorted and percent carbonate ranged from 2.8-13.4\%, with maximum variability at any one time being $8 \%$ (File: Sediment Grain Size, Appendix II). 


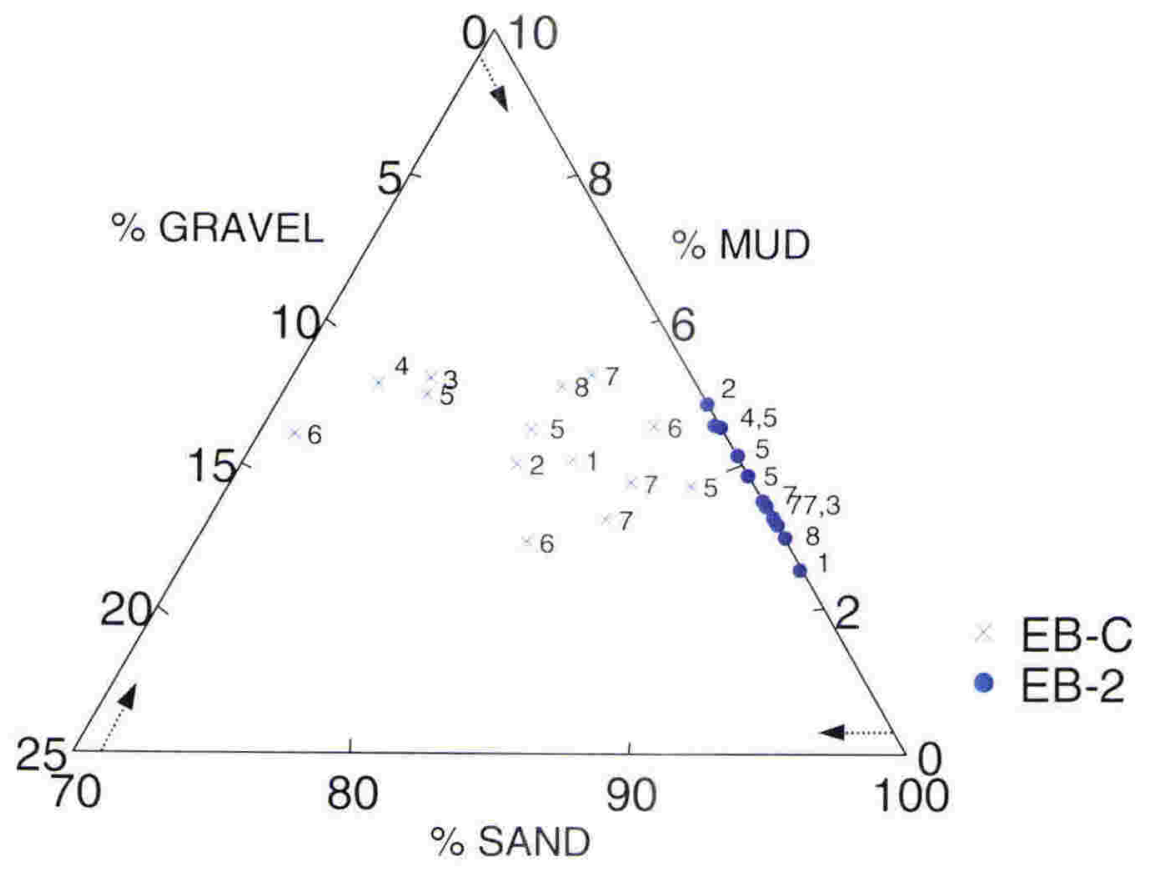

Figure 3.12: Sediment grain size, Evans Bay outlet and contol site over time

Times: 1 -September 98,2 - October 98,3 - November 98, 4-December 98 5 - September99, 6 - May00, 7 - August00, 8 - November00

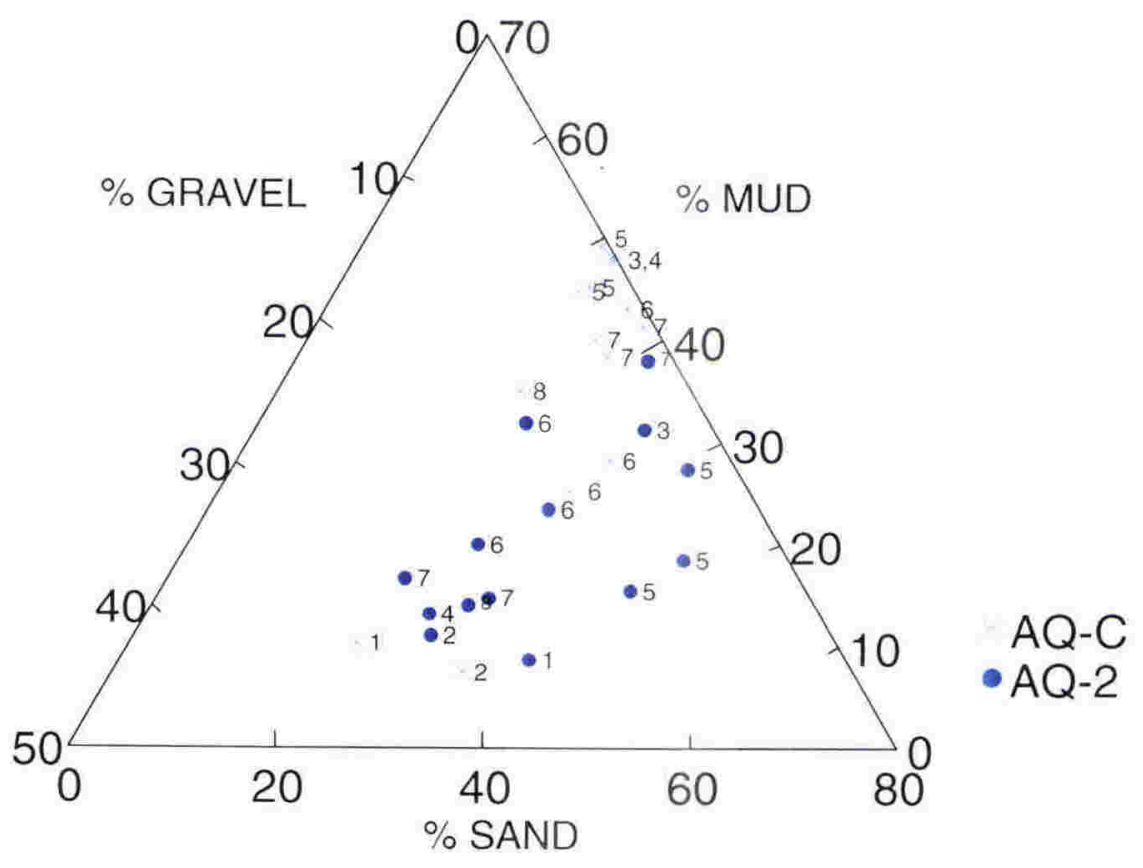

Figure 3.13: Sediment grain size at Aotea Quay outlet and control site over time.

Times: 1 - September98, 2 - October98, 3 - November98, 4 - December98

5-September99, 6-May00, 7 - August00, 8 - November00 


\subsection{DISCUSSION}

\subsubsection{Organic Matter Content}

The importance of using area-specific control sites in this study is highlighted by differences in the level of organic matter between control sites. Because of the difference in organic matter content between areas, determination of OME at FK was not possible as all control site values (from AQ-C, Q-C and EB-C) were either too high or too low compared to the levels $(4.3 \% \pm 0.5)$ at the stations furthest from the FK outlets. In addition, the OME values for OPT (calculated using AQ-C 'under-wharf' values) can only be considered as an indication of the level of enrichment. At AQ-C it was also found that 'under-wharf' organic matter levels were higher than 'beyond-the-wharf' levels. The reason for this is not clear, but the higher levels under the wharf may result from the debris and biodeposits (faecal and pseudofaecal material) of epifauna, such as mussels and barnacles, present on the wharf piles.

By using OME to quantify the impact of stormwater discharge on the organic matter content of the sediment in the vicinity of 8 outlets it is apparent that organic matter enrichment occurred at all the outlets studied (with the possible exception of the FK outlets). The amount and outer limit of enrichment is outlet-specific. The highest enrichment was 5.6 times that of the associated control site and the outer limit of enrichment at some sites extended beyond the limit of sampling i.e. more than 40 - $45 \mathrm{~m}$. Organic matter content in front of the outlets was also up to 6-7 times (and up to 16 times - Pilot study (Appendix I)) higher than central harbour sediment (Wear and Anderlini, 1995; Haddon and Wear, 1993; Goff, et al., 1998). By comparison, in Porirua Harbour (22 km north of Wellington Harbour) the organic matter content at $5 \mathrm{~m}$ was 1.9-4.2 higher than that at $140 \mathrm{~m}$ from the outlet (Botherway and Gardner, 2002). In Otago Harbour, the total organic carbon (a measure of organic matter content) was twice as high at 5 than $60 \mathrm{~m}$ in front of stormwater outlets (ORC, 1998).

At some outlet stations the organic matter content was lower than at the associated control site (Table 3.3). This may be due to differences in grain size between sites, as organic matter content is influenced by grain size. For example, within Wellington Harbour the coarsegrained (sandy) sediments contain 1-4-3\% and the fine-grained (muddy) sediments contain 3.5-7.7\% organic matter (Goff et al., 1998; Haddon and Wear, 1993; Wear and Anderlini, 1995). Such differences in grain size between sites in an area may be due to natural variation or to the effect of stormwater discharge. 
Organic matter content changed significantly with increasing distance from some outlets. In general, the most organically enriched sediments were close to an outlet, although the outward limit of enrichment was outlet-specific and extended more than $40-45 \mathrm{~m}$ in front of some outlets and thus was not determined in this study. Sediments with an organic matter content of $9 \%$ have been recorded up to $250 \mathrm{~m}$ along OPT wharf and up to $17 \mathrm{~m}$ alongshore from the wharf, with the OPT outlet considered to be the source of the organic matter (Haddon and Wear, 1993). This can be compared to the 'relatively unaffected fine sediments' with $4 \%$ organic matter at approximately $80 \mathrm{~m}$ alongshore from OPT wharf (Haddon and Wear, 1993).

Organic matter content is significantly different with direction from some outlets. The highest levels of organically enriched sediment occurred at stations straight in front of outlets, although enrichment was also evident on the left and/or right transects at some outlets. This enrichment pattern with direction is probably related to one of two processes:

- Stormwater flowing straight out from an outlet with moderate dispersal to the left and/or the right

- The greatest proportion of discharge events being directed straight out with some events flowing to the left and some to the right.

These variations in directional flows may result from the influence of the tide and/or wind. In Wellington Harbour the flood tide flow is clockwise (towards left transects) and the ebb tide flow counter-clockwise (towards right transects) (Brodie, 1958), while northerlies comprise $50-60 \%$ of the winds and southerlies 30\% (Quale as cited in Pilotto, 1995). Wind speed and direction influence sediment accumulation in Wellington Harbour through wind-driven surface circulation, wind-induced turbulence in shallow waters maintaining sediments in suspension (Goff et al., 1998) and wind-induced mixing of saline and fresh water. Short-term changes in wind speed and direction also have a significant impact on sediment accumulation in this harbour (Goff et al., 1998).

The significantly higher levels of organic matter at stations on the left than the right transect at EB-1 may be because:

- There were higher levels of mud along the left transect than along the right transect, with high levels of gravel along the right transect (Fig. 3.7). In general higher levels of organic matter occur in fine-grained muddy sediments than coarser sediments.

- The area to the left of this outlet is enclosed (Fig 2.6c) and water flow is likely to be reduced in this area allowing organic matter levels to build up. 
In front of outlets it is likely that there is irregular deposition of variable qualities and quantities of organic matter, deposition of variable types and quantities of sediment over the organic matter (from stormwater discharge and normal hydrological processes) and possible 'flushing' of the organic matter by occasional high rates of stormwater flow. For example, vigorous flushing of organic matter at the OPT outlet was evident with lower levels $(2-2.9 \%)$ at S15 than at S30 (29.6-43.7\%). By comparison, 72\% organic matter occurred $1.5 \mathrm{~m}$ from the OPT outlet in the pilot study (Appendix I). In addition, where there is a steep slope just beyond the outlet, e.g. Aotea Quay and Queens Wharf (Figs. 2.2 and 2.3), the organic matter can be easily transported and can accumulate both further down slope and at the break of slope at the bottom. This could account for the high levels of organic matter $20 \mathrm{~m}$ from Q-1 (Fig. 3.1A) and 10 and $20 \mathrm{~m}$ from AQ-2 (Fig 3.3B). Propeller backwash from large vessels moored alongside Aotea Quay and Queens Wharf also disturbs the sediment resulting in resuspension and redistribution of sediments and organic matter (Anderlini and Wear, 1995; Haddon and Wear, 1993; Wright and Glasby, 1992).

The organic matter in front of outlets AQ-1, AQ-2 and OPT was predominantly composed of whole leaves, seed pods, twigs and fragmented plant matter. These catchments contain a significant proportion of 'green' areas (Table 2.1), which includes tracts of hillside covered in exotic and native vegetation. This adds substantial amounts of 'rural' organic matter to the more typical urban material such as lawn clippings, tree litter, food scraps and animal faeces. The deposition of such material close to each outlet may appear anomalous because at the start of a storm event many of the leaves and twigs float on the surface (Williamson, 1993) and as such can be carried a considerable distance from the outlet. However the tidal influence at these three outlets extends 400-500 m landward up the pipe (R. Moore, New Zealand Dive and Salvage (NZDS), pers. com., 2002). This results in flocculation within the pipe with some settling of organic matter on the bottom of the pipe (video footage, Stormwater pipe structural survey, NZDS, 1999). It is therefore possible that during low rainfall periods, organic matter accumulates on the bottom of the pipe and in this non-floating state it is, over time, transported beyond the outlet by either tidal flushing or a subsequent high rainfall event.

The quantity of organic matter that accumulates on an impervious surface prior to a rainfall event results from a combination of:

1. The length of the preceding dry period. 
2. Meteorological conditions (particularly wind).

3. Season, especially in relation to lawn clippings [an important but occasional large contributor to organic matter in roadside gutter dust samples collected in urban residential areas in New Zealand (Kennedy, 1981)] and material from deciduous plants.

4. Supply of plant material in proximity to impervious surfaces (such surfaces are not conducive to normal decay processes because of the lack of soil invertebrates and micro-organisms).

5. Animal populations in the area (production of faecal matter).

6. The frequency of roadside gutter sweeping.

Consequently, large differences in the peak concentration of suspended solids have been found between separate rainfall events (Mosley et al., 1997). Normally, during a rainfall event, the organic matter is transported from the roadside gutters and through the stormwater system as part of the first flush of suspended solids (Williamson, 1993; Mosley et al., 1997). The size and intensity of the rainfall event is important because a vigorous flushing effect is necessary to mobilise large particulates (Mosley et al., 1997). The slope of the impervious surface is also important because the total flow and flood flows are greater in steeper catchments (Williamson, 1986). With so many factors influencing the supply of organic matter to the sediments beyond an outlet it is not surprising that in this study there was no discernable association evident between organic matter levels over time and meteorological and/or hydrological parameters.

Organic matter in marine sediment is decomposed over time by aerobic and/or anaerobic microbial activity. The rate of decomposition is dependent on the age and type (affects how degradable the matter is) of the material (Blackburn, 1980 cited in Kristensen and Blackburn, 1987) and the rate of microbial activity (Stanley et al. 1981 cited in Pearson, 1982). Higher rates of decomposition occur in anaerobic as opposed to aerobic sediments (Kristensen and Blackburn, 1987), with decomposition occurring principally through anaerobic sulphate reduction (Pearson, 1982). Typically $65-85 \%$ of decomposition is via this pathway while 3 $14 \%$ is via the aerobic pathway (Mackin and Swider, 1989). Anaerobic decomposition results in the production of black anoxic sediment. While all marine sediments are anoxic below a certain depth from the sediment surface (Diaz and Rosenberg, 1995), the presence of high levels of organic matter can result in the RPD (Redox Potential Discontinuity- the boundary between oxic and anoxic sediment) layer being closer to the sediment surface (Fenchel and Riedl, 1970). In this study the sediment surface at all sites and stations was oxic (as suggested 
by its brown-grey appearance) with black sulphurous smelling sediments a notable feature of the sediments containing elevated organic matter levels (particularly out to at least $20 \mathrm{~m}$ at AQ-1, 20-30 $\mathrm{m}$ at AQ-2, and $45 \mathrm{~m}$ at OPT).

The results of this study indicate that the large quantities of organic matter that occur in sediments in the vicinity of some outlets are as a result of stormwater discharge. The longterm fate of this organic matter is unknown. Organic matter may build up in some areas in proximity to the outlets although it is more probable that through hydrological processes and other disturbances it will be moved to other areas of the harbour over time where it could, through the action of the biota, become integrated into the benthic ecosystem. However, in sediment cores from Wellington Harbour, elevated levels of organic matter i.e. 3.1-7\% compared to $0.9-1.3 \%$ at deeper levels have been considered to represent an over-abundance of organic matter beyond the capacity of the benthic fauna to rework it (Goff et al., 1998).

\subsubsection{Grain Size}

Five sediment facies have been identified within greater Wellington Harbour, with the general grain size distribution resulting from a combination of the hydrological conditions, sediment supply, sediment texture and topographical characteristics (van der Linden, 1967). However, the sediment of the nearshore environment is not so easily categorised because shipping activities, wharf structures, reclamation, stream and stormwater discharge can all influence sediment characteristics. Stormwater discharge into the nearshore environment supplies sediment in the form of soils, dust, construction debris and roading materials (Morrisey, 1997; Vincent and Thomas, 1997) and generates irregular, but at times, high velocity water flows (Timperley and Kurschel, 2000), both of which influence grain size characteristics in the vicinity of an outlet. The quantity and grain size of sediment discharged via the stormwater system is therefore outlet-specific and varies over time (Pilotto, 1995).

The grain size in the vicinity of some stormwater outlets was different to that at the associated control site. The most marked impact of stormwater discharge was an elevated percentage of gravel extending out to at least $10-15 \mathrm{~m}$ in front of some outlets. Much of this gravel was comparable to (in terms of size and shape) that used for road construction and it is likely that it has been washed off roads, transported through the stormwater system and deposited beyond the outlet. Elevated percentages of sand also occurred close to, and as far away as 20$30 \mathrm{~m}$ from some outlets, while high mud percentages were recorded at stations $20 \mathrm{~m}$ or more 
from some outlets. The trend of a decrease in the proportion of coarse sediment and an increase in fine sediment with increasing distance from the outlet was most obvious in front of OPT, Q-2 and AQ-1. This trend was also found for sediments in front of stormwater outlets in Auckland (Bioresearches, 1997) and Otago Harbours (ORC, 1998), and Porirua Inlet (Botherway and Gardner, 2002). High percentages of gravel extended out to $10-15 \mathrm{~m}$, sand to $35 \mathrm{~m}$ and mud to $40-50 \mathrm{~m}$ from large stormwater outlets in Auckland Harbour (Bioresearches, 1997). In front of the Otago and Porirua outlets, the sediment $5 \mathrm{~m}$ away contained high percentages of sand while at stations 30 and $60 \mathrm{~m}$ (Otago Harbour) and $90 \mathrm{~m}$ (Porirua Inlet) finer grained sediments occurred (ORC, 1998; Botherway and Gardner, 2002).

In this study there was little variability in sediment grain size at station S24 of outlet EB-2 over time, while at EB-C station S24 the sand and gravel content varied markedly. By comparison, the sediment at station S10 at AQ-2 and AQ-C was more variable between both the replicate samples taken at one time and the samples taken over time. This variability at both AQ-2 and AQ-C probably results from propeller backwash causing the resuspension and redistribution of sediment. Sediment in front of AQ-2 was, in general, coarser (0.6-5.4 $\phi)$ than at AQ-C (4.1-8.4申) due to the presence of gravel and sand, the percentages of which varied more over time at AQ-2 than at AQ-C. This variability in gravel and sand at AQ-2 most probably resulted from the input of sediment via stormwater discharge.

Carbonate content was measured as part of the process of grain size analysis and consequently is included in this section of the study. Large and small fragments of carbonate contribute to the characteristics of sediment even though the carbonate fragments have a biological origin e.g. from mollusc shell and echinoderm test remains. Carbonate content can therefore also provide information on the biota present. Typically, Wellington Harbour sediment composed of $<80 \%$ mud contains $10 \%$ carbonate while sediment with $>80 \%$ mud contains $7 \%$ carbonate (van der Linden, 1967). However 25-70\% carbonate has been found in sediment where there was an accumulation of molluscs and echinoderm remains from biota living in the area (van der Linden, 1967). This is the case for the Evans Bay control sediment which contained 10$30 \%$ carbonate along with a diversity and abundance of bivalve molluses and echinoderms. By comparison, the sediment at all stations in the vicinity of EB-2 contained $0-8 \%$ carbonate which is less than both the control and reported level for Wellington Harbour (van der Linden, 1967). This is a reflection of the low abundance of bivalves and echinoderms in the sediment in front of this outlet (see chapter 5). 
Carbonate levels beneath Aotea Quay are elevated (control site 10-40\%) due to mussel shells and barnacle exoskeletons falling from the wharf piles above. Elevated levels (11.9-17\%) also occurred at the 'under wharf stations' in the vicinity of AQ-1 although not at AQ-2. Low carbonate levels in front of AQ-2 may be due to a low input of carbonate material and/or covering of the carbonate by sediment/organic matter discharged from the outlet. Low carbonate input to the sediment could result from the flushing of mussel and barnacle remains from the wharf piles in times of high stormwater flow or a lower abundance of mussels and barnacles on the wharf piles in front of this outlet than at AQ-1 and AQ-C. Further investigation is required to determine the impact of stormwater discharge on carbonate input to the 'under wharf' sediment in front of AQ-2.

\subsubsection{Seaward limit of impact of stormwater discharge on sediment characteristics}

From the results obtained, the seaward extent of the influence of stormwater discharge on organic matter content and grain size has been determined (Table 3.6).

Table 3.6: Seaward extent $(\mathrm{m})$ of impact of stormwater discharge on sediment characteristics.

\begin{tabular}{|lcll|}
\hline Outlet & Organic matter & \multicolumn{2}{l|}{ Grain size } \\
\hline AQ-1 & $>30$ & gravel & 10 \\
& & sand & 20 \\
AQ-2 & $>40$ & gravel & 10 \\
& & sand & 20 \\
& mud & 30 \\
Q-1 & 20 & sand & 10 \\
Q-2 & 10 & sand & 10 \\
OPT & $>45$ & gravel & 15 \\
EB-1 & 34 & mud & 44 (left transect) \\
EB-2 & 24 & -- \\
\hline
\end{tabular}

It is important to note that the determination of the seaward extent of the influence of stormwater discharge on mud content is difficult because stormwater-derived fine sediment is carried as suspended sediment well beyond the outlet in high flow conditions. Deposition of these fine particles will be in areas where currents are weak enough for this to occur 
(Williamson and Morrisey, 2000). The sediment in such areas is typically fine (van der Linden, 1967) and therefore the stormwater-derived particles would be indistinguishable from those already present and would be rapidly integrated into the existing sediments through bioturbation i.e. the mixing of sediment particles by the biota.

\subsection{CONCLUSIONS}

These data strongly suggest that stormwater discharge has altered organic matter content and grain size characteristics in the vicinity of all the outlets in this study [with the possible exception of the FK outlets where the effects could not be assessed due to the limitations in the sampling regime].

These data strongly suggest that stormwater discharge results in organic matter enrichment of sediments in the vicinity of stormwater outlets (with the possible exception of the FK outlets). Organic matter content is significantly different with both distance and direction from some outlets. The degree of enrichment, distance and direction of impact was outlet specific.

The most organically-enriched sediments occurred closest to outlets, with a decrease in organic matter content with increasing distance away from, an outlet. For grain size the trend was a decrease in the proportion of coarse sediment and an increase in fine sediment progressively away from an outlet. The seaward limit of impact of stormwater discharge on organic matter content and grain size at each outlet (except FK) has been determined.

The outlets have been ranked, based the level of organic matter enrichment, from the most to least organically enriched sediment. The ranking of outlets being:

1998: $\mathbf{A Q - 2}>$ OPT $>$ AQ-1 $>$ EB-1 $>$ Q-1 $>$ Q-2 $>$ EB-2

1999: $\mathbf{A Q - 2}>\mathbf{E B}-\mathbf{1}>$ Q-2 $>$ EB-2

The percent organic matter changed significantly over time at some of the outlet and control site stations. There were significant differences in organic matter content between some outlet and associated control stations over time. There was no relationship between organic matter content over time at outlet stations and meteorological parameters. Grain size at outlet and control stations, in general, varied markedly over time. 


\section{Chapter 4}

\section{THE EFFECT OF STORMWATER DISCHARGE ON SEDIMENT METAL CONCENTRATIONS}

\subsection{INTRODUCTION}

Within urban environments the principal diffuse sources of metals are: roading aggregate, roadway markings, building components, paint, materials from car tyres, exhaust fumes (petrol combustion, engine wear, oil, exhaust system particulates), car body corrosion, car brake pad wear and metallic litter (aluminium foil and cans) (Kennedy, 1981). In addition, localised industrial point sources such as washings from floors, accidental spills and general discharges (some illegal) also occur (Kennedy, 1981; Pilotto et al., 1998). Metals generally accumulate in roadside gutter dust to be washed away during rainfall events. Chromium $(\mathrm{Cr})$, copper $(\mathrm{Cu})$, nickel $(\mathrm{Ni})$, lead $(\mathrm{Pb})$ and zinc $(\mathrm{Zn})$ have been found at consistently high levels in roadside gutter dust, both in New Zealand and overseas (Hopke et al., 1980 as cited in Kennedy, 1981; Ward et al., 1977; Kennedy, 1981), while chemical analyses of stormwater and suspended solids within stormwater during rainfall events have found elevated levels of $\mathrm{Cu}, \mathrm{Pb}$ and $\mathrm{Zn}$ (Mosley et al., 1997; Williamson, 1986).

Within the Wellington region stormwater is discharged into the sea (harbour and open coast) and high concentrations of $\mathrm{Cu}, \mathrm{Pb}$ and $\mathrm{Zn}$ have been recorded from sediment collected in subtidal sediment traps adjacent to harbour stormwater outlets (Pilotto et al., 1998, 1999). In the pilot study, elevated concentrations of arsenic (As) (not a true metal but a metalloid, however referred to as a metal for simplicity in this study), $\mathrm{Cr}, \mathrm{Cu}, \mathrm{Pb}$ and $\mathrm{Zn}$ were found in the sediment in the vicinity of all 16 stormwater outlets studied (Appendix I). Detailed data on the effect of stormwater discharge on metal concentrations in soft sediment in close proximity to stormwater outlets is however lacking for inner Wellington Harbour, the Wellington region, and New Zealand in general. Analyses of metal concentrations in the vicinity of stormwater outlets will increase the knowledge base on the effect of stormwater discharge on the nearshore environment and in addition will provide data with which Local Authorities in Wellington will be able to make informed decisions with regard to regulating discharges into receiving waters under the Resource Management Act (1991). 
The overall aim of this section of the study is to quantify the spatial and temporal variability of the effect of stormwater discharge on the concentration of metals in nearshore sediments in the vicinity of selected stormwater outlets in inner Wellington Harbour. The total concentrations of $\mathrm{As}, \mathrm{Cr}, \mathrm{Cu}, \mathrm{Ni}, \mathrm{Pb}$ and $\mathrm{Zn}$ were assessed for this purpose. In addition, to determine if the temporal variability of metal concentrations is linked to meteorological conditions the relationship between metal concentrations and meteorological conditions were also investigated.

\subsection{METHODS}

\subsubsection{Sediment Sampling}

\subsection{1.a Sample Collection}

Each sample consisted of sediment from the top $2-3 \mathrm{~cm}$ of the seafloor obtained by a SCUBA diver using a purpose built plastic scoop with a $20 \mu \mathrm{m}$ mesh bag attached to collect the sediment. These samples were collected from stations at outlet and control sites (Section 2.3).

\subsection{1.b Spatial Variation sampling}

At each station sampled in November 1998 and May 1999 (Section 2.4.1.a) one random sediment sample was collected for analysis.

\subsection{1.c Temporal Variation sampling}

Quarterly sampling

At each station sampled quarterly (Section 2.4.2.a) from August 1998 to November 2000 (File: Sampling dates, Appendix II) one random sediment sample was collected for analysis. However, on the first sampling occasion 3 random samples were collected at each station in order to quantify variability.

\section{Monthly sampling for a year followed by quarterly sampling for 15 months}

At each station sampled monthly for a year (from August 1998 to September 1999) then quarterly for 15 months (from September 1999 to November 2000) (File: Sampling dates, Appendix II) (Section 2.4.2.b) one random sediment sample was collected for analysis.

Note: The sample collected as EB-2 station S24 in May 2000 was discarded because the station marker was not found due to low water visibility. 


\subsubsection{Sample Processing}

Sediment samples were washed with distilled water through a clean $63 \mu$ m nylon mesh into a distilled water/ethanol rinsed glass beaker. The fine sediment $(<63 \mu \mathrm{m})$ and distilled water were centrifuged at $5000 \mathrm{rpm}$ for $10 \mathrm{~min}$, the water was decanted off and sediment dried at $40^{\circ} \mathrm{C}$ until all moisture was removed. The dried sediment was ground to a fine powder using an alcohol cleaned, marble mortar and pestle. A representative sub-sample of $4 \mathrm{~g}$ was pressed into a pellet backed with boric acid and analysed using the Philips PW 1404 X-ray

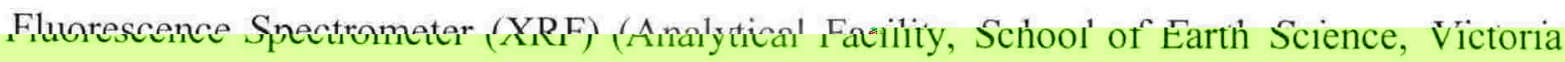
LIniversity of W Wellington). Ir each sample the total concentration (ppm) of ' 19 trace elements

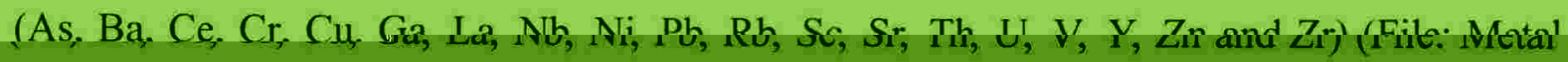
names in Appendix III) were determined. The detection limit for most elements is in the order of 2 ppm, while precision errors are \pm 3 ppm (Palmer, 1990).

Three pellets of a certified reference material (PACS-2) (National Research Council of Canada) were analysed with every batch of samples in 1999 and 2000 to determine the analytical accuracy of the XRF. A summary of the results for the elements of interest for this study (As, $\mathrm{Cr}, \mathrm{Cu}, \mathrm{Ni}, \mathrm{Pb}$, and $\mathrm{Zn}$ ) are presented in Table 4.1 (raw data in File: Reference sediment in Appendix III). Results were within $10 \%$ of the certified values for $\mathrm{Cr}, \mathrm{Cu}, \mathrm{Pb}$ and $\mathrm{Zn}$ and $20 \%$ for $\mathrm{Ni}$. For As, the concentration measured using the XRF while much higher had comparable variability to the certified value.

Table 4.1: Comparison of XRF analysis of PACS-2 with certified values (ppm)
\begin{tabular}{ccc|}
\hline & XRF & PACS-2 \\
\hline $\mathrm{As}$ & $41.4 \pm 1.8$ & $26.2 \pm 1.5$ \\
$\mathrm{Cr}$ & $99.8 \pm 2.5$ & $90.7 \pm 4.6$ \\
$\mathrm{Cu}$ & $335.5 \pm 12.4$ & $310.0 \pm 12$ \\
$\mathrm{Ni}$ & $47.3 \pm 5.9$ & $39.5 \pm 2.3$ \\
$\mathrm{~Pb}$ & $168.8 \pm 2.4$ & $183.0 \pm 8$ \\
$\mathrm{Zn}$ & $377.3 \pm 8.7$ & $364.0 \pm 23$ \\
\hline
\end{tabular}

In this study the total concentration rather than the concentration of the different chemical species (dissolved, exchangeable, carbonate bound, Fe and Mn oxide bound, organic bound, 
bioavailable), of each of the trace elements was measured, this was because of financial constraints. Nonetheless determination of the total concentration allows for an estimation of anthropogenic input and for the assessment of the quality of the sediments in the vicinity of the stormwater outlets as compared to sediment quality guideline values which are total concentrations in bulk sediment (Long et al., 1995).

$\mathrm{XRF}$ is a recognized method for determining the total concentration of trace elements in marine sediments (Grant and Middleton, 1990; Williams et al., 1997; Williamson et al., 1995). This method has been used in other studies of Wellington Harbour sediment (Dickinson et al., 1996; Pilotto et al., 1998) and the use of XRF for the analysis of the sediments in this study allows for a direct comparison of the results with those from the other studies in this region. The widely used alternative method for determining total concentration is sediment digestion with strong acid followed by AAS or ICP-MS analysis (e.g. Angelidis and Aloupi, 2000; Balls et al., 1997; Ferreira et al., 1996; Puig et al., 1999; Rubio et al., 2000; Stoffers et al., 1986). In acid digestion the proportion of the total metal extracted varies from one metal to another, and there is a wide range of acid digestion techniques used. Consequently, XRF analysis is regarded as the most reliable indicator of the true total concentration of trace elements (Cook et al., 1997).

Metals tend to be associated with the fine sediment fraction i.e. mud clay $(<63 \mu \mathrm{m})$ (Förstner and Wittman, 1983) and therefore the separation and analysis of the $<63 \mu \mathrm{m}$ fraction is widely used for trace elements (Chen and Wu, 1995; Everaarts and Fischer, 1992; Service et al., 1996; Williams et al., 1998). Analysis of elements in a specific size fraction precludes the need for normalisation of the data which is a method used to correct for grain size variation (Loring, 1991).

\subsubsection{Data Analyses}

\subsection{3.a Assessment of Anthropogenic Input of Metals}

Two methods were used to determine if, and by how much, stormwater discharge affected the metal concentrations in the vicinity of each outlet. The spatial variation data was used for these calculations.

The null hypothesis to be tested is:

Metal concentrations in sediments in the vicinity of stormwater outlets are the same as metal concentrations in sediments at the control sites 


\subsection{3.a.1 Enrichment Factor}

For each metal at each outlet station an enrichment factor (EF) (Aloupi and Angelidis, 2001; Balls et al., 1997; Dickinson et al., 1996; Lee et al., 1998; Rubio et al., 2000) was calculated as follows:

\section{$\mathbf{E F}=\underline{\text { metal concentration outlet station }}$ metal concentration control site}

The Aotea Quay control site was used for comparison with the OPT stations and the Queens Wharf control site was used for comparison with the FK stations (for all metals except $\mathrm{Cu}$ ). The Aotea Quay control site $\mathrm{Cu}$ concentration was used for $\mathrm{Cu}$ at FK because of the large discrepancy between FK Cu concentrations and the high concentrations at Queens Wharf.

In this study EF values $\geq 1.4$ (as opposed to $>1.0$ ) are considered to represent anthropogenic input via stormwater discharge. EF has been set at $\geq 1.4$ to account for analytical precision, control site variability and possible diagenesis. Descriptive terms ascribed to the EF values are given in Table 4.2 .

Table 4.2: Descriptors given to specific Enrichment Factor (EF) values

\begin{tabular}{|cl|}
\hline EF value & Enrichment \\
\hline $1.4-1.99$ & Slight \\
$2.0-2.99$ & Moderate \\
$3.0-4.99$ & Severe \\
$>5.0$ & Extreme \\
\hline
\end{tabular}

\subsection{3.a.2 Index of Geoaccumulation}

This index was originally defined by Müller (1979, cited in Stoffers et al., 1986) and is expressed as:

$$
\operatorname{Igeo}=\log _{2} \underline{C n}
$$

\section{$1.5 \mathrm{Bn}$}

where: - $\mathrm{Cn}$ is the measured concentration in the sediment for metal $\mathrm{n}$

- Bn the background value for metal $n$

- 1.5 is used to account for possible variations of background values (attributable to lithological variation in the sediment)

Background values used were those for Wellington argillite (Data from Roser, 1983). 
Descriptive terms for each of the seven Igeo classes are presented in Table 4.3. Each step from a lower class to the next class is a doubling in metal concentration. Negative values, which can arise from the use of the 1.5 variability factor applied to background values, are included in Class 0 .

Table 4.3: Geoaccumulation classes and descriptors (after Müller, 1979 (cited in Stoffers et al., 1986))

\begin{tabular}{|lcl|}
\hline Igeo & Class & Sediment Quality (Contamination) \\
0 & 0 & uncontaminated \\
$0-1$ & 1 & uncontaminated-moderately contaminated \\
$1-2$ & 2 & moderately contaminated \\
$2-3$ & 3 & moderately-strongly contaminated \\
$3-4$ & 4 & strongly contaminated \\
$4-5$ & 5 & strongly-extremely contaminated \\
$>5$ & 6 & extremely contaminated \\
\hline
\end{tabular}

\subsection{3.b Spatial Variability of metal concentrations}

The null hypotheses to be tested are:

There is no difference in metal concentrations with increasing distance from an outlet

There is no difference in metal concentrations with direction from an outlet

To determine if there were differences in the concentration of each metal with distance and direction from an outlet, $\mathrm{EF}$ values were used. EF, rather than Igeo, values were used as EF values are relative to the existing conditions in the areas of the outlet sites and are therefore a more relevant indication of changes in metal levels as a result of stormwater discharge than those for Igeo. No statistical analyses were performed on the data because of nonreplication (one sample only from each station).

\subsection{3.c Temporal Variability of metal concentrations}

4.2.3.c.1 Variability in metal concentration at each station over time

The null hypotheses to be tested are:

The variability in metal concentration over time is the same at outlet and associated control stations

The variability in metal concentration over time is the same at each station at an outlet site 
To determine if metal concentration changed over time (based upon one sample only from each station on each sampling occasion), the variability i.e. the concentration range of a metal at a station over time, has been used.

Comparisons were made of the variability of each metal:

- Between outlets and their associated control stations.

- Between stations at an outlet site.

\subsection{3.c. 2 Comparison of metal concentration between outlet and control stations} The null hypothesis to be tested is:

There is no significant difference in metal concentration between an outlet station and the associated control station over time

ANOVA was used to determine if there was a significant difference in the concentration of each metal between the outlet and control stations (AQ-2 vs AQ-C, and EB-2 vs EB-C) over time. Because of non-replication (one sample only from each station on each sampling occasion), station data consisted of all the values collected over time. Log transformed values were used for these analyses as geochemical parameters are log-normally distributed (Davis 1986) and diagnostic graphs of residuals were used to check for homogeneity of variance and normality (Pledger, 1998). Where the transformation did not remove the heterogeneity of variances, the non-parametric Kruskal-Wallis ANOVA was used. $A$ posteriori Tukey multiple-comparisons were carried out for the ANOVA analyses but were not available for the Kruskal-Wallis ANOVA. All analyses were carried out using SYSTAT 6.1 .

\subsection{3.d Environmental Relationships}

The null hypothesis to be tested is:

There is no significant relationship of metal concentration to each of the rainfall parameters

Over time the concentration of metals in sediment in the vicinity of the outlets could result from rainfall conditions prior to sampling, hence the relationships between metal concentration and rainfall parameters were investigated. For each metal, the metal concentration (transformed data) and EF for stations S10 at AQ-2 and S24 at EB-2 (monthly 
data for a year followed by quarterly data for 15 months) were used. The correlation of the concentration of each metal from each station to each of the rainfall parameters listed below was initially investigated by the generation of a Pearson correlation matrix. All correlations with a Pearson correlation coefficient value of $\geq 0.65$ or $\leq-0.65$ were assessed by linear regression (GLM: Estimate model). The simple linear regression significance level was $\alpha=$ 0.05 , with corrections made to $\alpha$ when multiple tests were performed (Rice, 1989). Rainfall data (daily total) for Evans Bay (Hataitai) and Aotea Quay (Kelburn) were provided by the Wellington City Council.

\section{Rainfall parameters used:}

- Number of days $>1 \mathrm{~mm}$ of rain

- Number of days $>10 \mathrm{~mm}$ of rain

- Highest daily rainfall (mm)

- Number of days of antecedent dry period (i.e. metals have time to accumulate) before the highest daily rainfall

in either the month prior to sampling (quarterly sampling) or the period between sampling (monthly sampling).

\subsection{RESULTS}

\subsubsection{Assessment of Anthropogenic Input of Metals}

\subsection{1.a Metal concentrations at control sites}

For each metal, an initial scatterplot (not shown) of all data from AQ-C, EB-C (spatial and temporal data) and Q-C (spatial data) (Files: Sphere metals, 3monthly metals, and monthly metal in Appendix III) showed differences between control sites and a consistency in concentrations both between stations and over time, within a control site (i.e. there was no difference in concentration of the metals with either distance or direction from the point on the shore).

$\mathrm{Ni}$ and $\mathrm{Cr}$ concentrations at each control site were comparable to that of argillite and harbour cores (Table 4.4). The As concentration at Aotea Quay is comparable to, while that at Evans Bay and Queens Wharf were slightly elevated above, that of argillite and harbour sediment. However, because of the discrepancy of the XRF analysis of As in reference sediment to the certified value (Table 4.1), there may be little difference in As concentrations between the 
control sites and between control sites, argillite and harbour sediment. $\mathrm{Cu}, \mathrm{Pb}$ and $\mathrm{Zn}$ concentrations at all control sites were elevated above those in argillite (Table 4.4). At Aotea Quay, the concentrations of $\mathrm{Cu}, \mathrm{Pb}$ and $\mathrm{Zn}$ were comparable to those of the shallow harbour sediment, as were the Evans Bay concentrations of $\mathrm{Cu}$ and $\mathrm{Zn}$ (Table 4.4). The Evans Bay $\mathrm{Pb}$ concentration was slightly higher, while at Queens Wharf, $\mathrm{Cu}$ was $2.3 \mathrm{x}, \mathrm{Pb} 1.6 \mathrm{x}$ and $\mathrm{Zn}$ slightly higher than in shallow harbour sediment.

Table 4.4: Total concentration (ppm) of metals (mean \pm 1 S.D.) from Wellington argillite, harbour cores and each control site. Aotea Quay $\mathrm{N}=84$; Queens Wharf $\mathrm{N}=9$; Evans Bay $\mathrm{N}=83$.

\begin{tabular}{lcccccc}
\hline & Argillite** $^{* *}$ & Deep $^{\#}$ & Shallow $^{*}$ & $\begin{array}{c}\text { Aotea } \\
\text { Quay }\end{array}$ & $\begin{array}{c}\text { Queens } \\
\text { Wharf }\end{array}$ & Evans Bay \\
\hline As & $11 \pm 6$ & 14 & 16 & $17 \pm 2$ & $23 \pm 2$ & $23 \pm 3$ \\
$\mathbf{C r}$ & $66 \pm 13$ & 69 & 72 & $69 \pm 3$ & $70 \pm 1$ & $74 \pm 3$ \\
$\mathbf{C u}$ & $30 \pm 8$ & 26 & 73 & $71 \pm 12$ & $171 \pm 9$ & $65 \pm 11$ \\
$\mathbf{N i}$ & $29 \pm 6$ & 28 & 29 & $23 \pm 2$ & $22 \pm 1$ & $24 \pm 3$ \\
$\mathbf{P b}$ & $28 \pm 7$ & 37 & 104 & $100 \pm 13$ & $171 \pm 13$ & $127 \pm 9$ \\
$\mathbf{Z n}$ & $106 \pm 20$ & 128 & 221 & $224 \pm 22$ & $274 \pm 12$ & $232 \pm 10$ \\
\hline
\end{tabular}

** - Argillite (Data from Roser, 1983)

\# - Harbour core. Averaged from sediment 100-370 cm from the sediment surface ( Dunbar, 1994)

* - Harbour core. Averaged from sediment 0-50 cm from the sediment surface (Dunbar, 1994)

\subsection{1.b Assessment of anthropogenic input of metals at outlet sites}

The raw data, i.e. the concentration (ppm) of each metal at each station at each outlet site are presented in Appendix III (File: Sphere metals). The range in concentration of each metal (over all outlets and all stations) was: As 14.2-124.1 ppm; Cr 61.3-123.8 ppm; Cu 52.8-794 ppm; Ni 17.1-56.2 ppm; Pb 90.5-1097 ppm; Zn 175.4-1608 ppm.

Enrichment Factor (EF) and Index of Geoaccumulation (Igeo) values were calculated from the raw data of each metal concentration at each station (values in File: Sphere metals in Appendix III). Because EF values were calculated using control site metal concentrations and Igeo values using argillite concentrations, inter-site discrepancies between these values occur. Both EF and Igeo values of the November 98 data are plotted into Figs. 4.1-4.6 where 
the EF values are given by reference to the $\mathrm{y}$-axis and the Igeo class values are denoted by the diameter of the symbol. A summary of the level of enrichment of each metal at the outlet sites is given in Tables 4.5 and 4.6; the descriptive terms for EF and Igeo are given in Tables 4.2 and 4.3 respectively.

As shown by Figs. 4.1-4.6 and Tables 4.5 and 4.6, stormwater discharge has resulted in EF values $>1.4$ and Igeo values $>0$ for all metals at some stations in the vicinity of the outlets.

The null hypothesis that metal concentrations in sediments in the vicinity of stormwater outlets are the same as metal concentrations in sediments at the control sites is rejected. Metal concentrations in sediments in the vicinity of stormwater outlets are higher at some of the stations at some outlets than at the control sites.

\subsubsection{Spatial Variability of metal concentrations}

\subsection{2.a Metal enrichment with distance from an outlet}

The highest levels of metal enrichment occurred close to the outlet and decreased seaward (Figs. 4.1-4.6) (File: Sphere metals and May Sphere in Appendix III).

The seaward extent of enrichment was both outlet-specific and contaminant-specific (Table 4.7). The seaward extent of enrichment could not be determined at OPT as the extent of enrichment was greater than the $45 \mathrm{~m}$ limit of sampling, while at EB-1 the determination of the seaward extent of the effect of stormwater discharge was complicated by the presence of marina structures. $\mathrm{Cu}$ and $\mathrm{Pb}$ concentrations at the outer stations (44 and $54 \mathrm{~m}$ (in November 1998 and May 1999 respectively) (which are located in the marina) did not decrease with increasing distance from the outlet (Figs. 4.3 and 4.5; Table 4.7; File: May Sphere in Appendix III). At AQ-1 enrichment of the sediment at station L20 with $\mathrm{Cu}$ and $\mathrm{Zn}$, and at station $\mathrm{R} 30$ with $\mathrm{As}, \mathrm{Cu}, \mathrm{Pb}$ and $\mathrm{Zn}$, was not consistent with a distance effect from the outlet and is therefore more likely to result from wharf/shipping activities than stormwater discharge. At FK Cu enrichment was $\geq 1.4 \mathrm{EF}$ even at the $44 \mathrm{~m}$ stations, which is attributed to the use of Aotea Quay control site values in the EF calculation.

The null hypothesis that there is no difference in metal concentrations with increasing distance from an outlet is rejected. The highest levels of metal enrichment occurred close to an outlet and decreased with increasing distance seaward. 

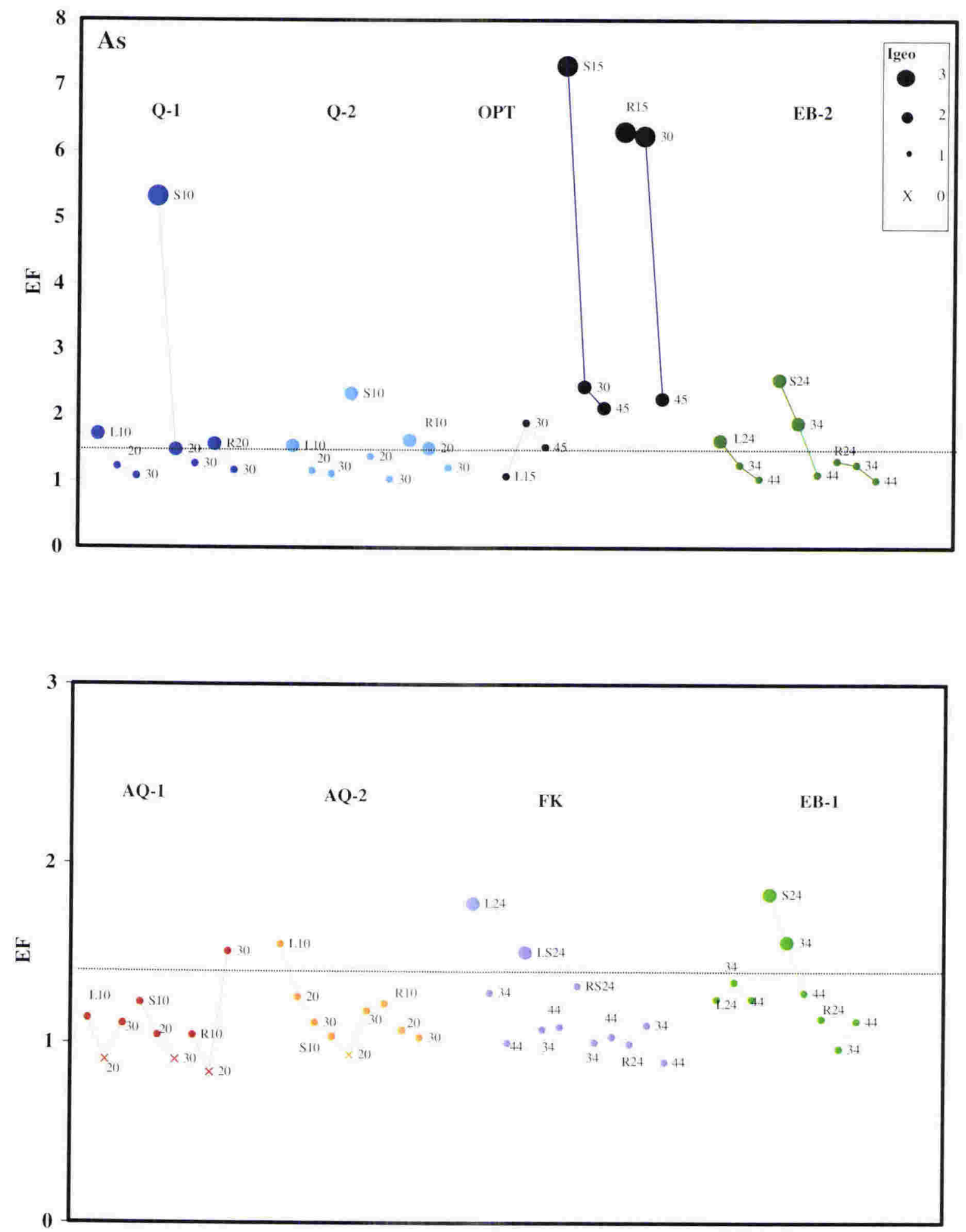

Figure 4.1: Spatial variability of sediment enrichment with arsenic at each outlet site L- Left transect, S- Straight Transect, R-Right Transect 10,20 ete - distance $(\mathrm{m})$ from the outlet location of point on $\mathrm{y}$-axis $=\mathrm{EF}$ diameter of point $=$ Igeo class (see box top right) 

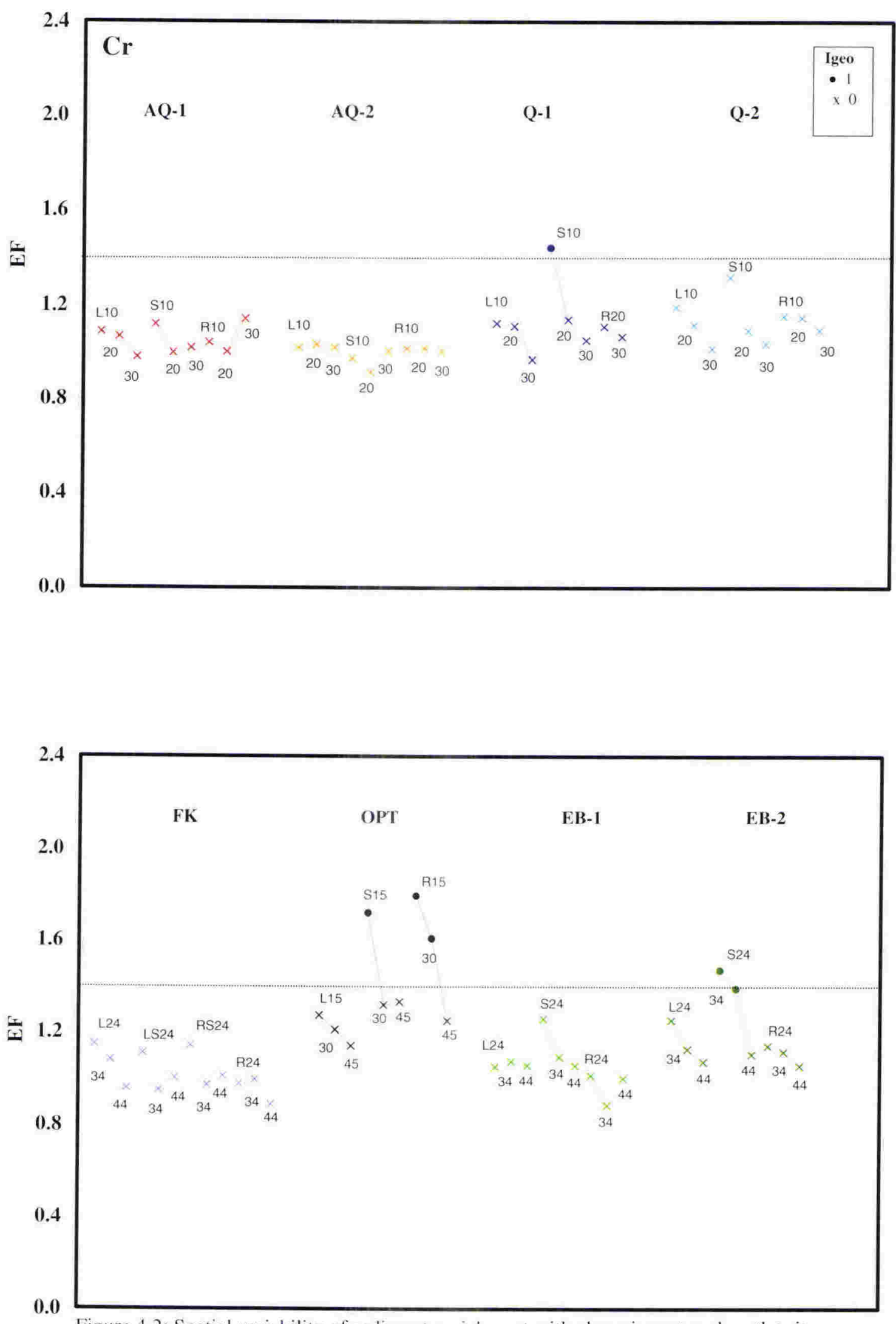

Figure 4.2: Spatial variability of sediment enrichment with chromium at each outlet site L - Left transect, $\mathrm{R}$ - Right transect, $\mathrm{S}$ - Straight transect

10,20 etc. - distance $(\mathrm{m})$ from the outlet

location of point on $y$-axis $=\mathrm{EF}$

diameter of point $=$ Igeo class (see box top right) 

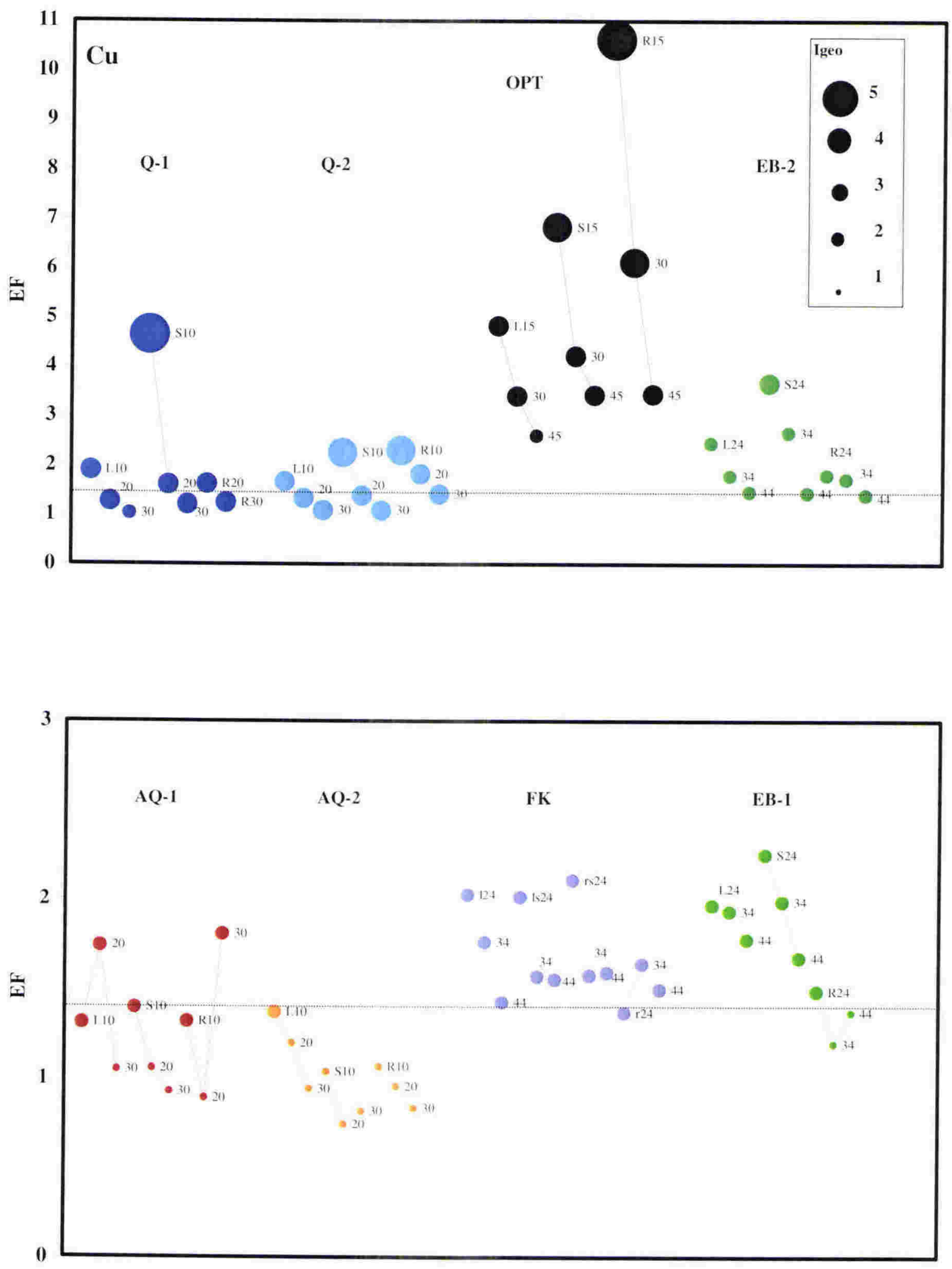

Figure 4.3: Spatial variability of sediment enrichment with copper at each outlet site L-Left transect, S-Straight Transect, R-Right Transect 10,20 etc-distance $(\mathrm{m})$ from the outlet location of point on $y$-axis $=\mathrm{EF}$ diameter of point $=$ Igeo class (see box top right) 

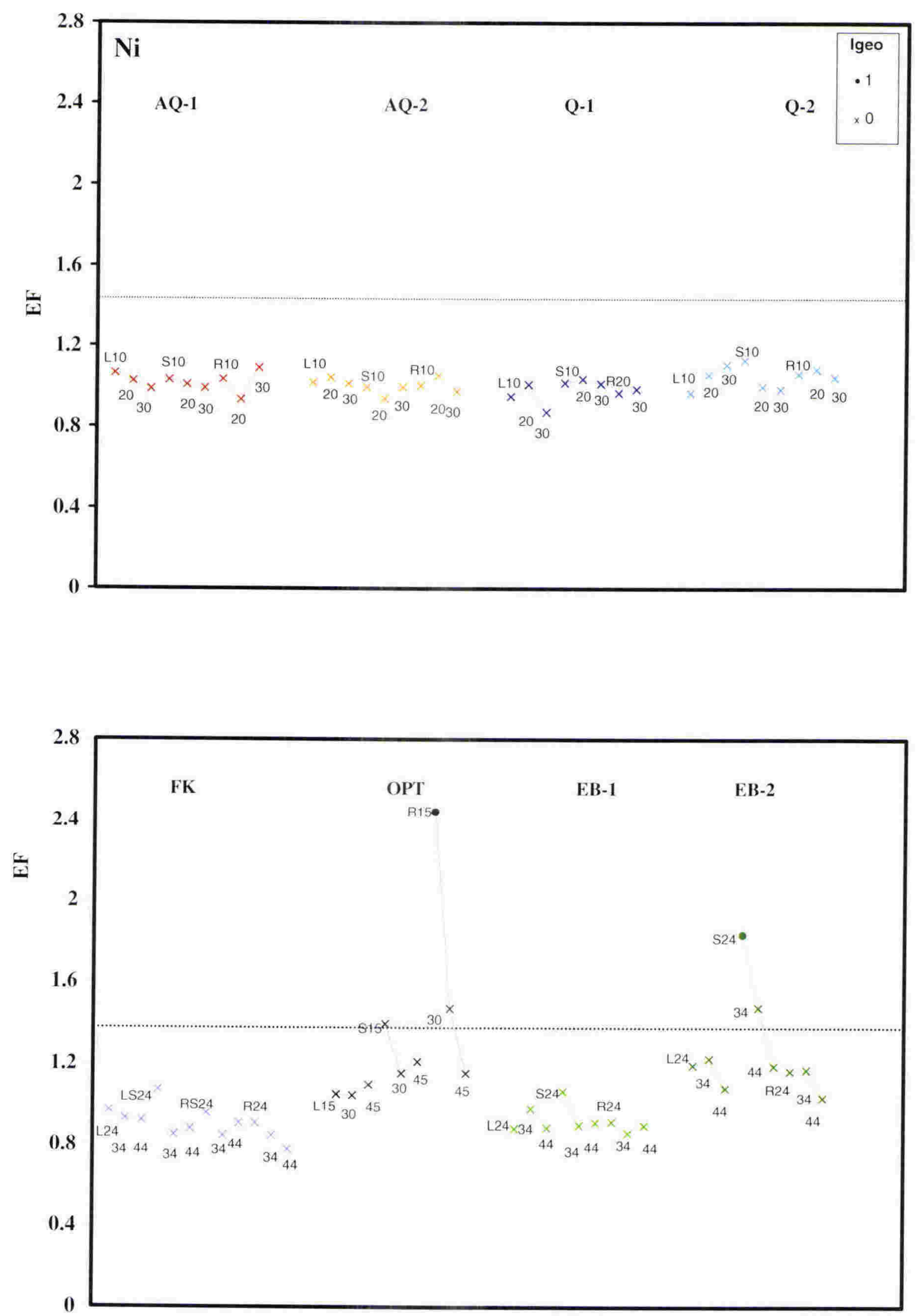

Figure 4.4: Spatial variability of sediment enrichment with nickel at each outlet site L - Left transect, S - Straight transect, R - Right transect 10,20 ete - distance $(\mathrm{m})$ from the outlet location of point on the $y$-axis $=E F$ diameter of point $=$ Igeo class (see box top right) 

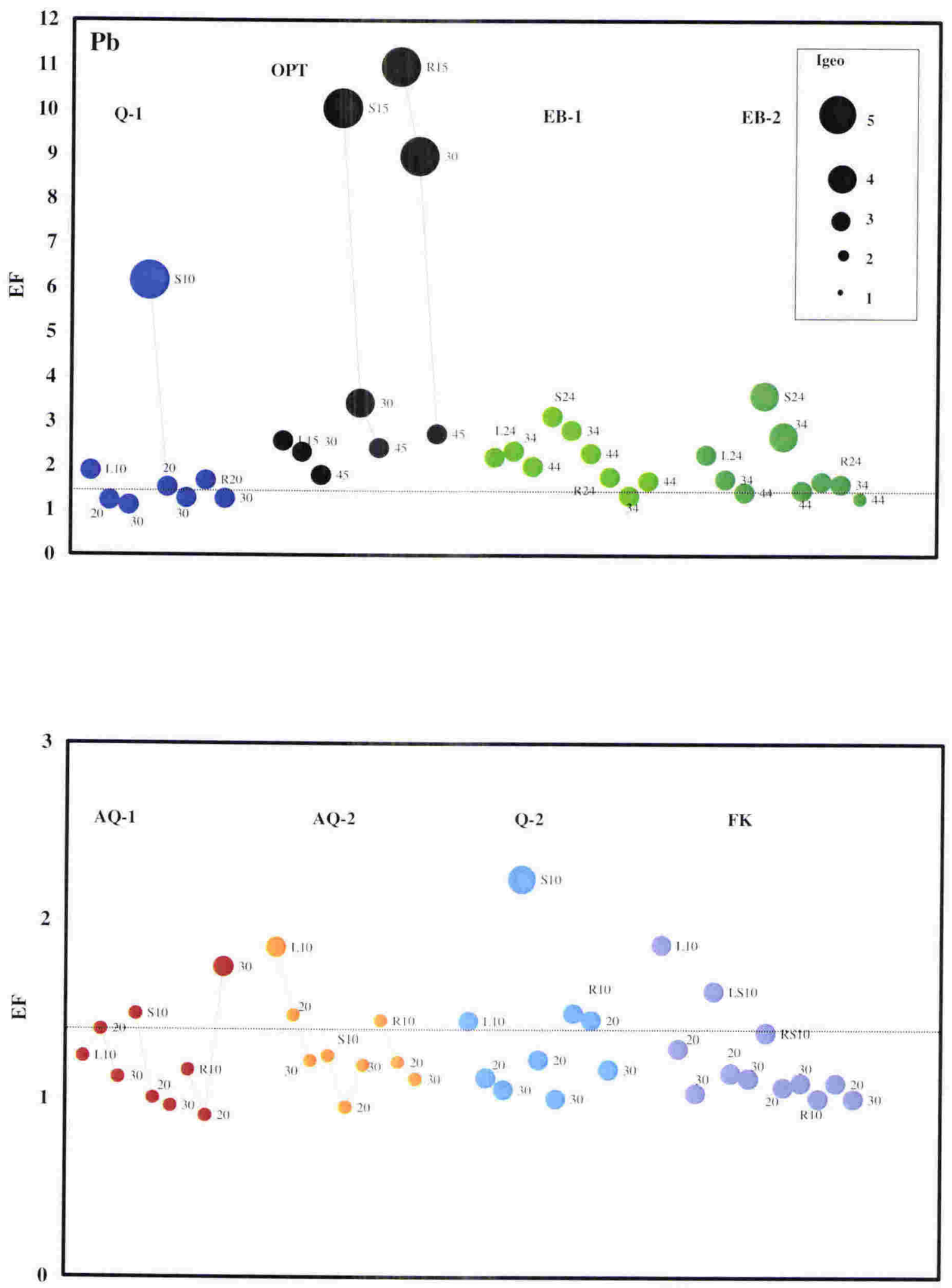

Figure 4.5: Spatial variability of sediment enrichment with lead at each outlet site L - Left transect, S - Straight transect, R - Right transect 10,20 , etc. - distance $(\mathrm{m})$ from the outlet location of point on $y$-axis $=E F$ diameter of point $=$ Igeo class $($ see box top right $)$ 

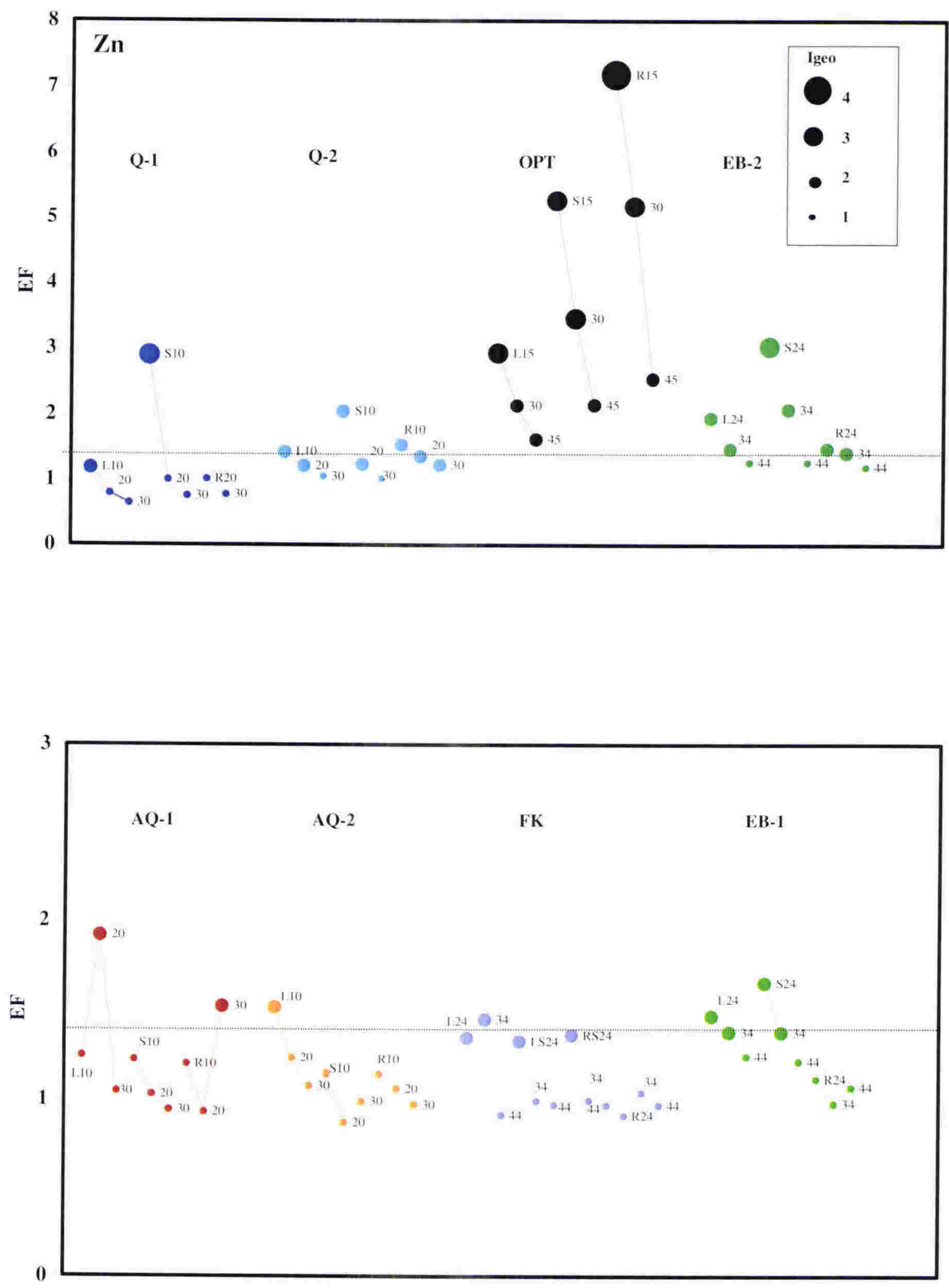

Figure 4.6: Spatial variability of sediment enrichment with zinc at each outlet site $\mathrm{L}$ - Left transect, $\mathrm{S}$ - Straight transect, $\mathrm{R}$ - Right transect 10,20 , etc. - distance $(\mathrm{m})$ from the outlet location of point on $y$-axis $=E F$ diameter of point $=$ Igeo class (see box top right) 
Table 4.5: Summary of metal enrichment in terms of EF values (refer to Table 4.2) at the outlet sites Number of stations sampled: $1998=74,1999=48$

\begin{tabular}{|c|c|c|}
\hline Contamination & Site: stations (1998) & Site: stations (1999) \\
\hline \multicolumn{3}{|l|}{$\underline{\text { As }}$} \\
\hline$\overline{\text { Extreme }}$ & $\begin{array}{l}\text { OPT: R15, R30, S15 } \\
\text { Q-1: S10 }\end{array}$ & \\
\hline Moderate & 5 stations & 1 station \\
\hline Slight & 16 stations & 11 stations \\
\hline \multicolumn{3}{|l|}{$\underline{\mathrm{Cr}}$} \\
\hline Slight & 6 stations & 1 station \\
\hline \multicolumn{3}{|l|}{$\underline{\mathrm{Cu}}$} \\
\hline$\overline{\text { Extreme }}$ & OPT: R15, R30, S15 & Q-2: R20 \\
\hline Severe & $\begin{array}{l}\text { Q-1: S10 } \\
\text { EB-2: S24 } \\
\text { OPT: L15, L30, S30, S45, R45 }\end{array}$ & EB-2: S24 \\
\hline Moderate & 9 stations & 5 stations \\
\hline Slight & 27 stations & 14 stations \\
\hline \multicolumn{3}{|l|}{$\underline{\mathrm{Ni}}$} \\
\hline$\overline{\text { Moderate }}$ & 1 station & \\
\hline Slight & 6 stations & 2 stations \\
\hline \multicolumn{3}{|l|}{$\underline{\mathrm{Pb}}$} \\
\hline$\overline{\text { Extreme }}$ & $\begin{array}{l}\text { OPT: R15, R30, S15 } \\
\text { Q-1: S10 }\end{array}$ & \\
\hline Severe & $\begin{array}{l}\text { OPT: } \text { S30 } \\
\text { EB-2: S24 } \\
\text { EB-1: S24 }\end{array}$ & \\
\hline $\begin{array}{l}\text { Moderate } \\
\text { Slight }\end{array}$ & $\begin{array}{l}12 \text { stations } \\
21 \text { stations }\end{array}$ & $\begin{array}{l}4 \text { stations } \\
20 \text { stations }\end{array}$ \\
\hline \multicolumn{3}{|l|}{$\underline{\mathrm{Zn}}$} \\
\hline$\overline{\text { Extreme }}$ & OPT: R15, R30, S15 & \\
\hline Severe & $\begin{array}{l}\text { EB-2: S24 } \\
\text { OPT: S30 }\end{array}$ & \\
\hline Moderate & 7 stations & 1 station \\
\hline Slight & 13 stations & 8 stations \\
\hline
\end{tabular}


Table 4.6: Summary of metal enrichment in terms of Igeo values (refer to Table 4.3) at the outlet sites Number of stations sampled: $1998=74,1999=48$

\begin{tabular}{|c|c|c|}
\hline Contamination & Site: stations (1998) & Site: stations (1999) \\
\hline \multicolumn{3}{|l|}{$\underline{\text { As }}$} \\
\hline$\overline{\text { Moderate-strong }}$ & OPT: R15, R30, S15 & \\
\hline Moderate & 17 stations & 10 stations \\
\hline \multicolumn{3}{|l|}{$\underline{\mathrm{Cu}}$} \\
\hline$\overline{\text { Strong-extreme }}$ & $\begin{array}{l}\text { OPT: R15 } \\
\text { Q-1: } \mathrm{S} 10\end{array}$ & \\
\hline Strong & $\begin{array}{l}\text { OPT: } \mathrm{S} 15, \mathrm{R} 30 \\
\text { Q-2: } \mathrm{S} 10, \mathrm{R} 10\end{array}$ & Q-2: R10, R20 \\
\hline Moderate-strong & $\begin{array}{l}\text { OPT: L15, L30, L45, S30, S45, R45 } \\
\text { Q-1: L10, L20, S20, S30, R20, R30 } \\
\text { Q-2: L10, L20, L30, S20, S30, R20, R30 } \\
\text { EB-2: S24 }\end{array}$ & $\begin{array}{l}\text { Q-2: L10, L20, L30, S10, } \\
\text { S20, S30, R30, R40 } \\
\text { EB-2: S24 }\end{array}$ \\
\hline Moderate & 34 stations & 20 stations \\
\hline \multicolumn{3}{|l|}{$\underline{\mathrm{Pb}}$} \\
\hline Strong-extreme & $\begin{array}{l}\text { OPT: R15, R30, S15 } \\
\text { Q-1: S10 }\end{array}$ & \\
\hline Strong & $\begin{array}{l}\text { OPT: S30 } \\
\text { Q-2: S10 } \\
\text { EB-2: S24, S34 }\end{array}$ & EB-2: S24 \\
\hline Moderate-strong & $\begin{array}{l}\text { OPT: L15, L30, L45, S30, S45, R45 } \\
\text { AQ-1: R30 } \\
\text { AQ-2: L10 } \\
\text { Q-1: L10, L20, L30, S20, S30, R20, R30 } \\
\text { Q-2: L10, L20, L30, S20, S30, R10, R20, R30 } \\
\text { FK: all } \\
\text { EB-1: L24, L34, L44, S24, S34, S44, R24 } \\
\text { EB-2: L24, L34, L44, S44, R24, R34 }\end{array}$ & $\begin{array}{l}\text { AQ-2: } \text { L10, S10 } \\
\text { Q-2: L10, L20, L30, S10 } \\
\text { S20, S30, R10, R20, R30 } \\
\text { EB-1: } \text { L24, L34, L44, L54 } \\
\text { S24, S34, S44, S54, R24 } \\
\text { EB-2: } \\
\quad \text { L24, L34, L44, S34 } \\
\text { S44, R24 }\end{array}$ \\
\hline Moderate & 19 stations & 21 stations \\
\hline \multicolumn{3}{|l|}{$\underline{\mathrm{Zn}}$} \\
\hline Strong & OPT: R15 & \\
\hline Moderate-strong & $\begin{array}{l}\text { OPT: L15, S15, S30, R30 } \\
\text { Q-1: S10 } \\
\text { EB-2: S24 }\end{array}$ & \\
\hline Moderate & 28 stations & 13 stations \\
\hline
\end{tabular}


Table 4.7: Distance $(\mathrm{m})$ of sediment enrichment $(>1.4 \mathrm{EF})$ with each metal at each outlet * - enriched sediment i.e. $>1.4 \mathrm{EF}$ at the station, but not at stations closer to the outlet ind - not possible to determine due to discrepancies in calculation of the EF value

?-enrichment at this distance could be due to either stormwater discharge or the presence of the marina

- no enrichment at stations sampled

\begin{tabular}{|c|c|c|c|c|c|c|c|c|}
\hline Time & Outlet & Transect & As & $\mathrm{Cr}$ & $\mathrm{Cu}$ & $\mathrm{Ni}$ & $\mathbf{P b}$ & Zn \\
\hline \multirow[t]{3}{*}{1998} & AQ-1 & $\mathrm{L}$ & - & - & $20^{*}$ & - & - & $20 *$ \\
\hline & & $\mathrm{S}$ & - & - & - & - & 10 & - \\
\hline & & $\mathrm{R}$ & $30^{*}$ & - & $30^{*}$ & - & $30^{*}$ & $30^{*}$ \\
\hline \multirow[t]{3}{*}{1998} & AQ-2 & $\mathrm{L}$ & 10 & - & - & - & 20 & 10 \\
\hline & & $\mathrm{S}$ & - & - & - & - & - & - \\
\hline & & $\mathrm{R}$ & - & - & - & - & 10 & - \\
\hline \multirow[t]{3}{*}{1999} & AQ-2 & $\mathrm{L}$ & 10 & - & 10 & - & 10 & 10 \\
\hline & & S & 10 & - & - & - & 10 & 10 \\
\hline & & $\mathrm{R}$ & - & - & - & - & 10 & - \\
\hline \multirow[t]{3}{*}{1998} & Q-1 & $\mathrm{L}$ & 10 & - & 10 & - & 10 & - \\
\hline & & $\mathrm{S}$ & 20 & 10 & 20 & - & 20 & 10 \\
\hline & & $\mathrm{R}$ & 20 & - & 20 & - & 20 & - \\
\hline \multirow[t]{3}{*}{1998} & Q-2 & $\mathrm{L}$ & 10 & - & 10 & - & 10 & 10 \\
\hline & & $\mathrm{S}$ & 10 & - & 10 & - & 10 & 10 \\
\hline & & $\mathrm{R}$ & 20 & - & 30 & - & 20 & 10 \\
\hline \multirow{3}{*}{1999} & Q-2 & $\mathrm{L}$ & 10 & - & 10 & - & 10 & - \\
\hline & & S & 10 & 10 & 10 & 10 & 10 & 10 \\
\hline & & $\mathrm{R}$ & 30 & - & 30 & 10 & 20 & $20 *$ \\
\hline \multirow[t]{3}{*}{1998} & FK & $\mathrm{L}$ & 24 & - & ind & - & 24 & $34 *$ \\
\hline & & S & 24 & - & ind & - & 24 & - \\
\hline & & $\mathrm{R}$ & - & - & ind & - & - & - \\
\hline \multirow[t]{3}{*}{1998} & OPT & L & $>45$ & - & ind & - & $>45$ & $>45$ \\
\hline & & $\mathrm{S}$ & $>45$ & 15 & ind & 15 & $>45$ & $>45$ \\
\hline & & $\mathrm{R}$ & $>45$ & 30 & ind & 30 & $>45$ & $>45$ \\
\hline \multirow[t]{3}{*}{1998} & EB-1 & $\mathrm{L}$ & - & - & $>44 ?$ & - & $>44$ ? & 24 \\
\hline & & $\mathrm{S}$ & 34 & - & $>44 ?$ & - & $>44$ ? & 24 \\
\hline & & $\mathrm{R}$ & - & - & 24 & - & 24 & 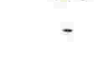 \\
\hline \multirow[t]{3}{*}{1999} & EB-1 & $\mathrm{L}$ & - & - & $>54 ?$ & - & $>54$ ? & - \\
\hline & & $\mathrm{S}$ & 34 & - & $>54 ?$ & - & $>54 ?$ & $34^{*}$ \\
\hline & & $\mathrm{R}$ & - & - & 24 & - & 24 & - \\
\hline \multirow[t]{3}{*}{1998} & EB-2 & $\mathrm{L}$ & 24 & - & 44 & - & 44 & 34 \\
\hline & & $\mathrm{S}$ & 34 & 24 & 44 & 34 & 44 & 34 \\
\hline & & $\mathrm{R}$ & - & - & 44 & - & 34 & 34 \\
\hline \multirow[t]{3}{*}{1999} & EB-2 & $\mathrm{L}$ & 24 & - & 44 & - & 44 & 24 \\
\hline & & $\mathrm{S}$ & 34 & - & 44 & - & 44 & 34 \\
\hline & & $\mathrm{R}$ & 24 & - & 24 & - & 24 & 24 \\
\hline
\end{tabular}




\subsection{2.b Metal enrichment with direction from an outlet}

For each metal, mean enrichment for ALL, Left, Straight and Right stations was calculated and used to investigate metal enrichment with direction from an outlet (Table 4.8). At OPT the highest levels of enrichment occurred on the right transect however there was also high enrichment at stations straight in front of this outlet (Figs. 4.1-4.6). At EB-1, EB-2, Q-1, Q-2 (except for $\mathrm{Cu}$ ) and FK ( $\mathrm{Cu}$ only) the highest level of enrichment occurred straight in front of the outlet. At Q-2, Cu enrichment was highest along the right transect (all stations of which were located beneath an extended wharf structure). At AQ-2 and FK ( $\mathrm{Pb}$ and As) the highest levels of enrichment occurred at stations on the left transect. Directional differences at AQ-1 result from the anomalous enrichment at some stations.

The null hypothesis that there is no difference in metal concentrations with direction from an outlet is rejected. Metal concentrations differed with direction at some outlets.

\subsubsection{Ranking of the outlets for metal enrichment}

For each metal, mean enrichment across ALL stations at a site (Table 4.8, File Sphere enrichment may in Appendix III) was used to rank the outlets from the most to least metal enriched sediment. The ranking of the outlets is:

\section{November 1998}

$\begin{array}{ll}\text { As } & \text { OPT }>\text { Q-1 }>\text { EB-2 }=\text { Q-2 }>\text { EB-1 }>\text { AQ-2 = FK }>\text { AQ-1 } \\ \text { Cr } & \text { OPT }>\text { EB-2 }>\text { Q-1 = Q-2 }>\text { EB-1 = FK = AQ-1 = AQ-2 } \\ \text { Cu } & \text { OPT }>\text { EB-2 }>\text { Q-1 }>\text { EB-1 = FK }>\text { Q-2 }>\text { AQ-1 }>\text { AQ-2 } \\ \text { Ni } & \text { OPT }>\text { EB-2 }>\text { AQ-1 = AQ-2 = Q-1 = Q-2 }>\text { EB-1 = FK } \\ \text { Pb } & \text { OPT }>\text { EB-1 }>\text { Q-1 = EB-2 }>\text { Q-2 = AQ-2 }>\text { AQ-1 = FK } \\ \text { Zn } & \text { OPT }>\text { EB-2 }>\text { Q-2 }>\text { EB-1 }>\text { AQ-1 }>\text { AQ-2 = Q-1 = FK }\end{array}$

May 1999

As and $\mathrm{Cr} \quad$ Q-2 $>$ EB-2 $>$ EB-1 $>$ AQ-2

$\mathrm{Cu} \quad \mathbf{E B}-1>\mathbf{E B}-2=\mathbf{Q}-2>\mathrm{AQ}-2$

Ni $\quad$ Q-2 $>$ EB-2 $>$ AQ-2 $>$ EB-1 
Table 4.8: Mean Enrichment of each contaminant for each outlet. November 1998

S2 - mean enrichment for the two S stations closest to the outlet

S3 - mean enrichment for the three $S$ stations in front of the outlet

$\mathrm{L}$ - mean enrichment left transect, $\mathrm{R}$ - mean enrichment right transect

As

\begin{tabular}{|cccccc|}
\hline Site & AlI & L & S2\# & S3\#\# & R \\
AQ-1 & 1.08 & 1.05 & 1.13 & 1.06 & 1.13 \\
AQ-2 & 1.15 & 1.3 & 0.98 & 1.05 & 1.11 \\
Q-1 & 1.85 & 1.34 & 3.4 & 2.69 & 1.37 \\
Q-2 & 1.44 & 1.27 & 1.86 & 1.58 & 1.45 \\
FK & 1.17 & 1.35 & 1.23 & 1.17 & 1 \\
OPT & 3.46 & 1.5 & 4.87 & 3.95 & 4.93 \\
EB-1 & 1.3 & 1.28 & 1.7 & 1.56 & 1.08 \\
EB-2 & 1.45 & 1.31 & 2.22 & 1.85 & 1.2 \\
\hline
\end{tabular}

Cr

\begin{tabular}{|cccccc|}
\hline Site & All & L & S2\# & S3\#\# & R \\
AQ-1 & 1.05 & 1.04 & 1.05 & 1.04 & 1.06 \\
AQ-2 & 1 & 1.02 & 0.94 & 0.96 & 1.01 \\
Q-1 & 1.125 & 1.07 & 1.29 & 1.21 & 1.09 \\
Q-2 & 1.13 & 1.11 & 1.2 & 1.15 & 1.13 \\
FK & 1.02 & 1.06 & 1.04 & 1.03 & 0.95 \\
OPT & 1.4 & 1.21 & 1.52 & 1.46 & 1.55 \\
EB-1 & 1.05 & 1.06 & 1.18 & 1.13 & 0.97 \\
EB-2 & 1.19 & 1.15 & 1.43 & 1.32 & 1.1 \\
\hline
\end{tabular}

Cu

\begin{tabular}{|cccccc|}
\hline Site & AlI & L & S2\# & S3\#\# & R \\
AQ-1 & 1.3 & 1.4 & 1.13 & 1.13 & 1.34 \\
AQ-2 & 1 & 1.2 & 0.89 & 0.97 & 0.95 \\
Q-1 & 1.8 & 1.4 & 3.13 & 2.48 & 1.43 \\
Q-2 & 1.6 & 1.4 & 1.82 & 1.6 & 1.85 \\
FK & 1.7 & 1.7 & 1.82 & 1.7 & 1.5 \\
OPT & 5.05 & 3.61 & 5.52 & 4.82 & 6.72 \\
EB-1 & 1.73 & 1.89 & 2.12 & 1.97 & 1.35 \\
EB-2 & 2.04 & 1.9 & 3.16 & 2.59 & 1.64 \\
\hline
\end{tabular}

$\mathrm{Ni}$

\begin{tabular}{|cccccc|}
\hline Site & AII & L & S2\# & S3\#\# & R \\
AQ-1 & 1.02 & 1.03 & 1.02 & 1.01 & 1.02 \\
AQ-2 & 1 & 1.02 & 0.97 & 0.98 & 1.01 \\
Q-1 & 0.98 & 0.94 & 1.03 & 1.02 & 0.98 \\
Q-2 & 1.05 & 1.05 & 1.07 & 1.04 & 1.07 \\
FK & 0.9 & 0.94 & 0.93 & 0.92 & 0.84 \\
OPT & 1.33 & 1.06 & 1.3 & 1.25 & 1.69 \\
EB-1 & 0.92 & 0.91 & 0.98 & 0.96 & 0.89 \\
EB-2 & 1.26 & 1.2 & 1.65 & 1.5 & 1.1 \\
\hline
\end{tabular}

Pb

\begin{tabular}{|cccccc|}
\hline Site & All & L & S2\# & S3\#\# & R \\
AQ-1 & 1.22 & 1.25 & 1.25 & 1.15 & 1.27 \\
AQ-2 & 1.3 & 1.51 & 1.1 & 1.13 & 1.25 \\
Q-1 & 2.02 & 1.41 & 3.85 & 2.99 & 1.47 \\
Q-2 & 1.35 & 1.21 & 1.73 & 1.49 & 1.43 \\
FK & 1.23 & 1.4 & 1.3 & 1.24 & 1.03 \\
OPT & 5.03 & 2.24 & 6.74 & 5.3 & 7.56 \\
EB-1 & 2.18 & 2.2 & 2.98 & 2.76 & 1.6 \\
EB-2 & 1.97 & 1.8 & 3.15 & 2.58 & 1.52 \\
\hline
\end{tabular}

Zn

\begin{tabular}{|cccccc|}
\hline Site & All & L & S2\# & S3\#\# & R \\
AQ-1 & 1.23 & 1.4 & 1.12 & 1.06 & 1.22 \\
AQ-2 & 1.11 & 1.27 & 1 & 1 & 1.06 \\
Q-1 & 1.13 & 0.87 & 1.95 & 1.55 & 0.9 \\
Q-2 & 1.34 & 1.23 & 1.64 & 1.43 & 1.37 \\
FK & 1.1 & 1.24 & 1.17 & 1.1 & 0.97 \\
OPT & 3.6 & 2.23 & 4.36 & 3.62 & 4.96 \\
EB-1 & 1.3 & 1.36 & 1.5 & 1.41 & 1.05 \\
EB-2 & 1.68 & 1.56 & 2.55 & 2.12 & 1.36 \\
\hline
\end{tabular}


$\mathrm{Pb}$

EB-1 $=$ EB-2 $>$ AQ-2 $>$ Q-2

$\mathrm{Zn}$

EB-2 $>$ EB-1 $=$ Q-2 $>$ AQ-2

Note: Sites are considered equal if the average values were within 0.05 of each other.

\subsubsection{Temporal Variability of metal concentrations}

\subsection{4.a Variability in metal concentration over time}

Variability i.e. the concentration range of a metal at a station over time, was determined for each metal at each station at AQ-2, Q-2, EB-2, AQ-C and EB-C using the quarterly data.

\subsection{4.a.1 Variability in metal concentration at outlet and control sites}

$A Q-2$

At AQ-2 station S2, As was 10.2 times, Cu 2.4 times, $\mathrm{Pb} 30.6$ times and $\mathrm{Zn} 4.7$ times more variable while at $\mathrm{S} 10 \mathrm{As}$ was 8.6 times, $\mathrm{Cu} 3.2$ times, $\mathrm{Pb} 7.3$ times and $\mathrm{Zn} 3.7$ times more variable and at $\mathrm{L10}, \mathrm{Pb}$ was 3 times and $\mathrm{As} 2.2$ times more variable than at the control site (over all stations) (File: Time summary in Appendix III). The variability of metals at L20, $\mathrm{S} 20, \mathrm{R} 10$ and R20 was comparable (i.e. there was $<2 \mathrm{x}$ difference) to that at the control site.

$E B-2$

At EB-2 station S24, Zn was 4.9 times, Pb 2.6 times and As, Cu and Ni 1.6-1.7 times more variable than at EB-C (over all stations). The variability of $\mathrm{Pb}, \mathrm{Cu}, \mathrm{As}$ and $\mathrm{Zn}$ was higher at L24 and S34 but at R34, L34 and S44 it was comparable to (i.e. there was $<2$ difference), that at the control site. At R24 the Cu variability was higher than at the control site (Table 4.9; File: Time summary in Appendix III).

The null hypothesis that the variability in metal concentration over time is the same at outlet and associated control stations is rejected. There was higher variability in metal concentration at some outlet stations than at the associated control site stations.

4.3.4.a.2 Variability in metal concentration at each station at an outlet site $A Q-2$ (Figs. 4.7 and 4.8)

The highest variability of $\mathrm{As}, \mathrm{Cr}, \mathrm{Pb}$ and $\mathrm{Zn}$ occurred at station $\mathrm{S} 2$ while for $\mathrm{Cu}$ it was at station S10 and for Ni it was at stations L10, S10 and S20. The high variability at S2 is a reflection of the high concentration of each metal at this station in November 2000. 
Table 4.9: Metal concentration (ppm) at each station at EB-2 over time. Quarterly sampling. $\mathrm{N}=9$

\begin{tabular}{|c|c|c|c|c|c|c|c|}
\hline As & $\overline{L 24}$ & $\mathrm{~L} 34$ & S24 & S34 & $\mathrm{S} 44$ & R24 & $\overline{R 34}$ \\
\hline Mean & 34.8 & 28.0 & 49.2 & 36.1 & 26.4 & 29.7 & 27.3 \\
\hline Standard Deviation & 2.5 & 4.1 & 6.0 & 3.8 & 3.1 & 3.2 & 3.3 \\
\hline Range (Variability) & 7.0 & 12.5 & 18.7 & 13.4 & 9.0 & 9.0 & 9.9 \\
\hline Minimum & 30.9 & 21.4 & 39.8 & 29.9 & 22.3 & 24.4 & 21.8 \\
\hline Maximum & 37.9 & 33.9 & 58.5 & 43.3 & 31.3 & 33.4 & 31.7 \\
\hline Confidence Level $(95.0 \%)$ & 1.9 & 3.1 & 4.6 & 2.9 & 2.4 & 2.5 & 2.6 \\
\hline $\mathrm{Cr}$ & $\mathrm{L} 24$ & L34 & S24 & S34 & S44 & R24 & $\overline{\mathrm{R} 34}$ \\
\hline Mean & 83.6 & 80.5 & 98.4 & 86.7 & 79.2 & 82.2 & 80.3 \\
\hline Standard Deviation & 5.9 & 3.5 & 4.4 & 6.3 & 1.8 & 2.1 & 1.6 \\
\hline Range (Variability) & 17.5 & 9.0 & 13.5 & 21.4 & 5.4 & 5.6 & 3.8 \\
\hline Minimum & 75.1 & 75.0 & 95.2 & 81.3 & 76.4 & 79.9 & 78.7 \\
\hline Maximum & 92.6 & 84.0 & 108.7 & 102.7 & 81.8 & 85.5 & 82.5 \\
\hline Confidence Level $(95.0 \%)$ & 4.5 & 2.7 & 3.4 & 4.9 & 1.4 & 1.6 & 1.3 \\
\hline $\mathrm{Cu}$ & $\mathrm{L24}$ & $\mathrm{L34}$ & S24 & S34 & $\overline{S 44}$ & $\overline{\mathrm{R} 24}$ & $\mathrm{R} 34$ \\
\hline Mean & 135.6 & 106.4 & 202.9 & 138.3 & 98.7 & 127.1 & 104.1 \\
\hline Standard Deviation & 17.3 & 17.3 & 14.1 & 13.9 & 12.8 & 16.7 & 11.1 \\
\hline Range (Variability) & 48.1 & 63.9 & 48.2 & 46.2 & 38.2 & 60.0 & 33.6 \\
\hline Minimum & 110.6 & 74.6 & 189.6 & 126.5 & 82.9 & 100.9 & 87.3 \\
\hline Maximum & 158.7 & 138.5 & 237.8 & 172.7 & 121.1 & 160.9 & 120.9 \\
\hline Confidence Level $(95.0 \%)$ & 13.3 & 13.3 & 10.8 & 10.7 & 9.8 & 12.8 & 8.6 \\
\hline Ni & $\mathrm{L} 24$ & L34 & S24 & $\overline{S 34}$ & $\overline{S 44}$ & $\overline{\mathrm{R} 24}$ & $\overline{\mathrm{R} 34}$ \\
\hline Mean & 27.1 & 26.7 & 34.5 & 28.6 & 24.9 & 27.0 & 27.0 \\
\hline Standard Deviation & 2.3 & 2.7 & 4.4 & 3.0 & 2.2 & 2.0 & 1.8 \\
\hline Range (Variability) & 7.1 & 8.2 & 14.4 & 10.6 & 7.3 & 6.1 & 6.5 \\
\hline Minimum & 22.6 & 23.1 & 29.6 & 24.8 & 21.2 & 23.9 & 23.9 \\
\hline Maximum & 29.7 & 31.3 & 44.0 & 35.4 & 28.5 & 30.0 & 30.4 \\
\hline Confidence Level $(95.0 \%)$ & 1,7 & 2.0 & 3.4 & 2.3 & 1.7 & 1.5 & 1.4 \\
\hline $\mathbf{P b}$ & $\mathrm{L} 24$ & $\mathbf{L 3 4}$ & S24 & $\mathrm{S34}$ & $\mathrm{S} 44$ & $\mathrm{R} 24$ & R34 \\
\hline Mean & 247.6 & 196.3 & 374.4 & 266.3 & 190.4 & 210.1 & 190.5 \\
\hline Standard Deviation & 34.6 & 16.3 & 35.3 & 31.5 & 10.2 & 6.3 & 10.3 \\
\hline Range (Variability) & 93.7 & 54.6 & 120.1 & 105.5 & 31.1 & 17.8 & 26.9 \\
\hline Minimum & 197.1 & 163.1 & 337.4 & 235.7 & 180.7 & 202.3 & 178.3 \\
\hline Maximum & 290.8 & 217.7 & 457.5 & 341.2 & 211.8 & 220.1 & 205.2 \\
\hline Confidence Level $(95.0 \%)$ & 26.6 & 12.5 & 27.1 & 24.2 & 7.9 & 4.8 & 8.0 \\
\hline Zn & $\mathrm{L24}$ & L34 & S24 & $\mathrm{S34}$ & 544 & $\mathrm{R} 24$ & $\mathrm{R} 34$ \\
\hline Mean & 374.3 & 306.3 & 543.5 & 389.3 & 296.7 & 343.0 & 311.1 \\
\hline Standard Deviation & 49.9 & 26.5 & 64.4 & 40.9 & 11.8 & 24.0 & 21.9 \\
\hline Range (Variability) & 142.6 & 85.0 & 214.7 & 144.6 & 42.2 & 68.4 & 65.2 \\
\hline Minimum & 307.3 & 262.0 & 487.7 & 336.8 & 280.7 & 305.3 & 286.1 \\
\hline Maximum & 449.9 & 347.0 & 702.4 & 481.4 & 322.9 & 373.7 & 351.3 \\
\hline Confidence Level $(95.0 \%)$ & 38.3 & 20.4 & 49.5 & 31.4 & 9.1 & 18.5 & 16.8 \\
\hline
\end{tabular}



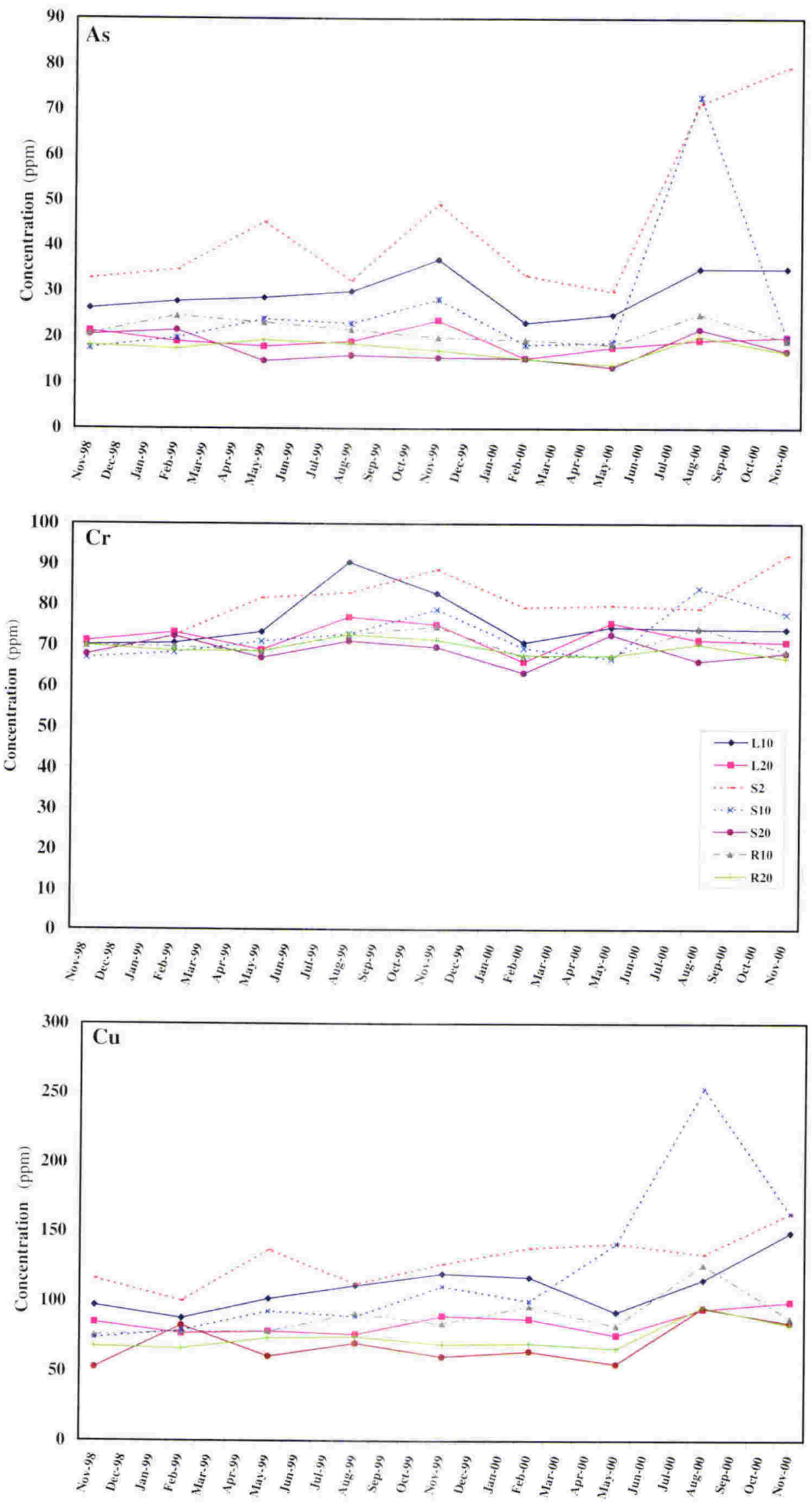

Figure 4.7: Concentration (ppm) of $\mathrm{As}, \mathrm{Cr}$ and $\mathrm{Cu}$ in the sediment at AQ-2 stations over time 

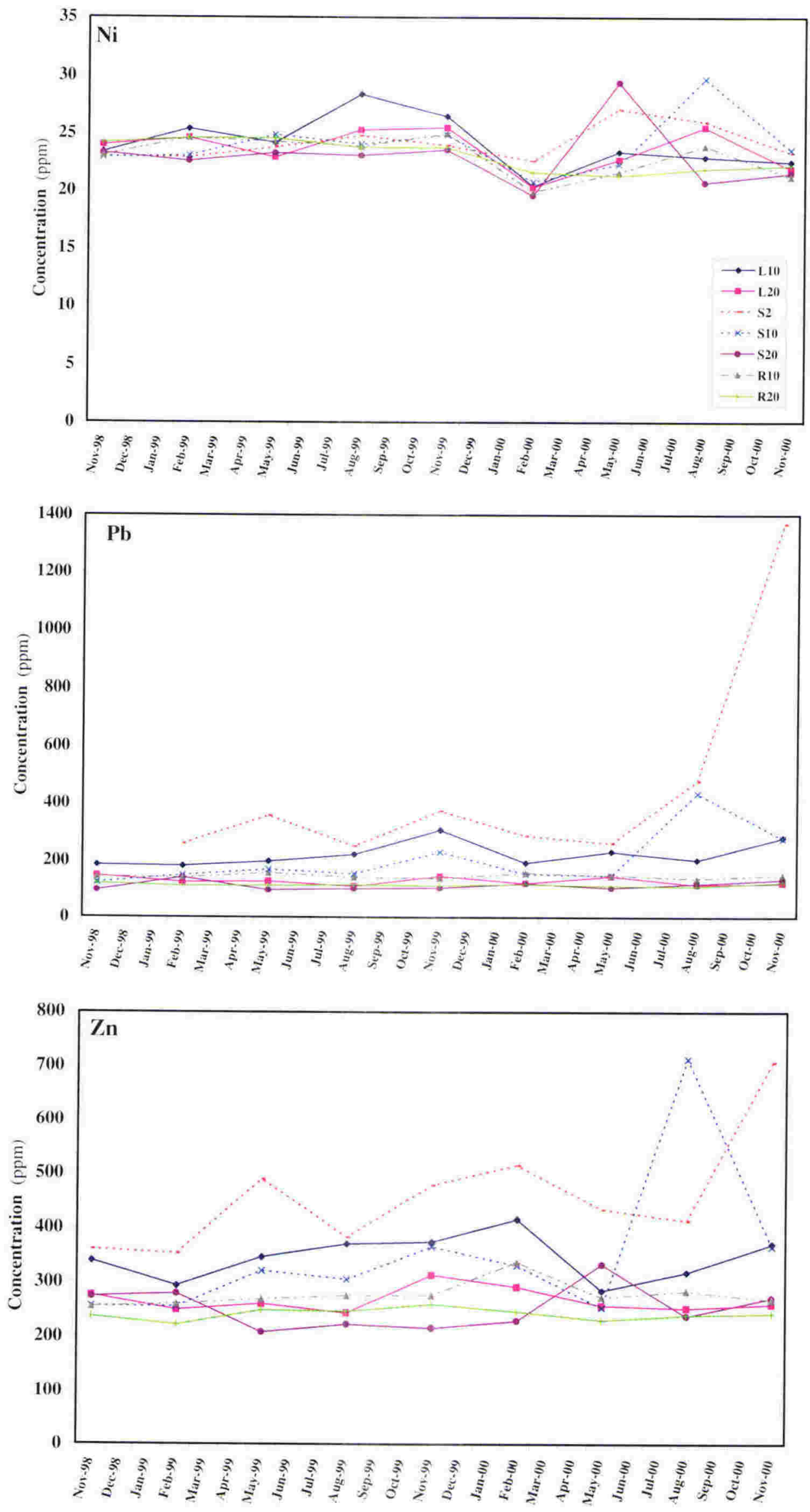

Figure 4.8: Concentration (ppm) of $\mathrm{Ni}, \mathrm{Pb}$ and $\mathrm{Zn}$ in the sediment at $\mathrm{AQ}-2$ stations over time 
The high variability of $\mathrm{As}, \mathrm{Cu}, \mathrm{Pb}$ and $\mathrm{Zn}$ at $\mathrm{S} 10$ is a reflection of the high concentration of each metal at this station in August 2000; on all other sampling occasions, the concentration of these metals at S10 was below that at $\mathrm{L} 10$. As, Cr, Pb and $\mathrm{Zn}$ concentrations were more variable at L10 than at stations L20, S20, R10 and R20.

\section{Q-2 (Figs. 4.9 and 4.10)}

The highest variability of $\mathrm{Zn}$ and $\mathrm{Cr}$ occurred at station $\mathrm{S} 10$, while for $\mathrm{As}$ and $\mathrm{Pb}$ it was at $\mathrm{S} 2$ and for $\mathrm{Cu}$ it was at R10; there was little difference in Ni variability between stations. $\mathrm{As}, \mathrm{Cu}$, and $\mathrm{Pb}$ were more variable at $\mathrm{S} 2$ than at $\mathrm{S} 20, \mathrm{~L} 10$ and $\mathrm{L} 20$, while $\mathrm{As}, \mathrm{Cu}, \mathrm{Pb}$ and $\mathrm{Zn}$ were more variable at S10 than at S20, L10 and L20. There was comparable variability for all metals, except $\mathrm{Cu}$ at L10 and R10.

Note: Station R20 has been excluded from this analysis because the concentrations of $\mathrm{Cu}$, $\mathrm{Pb}, \mathrm{Zn}$ and $\mathrm{As}$ were anomalous in relation to the other stations and with respect to distance from the outlet, that is high $\mathrm{Cu}, \mathrm{Pb}, \mathrm{Zn}$ and As concentrations at R20 may not be attributable to stormwater discharge (File: Time summary, Appendix III).

$E B-2$ (Figs. 4.11 and 4.12)

The highest variability of $\mathrm{As}, \mathrm{Pb}, \mathrm{Ni}$ and $\mathrm{Zn}$ occurred at station $\mathrm{S} 24$ while for $\mathrm{Cu}$ it was at $\mathrm{L} 34$ and for $\mathrm{Cr}$ it was at station S34 (Table 4.9). With respect to $\mathrm{Pb}, \mathrm{Cu}, \mathrm{As}$ and $\mathrm{Zn}$ variability, the remaining stations separated into two groups, L24-S34 and L34-S44-R34, with station R24 between the two groups. At L24-S34 there was generally higher variability than at L34-S44-R34, while at L34-S44-R34 variability was low (Table 4.9).

The null hypothesis that the variability in metal concentration over time is the same at each station at an outlet site is rejected. At outlet sites the variability in concentration of some of the metals is different at different stations with the highest variability generally being at stations closest to the outlet.

\subsection{4.b Comparison of metal concentration between outlet and control stations} $A Q-2$

At AQ-2, Ni concentration was not significantly different between outlet and control stations over time. Concentrations were significantly higher at the outlet than at the control site for:

- $\quad \mathbf{C r}$, stations S2 $(\mathrm{p}<0.001)$ and L10 $(\mathrm{p}<0.01)$

- $\quad$ As, stations S2 and L10 $(p<0.001)$ and R10 and L20 $(p<0.01)$ 

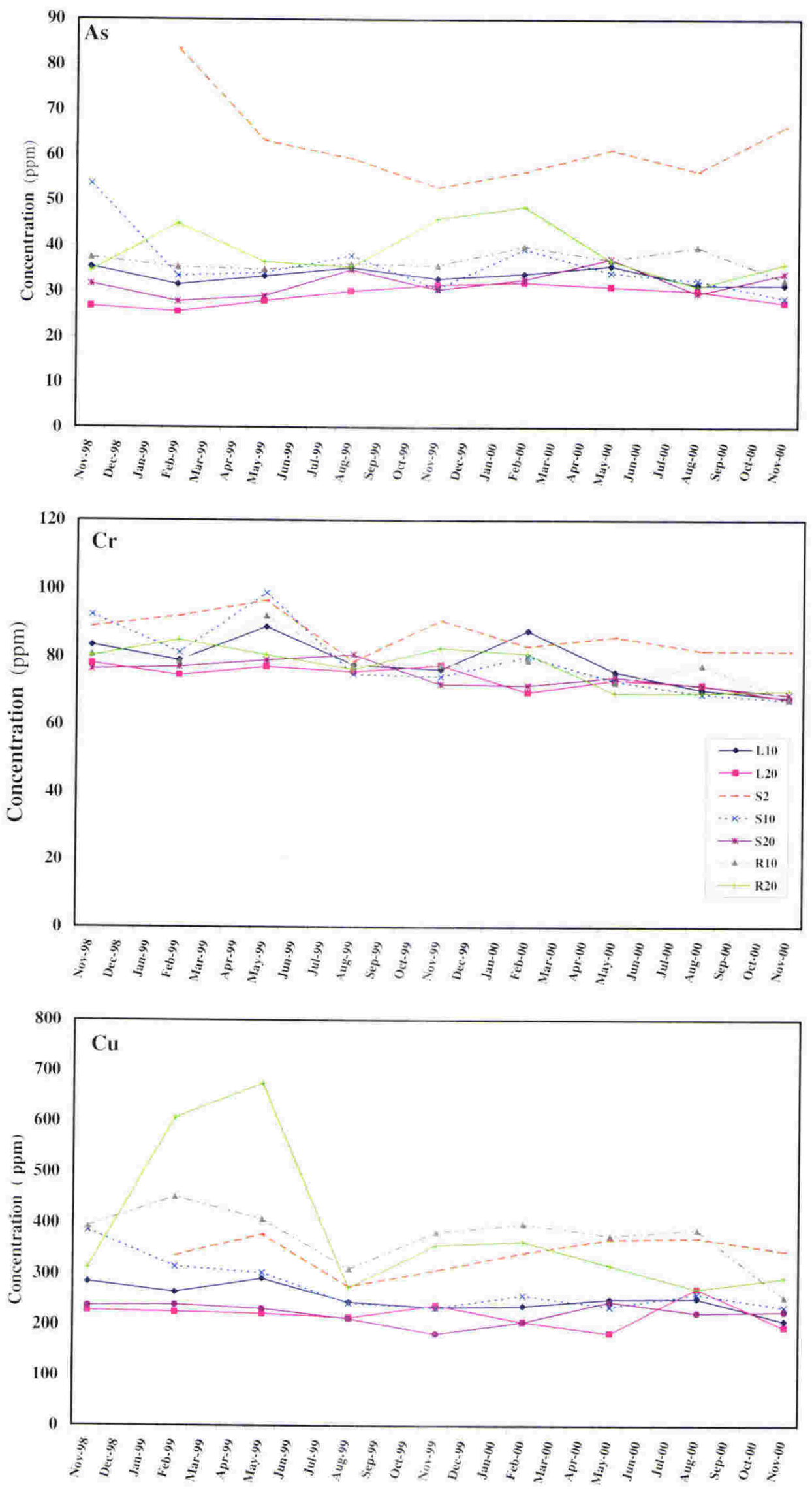

Figure 4.9: Concentration (ppm) of $\mathrm{As}, \mathrm{Cr}$ and $\mathrm{Cu}$ in the sediment at Q-2 stations over time 

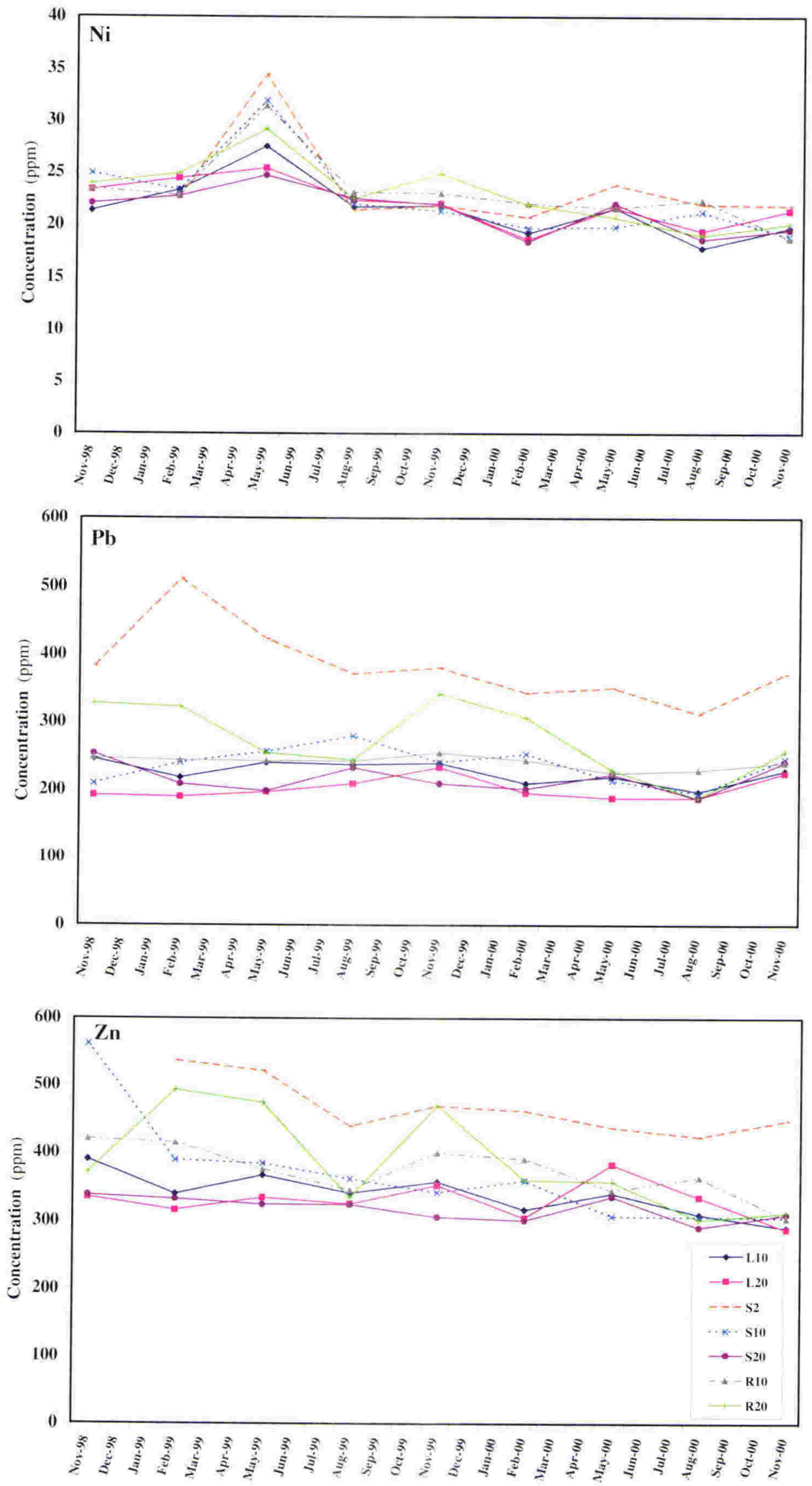

Figure 4.10: Concentration of $\mathrm{Ni}, \mathrm{Pb}$ and $\mathrm{Zn}$ in the sediment at Q-2 stations over time 

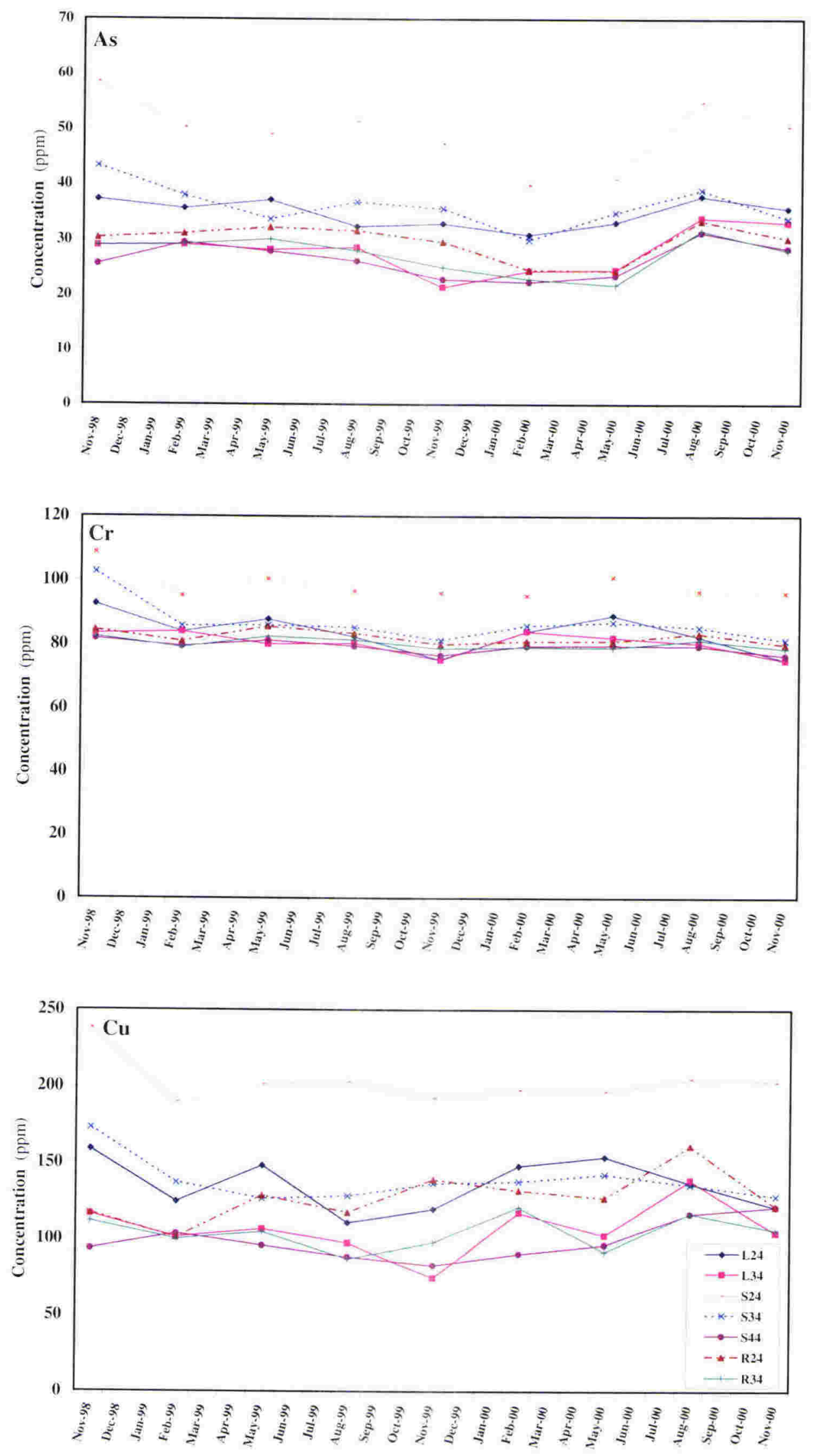

Figure 4.11: Concentration (ppm) of As, $\mathrm{Cr}$ and $\mathrm{Cu}$ in the sediment at EB-2 stations over time 

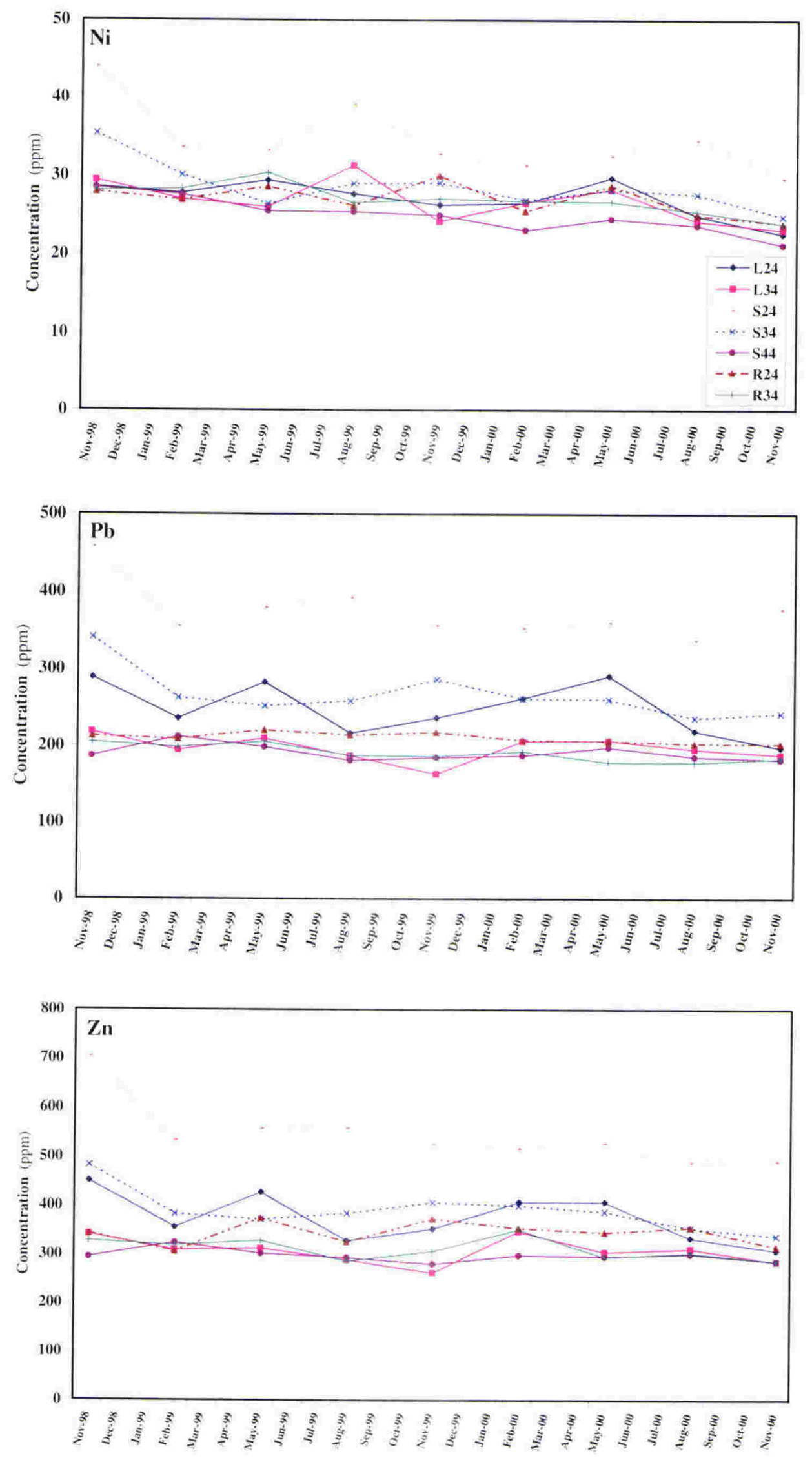

Figure 4.12: Concentration (ppm) of $\mathrm{Ni}, \mathrm{Pb}$ and $\mathrm{Zn}$ in the sediment at $\mathrm{EB}-2$ stations over time 
- $\quad$ Cu, stations S2 $(\mathrm{p}<0.001)$ and L10 and S10 $(\mathrm{p}<0.01)$

- $\quad$ Zn, stations S2, S10, L10, R10 $(\mathrm{p}<0.001)$

- $\quad$ Pb, stations S2, S10, L10, L20, R10, R20 ( $\quad$ < $<0.001)$

$E B-2$

At all EB-2 stations, $\mathrm{Pb}, \mathrm{Cu}$ and $\mathrm{Zn}$ concentrations were significantly higher $(\mathrm{p}<0.01)$ while As, Ni and $\mathrm{Cr}$ concentrations at some stations, were significantly higher $(\mathrm{p}<0.01)$, than at the control site. The concentrations of As at stations S24, S34, S44, L24 and R24, Ni at stations S24 and S34 and Cr at stations S24, S34, S44, L24, R24 and R34 were significantly higher than those at the control site.

The null hypothesis that there is no significant difference in metal concentration between an outlet station and the associated control station over time is rejected. Metal concentrations at some outlet stations were significantly higher than at the associated control site over time.

\subsubsection{Environmental Relationships}

The correlation of the concentration of each metal at AQ-2 station S10 and at EB-2 station S24 was tested against rainfall parameters (File: Meteorological in Appendix II). No significant correlations were found.

The null hypothesis that there is no significant relationship of metal concentration to each of the rainfall parameters is accepted.

\subsection{DISCUSSION}

In the Wellington region the basement rock (bedrock) is greywacke sandstone and argillite (Roser, 1983). A comparison of the metal composition of bedrock to the average concentration of $\mathrm{As}, \mathrm{Cr}, \mathrm{Cu} \mathrm{Ni}, \mathrm{Pb}$ and $\mathrm{Zn}$ from deep and surface sediment in cores from Wellington Harbour (Dickinson et al., 1996; Dunbar, 1994) reveals:

- $\mathrm{As}, \mathrm{Cr}$ and $\mathrm{Ni}$ concentrations in cores were comparable to those of argillite (Table 4.4) 
- $\mathrm{Cu}, \mathrm{Pb}$ and $\mathrm{Zn}$ concentrations in deep sediment were comparable to those of argillite (Table 4.4)

- $\mathrm{Cu}, \mathrm{Pb}$ and $\mathrm{Zn}$ concentrations in the surface sediment were up to a 4 times higher than in argillite (Table 4.4)

A harbour-wide study of metal concentrations in surface sediment revealed that the central harbour basin has minimal heavy metal pollution, with metal enrichment occurring in localised inshore areas, notably Lambton Harbour, Evans Bay, Petone and Kaiwharawhara (Stoffers et al., 1986). These metal-enriched sediments were attributed to an assortment of causes including wharf activities, marina facilities, stormwater discharge and historic sewage discharge contaminated by industrial waste (Dickinson et al., 1996; Smith, 1986; Stoffers et al., 1986). Compared with other harbours in New Zealand, Wellington Harbour, and in particular the inshore inner harbour area, is moderately to highly contaminated with metals (Table 1.1).

\subsubsection{Metal concentrations at control sites}

$\mathrm{Cu}, \mathrm{Pb}$ and $\mathrm{Zn}$ concentrations differed between control sites, while $\mathrm{Cr}$ and $\mathrm{Ni}$ concentrations did not. It is not possible to make a definitive comparison of As concentrations between control sites because of the discrepancy between the determined concentration of As and the accepted concentration of As in reference sediment (Table 4.1). Stoffers et al. (1986) also found differences in the concentration of $\mathrm{Cu}, \mathrm{Pb}$ and $\mathrm{Zn}$ between different inshore areas of this harbour. For example, the mean concentration of $\mathrm{Pb}$ in Lambton Harbour was $183 \mathrm{ppm}$, while in Evans Bay it was 85 ppm and at Kaiwharawhara and Ngauranga (near Aotea Quay) it was $125 \mathrm{ppm}$.

The fine sediment $(<63 \mu \mathrm{m})$ at the control sites was enriched with $\mathrm{Cu}, \mathrm{Pb}$ and $\mathrm{Zn}$ but not $\mathrm{Ni}$ and $\mathrm{Cr}$ compared to argillite (Table 4.4). It was not possible to make a definitive assessment of As enrichment. The $\mathrm{Cu}, \mathrm{Zn}$ and $\mathrm{Pb}$ concentrations at all sites were either comparable to (Aotea Quay) or elevated above (Evans Bay and Queens Wharf) those in harbour surface sediment (Table 4.4) as determined by Dickinson et al., (1996).

The Evans Bay sediment contained slightly elevated concentrations of $\mathrm{Zn}$ and $\mathrm{Pb}$, which could result from localised sources such as the airport or boat marina (Stoffers et al., 1986), or the hydrographic conditions of this bay, or a combination of both. The predominant 
N/NW winds of the region blow into Evans Bay and consequently contaminants from the greater Wellington region (e.g., Ngauranga and Petone) could be transported into this bay (Goff et al., 1998). In addition, the restricted water circulation pattern of Evans Bay (Booth, 1975; Heath, 1977) could facilitate the build up of these metals (Stoffers et al., 1986).

The concentrations of $\mathrm{Pb}(171 \pm 13 \mathrm{ppm})$ and $\mathrm{Zn}(274 \pm 12 \mathrm{ppm})$ found at the Queens Wharf control site are comparable to, while the concentration of $\mathrm{Cu}(171 \pm 9 \mathrm{ppm})$ is higher than, the mean concentrations recorded for Lambton Harbour basin sediment ( $\mathrm{Pb}: 183 \mathrm{ppm}, \mathrm{Zn}$ : 249 ppm, Cu: 68 ppm) (Stoffers et al., 1986). These high concentrations of these metals in this region have been attributed to extensive wharf facilities and shipping activities (Stoffers et al., 1986). In addition, there has been urban runoff and periodic emergency sewage overflows (Smith 1986) over a period of time into this area of restricted water circulation (Booth, 1975; Heath, 1977) resulting in a build-up of contaminants in the sediment. In this study higher $\mathrm{Cu}$ concentration than those found by Stoffers et al. (1986) could well result from sampling under and just beyond the wharf structures during the present study. Copper ions either dissolving from copper pile claddings or released from antifouling paint $(\mathrm{Cu}-$ based antifouling paints need to release $10 \mu \mathrm{g} \mathrm{cm}^{-2}$ day in order to prevent fouling (Williamson, 1993)) quickly become adsorbed onto fine sediment. Furthermore, pieces of cladding and paint particles could also drop and particles may accumulate in the sediment. There is a considerable accumulation of urban and maritime derived debris in the sediment in the vicinity of the wharf and this may also contribute to metal contamination.

The measurement of metal concentrations at control sites is necessary for the quantification of anthropogenic input, through both the comparison of control and impact site metal concentrations (ppm), and the calculation of an Enrichment Factor. The use of an Enrichment Factor is a recognised tool for the identification of anthropogenic input of metals into the marine environment (Aloupi and Angelidis, 2001, Balls et al., 1997, Dickinson et al., 1996, Gibbs, 1993, Grant and Middleton, 1990). In estuarine/harbour-wide evaluations of enrichment, historic metal concentrations (Dickinson et al., 1996, Grant and Middleton, 1990), average values in soil/rock (Gibbs, 1993), concentrations in uncontaminated sediment from a nearby location (Balls et al., 1997) or uncontaminated sediment concentrations (Aloupi and Angelidis, 2001) have been used as the comparison value for the calculation of an enrichment factor value. While the use of such values may be suitable for large scale evaluations of enrichment, this study highlights the need for area- 
specific control sites for precise quantification of 'hotspots' of anthropogenic enrichment from specific discharges such as stormwater discharge, into an already human impacted harbour environment. This is exemplified by the differences in values between control sites (Table 4.4) and by the anomalies which arose when calculating EF values for $\mathrm{Cu}$ at the FK outlet where there was no area-specific control site. EF values for $\mathrm{Cu}$ at $\mathrm{FK}$ were calculated using the $\mathrm{AQ}-\mathrm{C}$ value of $71 \mathrm{ppm}$, rather than the $\mathrm{Q}-\mathrm{C}$ value of $171 \mathrm{ppm}$ because the actual $\mathrm{Cu}$ concentrations at this site ranged from $96.8-149.7 \mathrm{ppm}$. This probably resulted in an overestimation of $\mathrm{Cu}$ enrichment in the vicinity of this outlet as neither control site values reflect background values for this precise area. In $1992 \mathrm{Cu}$ concentration at a station close to this outlet ( $\sim 120$ metres from shore) was $90 \mathrm{ppm}$ (Wright and Glasby, 1992). This value is comparable to the lowest $\mathrm{Cu}$ concentration at FK and hence $\sim 90 \mathrm{ppm}$ may well better approximate the background $\mathrm{Cu}$ concentration for this area. For all other metals the EF values at FK were calculated using the Q-C values. Because there was no area-specific control site for FK and OPT all EF values for the metals at these outlets can only be considered as an indication of the level of anthropogenic input. Thus, it is preferable to have adequate area-specific control sites to quantify the effect of discharges such as stormwater into an already human impacted harbour environment.

\subsubsection{Spatial Variability in metal concentrations}

The data indicates that stormwater discharge has resulted in elevated metal concentrations in the sediments at some stations in the vicinity of the 8 outlets, with maximum concentrations of As-124 ppm, Cr-124 ppm, Cu-794 ppm, Ni-56 ppm, Pb-1097 ppm and Zn-1608 ppm. By comparison, the metal concentrations found in the vicinity of stormwater outlets elsewhere in New Zealand are as follows:

- Otago Harbour, where the maximum concentrations (acid extraction of whole sediment, ICP-MS analysis) were $\mathrm{Cr}-41 \mu \mathrm{g} \mathrm{g}^{-1}$ (equivalent to ppm), $\mathrm{Cu}-210 \mu \mathrm{g} \mathrm{g}^{-1}$, $\mathrm{Ni}-15 \mu \mathrm{g} \mathrm{g}^{-1}, \mathrm{~Pb}-410 \mu \mathrm{g} \mathrm{g}^{-1}$ and $\mathrm{Zn}-1300 \mu \mathrm{g} \mathrm{g}^{-1}$ (ORC, 1998)

- Auckland Harbour, where the maximum concentrations (nitric acid microwave digestion of whole sediment, AAS analysis) were Cr-36 $\mathrm{mg} \mathrm{kg}^{-1}$ dry weight (equivalent to ppm), Cu-615 mg kg-1 ${ }^{-1} \mathrm{Ni}-20 \mathrm{mg} \mathrm{kg}^{-1}, \mathrm{~Pb}-588 \mathrm{mg} \mathrm{kg}^{-1}, \mathrm{Zn}-871 \mathrm{mg} \mathrm{kg}$ ${ }^{1}$ (Bioresearches, 1997)

- Porirua Inlet, where the maximum concentrations (XRF analysis of $<63 \mu \mathrm{m}$ sediment) were Cu-96.2 ppm, Pb-122.8 ppm, Zn-989.9 ppm (Botherway and Gardner 2002). 
Comparisons of the concentration of metals between localities do not give a true indication of anthropogenic input because of site-specific lithological differences which influence background concentrations. The use of an EF or an Igeo value is a possible means of making comparisons of anthropogenic input between sites/studies. For example the maximum $\mathrm{Zn}$ EF value was 7 for Porirua, 9.4 for Auckland, 13 for Otago and 7.2 for this study. This study was however the only one with area specific control site values to calculate the EF values (for the other studies a value from either the furthest station from the outlet or a harbour basin value was used). An Igeo comparison for these sites was not made because the calculation of Igeo values for other areas was not possible because the chemical composition of the background rock was not known. It can be confidently asserted that stormwater discharge results in elevated concentrations of metals in sediments in the vicinity of stormwater outlets in Wellington Harbour and other harbours and inlets in New Zealand.

For each metal the outlets were ranked from the most to least metal enriched sediment (section 4.3.4) with an overall ranking of the outlets (based on the number of stations with $\mathrm{EF}>1.4$ for each of the metals) being:

\section{November 1998: OPT $>$ EB-2 > EB-1 > Q-2 > Q-1 > AQ-2 > AQ-1}

FK was excluded due to discrepancies in the EF values.

May 1999: EB-2 > EB-1 > Q-2 > AQ-2

The ten most contaminated stations (Sum of all metal concentrations at a station) (list depicts: Outlet station) are as follows:

$$
\begin{aligned}
& \text { November 1998: OPT R15> OPT S15> Q-1 S10> OPT R30> EB-2 S24 > OPT S30 } \\
& >\text { Q-2 S2 > Q-2 S10> OPT L15> OPT L30 }
\end{aligned}
$$

May 1999: Q-2 R20 > Q-2 S2 > EB-2 S24>AQ-2 S2 > Q-2 R10 > Q-2 S10> Q-2 L10

$$
>\text { EB-2 L24 }>\text { EB-1 S34 > EB-1 S24 }
$$

That is, the level of contamination is outlet specific. In addition, the highest levels of metal enrichment occurred close to an outlet and decreased with increasing distance seaward (Figs. 4.1- 4.6) and there were differences in metal levels with direction at some of the outlets (Table 4.8).

While the highest levels of metal contamination occurred in the vicinity of the outlet from the largest catchment i.e. OPT, activities within a catchment, such as light industry, 
mechanical workshops, food processing plants, as well as high traffic densities, have been associated with localised points of contamination within the stormwater system (Pilotto et al., 1998) and could therefore affect the levels of metal contamination beyond an outlet. This may account for differences in the level of metal contamination between EB-2 and AQ-2; although, the effect of other factors (water depth and organic matter availability) cannot be discounted. Even though the closest sampling stations at EB-2 were $24 \mathrm{~m}$ from the outlet, metal contamination at EB-2 station S24 was higher than at stations $10 \mathrm{~m}$ from AQ-2. This would appear to indicate that stormwater discharged from EB-2 contains higher levels of metals than that discharged at AQ-2. The total catchment area of EB-2 is smaller than that of AQ-2 (Table 2.1) and it has 66.5 ha of 'other activities' (this includes such things as residential, retail, light industries, etc) compared to137 ha at AQ-2. The difference in 'other activities' area between AQ-2 and EB-2 may indicate that rather than the level of metal contamination being a function of the area of 'other activities' in a catchment it is a result of the actual activities in a catchment. The higher metal concentrations at EB-2 could be attributable to discharges related to the light industries and (at the time of sampling) the bus depot, in this catchment. Short-term activities such as renovation, construction and painting also result in elevated metal concentrations (Pilotto et al., 1998, Kennedy, 1981). However, other factors such as frequency of roadside gutter sweeping, accidental spills, illegal discharges, the wind regime between rainfall events, and duration and intensity of storm events all have the potential to influence the concentration of metal contaminants in stormwater.

The most contaminated sediments occurred in the vicinity of the OPT outlet where the maximum metal concentrations were As-124 ppm, Cr-124 ppm, Cu-794 ppm, Ni-56 ppm, $\mathrm{Pb}-1097 \mathrm{ppm}$ and $\mathrm{Zn}-1608 \mathrm{ppm}$. High concentrations of As (296 ppm), Cr (151 ppm), Cu (481 ppm), Ni (39 ppm), Pb (2158 ppm) and $\mathrm{Zn}(1508 \mathrm{ppm})$ have also been recorded in sediment collected in sediment traps deployed adjacent to this outlet (Pilotto et al., 1998). In this study, the sediment at stations closest to this outlet contained the highest concentrations of metals, with a decrease in concentration with increasing distance away from the outlet. Nonetheless based on both EF and Igeo values, sediment $45 \mathrm{~m}$ from this outlet (limit of this study) was still enriched with $\mathrm{As}, \mathrm{Cu}, \mathrm{Pb}$ and $\mathrm{Zn}$. While the EF values can only be considered as an indication of the level of enrichment, the Igeo values provide a more reliable measure of the level of metal enrichment (above bedrock) at OPT. At all $45 \mathrm{~m}$ stations the Igeo value for $\mathrm{Cu}$ and $\mathrm{Pb}$ was 3 and for $\mathrm{Zn}$ it was 2 . Igeo values of 2 and 3 for 
$\mathrm{Pb}$ and 1 for $\mathrm{Cu}$ have been recorded at stations approximately $150 \mathrm{~m}$ from this outlet (Wright and Glasby, 1992). Igeo values of 4 for $\mathrm{Pb}$, and 2 for $\mathrm{Cu}$ and $\mathrm{Zn}$ at $\sim 250 \mathrm{~m}$, and values of 3 for $\mathrm{Pb}$ and 1 for $\mathrm{Cu}$ and $\mathrm{Zn}$ at $350-400 \mathrm{~m}$ away, have also been reported (Stoffers et al., 1986). The high levels of $\mathrm{Pb}$ at stations $150-400 \mathrm{~m}$ away has been attributed to stormwater discharge from the OPT outlet (Wright and Glasby, 1992). However, with multiple activities within the wharf area, other sources cannot be discounted.

At OPT the highest levels of enrichment occurred at right transect stations with high enrichment also at stations straight in front of this outlet and comparatively low levels at left transect stations. The presence of a sediment embedded wooden wall along the left side of the wharf (Fig. 2.5) could possibly, through redirected stormwater flow, account for the comparatively low metal concentrations at station L15 and the high concentrations at stations R15, S15 and R30. Nonetheless, while stations L30 and L45 (Fig. 2.5) were within the marina, for $\mathrm{Cu}$ and $\mathrm{Zn}$ and to a lesser extent $\mathrm{Pb}$, there was still a decrease in concentration with increasing distance from the outlet which suggests that metal concentrations within the marina were affected more by stormwater discharge than by marina activities.

Highly contaminated sediments occurred at EB-2 with the maximum metal concentrations (As - 58 ppm; $\mathrm{Cr}-109$ ppm; $\mathrm{Cu}-238$ ppm; Ni - 44 ppm; $\mathrm{Pb}-457$ ppm and $\mathrm{Zn}-702$ ppm) being at station S24. Thus, stormwater discharged from EB-2 contains high levels of metals which results in high concentration of metals close to but decreasing concentrations with increasing distance seaward. Metal concentrations at $54 \mathrm{~m}$ were comparable to those at EB-C. In addition, the highest levels of enrichment occurred straight in front of EB-2.

The sediment at Q-1 station $\mathrm{S} 10$ contained high concentrations of $\mathrm{As}, \mathrm{Cu}, \mathrm{Pb}$ and $\mathrm{Zn}$ (Figs. $4.1,4.3,4.5-4.6)$. These high concentrations may not all result from stormwater as this station is located under the wharf close to the Queens Wharf boat refuelling pump (used by fishing, charter and pleasure boats) and a permanently moored charter vessel, both of which are possible sources of metals. However, with regard to metal input from stormwater, station S10 could be affected not only by stormwater flowing straight out from the outlet, but also by stormwater flow redirected toward it from the rock wall immediately to the right of the outlet (station R10 could not be sampled because of this wall) (Fig. 2.3B). 
At AQ-1 and AQ-2 metal concentrations were low with no clear pattern in distribution in relation to the outlet. While metal concentrations could be a reflection of the levels discharged, water depth and sediment redistribution may be important factors. In front of both outlets the water was deeper ( $11 \mathrm{~m}$ deep at $20 \mathrm{~m}$ from the outlet) than at other outlets (at Q-1 and Q-2 $6 \mathrm{~m}$ deep at $20 \mathrm{~m}$ from the outlet, and at EB-2 $3 \mathrm{~m}$ deep at $24 \mathrm{~m}$ from the outlet). The settling depth of particles is therefore greater, which probably results in a greater dispersal of particles. Sediment redistribution also occurs in this area through sediment disturbance by propeller action (Anderlini and Wear, 1995; Haddon and Wear, 1993; Wright and Glasby, 1992). This results in the suspension of the finer sediment particles (with adsorbed metals) in the water column whereby they can be transported by tidal and wind driven water flows and eventually settle to the bottom in low energy depositional zones of the harbour basin.

In this study the metal concentration measured i.e. the concentration in the $<63 \mu \mathrm{m}$ sediment fraction, may not be a complete measure of the contaminants discharged from a catchment. Organic matter and fine sediment particles can adsorb trace metals (Förstner 1987, Loring, 1991; Rubio et al., 2000; Zago et al., 2001) and as a result both organic matter and fine sediment particles within roadside gutters and the stormwater system sequester metal ions. Therefore in catchments producing large amounts of 'large particulate' (i.e. leaves, twigs, seed pods) organic matter such as occurs at AQ-1, AQ-2, OPT and, to a lesser extent, EB-1, some of the metals could be adsorbed onto these large particulates. Thus, the measured metal concentrations at EB-2, Q-1 and Q-2, where low levels of organic matter occurred in the sediment, may be a more accurate reflection of the amount of metal originating from the catchment than the measured concentrations at OPT, AQ-1 and AQ-2.

Beyond the outlet, the extent of contamination is most likely to be affected by flow rate from the outlet, water depth and state of the receiving environment (tide, sea state, wind direction, duration and strength). During periods of high stormwater flow, metals (dissolved and adsorbed onto particles) are likely to be carried some distance from the outlet, dispersed and diluted, thus contributing to the anthropogenically enhanced metal levels in the surface sediment of the harbour basin (Dickinson et al., 1996; Stoffers et al., 1986). Deposition of metals just beyond the outlet probably results from medium to low flows (from rainfall, accidental spills and illegal discharges) and tidal flushing (see section 3.4.1) of stormwater because the particles (with adsorbed metals) settle to the bottom just beyond the outlet, 
resulting in the highest concentration of metals being close to and decreasing with increasing distance away from an outlet e.g. at OPT, EB-2, EB-1, Q-1 and Q-2.

The occurrence of the highest metal concentrations straight in front of an outlet could result from either stormwater flowing straight out from an outlet with some dispersal (more so to the left than the right), or a greater proportion of the flow events being straight out with some events flowing to the left and fewer to the right. Directional flows could result from the influence of tidal flow (flood tide - clockwise (towards left transects); ebb tide - counterclockwise (towards right transects)) (Brodie, 1958) and wind with the prevailing strong winds being from the North-west and the South (Heath, 1977; Booth, 1975; Goff et al., 1998). Normal seawater circulation and stormwater flow must also be influenced by manmade structures such as walls (OPT, Q-1), marinas (OPT, EB-1) and large wharves (Q-2). The effect of these influences has not been quantified, but cannot be excluded.

\subsubsection{Temporal variability in metal concentrations}

Changes in sediment metal concentrations over time can result from continuous contaminant input and/or physical processes affecting the sediment.

With continued input of metals over time it has been found that the concentration of metals in sediments can increase, for example in the southern part of the Euripos Straits in central Greece where concentrations of $\mathrm{Cu}$ (concentration in 1980 was $14.4 \mu_{\mathrm{g} \mathrm{g}^{-1}}$ (range 12.2 16.0) and in 1993 it was $52.3 \mu \mathrm{g} \mathrm{g}^{-1}$ (range 28.4-80.4)), Ni and $\mathrm{Zn}$ were significantly higher in 1993 than in 1980 due to continued urban and industrial discharges into the marine environment (Dassenakis et al., 1996). The opposite has also been found i.e. a decrease in the discharge of metals has resulted in a decrease in metal concentrations as determined using biomonitoring species (Dobson, 2000).

Metals tend to be associated with the fine sediment fraction (silt clay; $<63 \mu \mathrm{m}$ ) because of its large surface area (Förstner and Wittman, 1983; Luoma, 1990). As a consequence, physical processes such as sediment resuspension and lateral transport, sediment input and bioturbation which affect sediment composition and distribution also influence the concentration of the metals. For example, the concentration of suspended particulate matter and the particulate bound metals in the water column in Manukau Harbour, New Zealand, was found to be due to the resuspension of contaminated surface sediment by wave action 
and shear stress generated by tidal currents with this mobilization being an important component of contaminant cycling in the sediments in this inlet (Williamson et al., 1996). The physical transport of sediment is also the most important factor affecting the distribution of metals in areas such as Delaware Bay (USA), the St Lawrence bay and estuary and the Bay of Fundy (Canada) and False Bay (South Africa), with fine sediments (with their bound metals) settling in zones as determined by natural depositional processes regardless of their point of introduction into the marine environment (Luoma, 1990). Sediment structure and distribution are also altered by bioturbation which is the process of sediment mixing due to macrofauna burrowing, feeding and reworking at the water-sediment interface. Bioturbation can mix sediment particles to the depth of penetration of the macrofauna and at the same time it changes the particles at the sediment surface with the scale of mixing dependent on the abundance and type of animals present (Gerino, 1990). In addition, the action of sediment surface dwellers regularly re-suspends the top layers of sediment which can then be redistributed by the transportation processes in an area.

Sediment resuspension and bioturbation influence the metal concentrations not only by changing the physical structure of the sediment but also by altering the sediment chemistry primarily through oxygenation of suspended particles (Simpson et al., 1998) and deeper sediment (Williamson et al., 1995). Oxygenation affects the chemical binding of metals. In oxic conditions, sulphide-bound metals in sediment at the sediment-water interface can be released to the water above; this release does not occur in anoxic conditions (Westerlund et al., 1986).

In this study the variability (the range in concentration of a metal at a station over time) in metal concentration at a station was used to determine if, and by how much, metal concentration changed over time. This approach was developed for this study because:

- Only one sample was processed from each station on each sampling occasion.

- Initial analysis of the results showed differences in variability between stations at an outlet site.

- Comparisons of variability can be made between an outlet and the associated control. In this study there was higher variability in metal concentrations at some outlet stations than at the associated control site station and at outlet sites there were differences in variability between stations with the highest variability generally being at stations closest to an outlet. 
At EB-2 metal concentrations were more variable at stations S24, S34 and L24 closer to, than at stations L34, S44, R34 further away from the outlet, with the highest variability of $\mathrm{As}, \mathrm{Ni}, \mathrm{Pb}$ and $\mathrm{Zn}$ occurring at station S24. Metal concentrations were also more variable at outlet than control stations (for example $\mathrm{Zn}$ variability -Table 4.9 and File: Time summary in Appendix III). The variability of each metal at the control site stations is considered as an indication of non-impacted or background variability particularly as variability values are mostly comparable between control site stations (File: Time summary in Appendix III).

In the time frame of this study (28 months) these changes did not occur as an overall increase in concentration, however over a time frame of decades there could well be an overall increase in metal concentrations at these stations. Over time stormwater discharge is highly variable in terms of flow rate, duration and contaminant load (Mosley et al., 1997) which results in an irregular input of metals to the nearshore environment. This irregular input, coupled with other physical processes (natural as well those resulting from stormwater flow), may account for the higher variability of metal concentrations, but no overall increase in concentration at the stations closer to than further away from this outlet. Sediment resuspension and transport over short distances i.e. metres rather than tens of metres, may account for some or all of the variability in metal concentrations at stations further from the outlet as well as no overall increase in concentration at stations closest to the outlet. Possible changes in metal concentrations at EB-C through sediment re-suspension and transport could not be detected because there was little difference in metal concentrations between stations.

At AQ-2 metal concentrations were most variable at stations S2 and S10 and for all metals except $\mathrm{Zn}$ there was higher variability at S2, S10 and L10 than at stations L20, S20, R10 and R20; for Zn the variability at L10 and S20 was comparable. Metal concentrations were also generally more variable at outlet than control stations (File: Time summary in Appendix III). The high variability of metals at AQ-2 stations S2 and S10 results from high metal concentrations at these stations in mid-late 2000. The high concentrations of $\mathrm{As}, \mathrm{Cr}, \mathrm{Cu}, \mathrm{Ni}$, $\mathrm{Pb}$ and $\mathrm{Zn}$ at S10 and $\mathrm{As}$ and $\mathrm{Pb}$ at S2 in August 2000 and $\mathrm{As}, \mathrm{Pb}$ and $\mathrm{Zn}$ at S2 in November 2000 seem most likely to have resulted from metal input by stormwater discharge. It is of note that two significant activities were occurring within the AQ-2 catchment in mid-late 2000. These were the construction of the Westpac Trust Stadium and the upgrading of the stormwater and sewage pipes along Tinakori Road. 
Variability in metal concentrations over time at AQ-2 could result from the combination of an irregular input of metals, sediment grain size variability, re-suspension and transport. For example, at AQ-2 and AQ-C station S10 sediment grain size distributions varied over time (Fig. 3.13). At AQ-2 some of this grain size variability could be due to the discharge of sediment through the outlet and because grain size variability occurred at AQ-2 and AQ-C it is likely that re-suspension by ship propeller action followed by re-distribution through transportation processes is occurring at both sites. This process of re-suspension and redistribution may account for higher variability of metals at stations L20 and R20 (both at the edge of the wharf, Fig 2.2) than at other stations at AQ-C and for metal concentrations being more variable at AQ-C than at EB-C (File: Time summary in Appendix III). It is postulated that the variability in metal concentrations at stations close to AQ-2 are more a result of input of metals while at stations further away it is more as a result of sediment re-suspension and re-distribution. A similar situation is likely in the vicinity of outlet Q-2.

\subsection{CONCLUSIONS}

The data strongly suggest that stormwater discharge has resulted in elevated levels of As, $\mathrm{Cr}$, $\mathrm{Cu}, \mathrm{Ni}, \mathrm{Pb}$ and $\mathrm{Zn}$ in the sediment in the vicinity of stormwater outlets.

The level of enrichment is outlet specific and contaminant-specific. The outlets have been ranked (based on the number of stations with $E F>1.4$ for each of the metals) from the most to least metal enriched sediment. The ranking of outlets being:

\section{November 1998: OPT $>$ EB-2 $>$ EB-1 > Q-2 > Q-1 > AQ-2 > AQ-1}

FK was excluded due to discrepancies in the EF values.

\section{May 1999: EB-2 > EB-1 > Q-2 > AQ-2}

The highest levels of metal enrichment occurred close to an outlet and decreased with increasing distance seaward with the seaward extent of enrichment being outlet-specific and contaminant-specific. Metal enrichment also differed with direction at some of the outlets.

To determine if and by how much metal concentration changed over time variability (the range in concentration of a metal at a station over time) in metal concentration at a station was used. This approach was developed to analyse the results of this study primarily because only one sample was processed from each station on each sampling occasion. In addition, 
initial analysis of the results showed differences in variability between stations at an outlet site and little difference in variability between stations at a control site, in particular at EBC.

Higher variability occurred at some outlet stations than at stations at the associated control site. At outlet sites there were differences in variability between stations with the highest variability generally being at stations closest to the outlet. 


\section{Chapter 5}

\section{SPATIAL DISTRIBUTION OF THE BENTHIC MACROBIOTA}

\subsection{INTRODUCTION}

The benthic macrobiota consists of animals larger than $500 \mu \mathrm{m}$ that live on or within the soft sediment. These animals are typically invertebrate species that are from a number of different taxonomic groups. The assessment of the benthic macrobiota based on the presence and abundance of species is a widely used tool for marine environmental impact and monitoring programmes (Bilyard, 1987; Blackstock, 1984; Dauer et al., 1993; Gray, 1980; Gray et al., 1988; Warwick, 1993; Warwick et al., 1990; Weston, 1990) for the following reasons:

- The animals are sedentary or have low dispersal capabilities and reflect the quality of their immediate environment

- Many species reside at the sediment-water interface where pollutants concentrate

- The taxonomically diverse community consists of species with different tolerances to habitat disturbance and pollutants

- The organisms have an important role in the cycling of nutrients and other chemicals between the sediments and water column

- The spatial distribution of benthic communities is comparatively easy to assess

- Quantitative data are easily obtained

In addition, a wide range of univariate and multivariate, parametric and non-parametric analyses have been developed for the assessment of such data (Clark and Warwick, 1994; Gray et al., 1988; Underwood, 1981, 1992; Warwick, 1993).

The aim of this section of the study was to investigate the spatial distribution i.e. presence and abundance of the benthic macrobiota at outlet and control sites in Wellington Harbour in order to determine whether stormwater discharge affects the spatial distribution of the macrobiota in the vicinity of stormwater outlets. 


\subsection{METHODS}

\subsubsection{Sample Collection}

Samples for benthic macrobiota analysis were collected at 6 stations at each site (except FK where no macrobiota samples were collected) in November 1998 and 7 stations at each site in May 1999. These stations were:

- all stations on the straight transect

- one station on the right transect - station R20 (Aotea Quay and Queens Wharf sites), R34 (Evans Bay sites), R30 (OPT)

- two stations on the left transect - stations L10 and L30 (Aotea Quay and Queens Wharf sites), L24 and L44 (Evans Bay sites), L15 and L45 (OPT)

At each station (detailed in Chapter 2), 4 randomly collected samples of $0.011 \mathrm{~m}^{2}$ were taken to a depth of $15 \mathrm{~cm}$ deep by a SCUBA diver using purpose-built stainless steel samplers. Three of these samples were processed, with the fourth available for use in case of accidental spillage or sample loss.

\subsubsection{Sample Processing}

Each sample was sieved through a $0.5 \mathrm{~mm}$ screen using a gentle flow of seawater. The material retained on the screen was fixed and preserved in formol $(10 \%$ formalin in seawater) for at least $24 \mathrm{~h}$ and then rinsed with freshwater, stained with Rose Bengal, and stored in $70 \%$ isopropanol until further processing was undertaken. The organisms present in each sample were sorted from the sediment using a dissecting microscope and stored in $70 \%$ isopropanol for later identification and counting. Organisms were identified where possible to the species level using a wide range of reference literature (Monro, 1930, 1936; Knox, 1960; Jones, 1963; Day, 1967; Cooper, 1969; Pawson, 1970; Barnard, 1972; Knox and Green, 1972a, 1972b; Rainer, 1973; Melrose, 1975; Read, 1975; Day, 1977; Fauchald, 1977; Blake and Kudenov, 1978; Day and Hutchings, 1979; Powell, 1979; Blake, 1984; McLay 1988; Spencer and Willan, 1995; Glasby, 1984; Glasby and Read, 1998; Bradford-Grieve, 1999; Beesley et al., 2000; Read, 2000; Böggemann and Fiege, 2001; www. museum.vic.govt.au.; keys for New Zealand Lumbrinerid (Hilbig and Glasby), and Glyceridae (Glasby) polychaetes and keys to the polychaete families Cirratulidae and Paraonidae (provided by C. Glasby)). A reference collection was built up and identifications verified by: Dr. N. Bruce (Isopoda), S. Eagar (Ostracoda), Dr. G Fenwick (Amphipoda), Dr. C. Glasby (Polychaeta), and Dr. B Marshall (Mollusca). 


\subsubsection{Data Analyses}

Data were analysed using and following recommendations of the software package PRIMER (version 5) (Plymouth Routines in Multivariate Ecological Research, Clarke and Warwick, 1994). Other statistical tests were carried using either SYSTAT (version 6.1) or STATISTICA (version 5.5).

\subsection{3.a The Biological Community}

\subsection{3.a.1 Determining if the Biological Community is Disturbed}

Using biological community abundance data a partial dominance curve was constructed for each station at each site. Partial dominance curves were used because it is recognised that in disturbed environments, as is expected in the vicinity of stormwater outlets, they better represent disturbance effects than does a cumulative dominance curve (Clarke, 1990; Clarke and Warwick, 1994). Partial dominance curves plot the abundance of each species relative to the total abundance of itself and all other less abundant species i.e. the dominance of the first ranked species is relative to itself and all remaining species, the dominance of the second ranked species is relative to itself and all remaining species ignoring the abundance of the first ranked species, and so on (Clarke and Warwick, 1994). Thus, if $a_{i}$ is the absolute abundance of the $i$ th species, when ranked in decreasing abundance order, the partial dominance curve is a plot of $\mathrm{p}_{i}$ against $\log i(i=1,2 \ldots \ldots \ldots, \mathrm{S}-1)$ where

$$
P_{I}=100 a_{I} /\left(\sum_{j=1} a_{j}\right), P_{2}=100 a_{2} /\left(\Sigma \mathrm{s}_{j=2} a_{j}\right), \ldots \ldots \ldots . . P_{s-1}=100 a_{s-1} /\left(a_{s-1}+a_{s}\right)
$$

Consequently earlier values can never affect later points on the curve. For undisturbed communities the plot is "a rather smooth abundance curve, decreasing slightly in the initial stages and then remaining largely constant before the inevitable final rise, as the number of species making up the denominator term drops towards unity" (Clarke, 1990). By comparison the abundance curve for a disturbed community is "much more variable. This implies that pollution effects are not just seen in changes to a few dominant species but are a phenomenon which pervades the complete suite of species in the community" (Clarke and Warwick, 1994). 


\subsection{3.a.2 Patterns of Community structure}

\section{Ordination}

Multi Dimensional Scaling (MDS) plots were used to investigate patterns of community structure:
a. among areas
b. between outlet and control stations in each area
c. with respect to distance from either a point on the shore or the outlet
d. with respect to direction from either a point on the shore or the outlet
e. at a station over time

The average abundance (from 3 replicates) of each taxon at each station was $\log (\mathrm{x}+1)$ transformed. From the transformed data a similarity matrix was generated using the BrayCurtis similarity measure. Non-metric MDS was performed on the similarity matrix to produce a 2 -dimensional ordination of stations.

\section{Analysis of Similarities}

The null hypotheses to be tested are:

There is no significant difference in the structure of the biological community between sites.

\section{There is no significant difference in the structure of the biological community with distance from an outlet.}

One way ANOSIM tests (5000 permutations) were performed on the Bray-Curtis similarity matrices (generated from $\log (x+1)$ transformed data) (i.e. the biological community) for both the November 1998 and May 1999 data.

To test the first hypothesis the pooled data from all stations at a site in a sampling period were used. To test the second hypothesis the pooled data from the two stations at each distance (6 replicates) at each site were used. Pairwise comparisons generated in each analysis were used for the identification of all specific significant differences. ANOSIM analyses of the community structure between stations (3 replicates) at a site were not possible because of low statistical power. 


\subsection{3.b $\underline{\text { Univariate Indices }}$}

The univariate biological indices of total number of taxa (S) and individuals (N), ShannonWeiner diversity index $\left(\mathrm{H}^{\prime}\right)$, number of taxa of molluses $\left(\mathrm{S}_{\mathrm{m}}\right)$, polychaetes $\left(\mathrm{S}_{\mathrm{p}}\right)$ and arthropods $\left(\mathrm{S}_{\mathrm{a}}\right)$ and number of individuals of molluses $\left(\mathrm{N}_{\mathrm{m}}\right)$, polychaetes $\left(\mathrm{N}_{\mathrm{p}}\right)$ and arthropods $\left(\mathrm{N}_{\mathrm{a}}\right)$ were enumerated for each station at each site.

The null hypotheses to be tested are:

There is no significant difference in each index $\left(\mathrm{S}, \mathrm{N}, \mathrm{H}^{\prime}, \mathrm{S}_{\mathrm{m}}, \mathrm{S}_{\mathrm{p}}, \mathrm{S}_{\mathrm{a}}, \mathrm{N}_{\mathrm{m}}, \mathrm{N}_{\mathrm{p}}, \mathrm{N}_{\mathrm{a}}\right.$ ) between an outlet site and associated control site.

There is no significant difference in each index $\left(\mathrm{S}, \mathrm{N}, \mathrm{H}^{\prime}, \mathrm{S}_{\mathrm{m}}, \mathrm{S}_{\mathrm{p}}, \mathrm{S}_{\mathrm{a}}, \mathrm{N}_{\mathrm{m}}, \mathrm{N}_{\mathrm{p}}, \mathrm{N}_{\mathrm{a}}\right.$ ) between outlet and associated control stations.

There is no significant difference in each index $\left(\mathrm{S}, \mathrm{N}, \mathrm{H}^{\prime}, \mathrm{S}_{\mathrm{m}}, \mathrm{S}_{\mathrm{p}}, \mathrm{S}_{\mathrm{a}}, \mathrm{N}_{\mathrm{m}}, \mathrm{N}_{\mathrm{p}}, \mathrm{N}_{\mathrm{a}}\right.$ ) with distance from an outlet.

There is no significant difference in each index $\left(\mathrm{S}, \mathbf{N}, \mathbf{H}^{\prime}, \mathrm{S}_{\mathrm{m}}, \mathrm{S}_{\mathrm{p}}, \mathrm{S}_{\mathrm{a}}, \mathbf{N}_{\mathrm{m}}, \mathbf{N}_{\mathrm{p}}, \mathbf{N}_{\mathrm{a}}\right)$ with direction from an outlet.

To test these hypotheses a multifactorial GLM ANOVA of each index against the factors of site, distance and direction was performed resulting in the total model, the individual factors of site, distance, direction, 2-way interactions of site $\mathrm{x}$ distance, site $\mathrm{x}$ direction, distance $\mathrm{x}$ direction and the 3-way interaction of site $\mathrm{x}$ distance $\mathrm{x}$ direction. Site, distance and direction are fixed factors. The data from all stations at a site were included in the site analyses (18 replicates). For distance, the pooled data from the two stations at each distance (6 replicates) at each site were used. As a result of the sampling regime at each site (section 5.2.1) two directions were used in the analyses, these were straight (incorporating data from all 3 stations) ( 9 replicates) and L/R (incorporating the data from the 2 left and 1 right station) (9 replicates). Where significant effects occurred, a posteriori multiple comparisons were performed using the Student-Newmans-Keuls test. From the a posteriori comparisons sitespecific distance and directions effects and significant differences between outlet and control sites and stations could be determined. Significant differences in the value of an index with distance at an outlet site but not at the associated control site are interpreted as being attributable to stormwater discharge from the outlet. Significant differences in the value of 
an index with direction at an outlet site but not at the associated control site are less easily interpreted because they could be due to stormwater discharge or the influence of wharf or marina structures, or other disturbance activities such as shipping. Analyses were performed on both the November 1998 and the May 1999 data.

Cochran's test $(\alpha=0.05)$ for Homogeneity of Variance (Underwood, 1981) was carried out on the raw data and where variances were heterogeneous the data were transformed (total, polychaete and mollusc individuals data were square root transformed and arthropod individual data $\log (\mathrm{x}+1)$ transformed). After data transformation, the variance for the 1998 polychaete individual data remained heterogeneous at $\alpha=0.05$ but not at $\alpha=0.01$; statistical significance for this variable was set at $\alpha=0.01$ while for all other variables it was set at $\alpha=0.05$. After transformation of the 1999 polychaete individual data the variance remained heteroscedastic, thus cautious interpretation of the results for this variable is required (Underwood, 1981).

\subsection{3.c Abundance of selected Taxa}

The SIMPER routine calculates the average dissimilarity of the macrobiota between samples and lists taxa in rank order of their percent contribution to the dissimilarity (Clarke and Warwick, 1994). SIMPER analyses of $\log (x+1)$ transformed data were performed on both the 1998 and the 1999 data to identify the taxa that contributed most to the biotic differences between control and outlet sites in each area. These taxa and/or the most abundant taxa within an area and/or taxa having sufficient numbers with distance and/or taxa having sufficient numbers at all sites in an area, were those selected for statistical analyses.

The null hypotheses to be tested are:

There is no significant difference in the abundance of selected taxa between outlet and associated control stations.

There is no significant difference in the abundance of selected taxa with increasing distance from an outlet.

There is no significant difference in the abundance of selected taxa with direction from an outlet. 
To test these hypotheses a multifactorial GLM ANOVA of each selected taxa against the factors of site, distance and direction was performed resulting in the total model, the individual factors of site, distance, direction, 2-way interactions of site $\mathrm{x}$ distance, site $\mathrm{x}$ direction, distance $\mathrm{x}$ direction and the 3 -way interaction of site $\mathrm{x}$ distance $\mathrm{x}$ direction. Site, distance and direction are fixed factors. The data from all stations at a site were included in the site analyses (18 replicates). For distance, the pooled data from the two stations at each distance (6 replicates) at each site were used. As a result of the sampling regime at each site (section 5.2.1) two directions were used in the analyses, these were straight (incorporating data from all 3 stations) ( 9 replicates) and L/R (incorporating the data from the 2 left and 1 right station) (9 replicates). Where significant effects occurred, a posteriori multiple comparisons were performed using the Student-Newmans-Keuls test. From the a posteriori comparisons site-specific distance and directions effects and significant differences between outlet and control stations could be determined. Significant differences in taxa abundance with distance at an outlet site but not at the associated control site is interpreted as being attributable to stormwater discharge from the outlet. Significant differences in the abundance of each taxon with direction at an outlet site but not at the associated control site are less easily interpreted because they could be due to stormwater discharge or the influence of wharf or marina structures, or other disturbance activities such as shipping. Analyses were performed on both the November 1998 and the May 1999 data.

For taxa with heteroscedastic raw data (Cochran's C, $\alpha=0.05$ ), the data were transformed $(\log (x+1)$ or square root) to achieve homogeneity of variance (Cochran's $C, p<0.05)$. Where the data remained heteroscedastic after transformation, univariate non-parametric KruskalWallis ANOVA was performed on the raw data.

\subsection{RESULTS}

\subsubsection{The Biological Community}

227 taxa consisting of 45 molluses, 100 polychaetes, 71 arthropods, 4 echinoderms and 7 others (oligochaeta, Nemertea, Phoronida, Coelenterata (2 taxa), Pycnogonida and Platyhelminthes) were identified (File: Species List in Appendix IV).

88,310 individuals (65,296 in November 1998 and 23,014 in May 1999) were recorded from all samples. Polychaetes were the most abundant group ( $87 \%$ of individuals in 1998 and $84 \%$ of individuals in 1999), followed by Molluscs ( $8 \%$ and $8 \%$ respectively) and 
arthropods (4\% and $6 \%$ respectively). A summary of the macrobiota at each site is presented in Table 5.1.

Table 5.1: The macrobiota (number of taxa and individuals) at each site in November 1998 and May 1999. Number of samples per site: November $1998=18$, May $1999=21$.

November 1998

SITE

\begin{tabular}{|c|c|c|c|c|c|c|c|c|c|c|}
\hline & EB-1 & EB-2 & EB-C & Q-1 & Q-2 & Q-C & A-1 & A-2 & A-C & OPT \\
\hline Total taxa & 96 & 79 & 119 & 62 & 68 & 69 & 64 & 55 & 71 & 36 \\
\hline Total individuals & 8520 & 4733 & 7251 & 5640 & 4209 & 6249 & 5079 & 8551 & 7300 & 7764 \\
\hline Molluse taxa & 22 & 15 & 24 & 13 & 15 & 17 & 11 & 9 & 12 & 4 \\
\hline Molluse individuals & 893 & 858 & 1349 & 504 & 492 & 420 & 188 & 131 & 198 & 329 \\
\hline Polychaete taxa & 43 & 35 & 49 & 36 & 38 & 35 & 36 & 34 & 42 & 27 \\
\hline Polychaete individuals & 7086 & 3014 & 5008 & 5016 & 3600 & 5656 & 4701 & 8259 & 6973 & 7374 \\
\hline Arthropod taxa & 23 & 22 & 37 & 9 & 10 & 11 & 13 & 9 & 13 & 4 \\
\hline Arthropod individuals & 402 & 777 & 716 & 112 & 98 & 144 & 165 & 123 & 86 & 25 \\
\hline Echinoderm taxa & 3 & 3 & 4 & 1 & 1 & 2 & 1 & 1 & 1 & 0 \\
\hline Echinoderm individuals & 82 & 9 & 100 & 2 & 2 & 2 & 4 & 1 & 2 & 0 \\
\hline Other taxa & 5 & 4 & 5 & 3 & 4 & 4 & 3 & 2 & 3 & 1 \\
\hline Other individuals & 57 & 75 & 78 & 6 & 17 & 27 & 21 & 37 & 41 & 36 \\
\hline
\end{tabular}

May 1999

SITE

\begin{tabular}{|lccccc|}
\hline & EB-1 & EB-2 & EB-C & A-2 & A-C \\
Total taxa & 105 & 82 & 124 & 81 & 86 \\
Total individuals & 4366 & 2668 & 6259 & 4680 & 5041 \\
Molluse taxa & 24 & 15 & 28 & 13 & 12 \\
Molluse individuals & 623 & 68 & 966 & 101 & 93 \\
Polychaete taxa & 48 & 37 & 50 & 47 & 50 \\
Polychaete individuals & 3426 & 2353 & 4263 & 4500 & 4834 \\
& & & & & \\
Arthropod taxa & 25 & 24 & 37 & 18 & 20 \\
Arthropod individuals & 235 & 176 & 819 & 46 & 83 \\
& & & & & \\
Echinoderm taxa & 4 & 2 & 4 & 1 & 1 \\
Echinoderm individuals & 36 & 12 & 120 & 1 & 5 \\
& & & & & \\
Other taxa & 4 & 4 & 5 & 2 & 3 \\
Other individuals & 46 & 59 & 91 & 32 & 26 \\
\hline
\end{tabular}




\subsection{1.a Is the Biological Community disturbed?}

Partial dominance plots were used to determine whether the biological community at outlet and control sites was disturbed (Figs 5.1-5.6; Files: PD Plots 98 and PD Plots 99 in Appendix IV).

The macrobiota at all stations at sites AQ-1, AQ-2, AQ-C, Q-1, Q-2, Q-C and OPT in November 1998 and AQ-2 and AQ-C in May 1999 was, as evidenced by the variable curves, disturbed (Figs. 5.1-5.4; Files: PD Plots 98 and PD Plots 99 in Appendix IV). At these sites the least disturbed macrobiota was at station S30 at AQ-1 in 1998 and at station L10 at AQ$\mathrm{C}$ in 1999. In general, the macrobiota at AQ-2 and AQ-C was less disturbed in May 1999 than in November 1998. The curves also show a low number of taxa at station S10 at AQ-1 and AQ- C, station S20 at Q-1, station R20 at AQ-C and stations L15, S30, L45 and S45 at OPT in 1998 and station S10 at AQ-2 in 1999.

In Evans Bay, the macrobiota at all control site stations was not disturbed in 1998 whereas in 1999 it was slightly disturbed, as evidenced by the slightly variable curve, at some stations (Figs. 5.5-5.6; Files: PD Plots 98 and PD Plots 99 in Appendix IV). By comparison, the macrobiota at each station at EB-1 was disturbed in both 1998 and 1999. However at EB-1, the macrobiota at straight transect stations was less disturbed in 1999 than in 1998 and on both sampling occasions it was less disturbed at straight than at left and right transect stations. At EB-2 in both 1998 and 1999 the macrobiota at all stations except S44 was slightly disturbed. In 1998 the macrobiota at EB-2 station S44 was not disturbed.

\subsection{1.b Patterns of Community Structure}

\subsection{1.b.1 Ordination of the Biological community}

Two-dimensional MDS plots (using $\log (\mathrm{x}+1)$ transformed, average abundance data of each taxa at a station) were used to investigate patterns of community structure.

\section{All sites and stations in 1998 (Fig. 5.7)}

There is a clear separation of the Evans Bay macrobiota (except for that of EB-1, station L24) from that of Queens Wharf, Aotea Quay and OPT. There is no clear separation between the Queens Wharf and Aotea Quay macrobiota. The macrobiota at some OPT stations is aligned with that at stations in the vicinity of outlet Q-1, while the macrobiota at the other OPT stations is distinctive from that at all other stations and sites. 


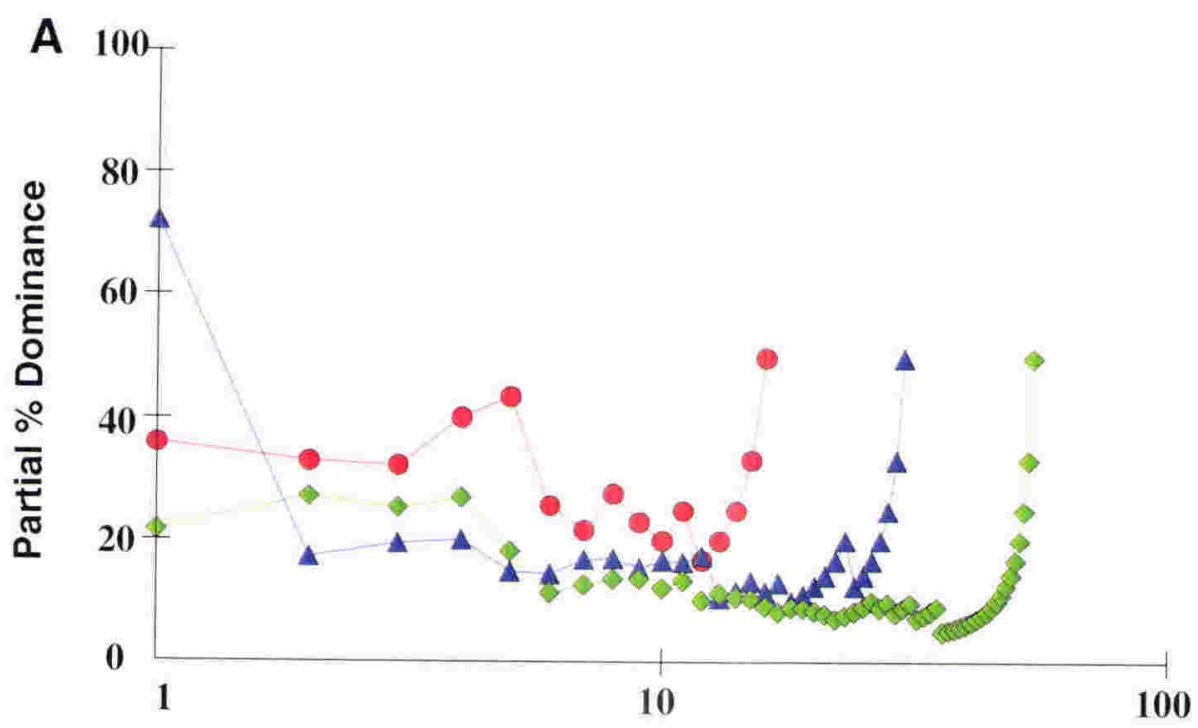

- S10

$\triangle \mathrm{S} 20$

- S30

Species rank
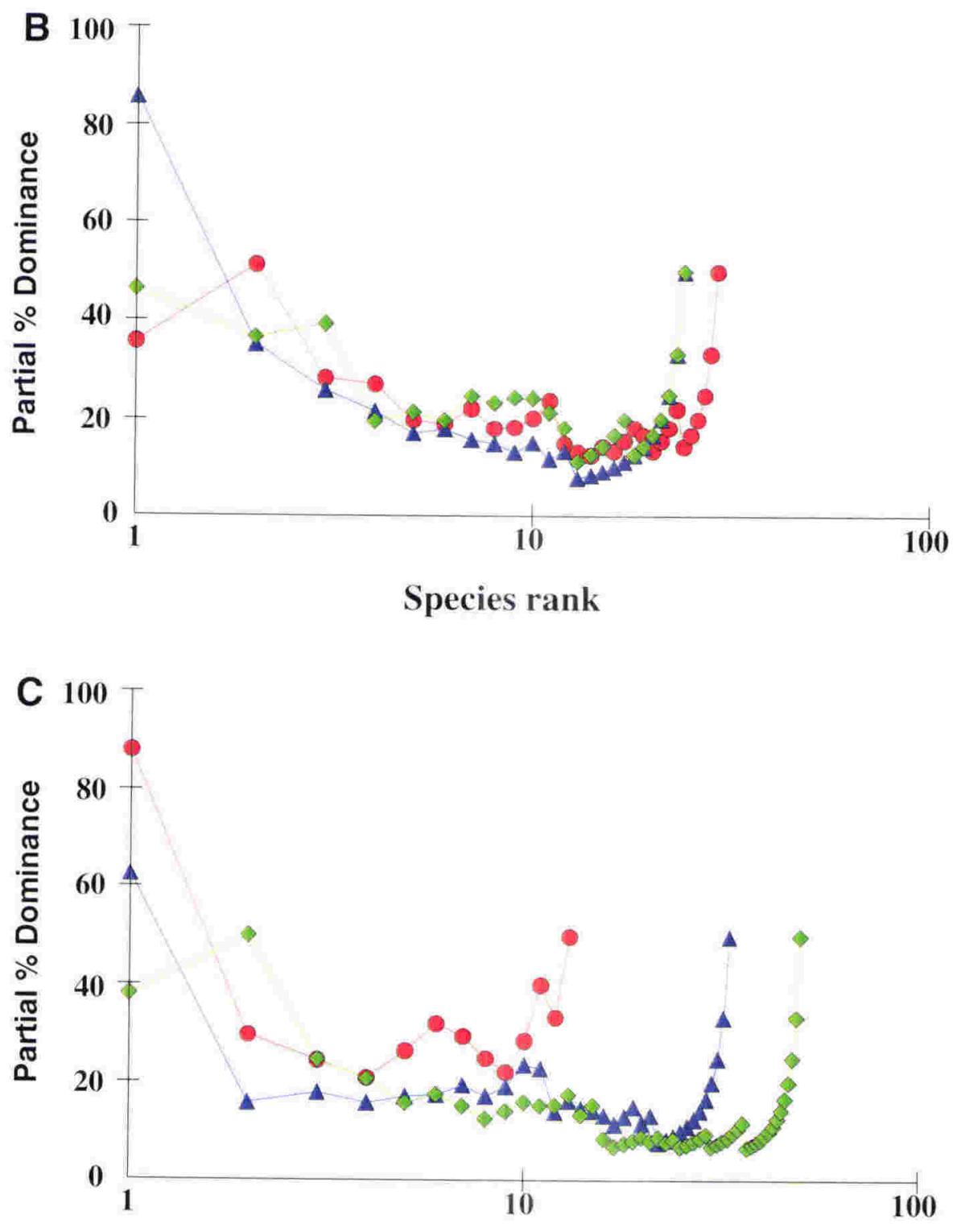

- $\mathrm{S} 10$

$\triangle \mathrm{S} 20$

- S30

\section{Species rank}

Figure 5.1: Partial Dominance Plots of the macrobiota at stations on the straight transect at Aotea Quay sites in November 1998.

A - Site AQ-1, B - Site AQ-2, C-Site AQ-C 

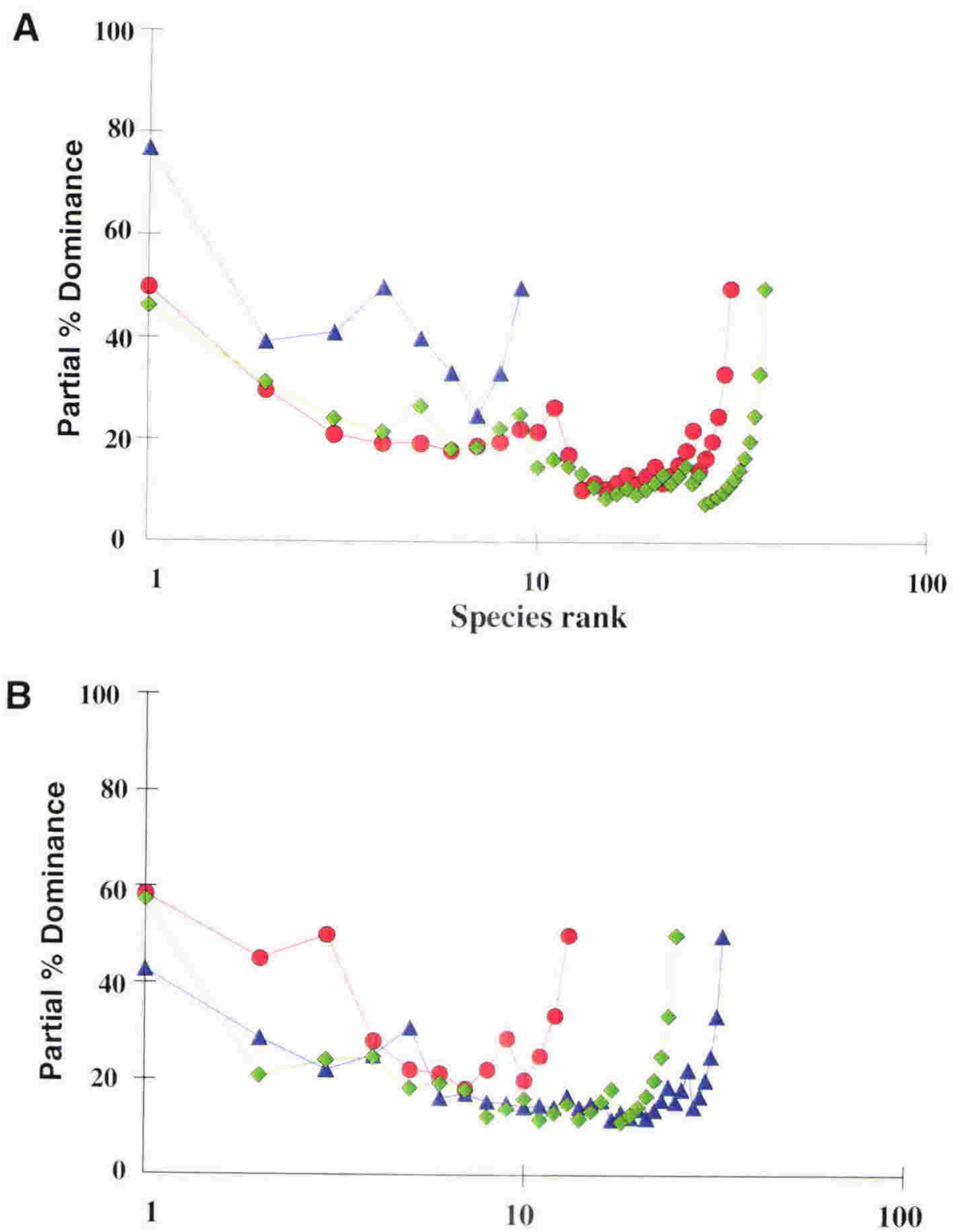

Species rank

C

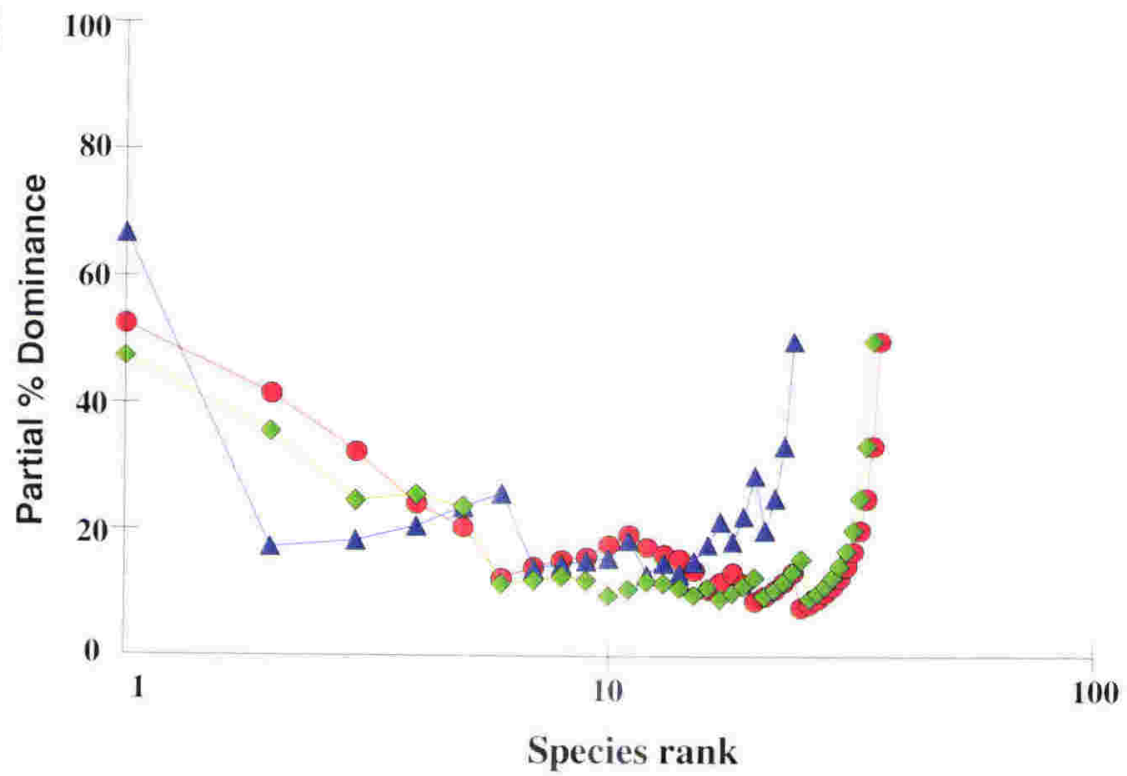

Figure 5.2: Partial Dominance Plots of the macrobiota at stations on the straight transect at Queens Wharf sites in November 1998.

A - Site Q-1, B - Site Q-2, C - Site Q-C 


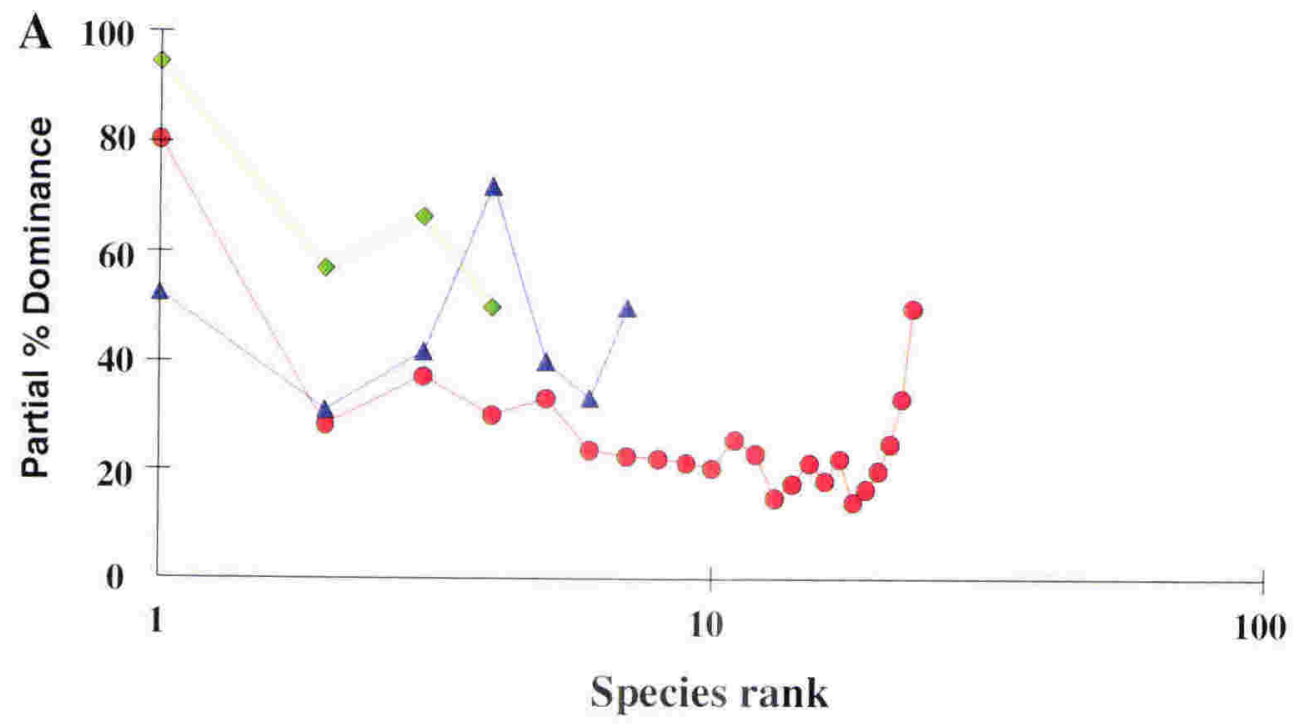

S15

$\triangle \mathrm{S} 30$

S45

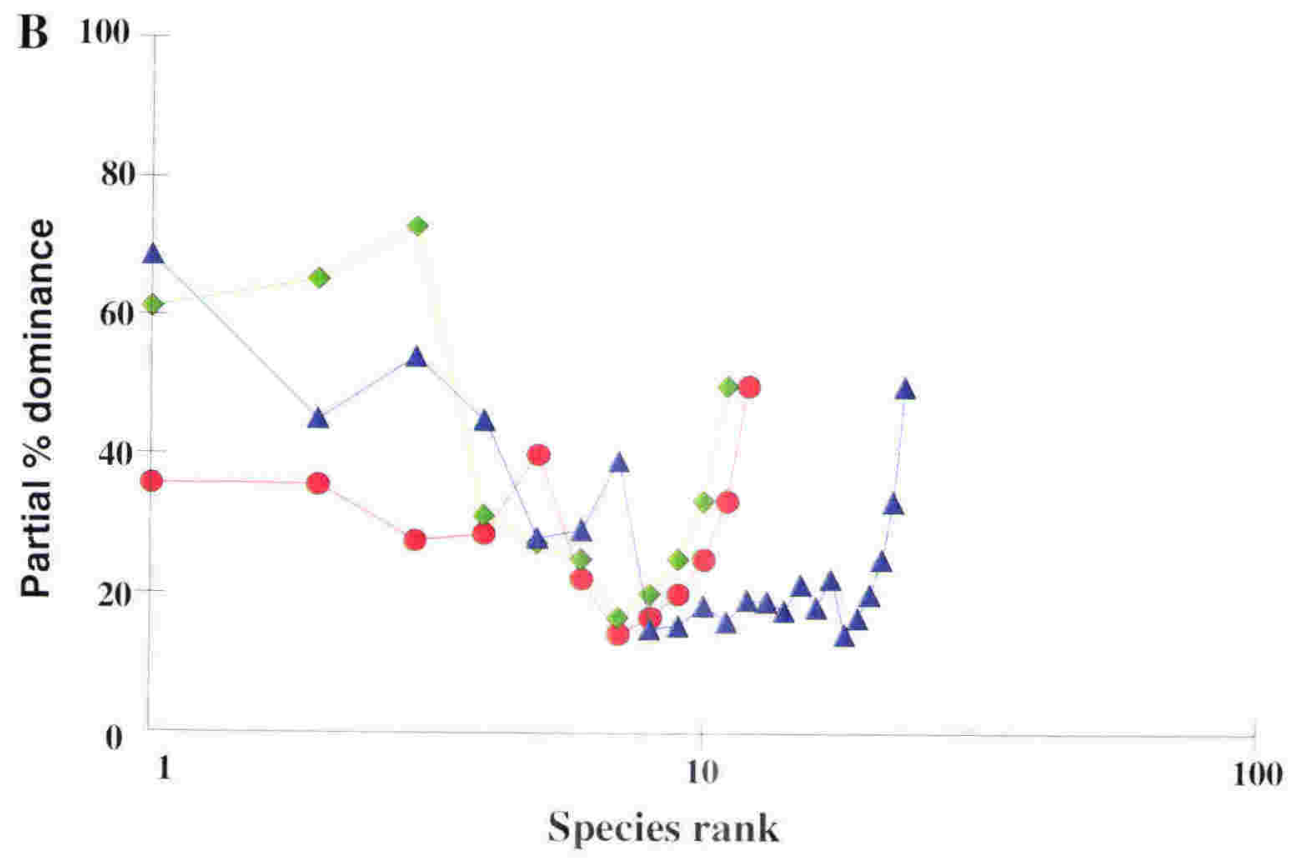

L15

$\triangle \mathrm{R} 30$

- L45

Figure 5.3: Partial Dominance Plots of the macrobiota at stations at OPT in November 1998.

A - Straight transect B - Left/right transects 

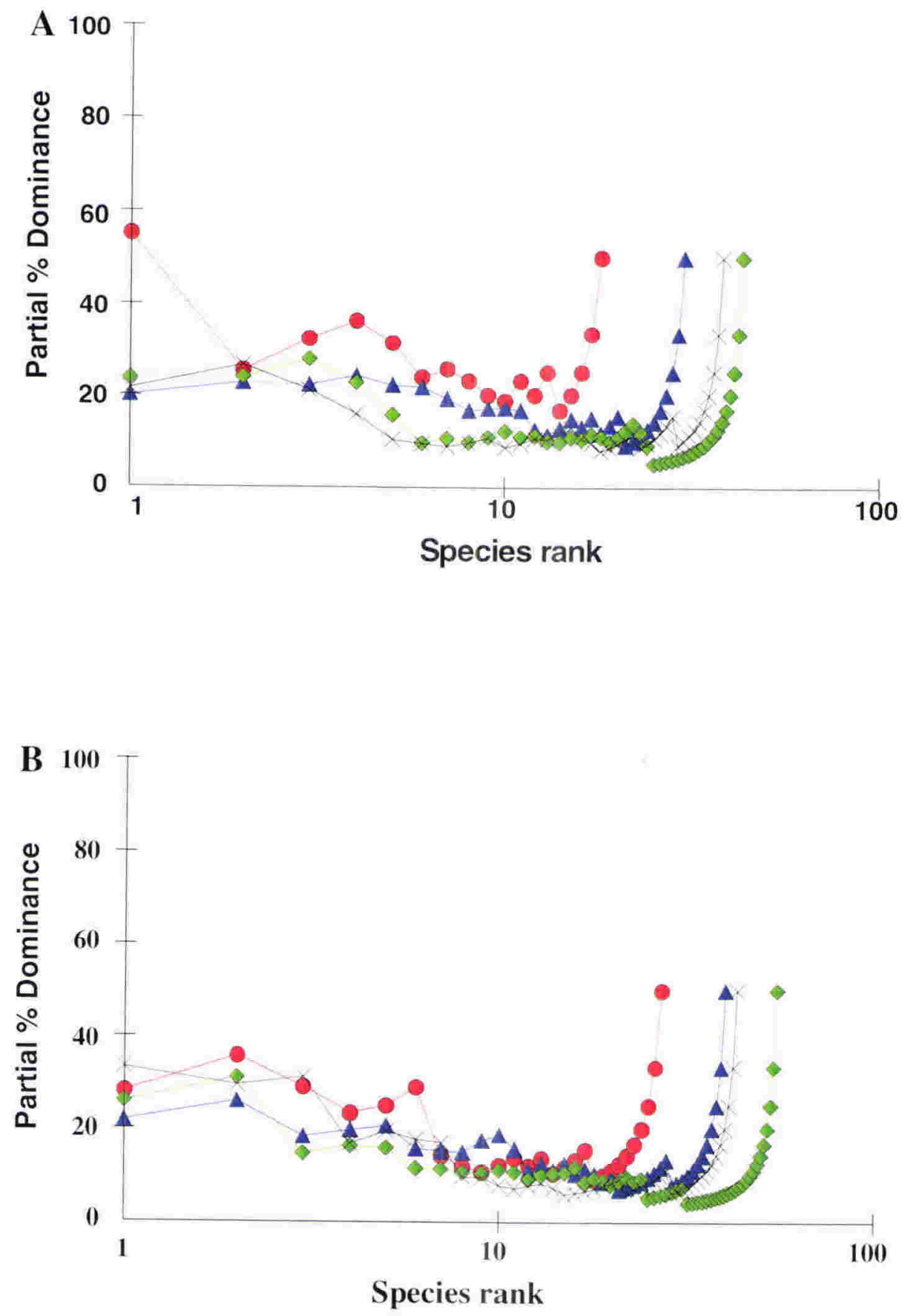

Figure 5.4: Partial Dominance Plots of the macrobiota at stations on the straight transect at Aotea Quay sites in May 1999. A - Site AQ-2 $\quad$ B - Site AQ-C 

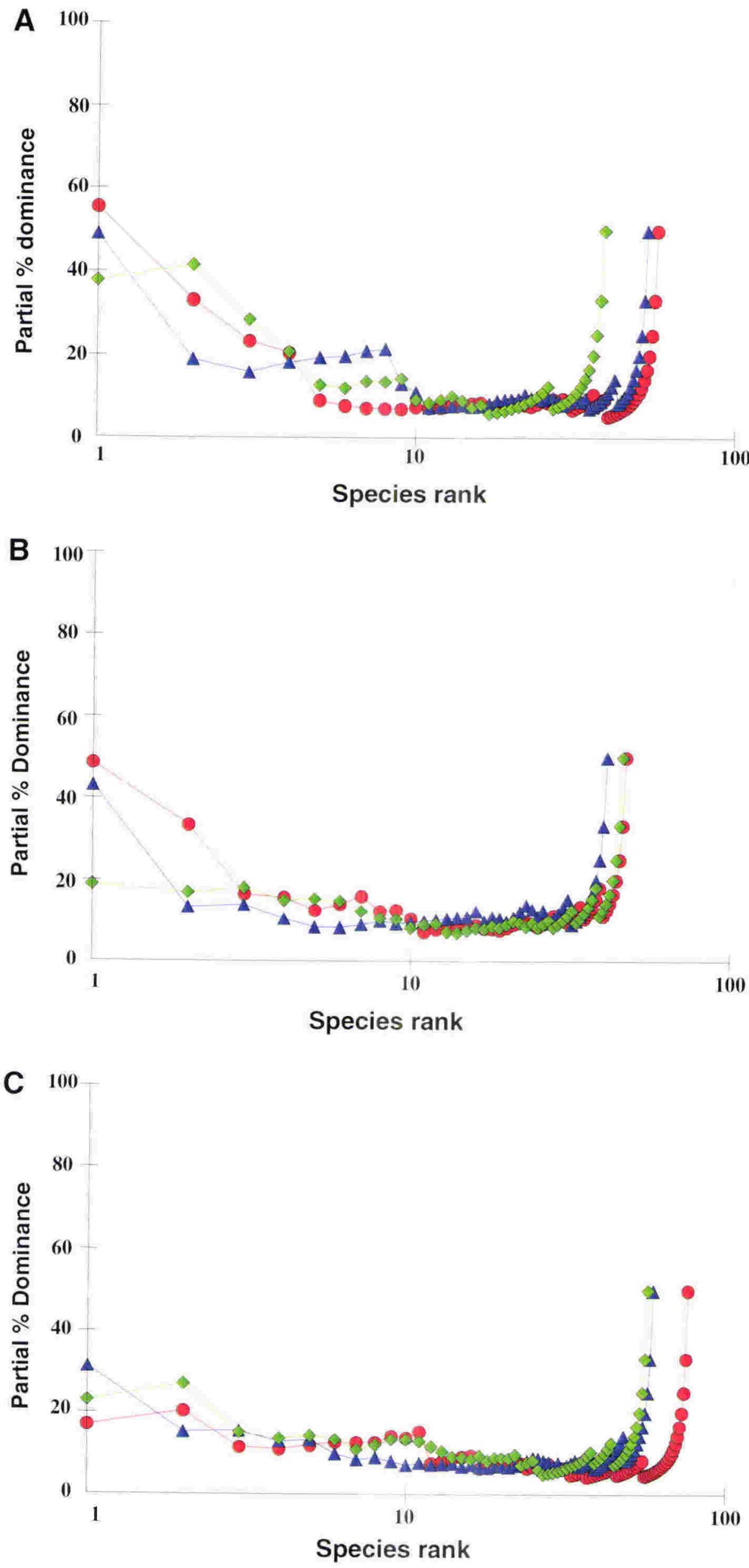

Figure 5.5: Partial Dominance Plots of the macrobiota at stations on the straight transect at Evans Bay sites in November 1998.

A - Site EB-1 B - Site EB-2 C - Site EB-C 

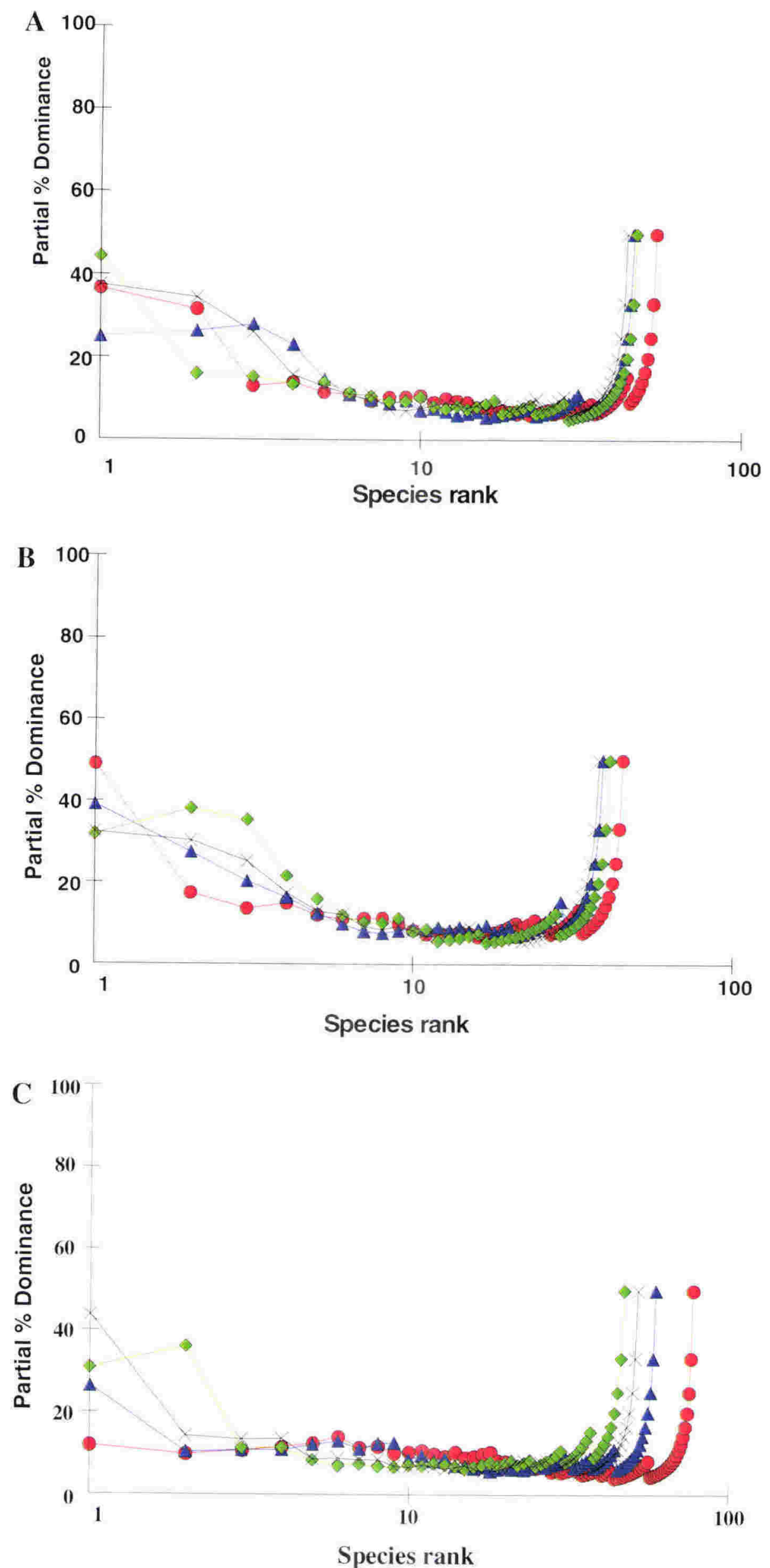

Figure 5.6: Partial Dominance Plots of the macrobiota at stations on the straight transect at Evans Bay sites in May 1999
A - Site EB-1
B - Site EB-2
C-Site EB-C 


\section{Evans Bay (Fig. 5.8)}

At EB-C the macrobiota at all straight transect stations was similar in 1998, i.e. little difference with distance from the shore, however in 1999 the macrobiota at stations S44 and S54 was distinct from that at stations S24 and S34 closer to the shore. There was also clear separation of straight, left and right transect macrobiota in both 1998 and 1999. Over time small changes occurred in the macrobiota at all EB-C stations except station S44 where a larger change occurred.

The macrobiota in the vicinity of EB-1 and EB-2 was distinct from each other and from that at EB-C. At both outlets the macrobiota did not become similar to that of the control site with increasing distance away from the outlet rather the macrobiota at stations furthest away from each outlet was the most separated from that at the control site. At the $44 \mathrm{~m}$ stations at EB-1 in 1998 and the 24 and 44 m stations at EB-2 in 1999 the macrobiota present, but on different transects, was similar. For all other stations the macrobiota at comparable distances but on different transects was distinct with the largest separation being between the macrobiota at stations L24 and S24 at EB-1. Over time the biotic community changed at all stations with the greatest change being at station L24 at EB-1. There was no pattern to the direction of change over time of the macrobiota at EB-1 and EB-2.

\section{Queens Wharf (Fig. 5.9)}

At Q-C the macrobiota $10 \mathrm{~m}$ from shore was distinct from that at 20 and $30 \mathrm{~m}$ and at $10 \mathrm{~m}$ there was a difference between the macrobiota at S10 and L10. The macrobiota at the 20 and $30 \mathrm{~m}$ stations was similar, and the macrobiota at the same distance but on different transects at both 20 and $30 \mathrm{~m}$ was similar.

At Q-1 the macrobiota at each station was distinct with only the macrobiota at station S30 having any similarity to that of the associated control site station. By comparison, at Q-2 the macrobiota at station S10 was the most distinct from that at the associated control site station, with the macrobiota becoming more similar to that at control site stations, with increasing distance from the outlet.

OPT (Figs. 5.9 and 5.10)

The macrobiota in the vicinity of OPT was distinct from that at both AQ-C and Q-C but for some stations it was similar to that at some stations in the vicinity of outlets Q-1 and Q-2. 


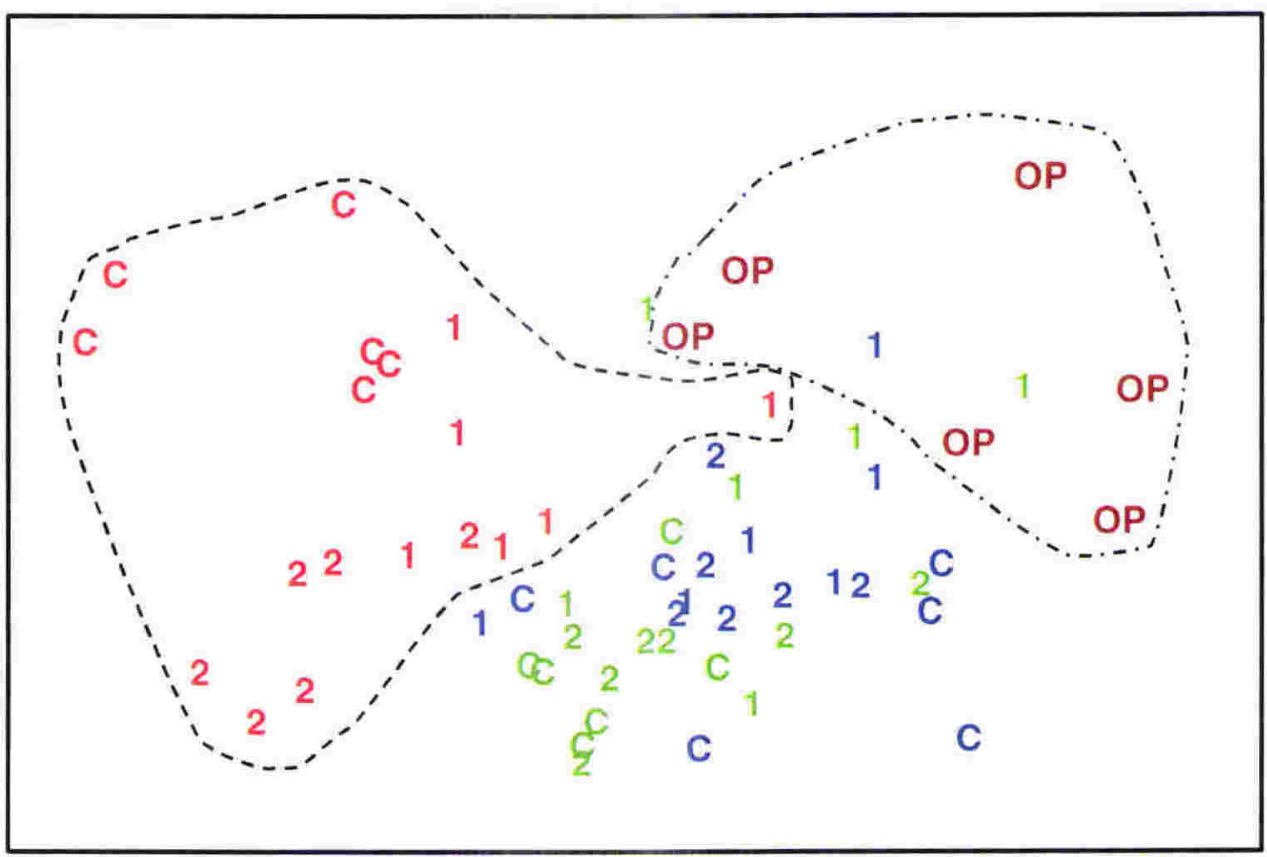

KEY

Evans Bay

$1=\mathrm{EB}-1$

$2=\mathrm{EB}-2$

$\mathrm{C}=\mathrm{EB}-\mathrm{C}$

Queens

$1=\mathrm{Q}-1$

$2=\mathrm{Q}-2$

$\mathrm{C}=\mathrm{Q}-\mathrm{C}$

Aotea Quay

$1=\mathrm{AQ}-1$

$2=A Q-2$

$C=A Q-C$

$\mathrm{OP}=\mathrm{OPT}$

Figure 5.7: MDS ordination of the average faunal abundance of the biota at each station at each site sampled in 1998. Stress value $=0.12$

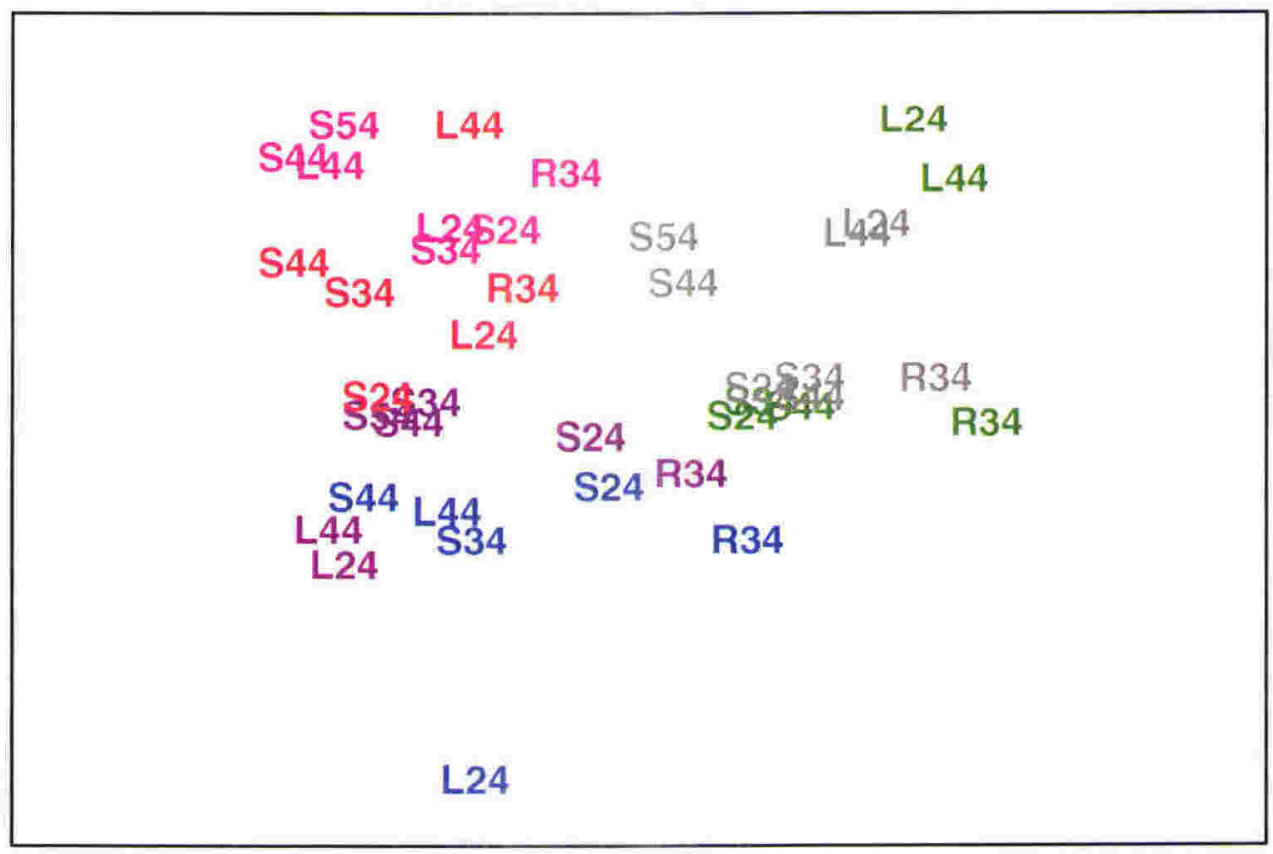

KEY

EB-1 98

EB-1 99

EB-2 98

EB-2 99

EB-C 98

EB-C 99

Figure 5.8: MDS ordination of the average faunal abundance of the biota at each station at each Evans Bay site in 1998 and 1999. Stress value $=0.14$

STATIONS: $\mathbf{S}$ - Straight transect $\mathbf{L}$ - Left transect $\quad \mathbf{R}$-Right transect $24,34,44,54$ - distance $(m)$ 
There was no trend to the change in the composition of the macrobiota with distance or direction from the OPT outlet.

Aotea Quay (Fig. 5.10)

At AQ-C the macrobiota at each distance i.e. 10, 20 and $30 \mathrm{~m}$ from shore was distinct. In 1998 the macrobiota at each distance on each transect was also distinct whereas in 1999, the macrobiota at stations $30 \mathrm{~m}$ from shore i.e. S30 and L30, was similar. The macrobiota present at all AQ-C stations changed over time.

At AQ-1 the macrobiota at each station was distinct, with the greatest similarity being between that at S20 and R20. The macrobiota at each AQ-1 station, except S30, was also distinct from that of the associated control site station. At AQ-2 in 1998 the macrobiota at stations S10 and S20 was distinct and that at stations R20, L10, L30 and S30 similar, whereas in 1999 the macrobiota at L10 was distinct with similarity between the macrobiota at stations S10 and R20, S20 and L30, and S30 and S40. At AQ-2 the macrobiota at all stations in 1998 was distinct from that at the associated control site stations whereas in 1999 the macrobiota at stations furthest from the outlet was similar to that at the associated control site stations. The direction of change over time was similar at AQ-2 and AQ-C stations.

\subsection{1.b.2 Analysis of Similarities (ANOSIM)}

One way ANOSIM analyses were carried out to determine if there were significant differences in the biological community between sites and with distance from each outlet.

\section{Between Sites}

In both 1998 and 1999 there was, over all sites sampled, a significant difference in biological communities between sites (1998: $\mathrm{r}=0.534, \mathrm{p}<0.001 ; 1999: \mathrm{r}=0.759, \mathrm{p}<0.001$ ). Pairwise comparisons between sites sampled in 1998 reveal a significant difference in the biological community between all sites, except between AQ-1 and AQ-C, and AQ-1 and Q1 where there no significant difference. Pairwise comparisons between sites sampled in 1999 reveal a significant difference in the biological community between all sites (File: ANOSIM, Appendix IV). 


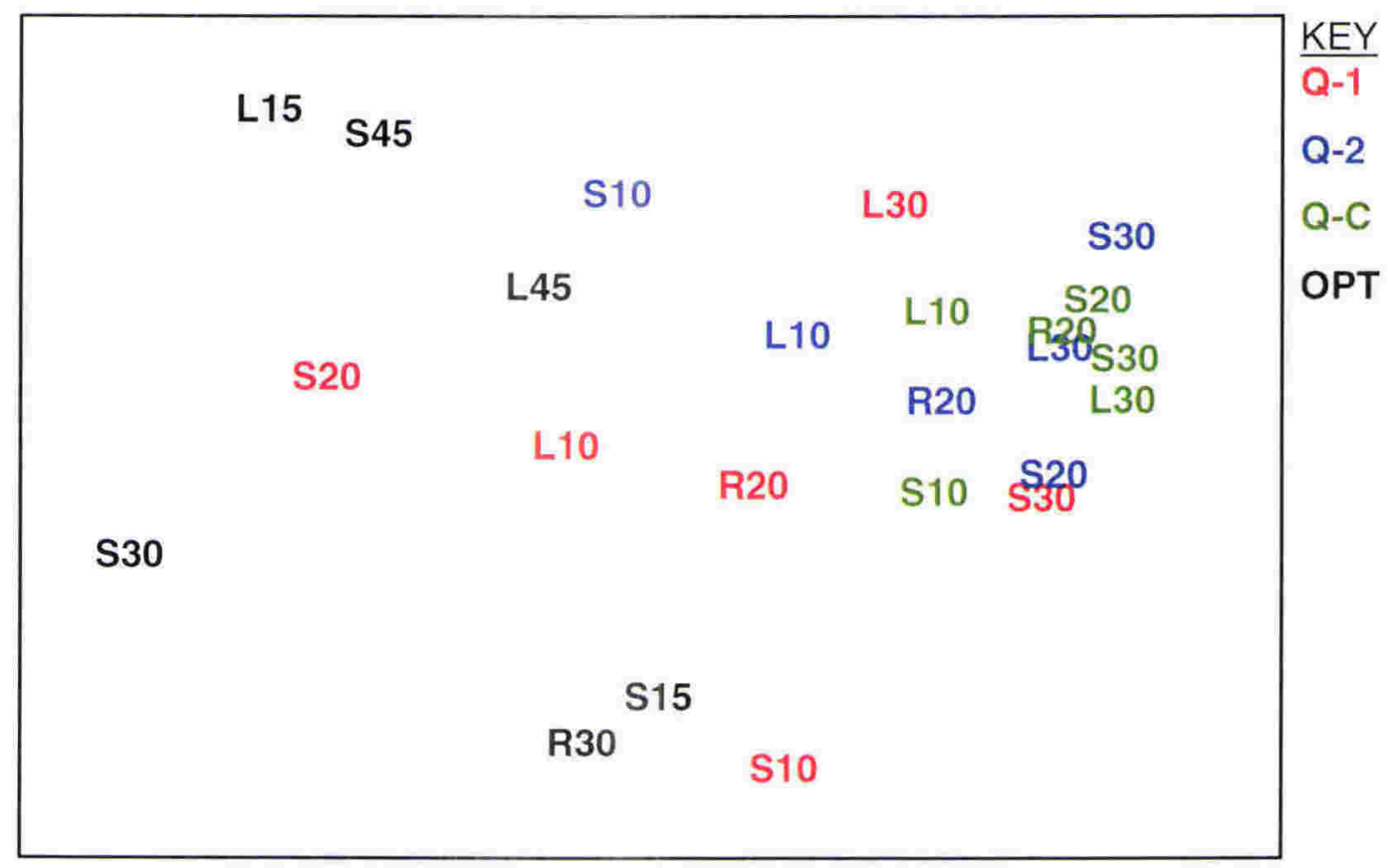

Figure 5.9: MDS ordination of the average faunal abundance of the biota at each station at each Queens Wharf site and at OPT in 1998. Stress value $=0.1$
STATIONS: $\mathrm{S}$ - Straight transect
$\mathbf{L}$ - Left transect
$\mathbf{R}$ - Right transect

10, 20, 30 - distance metres

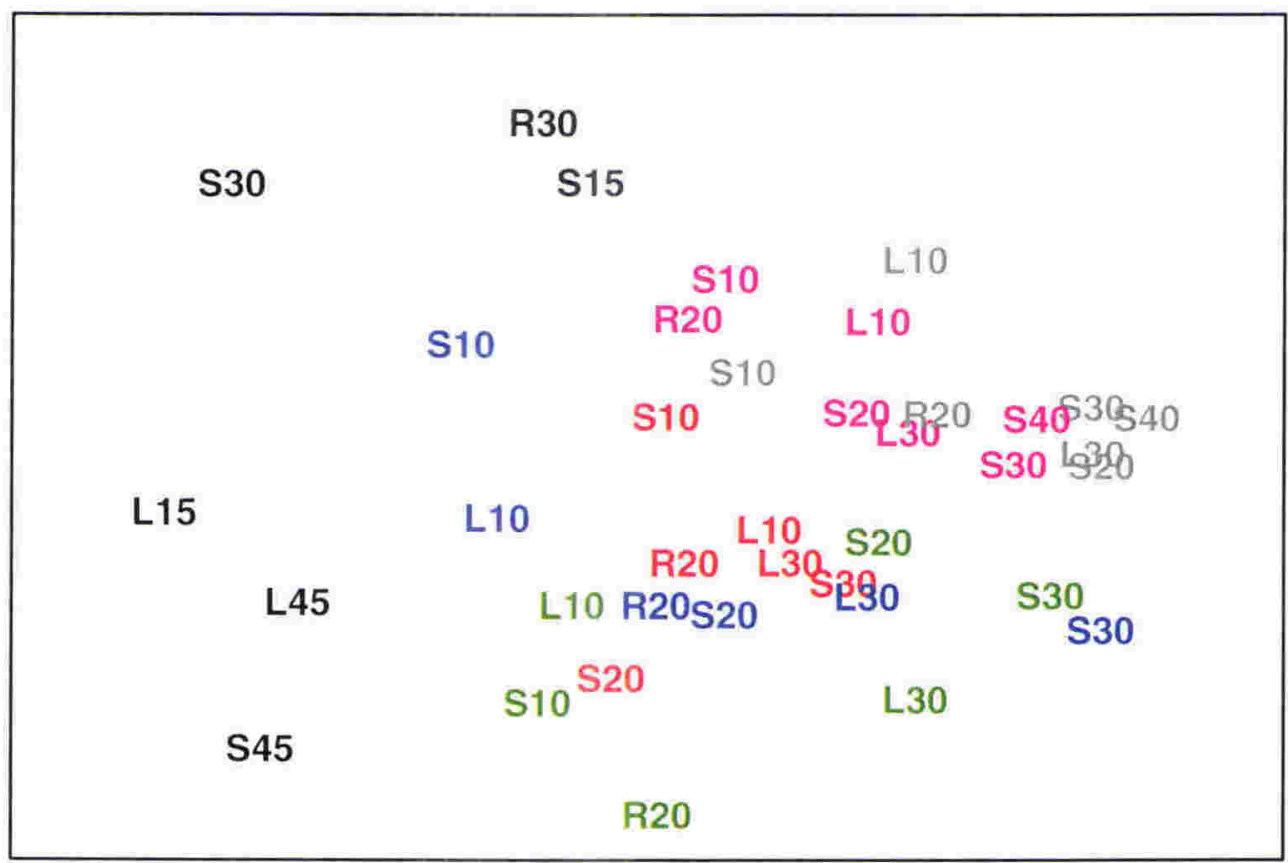

Figure 5.10: MDS ordination of the average faunal abundance of the biota at each station at each Aotea Quay site in 1998 and 1999, and at OPT. Stress value $=0.16$ 
The null hypothesis that there is no significant difference in the structure of the biological community between sites is rejected. There are significant differences in the biological community between sites.

\section{Distance from each outlet}

Evans Bay

At EB-C, in 1998 there was a significant difference in the biological community between the 24 and $34 \mathrm{~m}$ and 34 and $44 \mathrm{~m}$ stations but no significant difference between the 24 and $44 \mathrm{~m}$ stations, whereas in 1999 there was a significant difference in the biological community between the 34 and $44 \mathrm{~m}$ stations but no significant difference between the 24 and $34 \mathrm{~m}$ and the 24 and $44 \mathrm{~m}$ stations (Table 5.2; $\mathrm{R}$ values in File:ANOSIM, Appendix IV). Thus, significant differences in the biological community between the 24 and $44 \mathrm{~m}$ stations in 1998 and between the 24 and $34 \mathrm{~m}$ and 24 and $44 \mathrm{~m}$ stations at outlet sites in Evans Bay could be due to the effect of stormwater discharge.

At EB-1 in 1998 there was a significant difference in the biological community between the 24 and $44 \mathrm{~m}$; this significant difference could possibly be due to the effect of stormwater discharge. In both 1998 and 1999 the biological community at all EB-1 stations was significantly different to that at EB-C (Table 5.2; R values in File:ANOSIM, Appendix IV).

At EB-2 in 1998 there was a significant difference in the biological community between all stations and in 1999 a significant difference between that at the 24 and $34 \mathrm{~m}$ stations i.e. the significant differences between the 24 and $44 \mathrm{~m}$ stations in 1998 and 24 and $34 \mathrm{~m}$ stations in 1999 could possibly be due to the effect of stormwater discharge. In both 1998 and 1999 the biological community at all EB-2 stations was significantly different to that at EB-C.

\section{Queens Wharf}

At Q-C there were significant differences in the biological community with distance from shore, therefore it was not possible to interpret significant differences in the biological community with distance from outlets Q-1 and Q-2 (File: ANOSIM in Appendix IV). 
Table 5.2: The biological community (ANOSIM analysis) at each site in Evans Bay Pairwise comparisons between distance stations

ns - no significant difference, ${ }^{*}$ significance at $\mathrm{p}<0.05, * *$ significance at $\mathrm{p}<0.001$

\begin{tabular}{|c|c|c|c|c|c|c|c|c|c|c|}
\hline \multirow{2}{*}{\multicolumn{2}{|c|}{1998}} & \multicolumn{3}{|c|}{ EB-1 } & \multicolumn{3}{|c|}{ EB-2 } & \multicolumn{3}{|c|}{ EB-C } \\
\hline & & $24 \mathrm{~m}$ & $34 \mathrm{~m}$ & $44 \mathrm{~m}$ & $24 \mathrm{~m}$ & $34 \mathrm{~m}$ & $44 \mathrm{~m}$ & $24 \mathrm{~m}$ & $34 \mathrm{~m}$ & $44 \mathrm{~m}$ \\
\hline \multirow{3}{*}{ EB-1 } & $24 m$ & & & & & & & & & \\
\hline & $34 \mathrm{~m}$ & ns & & & & & & & & \\
\hline & $44 m$ & $* *$ & * & & & & & & & \\
\hline \multirow{3}{*}{ EB-2 } & $24 m$ & $* \hbar$ & $\% *$ & $* *$ & & & & & & \\
\hline & $34 \mathrm{~m}$ & $* *$ & $* *$ & $* *$ & $* *$ & & & & & \\
\hline & $44 m$ & $* *$ & $* *$ & $* *$ & $* *$ & $* *$ & & & & \\
\hline \multirow{3}{*}{ EB-C } & $24 m$ & $* *$ & $\% *$ & $* *$ & $\% *$ & $* *$ & $* *$ & & & \\
\hline & $34 m$ & $* *$ & $* *$ & $* *$ & $* *$ & $* *$ & $* *$ & $*$ & & \\
\hline & $44 m$ & $* *$ & $* *$ & $* *$ & $* *$ & $* *$ & $* *$ & ns & $* *$ & \\
\hline \multirow{2}{*}{\multicolumn{2}{|c|}{1999}} & \multicolumn{3}{|c|}{ EB-1 } & \multicolumn{3}{|c|}{ EB-2 } & \multicolumn{3}{|c|}{ EB-C } \\
\hline & & $24 \mathrm{~m}$ & $34 \mathrm{~m}$ & $44 m$ & $24 \mathrm{~m}$ & $34 \mathrm{~m}$ & $44 m$ & $24 \mathrm{~m}$ & $34 \mathrm{~m}$ & $44 \mathrm{~m}$ \\
\hline \multirow{3}{*}{ EB-1 } & $24 \mathrm{~m}$ & & & & & & & & & \\
\hline & $34 \mathrm{~m}$ & ns & & & & & & & & \\
\hline & $44 \mathrm{~m}$ & ns & $* *$ & & & & & & & \\
\hline \multirow{3}{*}{ EB-2 } & $24 \mathrm{~m}$ & $* *$ & $* *$ & $\% *$ & & & & & & \\
\hline & $34 \mathrm{~m}$ & $* *$ & $* *$ & $* *$ & ns & & & & & \\
\hline & $44 m$ & $* *$ & $* *$ & $* *$ & $* *$ & $*$ & & & & \\
\hline \multirow{3}{*}{ EB-C } & $24 m$ & $* *$ & $* *$ & $* *$ & $\hbar *$ & $\hbar *$ & $\% *$ & & & \\
\hline & $34 \mathrm{~m}$ & $* *$ & $* *$ & $* *$ & $* *$ & $* *$ & $* *$ & ns & & \\
\hline & 44m & $* *$ & $* *$ & $* *$ & $* *$ & $* *$ & $* *$ & ns & $* *$ & \\
\hline
\end{tabular}

Table 5.3: The biological community (ANOSIM analysis) at each site at Aotea Quay Pairwise comparisons between distance stations ns - no significant difference, ${ }^{*}$ significance at $\mathrm{p}<0.05,{ }^{* *}$ significance at $\mathrm{p}<0.001$

\begin{tabular}{|c|c|c|c|c|c|c|c|c|c|c|}
\hline \multirow{2}{*}{\multicolumn{2}{|c|}{1998}} & \multicolumn{3}{|c|}{ AQ-1 } & \multicolumn{3}{|c|}{ AQ-2 } & \multicolumn{3}{|c|}{ AQ-C } \\
\hline & & $10 \mathrm{~m}$ & $20 \mathrm{~m}$ & $30 \mathrm{~m}$ & $10 \mathrm{~m}$ & $20 \mathrm{~m}$ & $30 \mathrm{~m}$ & $10 \mathrm{~m}$ & $20 \mathrm{~m}$ & $30 \mathrm{~m}$ \\
\hline \multirow{3}{*}{ AQ-1 } & $10 \mathrm{~m}$ & & & & & & & & & \\
\hline & $20 \mathrm{~m}$ & $* *$ & & & & & & & & \\
\hline & $30 \mathrm{~m}$ & $* *$ & $*$ & & & & & & & \\
\hline \multirow{3}{*}{ AQ-2 } & $10 \mathrm{~m}$ & $* *$ & $* *$ & $* *$ & & & & & & \\
\hline & $20 \mathrm{~m}$ & $* *$ & ns & $* *$ & $* *$ & & & & & \\
\hline & $30 \mathrm{~m}$ & $* *$ & $* *$ & $* *$ & $* *$ & $* *$ & & & & \\
\hline \multirow{3}{*}{ AQ-C } & $10 \mathrm{~m}$ & $* *$ & $\% *$ & $\% \%$ & $* *$ & * & $* *$ & & & \\
\hline & $20 \mathrm{~m}$ & $*$ & $*$ & ns & $* *$ & $* *$ & ns & $* *$ & & \\
\hline & $30 \mathrm{~m}$ & $* *$ & & ns & $* *$ & & $*$ & $* *$ & ns & \\
\hline \multirow{2}{*}{\multicolumn{2}{|c|}{1999}} & & $A Q-2$ & & & $\mathrm{AQ}-\mathrm{C}$ & & & & \\
\hline & & $10 \mathrm{~m}$ & $20 \mathrm{~m}$ & $30 \mathrm{~m}$ & $10 \mathrm{~m}$ & $20 \mathrm{~m}$ & $30 \mathrm{~m}$ & & & \\
\hline \multirow{3}{*}{$A Q-2$} & $10 \mathrm{~m}$ & & & & & & & & & \\
\hline & $20 \mathrm{~m}$ & * & & & & & & & & \\
\hline & $30 \mathrm{~m}$ & $* *$ & * & & & & & & & \\
\hline \multirow{3}{*}{ AQ-C } & $10 \mathrm{~m}$ & $* *$ & ns & $* *$ & & & & & & \\
\hline & $20 \mathrm{~m}$ & $* *$ & $* *$ & ns & $* *$ & & & & & \\
\hline & $30 \mathrm{~m}$ & $* *$ & $* *$ & ns & $* *$ & ns & & & & \\
\hline
\end{tabular}


Aotea Quay

At AQ-C, in both 1998 and 1999, there was a significant difference in the biological community between the 10 and $20 \mathrm{~m}$ and 10 and $30 \mathrm{~m}$ stations but no significant difference between the 20 and $30 \mathrm{~m}$ stations (Table 5.3; R values in File:ANOSIM, Appendix IV). Thus, significant differences in the biological community between the 20 and $30 \mathrm{~m}$ stations at the outlet sites at Aotea Quay could be due to the effect of stormwater discharge.

At AQ-1 there was a significant difference in the biological community between all stations, i.e. the significant differences between the 20 and $30 \mathrm{~m}$ stations could possibly be due to the effect of stormwater discharge. There was no significant difference in the biological community between the $30 \mathrm{~m} \mathrm{AQ-1}$ and the 20 and $30 \mathrm{~m} \mathrm{AQ-C}$ stations. All other pairwise comparisons between outlet and control stations were significant (Table 5.3; R values in File:ANOSIM, Appendix IV).

At AQ-2 there was a significant difference in the biological community in 1998 and 1999 between all stations i.e. the significant difference between the 20 and $30 \mathrm{~m}$ stations in both 1998 and 1999 could possibly be due to the effect of stormwater discharge. In 1998 there was no significant difference in the biological community between the $30 \mathrm{~m} \mathrm{AQ-2}$ and the $20 \mathrm{~m}$ AQ-C stations. In 1999 there was no significant difference in the biological community between the $20 \mathrm{~m} \mathrm{AQ}-2$ and $10 \mathrm{~m} \mathrm{AQ-C}$ and the $30 \mathrm{~m} \mathrm{AQ-2}$ and 20 and $30 \mathrm{~m}$ AQ-C stations. All other pairwise comparisons between outlet and control stations were significant (Table 5.3; R values in File:ANOSIM, Appendix IV).

The null hypothesis that there is no significant difference in the structure of the biological community with distance from an outlet is rejected. There was a significant difference in the biological community with distance from all outlets. The significant differences in the biological community between the 20 and $30 \mathrm{~m}$ stations at the Aotea outlets, and between the 24 and $44 \mathrm{~m}$ stations in 1998 at EB-1 and EB-2 and the 24 and 34 $\mathrm{m}$ and 24 and $44 \mathrm{~m}$ stations at EB-2 in 1999 are possibly due to the effect of stormwater discharge.

\subsubsection{Univariate Indices}

GLM ANOVA were performed on the univariate biological indices of total number of taxa (S) and individuals (N), Shannon-Weiner diversity index $\left(\mathrm{H}^{\prime}\right)$ (diversity), number of taxa of 
molluses $\left(\mathrm{S}_{\mathrm{m}}\right)$, polychaetes $\left(\mathrm{S}_{\mathrm{p}}\right)$ and arthropods $\left(\mathrm{S}_{\mathrm{a}}\right)$ and number of individuals of molluscs $\left(\mathrm{N}_{\mathrm{m}}\right)$, polychaetes $\left(\mathrm{N}_{\mathrm{p}}\right)$ and arthropods $\left(\mathrm{N}_{\mathrm{a}}\right)$ to determine if there were significant differences in each index between control and outlet sites in each area, between control and outlet stations and with distance and direction at each site (File: Univariate Indices ANOVA in Appendix IV).

\subsection{2.a Between control and outlet sites in an area}

Evans Bay

In 1998 significantly more total taxa, higher diversity, and more mollusc taxa and individuals occurred at EB-C than at EB-1 and EB-2, significantly more arthropod taxa and individuals at EB-C than at EB-1 and significantly more polychaete individuals at EB-C than EB-2 (File: Univariate indices ANOVA in Appendix IV). There was no significant difference in the number of total individuals and polychaete taxa between control and outlet sites.

In 1999 significantly more total taxa, higher diversity, more mollusc and arthropod taxa and arthropod individuals occurred at EB-C than at EB-1 and EB-2 and significantly more total individuals, polychaete and mollusc individuals occured at EB-C than EB-2 (File: Univariate indices ANOVA in Appendix IV). There was no significant difference in the number of polychaete individuals between control and outlet sites.

\section{Queens Wharf}

Significantly more mollusc taxa occurred at Q-C than at Q-1 and Q-2, significantly higher diversity and more total taxa occurred at Q-C than Q-1 and significantly more total and polychaete individuals occurred at Q-C than at Q-2 in 1998 (File: Univariate indices ANOVA in Appendix IV). There was no significant difference in the number of polychaete and arthropod taxa and arthropod and mollusc individuals between control and outlet sites.

\section{OPT}

Significantly more total and polychaete taxa and arthropod individuals and higher diversity occurred at AQ-C than at OPT with no significant difference in the other indices between the two sites. 
Aotea Quay

There were no significant differences in the univariate indices between AQ-C and AQ-1 and AQ-2 in 1998 whereas in 1999 there were significantly more total, polychaete and arthropod taxa and higher diversity at AQ-C than AQ-2 (File: Univariate indices ANOVA in Appendix IV).

The null hypothesis that there is no significant difference in each index $\left(\mathrm{S}, \mathbf{N}, \mathbf{H}^{\prime}, \mathbf{S}_{\mathrm{m}}, \mathrm{S}_{\mathrm{p}}\right.$, $S_{a}, N_{m}, N_{p}, N_{a}$ ) between an outlet site and associated control site is rejected. There is a significant difference in each index between at least one outlet and the associated control site. Where a significant difference occurred, there was a higher number of taxa, individuals and higher diversity at the control site than at the outlet site.

\subsection{2.a Between control and outlet stations}

Evans Bay

In 1998 there were significantly fewer total and arthropod taxa, lower diversity and fewer mollusc individuals at the 24 and 44 but not the $34 \mathrm{~m}$ stations, fewer arthropod individuals at the $44 \mathrm{~m}$ stations and fewer mollusc taxa at the 24, 34 and $44 \mathrm{~m}$ stations at EB-1 than at EBC (Table 5.4). In 1999 these differences were repeated for diversity and the number of arthropod taxa, whereas there were significantly fewer total taxa only at the $44 \mathrm{~m}$ stations, fewer arthropod individuals at the $24 \mathrm{~m}$ stations and fewer mollusc taxa at the 34 and $44 \mathrm{~m}$ stations at EB-1 than at EB-C.

At the EB-2 $24 \mathrm{~m}$ stations there were significantly fewer total and mollusc taxa and arthropod and mollusc individuals and lower diversity in 1998 and 1999, and fewer arthropod taxa in 1998, than at the $24 \mathrm{~m}$ stations at EB-C (Table 5.4). In 1998 there was also significantly lower diversity and fewer arthropod and molluse taxa at the $34 \mathrm{~m}$ stations, and fewer molluse taxa at the $44 \mathrm{~m}$ stations at EB-2 than at the comparable EB-C stations. In 1999 there were significantly fewer total and mollusc taxa and mollusc individuals and lower diversity at the 34 and $44 \mathrm{~m}$ stations and fewer arthropod taxa at the $44 \mathrm{~m}$ stations than at the comparable EB-C stations.

\section{Queens Wharf}

At the Q-1 $10 \mathrm{~m}$ stations there were significantly lower diversity and at the $20 \mathrm{~m}$ stations significantly fewer total and molluse taxa than at the comparable Q-C stations (Table 5.4). 
Table 5.4: Significant differences in each index between outlet and control stations at each distance. Distances: $\mathrm{AQ}$ and $\mathrm{Q}-1=10 \mathrm{~m}, 2=20 \mathrm{~m}, 3=30 \mathrm{~m}, \mathrm{~EB}-1=24 \mathrm{~m}, 2=34 \mathrm{~m}, 3=44 \mathrm{~m}$. $\mathrm{S}$-number of total taxa, $\mathrm{N}$ - number of Total lndividuals, $\mathrm{H}^{\prime}$ - Shannon-Weiner Diversity $\mathrm{S}_{\mathrm{a}}$ - number of arthropod taxa, $\mathrm{S}_{\mathrm{m}}$ - number of mollusc taxa, $\mathrm{S}_{\mathrm{p}}$ - number of polychaete taxa $\mathrm{N}_{\mathrm{a}}$ - no. of arthropod individuals, $\mathrm{N}_{\mathrm{m}}$ - no. of mollusc individuals, $\mathrm{N}_{\mathrm{p}}$ - no. of polychaete individuals

\begin{tabular}{|c|c|c|c|c|c|c|}
\hline & \multicolumn{3}{|c|}{1998} & \multicolumn{3}{|c|}{1999} \\
\hline & \multicolumn{3}{|c|}{ Distance } & \multicolumn{3}{|c|}{ Distance } \\
\hline & 1 & 2 & 3 & 1 & 2 & 3 \\
\hline $\mathrm{S}$ & $\begin{array}{l}\text { EB-C }>\text { EB-1 } \\
E B-C>E B-2\end{array}$ & Q-C $>$ Q-1 & $\begin{array}{l}\mathrm{EB}-\mathrm{C}>\mathrm{EB}-1 \\
\mathrm{AQ}-\mathrm{C}>\mathrm{AQ}-2\end{array}$ & $\mathrm{~EB}-\mathrm{C}>\mathrm{EB}-2$ & $\begin{array}{l}\mathrm{EB}-\mathrm{C}>\mathrm{EB}-2 \\
\mathrm{AQ}-\mathrm{C}>\mathrm{AQ}-2\end{array}$ & $\begin{array}{l}\text { EB-C }>\text { EB-1 } \\
\text { EB-C }>\text { EB-2 }\end{array}$ \\
\hline $\mathbf{N}$ & $\begin{array}{c}\mathrm{AQ}-2>\mathrm{AQ}-\mathrm{C} \\
\mathrm{Q}-\mathrm{C}>\mathrm{Q}-2\end{array}$ & & & & & \\
\hline $\mathbf{H}^{\prime}$ & $\begin{array}{c}\text { EB-C }>\text { EB-1 } \\
\text { EB-C }>\text { EB-2 } \\
\text { Q-C }>\text { Q-1 } \\
\text { AQ-2 }>\text { AQ-C }\end{array}$ & $\begin{array}{c}\text { EB-C }>\text { EB-2 } \\
\text { Q- }>\text { Q-C }\end{array}$ & EB-C $>$ EB-1 & $\begin{array}{l}\text { EB-C }>\text { EB-1 } \\
\text { EB-C }>\text { EB-2 }\end{array}$ & EB-C $>$ EB-2 & $\begin{array}{l}\text { EB-C }>\text { EB-1 } \\
\text { EB-C }>\text { EB-2 }\end{array}$ \\
\hline$S_{p}$ & & & & $\mathrm{AQ}-\mathrm{C}>\mathrm{AQ}-2$ & & \\
\hline $\mathbf{N}_{p}$ & $\begin{array}{c}\mathrm{Q}-\mathrm{C}>\mathrm{Q}-2 \\
\mathrm{AQ}-2>\mathrm{AQ}-\mathrm{C}\end{array}$ & & & & & \\
\hline $\mathrm{S}_{\mathrm{a}}$ & $\begin{array}{l}\mathrm{EB}-\mathrm{C}>\mathrm{EB}-1 \\
\mathrm{~EB}-\mathrm{C}>\mathrm{EB}-2\end{array}$ & $\mathrm{~EB}-\mathrm{C}>\mathrm{EB}-2$ & EB-C $>$ EB-1 & $\mathrm{EB}-\mathrm{C}>\mathrm{EB}-1$ & & $\begin{array}{l}\text { EB-C }>\text { EB-1 } \\
\text { EB-C }>\text { EB-2 }\end{array}$ \\
\hline $\mathbf{N}_{\mathrm{a}}$ & $\mathrm{EB}-\mathrm{C}>\mathrm{EB}-2$ & $\mathrm{AQ}-2>\mathrm{AQ}-\mathrm{C}$ & $\begin{array}{l}\mathrm{EB}-\mathrm{C}>\mathrm{EB}-1 \\
\mathrm{AQ}-1>\mathrm{AQ}-\mathrm{C}\end{array}$ & $\begin{array}{l}\text { EB-C }>\text { EB-1 } \\
\text { EB-C }>\text { EB-2 }\end{array}$ & & \\
\hline$S_{m}$ & $\begin{array}{l}\text { EB-C }>\text { EB-1 } \\
\text { EB-C }>\text { EB-2 }\end{array}$ & $\begin{array}{c}\mathrm{EB}-\mathrm{C}>\mathrm{EB}-1 \\
\mathrm{~EB}-\mathrm{C}>\mathrm{EB}-2 \\
\mathrm{Q}-\mathrm{C}>\mathrm{Q}-1\end{array}$ & $\begin{array}{l}\mathrm{EB}-\mathrm{C}>\mathrm{EB}-1 \\
\mathrm{~EB}-\mathrm{C}>\mathrm{EB}-2 \\
\mathrm{AQ}-\mathrm{C}>\mathrm{AQ}-2\end{array}$ & $\mathrm{~EB}-\mathrm{C}>\mathrm{EB}-2$ & $\begin{array}{l}\text { EB-C }>\text { EB-1 } \\
\text { EB-C }>\text { EB-2 }\end{array}$ & $\begin{array}{l}\text { EB-C }>\text { EB-1 } \\
\text { EB-C }>\text { EB-2 }\end{array}$ \\
\hline $\mathbf{N}_{\mathbf{m}}$ & $\begin{array}{l}\mathrm{EB}-\mathrm{C}>\mathrm{EB}-1 \\
\mathrm{~EB}-\mathrm{C}>\mathrm{EB}-2\end{array}$ & $\mathrm{Q}-2>\mathrm{Q}-\mathrm{C}$ & $\begin{array}{l}\mathrm{EB}-\mathrm{C}>\mathrm{EB}-1 \\
\mathrm{AQ}-\mathrm{C}>\mathrm{AQ}-2\end{array}$ & $\mathrm{~EB}-\mathrm{C}>\mathrm{EB}-2$ & $\mathrm{~EB}-\mathrm{C}>\mathrm{EB}-2$ & $\mathrm{~EB}-\mathrm{C}>\mathrm{EB}-2$ \\
\hline
\end{tabular}


At the Q-2 $10 \mathrm{~m}$ stations there were significantly fewer total and polychaete individuals while at the $20 \mathrm{~m}$ stations there was significantly higher diversity and mollusc individuals than at the comparable Q-C stations (Table 5.4).

\section{Aotea Quay}

-In 1998 there were significantly more arthropod individuals at the AQ-1 $30 \mathrm{~m}$ stations, significantly higher diversity and more total and polychaete individuals at AQ-2 $10 \mathrm{~m}$ stations and more arthropod individuals at AQ-2 $20 \mathrm{~m}$ stations, than at the associated AQ-C stations. However, significantly more total and mollusc taxa and mollusc individuals occurred at the AQ-C $30 \mathrm{~m}$ stations than at the AQ-2 $30 \mathrm{~m}$ stations (Table 5.4). In 1999 there were significantly fewer polychaete taxa at the AQ-2 $10 \mathrm{~m}$ stations and fewer total taxa at the AQ-2 $20 \mathrm{~m}$ stations than at the associated AQ-C stations.

The null hypothesis that there is no significant difference in each index $\left(\mathrm{S}, \mathbf{N}, \mathbf{H}^{\prime}, \mathbf{S}_{\mathrm{m}}, \mathbf{S}_{\mathbf{p}}\right.$, $\mathbf{S}_{\mathrm{a}}, \mathbf{N}_{\mathrm{m}}, \mathbf{N}_{\mathrm{p}}, \mathbf{N}_{\mathrm{a}}$ ) between outlet and control stations is rejected. There was a significant difference in each index between at least one outlet and associated control site station. All significant differences in an index between outlet and control stations in Evans Bay and Queens Wharf (Q-1 only) resulted from a lower number of taxa, individuals or diversity at the outlet than associated control stations. At Q-2 and Aotea Quay some of the significant differences resulted from a higher number of taxa, individuals or diversity at the outlet than associated control stations. The differences in each index between outlet and control stations changed over time.

\subsection{2.c With distance from the shore or an outlet (Figs. 5.11, 5.12, 5.13)}

\section{Evans Bay}

At EB-C there were significant differences in the number of mollusc taxa in 1998 and arthropod taxa and individuals in 1998 and 1999, but no significant differences in the number of total and polychaete taxa, total, polychaete and mollusc individuals and diversity in 1998 and 1999 with distance from the shore (Tables 5.5 and 5.6). Thus, any significant difference in the number of total and polychaete taxa, total, polychaete and mollusc individuals and diversity in 1998 and 1999, and in the number of mollusc taxa in 1999 with distance from an outlet in this area could be due to the effect of stormwater discharge 

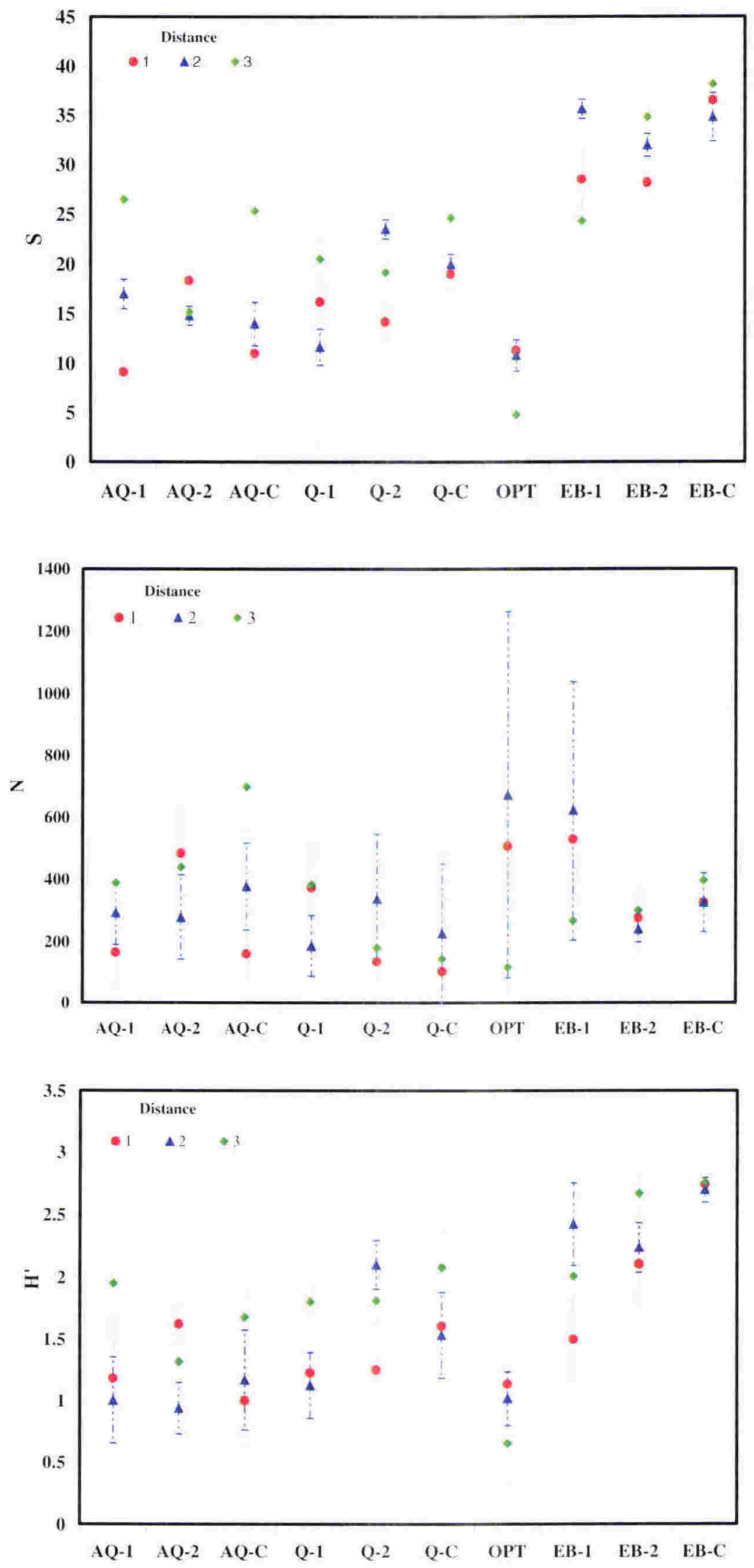

Figure 5.11: Mean ( $\pm 95 \% \mathrm{CI})$ of the number of Total taxa (S) and Total individuals (N) and Shannon-Weiner diversity $\left(\mathrm{H}^{\prime}\right)$ at each site in 1998 EB sites: Distance $1=24 \mathrm{~m}, 2=34 \mathrm{~m}, 3=44 \mathrm{~m}$ $\mathrm{AQ}$ and $\mathrm{Q}$ sites: Distance $\mathrm{I}=10 \mathrm{~m}, 2=20 \mathrm{~m}, 3=30 \mathrm{~m}$ OPT: Distance $1=15 \mathrm{~m}, 2=30 \mathrm{~m}, 3=45 \mathrm{~m}$ 

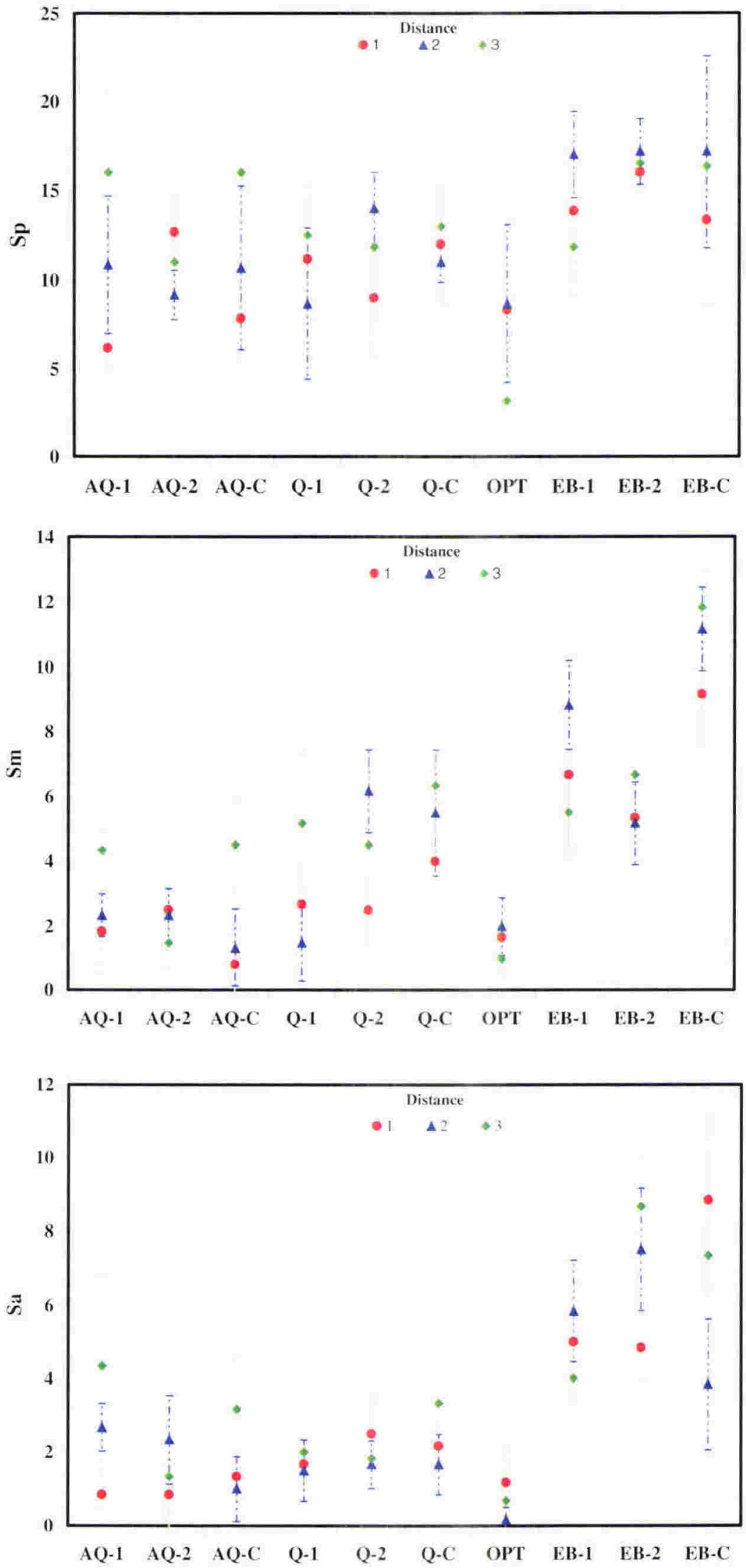

Figure 5.12: Mean $( \pm 95 \% \mathrm{CI})$ number of polychaete taxa $\left(\mathrm{S}_{\mathrm{p}}\right)$, mollusc taxa $\left(\mathrm{S}_{\mathrm{m}}\right)$ and arthropod taxa $\left(\mathrm{S}_{\mathrm{a}}\right)$ at each site in 1998.

EB sites: Distance I $=24 \mathrm{~m}, 2=34 \mathrm{~m}, 3=44 \mathrm{~m}$

$\mathrm{AQ}$ and $\mathrm{Q}$ sites: Distance $1=10 \mathrm{~m}, 2=20 \mathrm{~m}, 3=30 \mathrm{~m}$

OPT: Distance $\mathrm{I}=15 \mathrm{~m}, 2=30 \mathrm{~m}, 3=45 \mathrm{~m}$ 

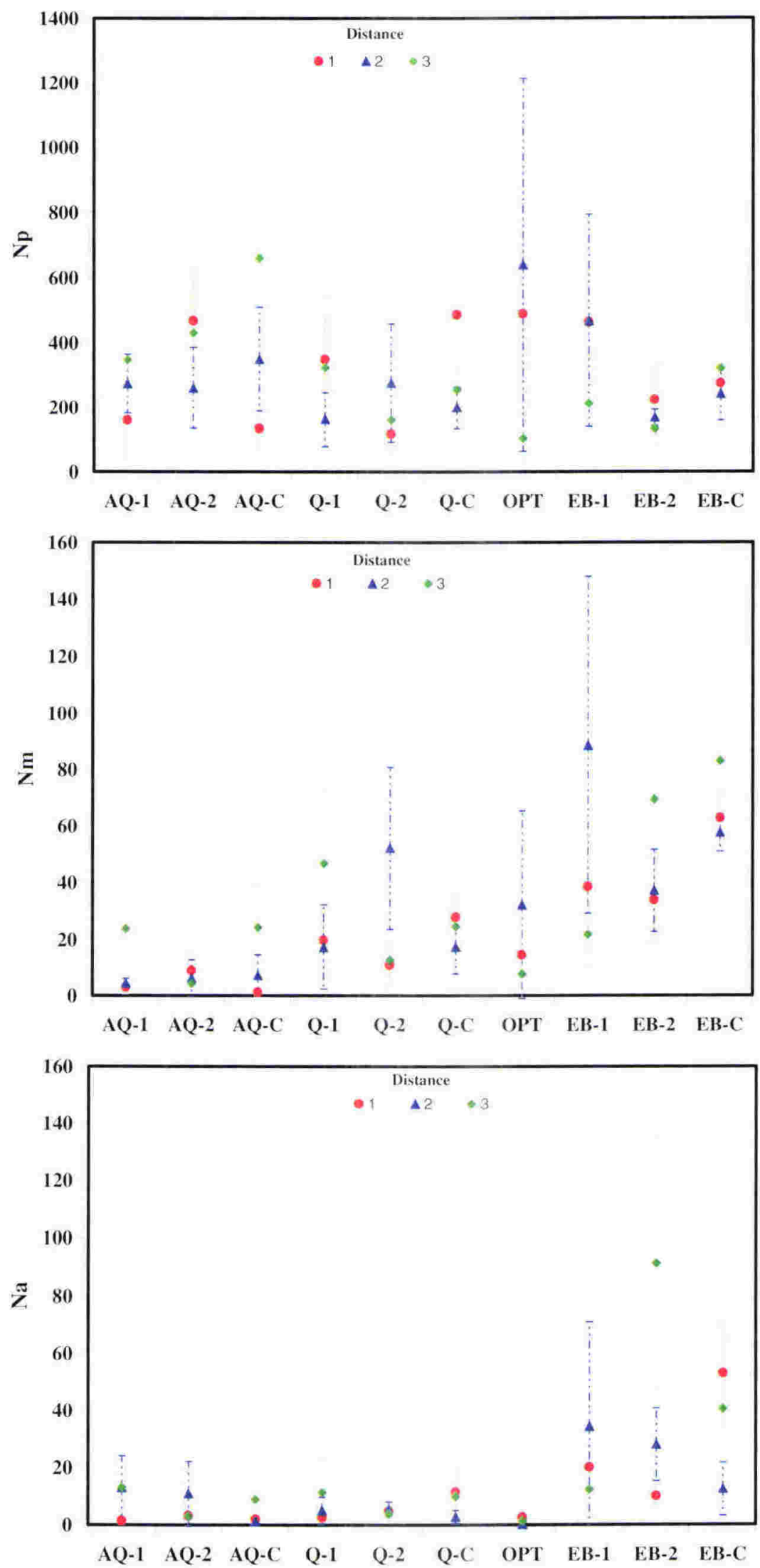

Figure 5.13: Mean $( \pm 95 \% \mathrm{CI})$ number of polychaete individuals $\left(\mathrm{N}_{\mathrm{p}}\right)$, molluse individuals $\left(\mathrm{N}_{\mathrm{m}}\right)$ and arthropod individuals ( $\mathrm{Na}$ ) at each site in 1998

EB sites: Distance $1=24 \mathrm{~m}, 2=34 \mathrm{~m}, 3=44 \mathrm{~m}$

$\mathrm{AQ}$ and $\mathrm{Q}$ sites: Distance $1=10 \mathrm{~m}, 2=20 \mathrm{~m}, 3=30 \mathrm{~m}$

OPT: Distance $\mathrm{I}=15 \mathrm{~m}, 2=30 \mathrm{~m}, 3=45 \mathrm{~m}$ 


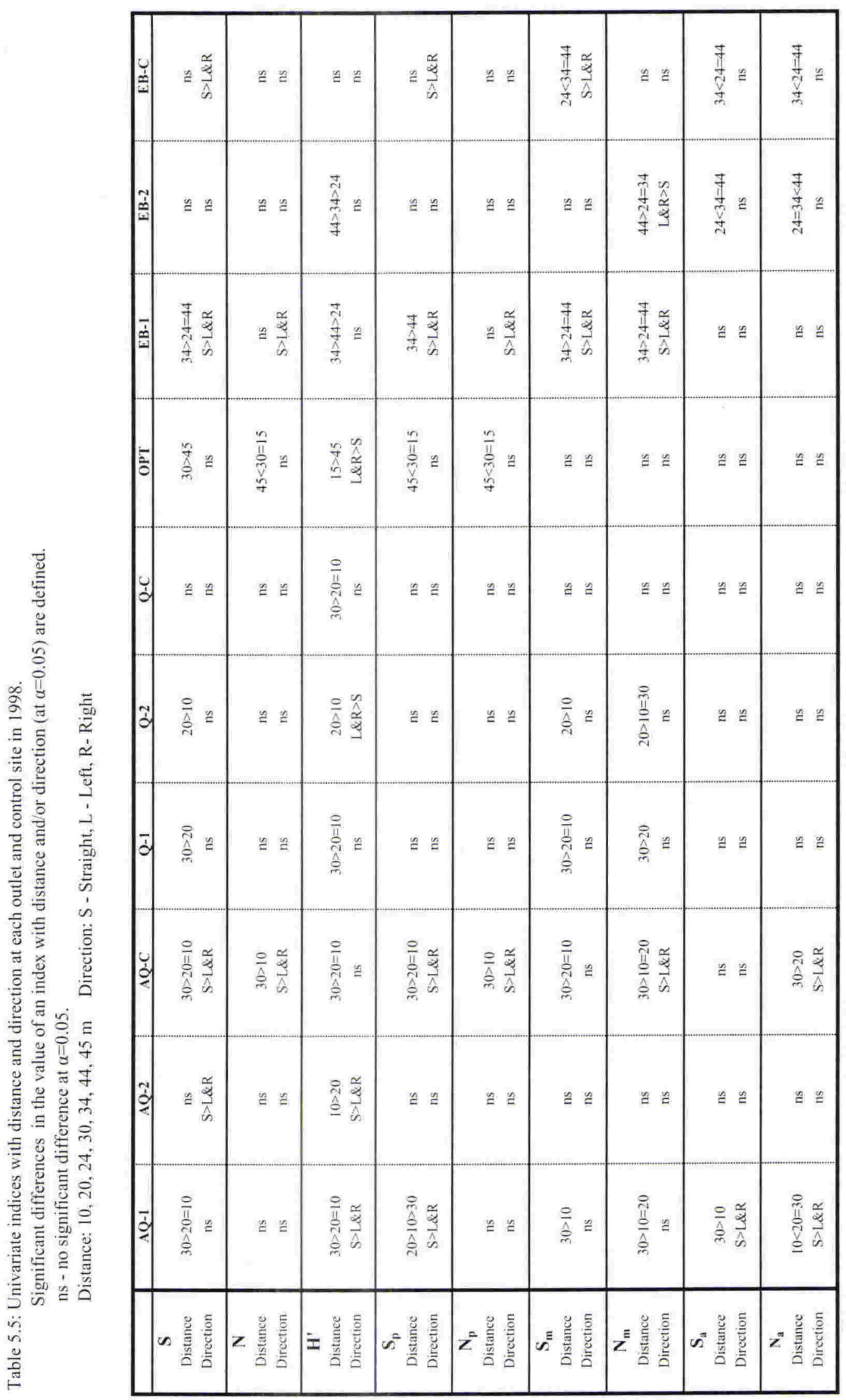


At EB-1 there were significant differences in number of total and polychaete taxa, mollusc individuals and diversity in 1998 and total taxa in 1999 with distance from the outlet. For these indices, values were significantly higher at the $34 \mathrm{~m}$ than at one or other or both the 24 and $44 \mathrm{~m}$ stations. There was no significant difference in the number of total and mollusc taxa between the 24 and $44 \mathrm{~m}$ stations but significantly higher diversity at the 44 than the 24 $\mathrm{m}$ stations in 1998. At EB-2 there was a significant increase in diversity with increasing distance from the outlet and significantly more mollusc taxa at the 44 than the 24 and $34 \mathrm{~m}$ stations in 1998.

Queens Wharf

At Q-C there was only a significant difference in diversity with distance from the shore (Table 5.5). Therefore, any significant difference in the number of total polychaete, mollusc and arthropod taxa, total, polychaete, mollusc and arthropod individuals with distance from an outlet in this area could be due to the effect of stormwater discharge.

At outlets Q-1 and Q-2 there was a significant difference in the number of total and molluse taxa and molluse individuals with distance from each outlet. At Q-1 significantly higher values of each of these indices occurred at the $30 \mathrm{~m}$ than at $20 \mathrm{~m}$ stations while at Q-2 they occurred at the $20 \mathrm{~m}$ than at the $10 \mathrm{~m}$ stations.

\section{OPT}

At OPT there were significantly fewer total and polychaete individuals, total and polychaete taxa and there was lower diversity at the $45 \mathrm{~m}$ than at one or other or both the 15 and $30 \mathrm{~m}$ stations.

\section{Aotea Quay}

At AQ-C there were significant differences in the value of all indices, except the number of arthropod taxa in 1998 and diversity in 1999, with distance from the shore (Tables 5.5 and 5.6). Therefore, any significant difference in the number of arthropod taxa in 1998 and diversity in 1999 with distance from an outlet in this area could be due to the effect of stormwater discharge. 
Table 5.6: Univariate indices with distance and direction at each outlet and control site in 1999.

Significant differences in the value of an index with distance and/or direction $(\alpha=0.05)$ are defined. ns - no significant difference at $\alpha=0.05$.

Distance: 10, 20, 30, 24, 34, 44 m Direction: S - Straight, L - Left, R - Right

\begin{tabular}{|c|c|c|c|c|c|}
\hline & AQ-2 & $\mathrm{AQ}-\mathrm{C}$ & EB-1 & EB-2 & EB-C \\
\hline $\begin{array}{c}\mathbf{S} \\
\text { Distance } \\
\text { Direction }\end{array}$ & $\begin{array}{l}\mathrm{ns} \\
\mathrm{ns}\end{array}$ & $\begin{array}{l}\text { ns } \\
\text { ns }\end{array}$ & $\begin{array}{c}34>44 \\
S>L \& R \\
\end{array}$ & $\begin{array}{l}\mathrm{ns} \\
\mathrm{ns}\end{array}$ & $\begin{array}{l}\text { ns } \\
\text { ns }\end{array}$ \\
\hline $\begin{array}{c}\mathbf{N} \\
\text { Distance } \\
\text { Direction } \\
\end{array}$ & $\begin{array}{l}\mathrm{ns} \\
\mathrm{ns}\end{array}$ & $\begin{array}{l}\text { ns } \\
\text { ns }\end{array}$ & $\begin{array}{l}\text { ns } \\
\text { ns }\end{array}$ & $\begin{array}{l}\mathrm{ns} \\
\mathrm{ns}\end{array}$ & $\begin{array}{l}\text { ns } \\
\text { ns }\end{array}$ \\
\hline $\begin{array}{c}\mathbf{H}^{\prime} \\
\text { Distance } \\
\text { Direction }\end{array}$ & $\begin{array}{c}30>20=10 \\
\text { ns }\end{array}$ & $\begin{array}{l}\text { ns } \\
\text { ns }\end{array}$ & $\begin{array}{l}\text { ns } \\
\text { ns }\end{array}$ & $\begin{array}{l}\text { ns } \\
\text { ns }\end{array}$ & $\begin{array}{l}\mathrm{ns} \\
\mathrm{ns}\end{array}$ \\
\hline $\begin{array}{c}\mathbf{S}_{\mathrm{p}} \\
\text { Distance } \\
\text { Direction }\end{array}$ & $\begin{array}{l}\text { ns } \\
\text { ns }\end{array}$ & $\begin{array}{c}\text { ns } \\
S>L \& R\end{array}$ & $\begin{array}{l}\text { ns } \\
\text { ns }\end{array}$ & $\begin{array}{l}\text { ns } \\
\text { ns }\end{array}$ & $\begin{array}{c}\text { ns } \\
\mathrm{S}>\mathrm{L} \& \mathrm{R} \\
\end{array}$ \\
\hline $\begin{array}{c}\mathbf{N}_{\mathrm{p}} \\
\text { Distance } \\
\text { Direction }\end{array}$ & $\begin{array}{l}\text { ns } \\
\text { ns }\end{array}$ & $\begin{array}{l}\mathrm{ns} \\
\mathrm{ns}\end{array}$ & $\begin{array}{l}\text { ns } \\
\text { ns }\end{array}$ & $\begin{array}{l}\mathrm{ns} \\
\mathrm{ns}\end{array}$ & $\begin{array}{l}\text { ns } \\
\text { ns }\end{array}$ \\
\hline $\begin{array}{c}\mathbf{S}_{\mathbf{m}} \\
\text { Distance } \\
\text { Direction }\end{array}$ & $\begin{array}{l}\mathrm{ns} \\
\mathrm{ns}\end{array}$ & $\begin{array}{l}\text { ns } \\
\text { ns }\end{array}$ & $\begin{array}{l}\mathrm{ns} \\
\mathrm{ns}\end{array}$ & $\begin{array}{l}\text { ns } \\
\text { ns }\end{array}$ & $\begin{array}{l}\mathrm{ns} \\
\mathrm{ns}\end{array}$ \\
\hline $\begin{array}{c}\qquad \mathbf{N}_{\mathbf{m}} \\
\text { Distance } \\
\text { Direction }\end{array}$ & $\begin{array}{l}\mathrm{ns} \\
\mathrm{ns}\end{array}$ & $\begin{array}{l}\mathrm{ns} \\
\mathrm{ns}\end{array}$ & $\begin{array}{l}\mathrm{ns} \\
\mathrm{ns}\end{array}$ & $\begin{array}{l}\text { ns } \\
\text { ns }\end{array}$ & $\begin{array}{c}n s \\
L \& R>S \\
\end{array}$ \\
\hline $\begin{array}{c}\mathbf{S}_{\mathrm{a}} \\
\text { Distance } \\
\text { Direction }\end{array}$ & $\begin{array}{l}\text { ns } \\
\text { ns }\end{array}$ & $\begin{array}{l}\text { ns } \\
\text { ns }\end{array}$ & $\begin{array}{l}\text { ns } \\
\text { ns }\end{array}$ & $\begin{array}{l}\text { ns } \\
\text { ns }\end{array}$ & $\begin{array}{c}24=44>34 \\
\text { ns }\end{array}$ \\
\hline $\begin{array}{c}\mathbf{N}_{\mathrm{a}} \\
\text { Distance } \\
\text { Direction }\end{array}$ & $\begin{array}{l}\text { ns } \\
\text { ns }\end{array}$ & $\begin{array}{l}\text { ns } \\
\text { ns }\end{array}$ & $\begin{array}{l}\mathrm{ns} \\
\mathrm{ns}\end{array}$ & $\begin{array}{l}\text { ns } \\
\text { ns }\end{array}$ & $\begin{array}{c}24>34-44 \\
\text { ns }\end{array}$ \\
\hline
\end{tabular}

At AQ-1 in 1998 there were significantly more arthropod taxa at the $30 \mathrm{~m}$ than the $10 \mathrm{~m}$ stations and at AQ-2 in 1999 there was significantly higher diversity at the $30 \mathrm{~m}$ than at the 10 and $20 \mathrm{~m}$ stations.

The null hypothesis that there is no significant difference in each index $\left(\mathrm{S}, \mathbf{N}, \mathbf{H}^{\prime}, \mathbf{S}_{\mathrm{m}}, \mathbf{S}_{\mathrm{p}}\right.$, $\mathrm{S}_{\mathrm{a}}, \mathbf{N}_{\mathrm{m}}, \mathbf{N}_{\mathrm{p}}, \mathbf{N}_{\mathrm{a}}$ ) with distance from an outlet is rejected. There are significant differences 
in the number of total, polychaete, arthropod and mollusc taxa, polychaete and mollusc individuals and diversity with distance from at least one outlet.

\subsection{2.d With direction from the shore or an outlet}

Significant differences in the value of an index with direction at an outlet site but not at the associated control site could be due to stormwater discharge or the influence of wharf or marina structures or other disturbance activities such as shipping.

\section{Evans Bay}

At EB-1 there were significantly more total, polychaete and mollusc individuals in 1998 and more total taxa in 1999 on the straight than on the left/right transects and at EB-2 there were significantly more molluse individuals on the left/right than the straight transect in 1998 . Direction effects did not occur for these indices at EB-C. However, direction effects occurred at both outlet and control sites for the number of total, polychaete and mollusc taxa in 1998 and at the control site only for the number of polychaete and mollusc taxa in 1999 (Tables 5.5 and 5.6).

Queens Wharf

Significantly higher diversity occurred on the left/right than the straight transect at Q-2.

OPT

Significantly higher diversity occurred on the left/right than the straight transect.

\section{Aotea Quay}

At AQ-1 there was significantly higher diversity and more arthropod taxa and at AQ-2 significantly higher diversity on the straight than on the left/right transects in 1998. Direction effects did not occur for these indices at AQ-C. However, direction effects occurred at both outlet and control sites for the number of total and polychaete taxa and arthropod individuals in 1998 and at the control site only for the number of total, polychaete and mollusc individuals in 1998 and polychaete taxa in 1999 (Tables 5.5 and 5.6).

The null hypothesis that there is no significant difference in each index $\left(\mathrm{S}, \mathbf{N}, \mathbf{H}^{*}, \mathbf{S}_{\mathrm{m}}, \mathrm{S}_{\mathrm{p}}\right.$, $\mathbf{S}_{\mathrm{a}}, \mathbf{N}_{\mathrm{m}}, \mathbf{N}_{\mathrm{p}}, \mathbf{N}_{\mathrm{a}}$ ) with direction from an outlet is rejected. There are significant differences 
in the number of total and arthropod taxa, total, polychaete and molluse individuals and diversity with direction at, at least one outlet site.

\subsubsection{Patterns of Taxon Abundance}

The taxa selected for analysis were those identified in the SIMPER analyses (used to identify the taxa that contributed most to the differences between control and outlet sites in an area) and/or the most abundant taxa within an area and/or taxa having sufficient numbers with distance and/or taxa having sufficient numbers at all sites in an area. Because of differences in the biological community between areas, different taxa were selected in each area. ANOVA was then carried out to determine if there were significant differences in taxa abundance between outlet and control stations in an area and with distance and direction from an outlet or a point on the shore.

\subsection{3.a Evans Bay}

Comparison of taxon abundance at outlet and control sites

In Evans Bay, the bivalves Corbula zelandica and Tawera spissa were common at the control site but absent at both outlet sites. The bivalves Gari stangeri, Leptomya retiaria, Nucula hartvigiana, the gastropods Notoacmea helmsi, Caecum digitatum, the echinoderm Trochodota dendyi, the copepods Stephos spp., the amphipods Melita spp. and Ventojassa sp., the polychaetes Caraziella philipensis, Goniadid sp., Hemipodus simplex, Hesionid sp.A, Prionospio spp., Sphaerosyllis sp.A and Sphaerosyllis sp.B, and the coelenterate Scolanthus sp. were all at least twice as abundant at the control than the outlet sites (Table 5.7; File: EB species in Appendix IV). Species at least twice as abundant at the outlet than at the control sites were the bivalves Dosina zelandica and Macomona liliana, the crab Macrophthalmus hirtipes, the amphipods Proharpinia spp., Meridiolembos sp. and Corophium acherusicum and the polychaetes Capitella spp. and Heteromastus filiformis.

\section{Comparison of taxon abundance at outlet and control stations}

Of the taxa analysed using GLM ANOVA there were significant differences in the abundance of 27 taxa in 1998 and 23 taxa in 1999 between control and outlet stations. On both sampling occasions Gari stangeri, Amphiura sp., Armandia maculata, Hemipodus simplex, Owenia fusiformis, Prionospio spp., Schistomeringos loveni?, Hesionid sp.A and Exogone sp.A were more abundant at control site than outlet site stations, whereas Proharpinia spp., Capitella sp., Glycinde dorsalis, Heteromastus filiformis and Prionospio 
yuriel were more abundant at outlet site than control site stations (Tables 5.8 and 5.9). For the remaining taxa their abundance at some stations was higher at an outlet than at the control site, but at other stations was higher at the control site than at an outlet site.

Table 5.7: Mean abundance of taxa contributing $\geq 2.5 \%$ to faunal dissimilarity between outlet and control sites in Evans Bay

Groups : P - Polychaetes, A-Arthropods, B - Bivalves

Number of samples at each site: $1998 \mathrm{~N}=18, \quad 1999 \mathrm{~N}=21$

\begin{tabular}{|lrrrrrr:r|r|}
\hline Taxon & Group & \multicolumn{2}{c}{ EB-1 } & \multicolumn{2}{c|}{ EB-2 } & \multicolumn{2}{c|}{ EB-C } \\
\hline Corbula zelandica & & $\mathbf{1 9 9 8}$ & $\mathbf{1 9 9 9}$ & $\mathbf{1 9 9 8}$ & $\mathbf{1 9 9 9}$ & $\mathbf{1 9 9 8}$ & $\mathbf{1 9 9 9}$ \\
Gari stangeri & $\mathrm{B}$ & 0.00 & 0.00 & & 0.00 & 0.00 & 9.86 & 8.46 \\
Macomona liliana & $\mathrm{B}$ & 1.06 & 0.19 & 2.71 & 0.08 & 11.00 & 6.75 \\
Proharpinia spp. & $\mathrm{B}$ & 12.39 & 14.86 & 22.52 & 1.33 & 1.48 & 0.58 \\
Stephos spp. & $\mathrm{A}$ & 10.67 & 3.19 & 1.05 & 1.13 & 0.10 & 0.50 \\
Armandia maculata & $\mathrm{A}$ & 0.22 & 0.48 & 0.57 & 2.50 & 14.71 & 12.08 \\
Barantolla sp. & $\mathrm{P}$ & 35.67 & 5.29 & 3.57 & 0.38 & 31.86 & 15.54 \\
Caraziella phillipensis & $\mathrm{P}$ & $\mathrm{P}$ & 0.61 & 51.62 & 77.43 & 48.04 & 58.90 & 42.00 \\
Exogone sp.A & $\mathrm{P}$ & 3.33 & 3.48 & 0.05 & 0.08 & 6.76 & 12.13 \\
Hemipodus simplex & $\mathrm{P}$ & 1.61 & 2.57 & 0.52 & 0.38 & 11.86 & 14.13 \\
Heteromastus filiformis & $\mathrm{P}$ & 13.83 & 4.67 & 5.33 & 5.54 & 17.00 & 14.17 \\
Owenia fusiformis & $\mathrm{P}$ & 1.39 & 2.48 & 5.90 & 6.67 & 0.33 & 0.21 \\
Prionospio aucklandica & $\mathrm{P}$ & 226.39 & 48.81 & 48.57 & 2.50 & 7.57 & 9.25 \\
Prionospio spp. & $\mathrm{P}$ & 4.44 & 2.67 & 1.52 & 2.00 & 39.43 & 8.04 \\
Schistomeringos loveni? & $\mathrm{P}$ & 3.33 & 2.14 & 0.00 & 0.08 & 20.62 & 15.29 \\
Oligochaete spp. & $\mathrm{P}$ & 11.78 & 15.00 & 2.19 & 1.08 & 7.52 & 9.96 \\
& & & & & & 7.86 & 6.42 \\
\hline
\end{tabular}

\section{Taxon abundance with distance and direction}

At Evans Bay the effect of distance and direction on the abundance of 28 taxa in 1998 and 25 taxa in 1999 was investigated (Table 5.10). At EB-C there was a significant difference in the abundance of 12 taxa in 1998 and 13 taxa in 1999 with distance from the shore. Of the taxa whose abundance did not change significantly with distance from the shore at the control site, the abundance of the polychaetes Capitella spp., Exogone sp.A., Hesionid sp.A., Heteromastus filiformis, Ophiodromus sp., Owenia fusiformis, Prionospio aucklandica and Prionospio yuriel, and the amphipods Proharpinia spp., Meridiolembos sp. and Corophium acherusicum changed significantly with distance from an outlet.

At EB-1 the abundance of Capitella spp., Ophiodromus sp., Proharpinia spp. and Prionospio aucklandica decreased with increasing distance from the outlet. Owenia fusiformis and Heteromastus filiformis (1998) were significantly more abundant at the $34 \mathrm{~m}$ than the 24 and $44 \mathrm{~m}$ stations whereas Exogone sp. A was more abundant at the 34 than 44 
Table 5.8: Taxa with a significant difference in abundance between outlet and control at each distance (m), Evans Bay sites, November 1998

Outlets: EB-1, EB-2, Control: EB-C

Groups: B - Bivalve Mollusc, E-Echinoderm, A-Arthropod, P-Polychaete

\begin{tabular}{|c|c|c|c|c|}
\hline & & & Distance (m) & \\
\hline Taxa & Group & 24 & 34 & 44 \\
\hline Arthritica bifurca & B & $\mathrm{EB}-1>\mathrm{EB}-\mathrm{C}$ & & \\
\hline Dosina zelandica & B & & $\begin{array}{l}\mathrm{EB}-\mathrm{I}>\mathrm{EB}-\mathrm{C} \\
\mathrm{EB}-2>\mathrm{EB}-\mathrm{C}\end{array}$ & EB-2>EB-C \\
\hline Gari stangeri & B & $\begin{array}{l}\mathrm{EB}-\mathrm{C}>\mathrm{EB}-1 \\
\mathrm{~EB}-\mathrm{C}>\mathrm{EB}-2\end{array}$ & $\begin{array}{l}\mathrm{EB}-\mathrm{C}>\mathrm{EB}-1 \\
\mathrm{~EB}-\mathrm{C}>\mathrm{EB}-2\end{array}$ & $\mathrm{~EB}-\mathrm{C}>\mathrm{EB}-\mathrm{I}$ \\
\hline Trochodota dendyi & $\mathrm{E}$ & & EB-I $>$ EB-C & $\begin{array}{l}\mathrm{EB}-\mathrm{C}>\mathrm{EB}-1 \\
\mathrm{~EB}-\mathrm{C}>\mathrm{EB}-2\end{array}$ \\
\hline Amphiura sp. & $\mathrm{E}$ & & $\mathrm{EB}-\mathrm{C}>\mathrm{EB}-2$ & \\
\hline Callianassa filholi & A & $\begin{array}{l}\mathrm{EB}-\mathrm{C}>\mathrm{EB}-1 \\
\mathrm{~EB}-2>\mathrm{EB}-\mathrm{C}\end{array}$ & $\mathrm{EB}-2>\mathrm{EB}-\mathrm{C}$ & $\begin{array}{l}\mathrm{EB}-\mathrm{C}>\mathrm{EB}-1 \\
\mathrm{~EB}-2>\mathrm{EB}-\mathrm{C}\end{array}$ \\
\hline Proharpinia spp. & A & $\mathrm{EB}-\mathrm{I}>\mathrm{EB}-\mathrm{C}$ & $\mathrm{EB}-\mathrm{I}>\mathrm{EB}-\mathrm{C}$ & EB-I $>$ EB-C \\
\hline Melita spp. & A & $\begin{array}{l}\mathrm{EB}-\mathrm{C}>\mathrm{EB}-1 \\
\mathrm{~EB}-\mathrm{C}>\mathrm{EB}-2\end{array}$ & $\begin{array}{l}\mathrm{EB}-\mathrm{C}>\mathrm{EB}-1 \\
\mathrm{~EB}-\mathrm{C}>\mathrm{EB}-2\end{array}$ & $\begin{array}{l}\mathrm{EB}-\mathrm{C}>\mathrm{EB}-1 \\
\mathrm{~EB}-\mathrm{C}>\mathrm{EB}-2\end{array}$ \\
\hline Corophium acherusium & A & & & $\mathrm{EB}-2>\mathrm{EB}-\mathrm{C}$ \\
\hline Meridiolembos sp. & A & $\mathrm{EB}-2>\mathrm{EB}-\mathrm{C}$ & $\mathrm{EB}-2>\mathrm{EB}-\mathrm{C}$ & $\mathrm{EB}-2>\mathrm{EB}-\mathrm{C}$ \\
\hline Armandia maculata & $\mathrm{P}$ & $\mathrm{EB}-\mathrm{C}>\mathrm{EB}-2$ & $\mathrm{~EB}-\mathrm{C}>\mathrm{EB}-2$ & $\mathrm{~EB}-\mathrm{C}>\mathrm{EB}-2$ \\
\hline Baramtella sp. & $\mathrm{P}$ & $\mathrm{EB}-2>\mathrm{EB}-\mathrm{C}$ & & $\begin{array}{l}\mathrm{EB}-\mathrm{I}>\mathrm{EB}-\mathrm{C} \\
\mathrm{EB}-2>\mathrm{EB}-\mathrm{C}\end{array}$ \\
\hline Capitella spp. & $\mathrm{P}$ & $\begin{array}{l}\mathrm{EB}-1>\mathrm{EB}-\mathrm{C} \\
\mathrm{EB}-2>\mathrm{EB}-\mathrm{C}\end{array}$ & $\begin{array}{l}\mathrm{EB}-\mathrm{I}>\mathrm{EB}-\mathrm{C} \\
\mathrm{EB}-2>\mathrm{EB}-\mathrm{C}\end{array}$ & $\mathrm{EB}-1>\mathrm{EB}-\mathrm{C}$ \\
\hline Glycinde dorsalis & $\mathrm{P}$ & $\mathrm{EB}-2>\mathrm{EB}-\mathrm{C}$ & $\mathrm{EB}-2>\mathrm{EB}-\mathrm{C}$ & $\mathrm{EB}-2>\mathrm{EB}-\mathrm{C}$ \\
\hline Hemipodus simplex & $\mathrm{P}$ & & $\begin{array}{l}\mathrm{EB}-\mathrm{C}>\mathrm{EB}-1 \\
\mathrm{~EB}-\mathrm{C}>\mathrm{EB}-2\end{array}$ & $\begin{array}{l}\mathrm{EB}-\mathrm{C}>\mathrm{EB}-1 \\
\mathrm{~EB}-\mathrm{C}>\mathrm{EB}-2\end{array}$ \\
\hline Heteromastus filiformis & $\mathrm{P}$ & & EB-1 $>$ EB-C & $\begin{array}{l}\mathrm{EB}-1>\mathrm{EB}-\mathrm{C} \\
\mathrm{EB}-2>\mathrm{EB}-\mathrm{C}\end{array}$ \\
\hline Notomastus sp. & $\mathrm{P}$ & & $\mathrm{EB}-1>\mathrm{EB}-\mathrm{C}$ & $\begin{array}{l}\mathrm{EB}-\mathrm{C}>\mathrm{EB}-1 \\
\mathrm{~EB}-\mathrm{C}>\mathrm{EB}-2\end{array}$ \\
\hline Ophiodromus sp. & $\mathrm{P}$ & EB-1 $>$ EB-C & & \\
\hline Owenia fusiformis & $\mathrm{P}$ & $\begin{array}{l}\mathrm{EB}-\mathrm{C}>\mathrm{EB}-1 \\
\mathrm{~EB}-\mathrm{C}>\mathrm{EB}-2\end{array}$ & $\mathrm{~EB}-\mathrm{C}>\mathrm{EB}-1$ & $\mathrm{~EB}-\mathrm{C}>\mathrm{EB}-1$ \\
\hline Pectinaria australis & $\mathrm{P}$ & $\mathrm{EB}-1>\mathrm{EB}-\mathrm{C}$ & $\mathrm{EB}-\mathrm{I}>\mathrm{EB}-\mathrm{C}$ & $\mathrm{EB}-1>\mathrm{EB}-\mathrm{C}$ \\
\hline Prionospio aucklandica & $\mathrm{P}$ & $\begin{array}{l}\mathrm{EB}-1>\mathrm{EB}-\mathrm{C} \\
\mathrm{EB}-2>\mathrm{EB}-\mathrm{C}\end{array}$ & $\mathrm{EB}-\mathrm{I}>\mathrm{EB}-\mathrm{C}$ & $\begin{array}{l}\mathrm{EB}-\mathrm{I}>\mathrm{EB}-\mathrm{C} \\
\mathrm{EB}-\mathrm{C}>\mathrm{EB}-2\end{array}$ \\
\hline Prionospio spp. & $\mathrm{P}$ & $\begin{array}{l}\mathrm{EB}-\mathrm{C}>\mathrm{EB}-1 \\
\mathrm{~EB}-\mathrm{C}>\mathrm{EB}-2\end{array}$ & $\begin{array}{l}\mathrm{EB}-\mathrm{C}>\mathrm{EB}-1 \\
\mathrm{~EB}-\mathrm{C}>\mathrm{EB}-2\end{array}$ & $\begin{array}{l}\mathrm{EB}-\mathrm{C}>\mathrm{EB}-1 \\
\mathrm{~EB}-\mathrm{C}>\mathrm{EB}-2\end{array}$ \\
\hline Prionospio yuriel & $\mathrm{P}$ & $E B-2>E B-C$ & & \\
\hline Schistomeringos loveni? & $\mathrm{P}$ & & $\mathrm{EB}-\mathrm{C}>\mathrm{EB}-2$ & \\
\hline Hesionid sp.A & $\mathrm{P}$ & $\mathrm{EB}-\mathrm{C}>\mathrm{EB}-1$ & & $\begin{array}{l}\mathrm{EB}-\mathrm{C}>\mathrm{EB}-1 \\
\mathrm{~EB}-\mathrm{C}>\mathrm{EB}-2\end{array}$ \\
\hline Exogone sp.A & P & $\begin{array}{l}\mathrm{EB}-\mathrm{C}>\mathrm{EB}-1 \\
\mathrm{~EB}-\mathrm{C}>\mathrm{EB}-2\end{array}$ & $\begin{array}{l}\mathrm{EB}-\mathrm{C}>\mathrm{EB}-1 \\
\mathrm{~EB}-\mathrm{C}>\mathrm{EB}-2\end{array}$ & $\begin{array}{l}\mathrm{EB}-\mathrm{C}>\mathrm{EB}-1 \\
\mathrm{~EB}-\mathrm{C}>\mathrm{EB}-2\end{array}$ \\
\hline Oligochaetes & & & $\mathrm{EB}-1>\mathrm{EB}-\mathrm{C}$ & $\begin{array}{l}\mathrm{EB}-1>\mathrm{EB}-\mathrm{C} \\
\mathrm{EB}-\mathrm{C}>\mathrm{EB}-2\end{array}$ \\
\hline
\end{tabular}


Table 5.9: Taxa with a significant difference in abundance between outlet and control at each distance (m), Evans Bay sites, May 1999 Outlets: EB-1, EB-2 Control EB-C

Groups: B - Bivalve Mollusc, E - Echinoderm, A -Arthropod, P - Polychaete

\begin{tabular}{|c|c|c|c|c|}
\hline & & \multicolumn{3}{|c|}{ Distance (m) } \\
\hline Taxa & Group & 24 & 34 & 44 \\
\hline Gari stangeri & $\mathrm{B}$ & $\begin{array}{l}\mathrm{EB}-\mathrm{C}>\mathrm{EB}-1 \\
\mathrm{~EB}-\mathrm{C}>\mathrm{EB}-2\end{array}$ & $\begin{array}{l}\mathrm{EB}-\mathrm{C}>\mathrm{EB}-1 \\
\mathrm{~EB}-\mathrm{C}>\mathrm{EB}-2\end{array}$ & \\
\hline Ruditapes largillierti & B & $\mathrm{EB}-1>\mathrm{EB}-\mathrm{C}$ & $\mathrm{FB}-\mathrm{C}>\mathrm{FB}_{-} 2$ & \\
\hline Trochodota dendyi & $\mathrm{E}$ & & & $\begin{array}{l}\text { EB-C }>\text { EB-1 } \\
\text { EB-C }>\text { EB-2 }\end{array}$ \\
\hline Amphiura sp. & $\mathrm{E}$ & & $\begin{array}{l}\mathrm{EB}-\mathrm{C}>\mathrm{EB}-1 \\
\mathrm{~EB}-\mathrm{C}>\mathrm{EB}-2\end{array}$ & \\
\hline Callianassa filholi & A & $\begin{array}{l}\mathrm{EB}-\mathrm{C}>\mathrm{EB}-1 \\
\mathrm{~EB}-\mathrm{C}>\mathrm{EB}-2\end{array}$ & & \\
\hline Proharpinia spp. & A & EB-1>EB-C & & \\
\hline Melita spp. & A & & $\begin{array}{l}\text { EB-1>EB-C } \\
\text { EB-C }>\text { EB-2 }\end{array}$ & \\
\hline Armandia maculata & $\mathrm{P}$ & $\mathrm{EB}-\mathrm{C}>\mathrm{EB}-2$ & $\begin{array}{l}\text { EB-C }>\text { EB-1 } \\
\text { EB-C }>\text { EB-2 }\end{array}$ & $\begin{array}{l}\text { EB-C }>\text { EB-1 } \\
\text { EB-C }>\text { EB-2 }\end{array}$ \\
\hline Barantolla sp. & $\mathrm{P}$ & $\begin{array}{l}\text { EB-1>EB-C } \\
\text { EB-2>EB-C }\end{array}$ & & $\begin{array}{l}\text { EB-1>EB-C } \\
\text { EB-2>EB-C }\end{array}$ \\
\hline Capitella spp. & $\mathrm{p}$ & EB-1>EB-C & & \\
\hline Glycinde dorsalis & $\mathrm{P}$ & EB-2>EB-C & & $\mathrm{EB}-2>\mathrm{EB}-\mathrm{C}$ \\
\hline Hemipodus simplex & $P$ & $\mathrm{~EB}-\mathrm{C}>\mathrm{EB}-1$ & $\begin{array}{l}\mathrm{EB}-\mathrm{C}>\mathrm{EB}-1 \\
\mathrm{~EB}-\mathrm{C}>\mathrm{EB}-2\end{array}$ & $\begin{array}{l}\mathrm{EB}-\mathrm{C}>\mathrm{EB}-1 \\
\mathrm{~EB}-\mathrm{C}>\mathrm{EB}-2\end{array}$ \\
\hline Heteromastus filiformis & $\mathrm{P}$ & $\mathrm{EB}-1>\mathrm{EB}-\mathrm{C}$ & & $\begin{array}{l}\text { EB-1 }>\text { EB-C } \\
\text { EB-2>EB-C }\end{array}$ \\
\hline Owenia fusiformis & $\mathrm{P}$ & $\begin{array}{l}\mathrm{EB}-\mathrm{C}>\mathrm{EB}-1 \\
\mathrm{~EB}-\mathrm{C}>\mathrm{EB}-2\end{array}$ & & $\mathrm{~EB}-\mathrm{C}>\mathrm{EB}-1$ \\
\hline Prionospio aucklandica & $\mathrm{P}$ & EB-1>EB-C & $\begin{array}{l}\text { EB-1 }>\text { EB-C } \\
\text { EB-C }>\text { EB-2 }\end{array}$ & EB-1 $>$ EB-C \\
\hline Prionospio spp. & $P$ & $\mathrm{~EB}-\mathrm{C}>\mathrm{EB}-2$ & $\begin{array}{l}\mathrm{EB}-\mathrm{C}>\mathrm{EB}-1 \\
\mathrm{~EB}-\mathrm{C}>\mathrm{EB}-2\end{array}$ & $\begin{array}{l}\mathrm{EB}-\mathrm{C}>\mathrm{EB}-1 \\
\mathrm{~EB}-\mathrm{C}>\mathrm{EB}-2\end{array}$ \\
\hline Prionospio yuriel & $\mathrm{P}$ & & EB-2>EB-C & \\
\hline Pseudopolydora cf. paucibranchiata & $\mathrm{P}$ & & $\mathrm{EB}-2>\mathrm{EB}-\mathrm{C}$ & EB-2>EB-C \\
\hline Schistomeringos loveni? & $P$ & $\mathrm{~EB}-\mathrm{C}>\mathrm{EB}-2$ & $\begin{array}{l}\mathrm{EB}-\mathrm{C}>\mathrm{EB}-1 \\
\mathrm{~EB}-\mathrm{C}>\mathrm{EB}-2\end{array}$ & \\
\hline Hesionid sp.A & $\mathrm{P}$ & $\begin{array}{l}\mathrm{EB}-\mathrm{C}>\mathrm{EB}-1 \\
\mathrm{~EB}-\mathrm{C}>\mathrm{EB}-2\end{array}$ & & \\
\hline Exogone sp.A & P & $\begin{array}{l}\mathrm{EB}-\mathrm{C}>\mathrm{EB}-1 \\
\mathrm{~EB}-\mathrm{C}>\mathrm{EB}-2\end{array}$ & $\begin{array}{l}\mathrm{EB}-\mathrm{C}>\mathrm{EB}-1 \\
\mathrm{~EB}-\mathrm{C}>\mathrm{EB}-2\end{array}$ & $\begin{array}{l}\mathrm{EB}-\mathrm{C}>\mathrm{EB}-1 \\
\mathrm{~EB}-\mathrm{C}>\mathrm{EB}-2\end{array}$ \\
\hline Oligochaetes & & & & EB- $1>$ EB-C \\
\hline
\end{tabular}


Table 5.10: Taxon abundance with distance $(\mathrm{m})$ and direction at each site in Evans Bay in 1998 and 1999 The significant differences $(\alpha=0.05)$ with distance and/or direction are defined Outlets: EB-I, EB-2 Control: EB-C

Directions: S- Straight, L - Left, R - Right

Groups: B - Bivalve Mollusc, E - Echinoderm, A - Arthropod, P - Polychaete

\begin{tabular}{|c|c|c|c|c|c|c|c|}
\hline \multirow{2}{*}{\multicolumn{2}{|c|}{1998}} & \multicolumn{2}{|c|}{ EB-1 } & \multicolumn{2}{|c|}{ EB-2 } & \multicolumn{2}{|c|}{ EB-C } \\
\hline & & \multirow{2}{*}{$\begin{array}{c}\text { distance } \\
\text { sign.diff. }\end{array}$} & \multirow{2}{*}{\begin{tabular}{|l|} 
direction \\
sign.diff.
\end{tabular}} & \multirow{2}{*}{$\begin{array}{c}\text { distance } \\
\text { sign.diff. }\end{array}$} & \multirow{2}{*}{\begin{tabular}{|c|} 
direction \\
sign.diff.
\end{tabular}} & \multirow{2}{*}{$\begin{array}{l}\text { distance } \\
\text { sign.diff. }\end{array}$} & \multirow{2}{*}{\begin{tabular}{|l|l} 
direction \\
sign.diff \\
\end{tabular}} \\
\hline Taxa & Group & & & & & & \\
\hline Arthritica bifurca & B & & & & \multirow{5}{*}{$\mathrm{L} \& \mathrm{R}>\mathrm{S}$} & & \multirow{3}{*}{$L \& R>S$} \\
\hline Dosina zelandica & B & $34>44$ & $\mathrm{~S}>\mathrm{L} \& \mathrm{R}$ & $44>34=24$ & & $24>34$ & \\
\hline Gari zelandica & B & $34>44$ & & & & $34>44$ & \\
\hline Ruditapes largillierti & B & & & & & & $S>L \& R$ \\
\hline Trochodota dendyi & $\mathrm{E}$ & $34>44$ & & & & $44>24=34$ & $\mathrm{~L} \& \mathrm{R}>\mathrm{S}$ \\
\hline Amphiura sp. & $\mathrm{E}$ & $34>24=44$ & $L \& R>S$ & & \multirow{4}{*}{$L \& R>S$} & $34>24=44$ & \multirow{3}{*}{$L \& R>S$} \\
\hline Callianassa filholi & A & & & & & $24=34>44$ & \\
\hline Proharpinia spp. & A & & & & & & \\
\hline Melita sp. & A & & & & & & \multirow[t]{3}{*}{$S>L \& R$} \\
\hline Corophium acherusicum & A & & & $44>24=34$ & \multirow{2}{*}{$\begin{array}{l}S>L \& R \\
S>L \& R\end{array}$} & & \\
\hline Meridiolembos sp. & A & & & $44>34>24$ & & & \\
\hline Armandia maculata & $P$ & & & & & & \\
\hline Barantolla sp. & $P$ & $34-44>24$ & $S>L \& R$ & & \multirow{7}{*}{$S>L \& R$} & $34>44>24$ & $S>L \& R$ \\
\hline Capitella sp. & $P$ & $24>34-44$ & $S>L \& R$ & $24>34>44$ & & & \\
\hline Glycinde dorsalis & $\mathrm{P}$ & $34-44>24$ & & & & & \\
\hline Hemipodus simplex & $\mathrm{P}$ & & & & & $44=34>24$ & \\
\hline Heteromastus filiformis & $P$ & $34>44>24$ & $\mathrm{~S}>\mathrm{L} \& \mathrm{R}$ & $44>24$ & & & \\
\hline Notomastus sp. & $P$ & $34>44$ & & & & $44>34$ & \\
\hline Ophiodromus sp. & $P$ & $24>34>44$ & $L \& R>S$ & & & & \\
\hline Owenia filiformis & $P$ & $24=34>44$ & $S>L \& R$ & $44>34>24$ & $\mathrm{~L} \& \mathrm{R}>\mathrm{S}$ & $44>24$ & $L \& R>S$ \\
\hline Pectinaria australis & $P$ & & & & & & \\
\hline Prionospio aucklandica & $P$ & $24>34-44$ & $S>L \& R$ & $24>34>44$ & & & $S>L \& R$ \\
\hline Prionospio spp. & $P$ & & & & & $44>24$ & $S>L \& R$ \\
\hline Prionospio yuriel & $P$ & & & $24>34-44$ & & & \\
\hline Schistomeringos loveni? & $P$ & $34>44$ & $L \& R>S$ & & & $34>24$ & $S>L \& R$ \\
\hline Hesionid sp.A & $P$ & & & $24>34-44$ & $\mathrm{~S}>\mathrm{L} \& \mathrm{R}$ & & $S>L \& R$ \\
\hline Exogone sp.A & $\mathrm{P}$ & $34>44$ & & & & & \\
\hline Oligochaete spp. & & $44>34>24$ & $S>L \& R$ & $24>34-44$ & & $24=44>34$ & $\mathrm{~S}>\mathrm{L} \& \mathrm{R}$ \\
\hline 1999 & & & & & & & \\
\hline Arthritica bifurca & B & & & & & & \\
\hline Dosina zelandica & B & & & & & & \\
\hline Gari zelandica & B & & & & & $34>24>44$ & $L \& R>S$ \\
\hline Ruditapes largillierti & B & $24>34=44$ & & & & $34>44$ & \\
\hline Trochodota dendyi & $\mathrm{E}$ & & & & & $44>24=34$ & $L \& R>S$ \\
\hline Amphiura sp & $\mathrm{E}$ & & & & & $34>24-44$ & \\
\hline Callianassa filholi & A & & & & & $24>34=44$ & \\
\hline Proharpinia spp. & A & $24>34-44$ & & & & & \\
\hline Melita sp. & A & $34>24=44$ & $L \& R>S$ & & & $34>24-44$ & $S>L \& R$ \\
\hline Armandia maculata & $\mathrm{P}$ & $24>34=44$ & & & & $34>24-44$ & $L \& R>S$ \\
\hline Barantolla sp. & $\mathrm{P}$ & $44>24$ & $S>L \& R$ & & & $34>44>24$ & $S>L \& R$ \\
\hline Capitella spp. & $P$ & $24>34$ & & & & & \\
\hline Glycinde dorsalis & $P$ & & & & & & \\
\hline Hemipodus simplex & $P$ & $24=34>44$ & & $24=34>44$ & & $33>24$ & \\
\hline Heteromastus filiformis & $\mathrm{P}$ & $24=44>34$ & $L \& R>S$ & & & & \\
\hline Ophiodromus sp. & $\mathrm{P}$ & & & & & & \\
\hline Owenia filiformis & $P$ & $34>24=44$ & $S>L \& R$ & $44>24=34$ & & & \\
\hline Prionospio aucklandica & $P$ & $24>44$ & & $24>44$ & & $34>24-44$ & $S>L \& R$ \\
\hline Prionospio spp. & $\mathrm{P}$ & & & & & & \\
\hline Prionospio yuriel & $P$ & & & & $L \& R>S$ & & \\
\hline Pseudopolydora & $P$ & & $S>L \& R$ & & $S>L \& R$ & & \\
\hline Schistomeringos loveni? & $\mathrm{P}$ & $24>34=44$ & & & & $34>24>44$ & IS $>L \& R$ \\
\hline Hesionid sp.A & $P$ & & & & & $24>34-44$ & $S>L \& R$ \\
\hline Exogone sp.A & $\mathrm{P}$ & & & & & $34>24>44$ & \\
\hline Oligochaete spp. & & & $S>L \& R$ & & & & $S>L \& R$ \\
\hline
\end{tabular}


$\mathrm{m}$ stations and Heteromastus filiformis (1999) was more abundant at the 24 and $44 \mathrm{~m}$ than at $34 \mathrm{~m}$ stations.

At EB-2 there was a significant decrease in the abundance of Capitella spp., Prionospio aucklandica, Prionospio yuriel and Hesionid sp.A with increasing distance from the outlet whereas for Meridiolembos sp. there was a significant increase in abundance with increasing distance from the outlet. Owenia fusiformis and Corophium acherusicum were significantly more abundant at $44 \mathrm{~m}$ than at stations closer to the outlet and Heteromastus filiformis was significantly more abundant at 44 than $24 \mathrm{~m}$ from the outlet.

There were significant differences in the abundance of 12 taxa in 1998 and 9 taxa in 1999 with direction at the control site. At EB-1, 10 taxa in 1998 and 6 taxa in 1999 and at EB-2, 7 taxa in 1998 and 2 taxa in 1999 had significant differences in abundance with direction. At each site there was no consistent direction pattern as some taxa were more abundant on the

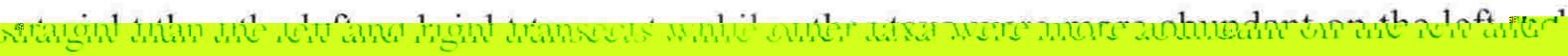
right than the straight transect.

\subsection{3.b Queens Wharf}

Comparison of taxon abundance at outlet and control sites

Of the 15 taxa ( 6 polychactes, 4 bivalve molluses and 2 arthropods) contributing $\geq 2.5^{\circ} \circ$ to the faunal dissimilarity between sites, there was a two fold or more difference in the abundance of 9 taxa between one or both outlet sites and the control site (Table 5.11).

The polychaetes Capitella spp. Questa sp. and Schistomeringos loveni? and the bivalve Dosina zelandica were more abundant, whereas the polychaetes Barantolla sp.. Heteromastus filiformis, Prionospio ruriel and Prionospio spp. and the bivalve Theora lubricu were less abundant at one or both outlet sites than at the control site.

Taxon abundance between control and outlet stations

Of the taxa analysed using ANOVA there were significant differences in the abundance of 10 taxa between control and outlet stations (Table 5.12). Arthritica bifurca. Proharpinica spp., Armandia maculata. Heteromastus filiformis, Pronospio spp. Prionospio vartel and Questa sp. were significantly more abundant at the $10 \mathrm{~m} \mathrm{Q-C}$ than the $10 \mathrm{~m} \mathrm{Q-1}$ and Q-2 stations. The abundance of Arthritica bifurea. Dosinazelandica, Heteromastus filiformis. 
Table 5.11: Mean abundance of taxa contributing $\geq 2.5 \%$ to faunal dissimilarity between outlet and control sites at Queens Wharf in 1998

Groups: P - Polychaete, B - Bivalve Mollusc, A - Arthropod, O - Other

Number of samples at each site : Q-2 and Q-C N=18, Q-1 $N=15$

\begin{tabular}{|lcrrr|}
\hline Taxa & Group & Q-1 & Q-2 & QC \\
\hline Arthritica bifurca & $\mathrm{B}$ & 15.78 & 14.39 & 12.94 \\
Dosina zelandica & $\mathrm{B}$ & 7.00 & 2.67 & 1.50 \\
Leptomya retiaria & $\mathrm{B}$ & 0.39 & 2.67 & 2.85 \\
Theora lubrica & $\mathrm{B}$ & 0.44 & 1.39 & 3.00 \\
Macrophthalmus hirtipes & $\mathrm{A}$ & 2.72 & 1.17 & 2.77 \\
Proharpinia spp. & $\mathrm{A}$ & 2.94 & 2.22 & 3.00 \\
Armandia maculata & $\mathrm{P}$ & 12.06 & 18.39 & 19.33 \\
Barantolla sp. & $\mathrm{P}$ & 15.89 & 6.89 & 20.28 \\
Capitella spp. & $\mathrm{P}$ & 4.94 & 0.28 & 0.11 \\
Heteromastus filiformis & $\mathrm{P}$ & 21.44 & 48.44 & 101.94 \\
Prionospio aucklandica & $\mathrm{P}$ & 179.94 & 73.94 & 99.50 \\
Prionospio yuriel & $\mathrm{P}$ & 3.44 & 3.78 & 8.39 \\
Prionospio spp. & $\mathrm{P}$ & 2.78 & 4.50 & 11.06 \\
Schistomeringos loveni? & $\mathrm{P}$ & 8.89 & 1.06 & 1.06 \\
Questa sp. & $\mathrm{P}$ & 5.00 & 19.39 & 6.95 \\
\hline
\end{tabular}

Prionospio spp, and Prionospio yuriel was also significantly higher at the $20 \mathrm{~m}$ and the abundance of Theora lubrica, Proharpinia spp. and Prionospio spp significantly higher at the $30 \mathrm{~m}$ Q-C than at Q-1 and/or Q-2 stations. By comparision Capitella spp. was significantly more abundant at the $10 \mathrm{~m} \mathrm{Q}-1$ than the $10 \mathrm{~m} \mathrm{Q-C}$ stations, and at the 20 and $30 \mathrm{~m}$ stations some taxa were more abundant at Q-1 and/or Q-2 than Q-C stations.

\section{Taxon abundance with distance and direction}

At Queens Wharf the effect of distance and direction on the abundance of 14 taxa was investigated (Table 5.13). At the control site there was a significant difference in the abundance of 8 taxa but no significant difference in abundance of 6 taxa with distance from the shore. Of these 6 taxa, there were significant differences in the abundance of the polychaetes Capitella spp., Heteromastus filiformis and Prionospio yuriel with distance from at least one of the Queens Wharf outlets.

At Q-1 Capitella spp. was significantly more abundant at 10 than $30 \mathrm{~m}$ away whereas Heteromastus filiformis and Prionospio yuriel were significantly more abundant at $30 \mathrm{~m}$ than closer to the outlet. At Q-2 Prionospio yuriel was significantly more abundant at 20 than $10 \mathrm{~m}$ away, and Heteromastus filiformis significantly more abundant at 20 and $30 \mathrm{~m}$ than $10 \mathrm{~m}$, from the outlet. 
Table 5.12: Taxa with a significant difference in abundance between outlet and control at each distance (m), Queens Wharf sites, 1998

Outlets: Q-1, Q-2 Control: Q-C

Groups: B- Bivalve Mollusc, A - Arthropod, P - Polychaete

\begin{tabular}{|c|c|c|c|c|}
\hline \multirow[b]{2}{*}{ Taxa } & \multirow[b]{2}{*}{ Group } & \multicolumn{3}{|c|}{ Distance } \\
\hline & & 10 & 20 & 30 \\
\hline Arthritica bifurca & $\mathrm{B}$ & $\begin{array}{l}\mathrm{Q}-\mathrm{C}>\mathrm{Q}-1 \\
\mathrm{Q}-\mathrm{C}>\mathrm{Q}-2\end{array}$ & $\mathrm{Q}-2>\mathrm{Q}-\mathrm{C}$ & \\
\hline Dosina zelandica & B & & $\mathrm{Q}-\mathrm{C}>\mathrm{Q}-1$ & $\mathrm{Q}-1>\mathrm{Q}-\mathrm{C}$ \\
\hline Theora lubrica & B & & & $\begin{array}{l}\mathrm{Q}-\mathrm{C}>\mathrm{Q}-1 \\
\mathrm{Q}-\mathrm{C}>\mathrm{Q}-2\end{array}$ \\
\hline Proharpinia spp. & A & $\begin{array}{l}\mathrm{Q}-\mathrm{C}>\mathrm{Q}-1 \\
\mathrm{Q}-\mathrm{C}>\mathrm{Q}-2\end{array}$ & $\mathrm{Q}-\mathrm{C}<\mathrm{Q}-2$ & $\mathrm{Q}-\mathrm{C}>\mathrm{Q}-2$ \\
\hline Armandia maculata & $\mathrm{P}$ & $\begin{array}{l}\mathrm{Q}-\mathrm{C}>\mathrm{Q}-1 \\
\mathrm{Q}-\mathrm{C}>\mathrm{Q}-2\end{array}$ & & \\
\hline Capitella spp. & $P$ & $\mathrm{Q}-1>\mathrm{Q}-\mathrm{C}$ & & \\
\hline Heteromastus filiformis & $P$ & $\begin{array}{l}\mathrm{Q}-\mathrm{C}>\mathrm{Q}-1 \\
\mathrm{Q}-\mathrm{C}>\mathrm{Q}-2\end{array}$ & $\mathrm{Q}-\mathrm{C}>\mathrm{Q}-1$ & \\
\hline Prionospio spp. & $\mathrm{P}$ & $\begin{array}{l}\mathrm{Q}-\mathrm{C}>\mathrm{Q}-1 \\
\mathrm{Q}-\mathrm{C}>\mathrm{Q}-2\end{array}$ & $\mathrm{Q}-\mathrm{C}>\mathrm{Q}-1$ & $\begin{array}{l}\mathrm{Q}-\mathrm{C}>\mathrm{Q}-1 \\
\mathrm{Q}-\mathrm{C}>\mathrm{Q}-2\end{array}$ \\
\hline Prionospio yuriel & P & $\begin{array}{l}\mathrm{Q}-\mathrm{C}>\mathrm{Q}-1 \\
\mathrm{Q}-\mathrm{C}>\mathrm{Q}-2\end{array}$ & $\mathrm{Q}-\mathrm{C}>\mathrm{Q}-1$ & \\
\hline Questa sp. & $\mathrm{P}$ & $\begin{array}{l}\mathrm{Q}-\mathrm{C}>\mathrm{Q}-1 \\
\mathrm{Q}-\mathrm{C}>\mathrm{Q}-2\end{array}$ & $\mathrm{Q}-\mathrm{C}<\mathrm{Q}-2$ & $\begin{array}{l}\text { Q-C }<\text { Q-1 } \\
\text { Q-C }<\text { Q-2 }\end{array}$ \\
\hline
\end{tabular}

Table 5.13: Taxa abundance with distance $(\mathrm{m})$ and direction at each site at Queens Wharf in 1998. The significant difference $(\alpha=0.05)$ with distance and/or direction are defined. Outlets: Q-1, Q-2 Control: Q-C Directions: S - Straight, L - Left, R - Right Groups: B - Bivalve Mollusc, A - Arthropod, P - Polychaete

\begin{tabular}{|c|c|c|c|c|c|c|c|}
\hline \multirow[b]{3}{*}{ Taxa } & \multirow[b]{3}{*}{ Group } & \multicolumn{2}{|c|}{ Q-1 } & \multicolumn{2}{|c|}{ Q-2 } & \multicolumn{2}{|c|}{ Q-C } \\
\hline & & Distance & Direction & Distance & Direction & Distance & Direction \\
\hline & & sign.diff. & sign.diff. & sign.diff. & sign.diff. & sign.diff. & sign.diff. \\
\hline Arthritica bifurca & $\mathrm{B}$ & & & $20>10=30$ & & $10>20=30$ & \\
\hline Dosina zelandica & B & $30>20=10$ & $L \& R>S$ & $20>10=30$ & $S>L \& R$ & $20>10$ & \\
\hline Leptomya retiaria & B & & & & & & \\
\hline Theora hubrica & B & & & & & $30>20>10$ & \\
\hline Macrophthalmus hirtipes & A & & & & & & \\
\hline Proharpinia spp. & A & $30>20=10$ & $S>L \& R$ & $20>10=30$ & & $10=30>20$ & \\
\hline Armandia maculata & $P$ & & & & & $10>20=30$ & \\
\hline Barantolla sp. & $P$ & $30>10 \& 20$ & & $20=30>10$ & & $30>10=20$ & \\
\hline Capitella sp. & $\mathrm{P}$ & $10>30$ & & & & & \\
\hline Heteromastus filiformis & $\mathrm{P}$ & $30>20=10$ & & $20=30>10$ & & & \\
\hline Prionospio spp. & $\mathrm{P}$ & $30>2010$ & & $20=30>10$ & & $30>10=20$ & $S>L \& R$ \\
\hline Prionospio yuriel & $\mathrm{P}$ & $30>20=10$ & & $20>10$ & & & \\
\hline Questa sp. & $\mathrm{P}$ & & & $10>30$ & & $I 0>20=30$ & \\
\hline Schistomeringos loveni? & $\mathrm{P}$ & & & & & & \\
\hline
\end{tabular}


Of the 14 taxa, there was no significant difference in the abundance of 11 taxa, but significant differences in the abundance of the bivalve Dosina zelandica, the amphipods Proharpinia spp. and the polychaetes Prionospio spp., with direction from either an outlet or a point on the shore.

\subsection{3.c Overseas Passenger Terminal}

At OPT the effect of distance and direction on the abundance of 9 taxa was investigated (Table 5.14). Of these 9 taxa, Barantolla sp. and Schistomeringos loveni? were significantly more abundant at $15 \mathrm{~m}$ stations, and Capitella spp., Dosina zelandica and Oligochaetes were significantly more abundant at $30 \mathrm{~m}$ stations, than at stations at the other 2 distances. Capitella spp., Barantolla sp. and Schistomeringos loveni? were significantly more abundant on the straight than the left and right transects whereas Dosina zelandica and Armandia maculata were significantly more abundant on the left and right than the straight transect.

Table 5.14: Taxa abundance with distance $(\mathrm{m})$ and direction at OPT in November 1998. The significant differences $(\alpha=0.05)$ with distance and/or direction are defined. Groups: P - Polychaete, B - Bivalve mollusc, O-Other

\begin{tabular}{|lc|cc|}
\hline Taxa & Group & $\begin{array}{l}\text { distance } \\
\text { sign. diff. }\end{array}$ & $\begin{array}{c}\text { direction } \\
\text { sign diff. }\end{array}$ \\
\hline Arthritica bifurca & $\mathrm{B}$ & & \\
Dosina zelandica & $\mathrm{B}$ & $30>15>45$ & $\mathrm{~L} \& \mathrm{R}>\mathrm{S}$ \\
Armandia maculata & $\mathrm{P}$ & & $\mathrm{L} \& \mathrm{R}>\mathrm{S}$ \\
Bartantolla sp. & $\mathrm{P}$ & $15>30=45$ & $\mathrm{~S}>\mathrm{L} \& \mathrm{R}$ \\
Capitella spp. & $\mathrm{P}$ & $30>15>45$ & $\mathrm{~S}>\mathrm{L} \& \mathrm{R}$ \\
Perineris ?brevicirris & $\mathrm{P}$ & & \\
Prionospio aucklandica & $\mathrm{P}$ & & \\
Schistomeringos loveni? & $\mathrm{P}$ & $15>30=45$ & $\mathrm{~S}>\mathrm{L} \& \mathrm{R}$ \\
Oligochaete spp. & $\mathrm{O}$ & $30>15=45$ & \\
\hline
\end{tabular}

\subsection{3.d Aotea Quay}

\section{Comparison of taxon abundance at outlet and control sites}

Of the 20 taxa (16 polychaetes, 2 bivalve molluscs, 1 arthropod and 1 other) contributing $\geq 2.5 \%$ to the faunal dissimilarity between sites, there was a two fold or more difference in the abundance of 9 taxa between one or both outlet sites and the control site (Table 5.15). 
The polychaetes Armandia maculata, Capitella spp., Ophiodromus sp., Schistomeringos loveni? and the crab Macrophthalmus hirtipes were more abundant, whereas the polychaetes Heteromastus filiformis and Paraprionospio pinnata were less abundant, in the vicinity of one or both outlets than at the control site in 1998 (Table 5.15). In 1999 Armandia maculata, Capitella spp. were more abundant and Barantolla sp., Heteromastus filiformis, Prionospio spp. and Jasminiera sp., were less abundant at outlet AQ-2 than at the control site.

Table 5.15: Mean abundance of taxa contributing $\geq 2.5 \%$ to faunal dissimilarity between sites at Aotea Quay.

Outlets: AQ-1, AQ-2 Control: AQ-C

Groups: P - Polychaete, B - Bivalve Mollusc, A - Arthropod, O - Other

Number of samples at each site: $1998 \mathrm{~N}=18, \quad 1999 \mathrm{~N}=21$

\begin{tabular}{|lccccc:c}
\hline Taxa & Group & AQ-1 & AQ-2 & \multicolumn{2}{c|}{ AQ-C } \\
\hline & & $\mathbf{1 9 9 8}$ & $\mathbf{1 9 9 8}$ & $\mathbf{1 9 9 9}$ & $\mathbf{1 9 9 8}$ & $\mathbf{1 9 9 9}$ \\
Arthritica bifurca & $\mathrm{B}$ & 4.39 & 4.33 & 1.74 & 3.00 & 0.50 \\
Leptomya retiaria & $\mathrm{B}$ & 4.11 & 0.86 & 0.13 & 4.19 & 0.17 \\
Macrophthalmus hirtipes & $\mathrm{A}$ & 5.83 & 4.48 & 0.25 & 2.76 & 0.25 \\
Armandia maculata & $\mathrm{P}$ & 12.94 & 64.67 & 13.87 & 7.71 & 3.79 \\
Barantolla sp. & $\mathrm{P}$ & 25.06 & 9.90 & 10.13 & 17.52 & 24.58 \\
Capitella spp. & $\mathrm{P}$ & 3.00 & 11.24 & 55.17 & 0.33 & 3.33 \\
Glycera ovigera & $\mathrm{P}$ & 2.28 & 0.19 & 2.52 & 2.00 & 5.30 \\
Glycinde dorsalis & $\mathrm{P}$ & 0.05 & 0.05 & 4.09 & 0.00 & 4.04 \\
Heteromastus filiformis & $\mathrm{P}$ & 25.67 & 19.71 & 15.17 & 60.10 & 22.54 \\
Jasminiera sp. & $\mathrm{P}$ & 0.14 & 0.00 & 1.00 & 0.05 & 3.17 \\
Lumbrineris sp.1 & $\mathrm{P}$ & 0.00 & 0.05 & 2.30 & 0.14 & 4.42 \\
Ophiodromus sp. & $\mathrm{P}$ & 3.61 & 5.86 & 0.65 & 1.95 & 1.54 \\
Paraprionospio pinnata & $\mathrm{P}$ & 2.61 & 1.19 & 1.22 & 6.48 & 1.83 \\
Prionospio aucklandica & $\mathrm{P}$ & 142.50 & 230.86 & 24.70 & 191.05 & 25.13 \\
Prionospio yuriel & $\mathrm{P}$ & 1.22 & 3.42 & 1.00 & 4.38 & 2.50 \\
Prionospio spp. & $\mathrm{P}$ & 16.56 & 2.43 & 19.61 & 10.19 & 42.13 \\
Pseudopolydora cf.paucibranchiata & $\mathrm{P}$ & 0.06 & 0.00 & 5.25 & 0.1 & 6.10 \\
Questa sp. & $\mathrm{P}$ & 14.28 & 32.89 & 26.53 & 24.41 & 35.95 \\
Schistomeringos loveni? & $\mathrm{P}$ & 4.22 & 9.43 & 8.52 & 4.38 & 6.96 \\
Nemertine spp. & $\mathrm{O}$ & 0.83 & 1.17 & 1.15 & 2.12 & 1.00 \\
& & & & & & \\
\hline
\end{tabular}

\section{Taxon abundance between control and outlet stations}

Of the taxa analysed using ANOVA, there were significant differences in the abundance of 9 taxa in 1998 and 4 taxa in 1999 between control and outlet stations (Table 5.16). Capitella spp., Armandia maculata, Barantolla sp., Heteromastus filiformis, Pseudopolydora cf. paucibranchiata and Schistomeringos loveni were significantly more abundant at $10 \mathrm{~m}$ at one or both outlet sites than at $10 \mathrm{~m}$ at the control site. At $20 \mathrm{~m}$ Capitella spp., Macrophthalmus hirtipes and Ophiodromus sp. were significantly more abundant at one or both outlet sites than at the control site whereas Barantolla sp., Paraprionospio pinnata, 
Glycera ovigera were significantly more abundant at the control than at one or both outlets. At $30 \mathrm{~m} 5$ taxa were more abundant at the control than at one or both outlet sites.

\section{Taxon abundance with distance and direction}

At Aotea Quay the effect of distance and direction on the abundance of 14 taxa in 1998 and 15 taxa in 1999, was investigated (Table 5.17). At AQ-C there were significant differences in the abundance of 7 taxa in 1998 and 4 taxa in 1999, but no significant differences in the abundance of 7 taxa in 1998 and 11 taxa in 1999, with distance from the shore. Of these 7 taxa in 1998 and 11 taxa in 1999, there were significant differences in the abundance of the polychaetes Capitella spp., Armandia maculata, Ophiodromus sp and Schistomeringos loveni with distance from at least one of the Aotea Quay outlets.

At AQ-1 Capitella spp. was significantly more abundant at 10 than at 20 and $30 \mathrm{~m}$ away from the outlet. At AQ-2, Armandia maculata, Capitella spp., Ophiodromus sp. and Schistomeringos loveni? were significantly more abundant at 10 than 20 and $30 \mathrm{~m}$ away in 1998, whereas in 1999 Capitella spp. were significantly more abundant at 10 and 20 than 30 m away from the outlet. For all these taxa except Capitella spp. at AQ-2 in 1999, there were significantly more individuals at $10 \mathrm{~m}$ on the straight than at $10 \mathrm{~m}$ on the left transect.

Significant differences occurred in the abundance of 10 taxa with direction at one or both outlets and/or at the control site.

The null hypothesis that there is no significant difference in the abundance of selected taxa between outlet and associated control stations is rejected. Arthritica bifurca, Armandia maculata (Queens Wharf and Evans Bay), Amphiura sp., Dosina zelandica, Exogone sp.A, Gari stangeri, Glycera ovigera, Heteromastus filiformis (Queens Wharf), Hemipodus simplex, Hesionid sp.A, Owenia fusiformis, Paraprionospio pinnata, Prionospio spp, Prionospio yuriel, Proharpinia spp., Schistomeringos loveni? (in Evans Bay) Theora lubrica and Questa sp. are significantly more abundant at some control than associated outlet stations while Capitella spp., Armandia maculata (Aotea Quay), Heteromastus filiformis (Aotea Quay and Evans Bay), Pseudopolydora cf. paucibranchiata and Schistomeringos loveni (at Aotea Quay) are significantly more abundant at some outlet than associated control stations. 
Table 5.16: Taxa with a significant difference in abundance between outlet and control at each distance $(\mathrm{m})$, Aotea Quay sites, 1998 and 1999

Outlets: $\mathrm{AQ}-1, \mathrm{AQ}-2$ control: $\mathrm{AQ}-\mathrm{C}$

Groups: A - Arthropod P - Polychaete

\begin{tabular}{|c|c|c|c|c|}
\hline \multicolumn{2}{|l|}{1998} & \multicolumn{3}{|c|}{ Distance } \\
\hline Taxa & Group & 10 & 20 & 30 \\
\hline Macrophthalmus hirtipes & $\mathrm{A}$ & & $\begin{array}{l}\mathrm{AQ}-1>\mathrm{AQ}-\mathrm{C} \\
\mathrm{AQ}-2>\mathrm{AQ}-\mathrm{C}\end{array}$ & \\
\hline Armandia maculata & $P$ & $\mathrm{AQ}-2>\mathrm{AQ}-\mathrm{C}$ & & \\
\hline Barantolla sp. & $P$ & $\mathrm{AQ}-2>\mathrm{AQ}-\mathrm{C}$ & $\begin{array}{l}\mathrm{AQ}-\mathrm{C}>\mathrm{AQ}-1 \\
\mathrm{AQ}-\mathrm{C}>\mathrm{AQ}-2\end{array}$ & $\mathrm{AQ}-\mathrm{C}>\mathrm{AQ}-2$ \\
\hline Capitella spp. & $\mathrm{P}$ & $\begin{array}{l}\mathrm{AQ}-\mathrm{I}>\mathrm{AQ}-\mathrm{C} \\
\mathrm{AQ}-2>\mathrm{AQ}-\mathrm{C}\end{array}$ & & \\
\hline Glvcera ovigera & P & & & $\mathrm{AQ}-\mathrm{C}>\mathrm{AQ}-2$ \\
\hline Heteromastus filiformis & $P$ & $\mathrm{AQ}-2>\mathrm{AQ}-\mathrm{C}$ & & $\begin{array}{l}\mathrm{AQ}-\mathrm{C}>\mathrm{AQ}-1 \\
\mathrm{AQ}-\mathrm{C}>\mathrm{AQ}-2\end{array}$ \\
\hline Ophiodromus sp. & $P$ & & $\mathrm{AQ}-1>\mathrm{AQ}-\mathrm{C}$ & \\
\hline Paraprionospio pinnata & $P$ & & $\mathrm{AQ}-\mathrm{C}>\mathrm{AQ}-1$ & $\begin{array}{l}A Q-C>A Q-1 \\
A Q-C>A Q-2\end{array}$ \\
\hline Schistomeringos loveni? & $\mathrm{P}$ & $\mathrm{AQ}-2>\mathrm{AQ}-\mathrm{C}$ & & \\
\hline \begin{tabular}{|r|}
1999 \\
\end{tabular} & & 10 & 20 & 30 \\
\hline Capitella spp. & $\mathrm{P}$ & $\mathrm{AQ}-2>\mathrm{AQ}-\mathrm{C}$ & $A Q-2>A Q-C$ & \\
\hline Glycera ovigera & $P$ & & $\mathrm{AQ}-\mathrm{C}>\mathrm{AQ}-2$ & \\
\hline Ophiodromus sp. & $\mathrm{P}$ & $\mathrm{AQ}-\mathrm{C}>\mathrm{AQ}-2$ & & \\
\hline Pseudopolydora ef paucibranchiata & $\mathrm{P}$ & $\mathrm{AQ}-2>\mathrm{AQ}-\mathrm{C}$ & $\mathrm{AQ}-\mathrm{C}>\mathrm{AQ}-2$ & $\mathrm{AQ}-\mathrm{C}>\mathrm{AQ}-2$ \\
\hline
\end{tabular}

Table 5.17: Taxa abundance with distance $(\mathrm{m})$ and direction at each site at Aotea Quay in 1998 and 1999. The significant differences $(\alpha=0.05)$ with distance and/or direction are defined Outlets: $\mathrm{AQ}-1, \mathrm{AQ}-2$ Control: $\mathrm{AQ}-\mathrm{C}$

Groups: B- Bivalve Mollusc, A-Arthropod, P-Polychaete

\begin{tabular}{|c|c|c|c|c|c|c|c|}
\hline \multirow{2}{*}{1998} & & \multicolumn{2}{|c|}{$\mathrm{AQ}-1$} & \multicolumn{2}{|c|}{$\mathrm{AQ}-2$} & \multicolumn{2}{|c|}{$\mathrm{AQ}-\mathrm{C}$} \\
\hline & & Distance & Direction & Distance & Direction & Distance & Direction \\
\hline Taxa & Group & sign. diff. & sign. diff. & sign. diff. & sign. diff. & sign. diff. & sign. diff. \\
\hline Arthritica bifurca & $B$ & $30>10=20$ & $S>L \& R$ & & & $30>20=10$ & $S>L \& R$ \\
\hline Macrophthalmus hirtipes & A & $20>10$ & & & & $30>20$ & \\
\hline Armandia maczulata & $\mathrm{P}$ & & & $10>20=30$ & & & \\
\hline Barantolla sp. & $P$ & $30>20>10$ & $S>L \& R$ & $10=30>20$ & & $30>20>10$ & $S>L \& R$ \\
\hline Capitella sp. & $P$ & $10>20=30$ & & $10>20=30$ & & & \\
\hline Glycera ovigera & $\mathrm{P}$ & $30>10=20$ & $S>L \& R$ & & & $30>20=10$ & $S>L \& R$ \\
\hline Heteromastus filiformis & $P$ & $30>10=20$ & & $30>10=20$ & & $30>20>10$ & $\mathrm{~S}>\mathrm{L} \& \mathrm{R}$ \\
\hline Ophiodromus sp. & $P$ & & $S>L \& R$ & $10>20=30$ & $S>L \& R$ & & \\
\hline Paraprionospio pinnata & $\mathrm{P}$ & $30>20=10$ & $\mathrm{~S}>\mathrm{L} \& \mathrm{R}$ & $30>20$ & & $30>20>10$ & $S>L \& R$ \\
\hline Prionospio aucklandica & $\mathrm{P}$ & & & & & & \\
\hline Prionospio spp. & $\mathrm{P}$ & $30>10=20$ & $S>L \& R$ & & & $30>10$ & $S>L \& R$ \\
\hline Prionospio yturiel & $\mathrm{P}$ & & & & & & $\mathrm{S}>\mathrm{L} \& \mathrm{R}$ \\
\hline Questa sp. & $P$ & & & & $L \& R>S$ & & \\
\hline Schistomeringos loveni? & $P$ & & & $10>20=30$ & & & \\
\hline
\end{tabular}

\begin{tabular}{|c|c|c|c|c|c|}
\hline \multirow{2}{*}{1999} & & \multicolumn{2}{|c|}{$\mathrm{AQ}-2$} & \multicolumn{2}{|c|}{$\mathrm{AQ}-\mathrm{C}$} \\
\hline & & Distance & Direction & Distance & Direction \\
\hline Taxa & Group & sign, diff. & sign. diff. & sign. diff. & sign. diff. \\
\hline Arthritica bifurca & $\mathrm{B}$ & & & & \\
\hline Macrophthalmus hirtipes & A & & & & \\
\hline Armandia maculata & $P$ & & & & \\
\hline Barantolla sp. & $\mathrm{P}$ & & & & \\
\hline Capitella sp. & $\mathrm{P}$ & $10=20>30$ & & & \\
\hline Glycera ovigena & $\mathrm{P}$ & $30>20$ & & $20=30>10$ & \\
\hline Heteromastus sp. & $P$ & $30>10=20$ & & $20=30>10$ & \\
\hline Ophiodromus sp. & $\mathrm{P}$ & & & $10>20=30$ & \\
\hline Paraprionospio pimuata & $\mathrm{P}$ & & & & \\
\hline Prionospio aucklandica & $\mathrm{P}$ & & & & \\
\hline Prionospie spp. & $P$ & & & & \\
\hline Prionospio yuriel & $\mathrm{P}$ & & & & $S>L \& R$ \\
\hline Pseudopelydora cf paucibranchiata & $P$ & $10>20=30$ & $L \& R>S$ & $30>10$ & $S>L \& R$ \\
\hline Questa $\mathrm{sp}$ & $\mathrm{P}$ & & & & \\
\hline Schistomeringos loveni? & $\mathrm{P}$ & & & & \\
\hline
\end{tabular}


The null hypothesis that there is no significant difference in the abundance of selected taxa with increasing distance from an outlet is rejected. The abundance of the polychaetes Armandia maculata, Capitella spp., Heteromastus filiformis, Hesionid sp.A, Ophiodromus sp., Owenia fusiformis, Prionospio aucklandica, Prionospio yuriel and Schistomeringos loveni?, Oligochaetes, the bivalve Dosina zelandica and the amphipods Corophium acherusicum, Meridiolembos sp. and Proharpinia spp. changed significantly with increasing distance from one or more of the outlets.

The null hypothesis that there is no significant difference in the abundance of selected taxa with direction from an outlet is rejected. The abundance of a number of taxa was significantly different with direction from an outlet.

\subsubsection{Summary of the macrobiota at each outlet}

A summary of the macrobiota at each outlet in terms of the biological community, univariate indices and selected taxa, as well as the distance and direction of the effect of stormwater discharge on the macrobiota is presented in Tables 5.18 and 5.19.

\subsection{DISCUSSION}

In this highly modified inner harbour environment the comparison of macrobiota in the vicinity of an outlet with that at a comparable control site is confounded by the complexity of natural and other factors affecting the macrobiota. It has been assumed that by locating control sites in the same general area as outlet sites the macrobiota present at control sites provides a representative picture of non-stormwater impacted macrobiota. At the control sites the biological community present at the time of sampling is the sum of all biological responses, processes and interactions, such as recruitment, behaviour, competition, migration, predation, mortality, stress and tolerance which have occurred in response to natural and other factors e.g. wharf structures, shipping activities, while at the outlet sites it is considered to be the sum of all these factors plus those resulting from stormwater discharge. Thus differences in the presence, abundance and distribution of the macrobiota between an outlet and the associated control site could be as a result of stormwater discharge. However the effect of wharf and marina structures and activities on the macrobiota at some outlet sites cannot be discounted. 


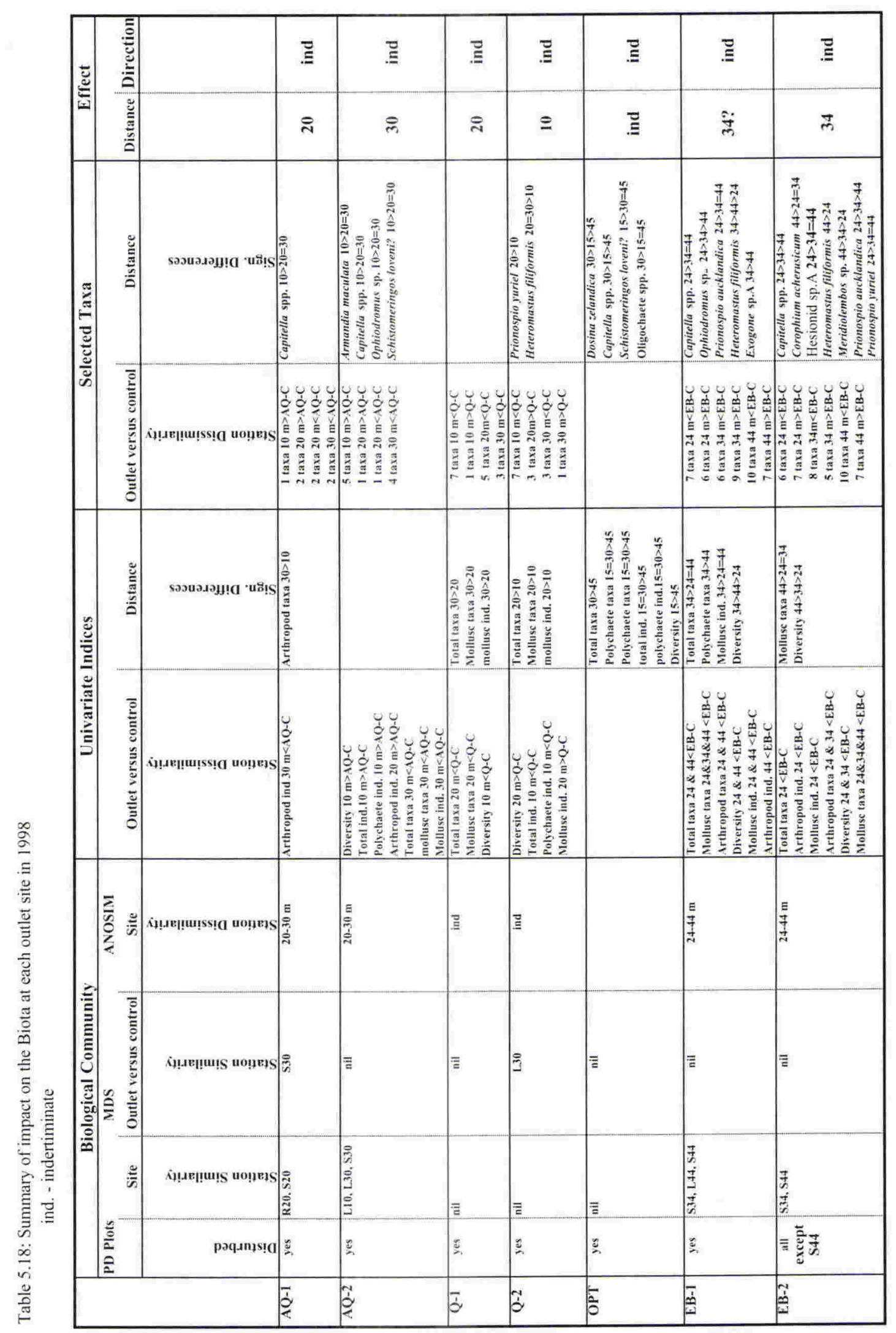




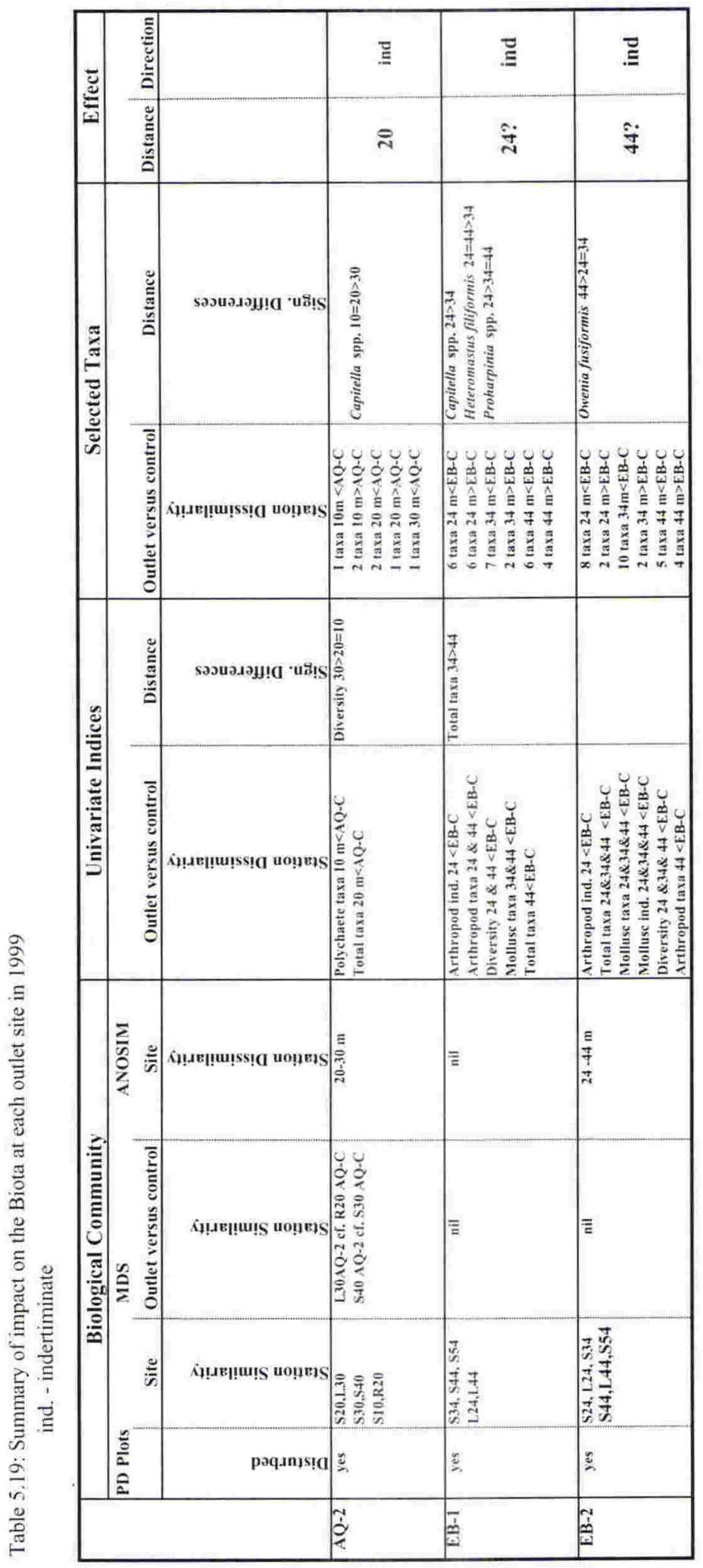


The macrobiota at the Aotea Quay and Queens wharf control sites was disturbed and changed with distance and direction from shore. This could result from the disturbance of the sediments by the manoeuvring of vessels (container ships, Interisland ferry, foreign fishing vessels, logging ships, cruise ships at Aotea Quay and fishing and charter vessels, pleasure craft and the harbour ferry at Queens Wharf) near the wharf edge (Haddon and Wear, 1993). At Aotea Quay such disturbance is not uniform as different activities occur along different sections of the wharf e.g. the container berths, logging and fishing vessel berths. Physical instability of sediments caused by shipping activities has been found to result in a disturbed biological community as evidenced by lower species diversity and the shape of Abundance/Biomass Comparison curves (Warwick et al., 1990). By comparison, the macrobiota at the Evans Bay control site was not disturbed, but there was a difference in the biotic community between stations on different transects, that is, the macrobiota is patchy. Heterogeneity (patchiness) is a recognized attribute of benthic macrobiota (Legendre et al., 1997; Morrisey et al., 1992; Thrush et al., 1989) and is attributed to a variety of disturbances, biotic factors (recruitment, competition, predation) and abiotic factors (physical environmental factors such as water depth and movement and sediment type) (Bell et al., 1997; Hewitt, et al., 1997; Legendre et al., 1997; Morrisey et al., 1992; Thrush et al., 1991; Thrush, 1999; Whitlatch, et al., 1997). The abundance of soft-sediment macrobiota is patchy over spatial scales of less than $1 \mathrm{~m}$ (Hewitt et al., 1996; Thrush, 1986) to those ranging from $1 \mathrm{~m}$ to several $\mathrm{km}$ (Morrisey et al., 1992).

There is no evidence of gross pollution of the macrobiota, i.e. abiotic conditions, as a result of stormwater discharge at any of the stations sampled in the vicinity of the 7 outlets. However, there were fewer taxa at station S10 at AQ-1 $(0=10.7)$ and AQ-C $(0=9.7)$, station S20 at Q-1 $(0=5.7)$, station R20 at AQ-C $(0=6.3)$ and stations L15 $(0=7), \mathrm{S} 30(0=5), \mathrm{S} 45$ $(0=3.3)$ and L45 $(0=6.3)$ at OPT compared to the overall number of taxa at EB-C $(0=36.5)$, AQ-C $(0=16.8)$ and at Q-C $(0=21.2)$ in 1998 , and in 1999 there were fewer taxa at station $\mathrm{S} 10$ at AQ-2 $(0=12.7)$ compared to the overall number of taxa at AQ-C $(0=24.8)$. The low number of taxa at the AQ-C stations could result from sediment disturbance through shipping activities whereas the low number at the S10 station at AQ-1 and AQ-2 may be due to stormwater discharge and/or sediment disturbance through shipping activities. The low number at station S20 at Q-1 may be due to one or a combination of stormwater discharge, shipping activities and the operation of a boat refueling pump (used by commercial fishing vessels and pleasure craft) (this pump is no longer at this location) on the nearby wharf. At 
OPT there were more taxa at stations closer to than further way from the outlet, with low numbers at stations both under the wharf but $30 \mathrm{~m}$ or more away from the outlet, and in the adjacent marina. These differences in the number of taxa between stations could be due to:

- Sediment differences between stations-the sediment at stations S15 and R30 was gravelly sand or muddy sand while at stations.L15, S30, S45 and L45 it was mud (Fig. 3.11).

- Other factors such as rubbish, shipping activities and discharges from boats in the marina.

- Stormwater flow resulting in oxygenation of the surface sediment close to the outlet while further away the surface sediment is anoxic because there is little water movement and sediment disturbance. A low diversity and abundance of species occur in anoxic conditions (Diaz and Rosenberg, 1995).

At Aotea Quay and Queens Wharf the biological communities at outlet site stations became more similar to that at control site stations with increasing distance away from the outlet. This suggests that the biological community is affected by stormwater discharge, with the effect occurring at stations closer to but not further away from the outlets in these two areas. In Evans Bay the biological community changed with increasing distance from the outlets, with the biological community at stations furthest from both outlets the most different from those at the control site. In 1998 the biological community at EB-2 stations S24, L24, S34 and R34 were disturbed with very slight disturbance at L44 and no disturbance at S44, while those at all control site stations were not disturbed. This suggests that stormwater discharge has affected the biological community out to $34 \mathrm{~m}$ while the non-similarity of the biological community between that at the $44 \mathrm{~m} \mathrm{~EB}-2$ and EB-C stations could result from the spatial heterogeneity of the benthic macrobiota in Evans Bay rather than from stormwater discharge. At EB-1, the biological community at all stations was disturbed which could, at the 24 and $34 \mathrm{~m}$ stations result from stormwater discharge, and at the $44 \mathrm{~m}$ stations (in proximity to marina structures) result from marina activities. The non-similarity of the biological community between that at the $44 \mathrm{~m} \mathrm{~EB}-1$ and EB-C stations could result from the spatial heterogeneity of the benthic macrobiota in Evans Bay and/or the effect of marina structures and activities on the biological community.

In this study the biological community and univariate index analyses included, where there was sufficient data, analyses of taxonomic groups. The breakdown of the macrobiota into 
these groups was undertaken because sensitivity to contaminants varies between groups. For example, Warwick and Clarke (1994) found that annelids i.e. polychaetes, were generally the least sensitive to pollution followed by molluscs, arthropods and echinoderms in order of increasing sensitivity. Arthropods and molluses are known to be sensitive to elevated levels of metals (Chiaroni, 1998; Marsden et al., 2000; Roper and Hickey, 1994; Roper et al., 1995), and the response of polychaetes to sediment organic matter levels is well documented (Pearson and Rosenberg, 1978). However, in this chapter no attempt is made to determine if organic matter content or the concentration of each of the measured metals cause any of the distribution patterns detected for each of the taxonomic groups. Relationships between the macrobiota and the measured sediment organic matter levels and metal concentrations are investigated in Chapter 7.

Significant differences in all univariate indices i.e. number of total, polychaete, mollusc and arthropod taxa, number of total, polychaete, mollusc and arthropod individuals and diversity, occurred between outlet and control stations. However, these differences did not occur for all indices at all outlets rather the indices affected were outlet-specific, they were different over time and one (at AQ-1) to 7 (at AQ-2) indices were affected at any one outlet. At outlets AQ-1, Q-1, EB-1 and EB-2 all index values were lower than at the associated control, whereas at Q-2 $20 \mathrm{~m}$ there was higher diversity and a higher number of mollusc individuals than at Q-C $20 \mathrm{~m}$, at AQ-2 $10 \mathrm{~m}$ there was higher diversity and number of total, polychaete and individuals than at AQ-C $10 \mathrm{~m}$ and at AQ-2 $20 \mathrm{~m}$ more arthropod individuals than at AQ-C $20 \mathrm{~m}$. At Q-1, Q-2, EB-1 and EB-2 the lowest index values, when compared to those at the associated control site, occurred at stations close to the outlet however index values at the $30 \mathrm{~m}$ stations at AQ-1 and AQ-2 and the 44 station at EB-1 were also much lower than at the associated control site. Significantly lower index values at stations close to an outlet are possibly as a result of stormwater discharge. Lower index values at the Aotea Quay $30 \mathrm{~m}$ stations could be due to stormwater discharge and/or the effect of sediment disturbance through shipping activities at control and/or outlet sites. At EB-1 lower values at $44 \mathrm{~m}$ are more likely as a result of marina structures and activities than stormwater discharge because significant differences in indices occurred between the outlet and control 24 and $44 \mathrm{~m}$ but not the $34 \mathrm{~m}$ stations, and significant differences in 4 indices with distance from EB-1 were as a result of higher values at the $34 \mathrm{~m}$ than at 24 and/or $44 \mathrm{~m}$ stations (Table 5.18). However, the possibility that lower values at $44 \mathrm{~m}$ were due to the 
combined influence of stormwater discharge and marina structures and activities cannot be discounted.

There were significant differences in the number of total, polychaete, arthropod and mollusc taxa, polychaete and mollusc individuals and diversity with distance from at least one outlet. At AQ-1, Q-2 and EB-2 the lowest value of an index occurred close to the outlet with higher values further away. This suggests that stormwater discharge has caused the significant differences with distance from these outlets. At Q-1 significantly lower index values occurred at the $20 \mathrm{~m}$ than the $30 \mathrm{~m}$ stations which supports the previous assessment of one or a combination of factors affecting the macrobiota at the $20 \mathrm{~m}$ stations at this site i.e. stormwater discharge, shipping activities and the operation of a boat refuelling pump on the nearby wharf. At EB-1 higher index values occurred at $34 \mathrm{~m}$ than at 24 and/or $44 \mathrm{~m}$ i.e. the least affected macrobiota at this site occurred at the $34 \mathrm{~m}$ stations with that at $24 \mathrm{~m}$ affected by stormwater discharge and that at $44 \mathrm{~m}$ by the factor/s mentioned in the paragragh above. At OPT the results are anomalous as the lowest index values occurred at $45 \mathrm{~m}$ i.e. the stations furthest away from the outlet. The possible reasons for the differences in index values at this site are outlined in paragraph 2 of this discussion.

In this study differences in the abundance of selected taxa between outlet and control stations and with distance and direction from an outlet was evaluated. Taxa used in the analyses were selected because of their overall abundance in an area and because a sufficient number of individuals occurred at a site and at stations at a site. Consequently the taxa analyzed varied between areas (Aotea Quay, Queens Wharf and Evans Bay) and overall only 35 of the 227 taxa recorded were assessed.

Of the selected taxa, the bivalve molluses Arthritica bifurca, Dosina zelandica, Gari stangeri and Theora lubrica, the arthropod Proharpinia spp., the echinoderm Amphiura sp. and the polychaetes Armandia maculata (Queens Wharf and Evans Bay), Exogone sp.A, Glycera ovigera, Heteromastus filiformis (Queens Wharf), Hemipodus simplex, Hesionid sp.A, Owenia fusiformis, Paraprionospio pinnata, Prionospio spp, Prionospio yuriel, Schistomeringos loveni? (in Evans Bay) and Questa sp. were significantly more abundant at some control than associated outlet stations. Lower abundances of these taxa at outlet stations could be due to stormwater discharge but this may not account for all differences. At the Aotea Quay outlets in 1998 the lower abundances occurred at the 20 and $30 \mathrm{~m}$ but not 
the $10 \mathrm{~m}$ stations, therefore the differences could be due to stormwater discharge and/or the effect of sediment disturbance through shipping activities at control and/or outlet sites or other factors. In Evans Bay at all stations at both outlet sites in 1998, 6-10 of these taxa were significantly less abundant and 5-9 taxa were significantly more abundant than at the control site. While these differences could, particularly at stations closer to the outlet, be due to stormwater discharge the situation in Evans Bay is complex because of the presence of marina structures at EB-1, the heterogeneity of the macrobiota in Evans Bay (as evidenced at the control site), and the non-similarity of the macrobiota between that at both EB-1 and EB-2 $44 \mathrm{~m}$ to EB-C $44 \mathrm{~m}$ (Fig 5.8).

By comparison the polychaetes Capitella spp., Armandia maculata (Aotea Quay), Heteromastus filiformis (Aotea Quay and Evans Bay), Pseudopolydora cf. paucibranchiata and Schistomeringos loveni (at Aotea Quay) were significantly more abundant at some outlet than associated control stations i.e. stormwater discharge could have resulted in the increased abundance of these taxa. Of note is that the difference in abundance between outlet and control was anomalous for the polychaetes Armandia maculata, Heteromastus filiformis, Pseudopolydora cf. paucibranchiata and Schistomeringos loveni?, with these taxa being more abundant at the control in some areas and more abundant at an outlet in other areas. The presence and abundance of a taxon results from the complex interaction of biotic and abiotic (including contaminants) factors. As a range of contaminants are discharged in stormwater and the type and amount of contaminant is outlet specific, the biotic effects will be different at different outlets. The relationship of the selected taxa to organic matter levels and metal concentrations are investigated in Chapter 7.

The abundance of the polychaetes Armandia maculata, Capitella spp., Heteromastus filiformis (EB-1 1999), Hesionid sp.A, Ophiodromus sp., Prionospio aucklandica, Prionospio yuriel (EB-2 1998) and Schistomeringos loveni?, and the amphipod Proharpinia spp. (EB-1 1999) was significantly higher closer to than further away from one or more of the outlets while the polychaetes Owenia fusiformis, Heteromastus filiformis (Q-2, EB-1 and EB-2, 1998) Prionospio yuriel (Q-2, 1998) and the amphipods Corophium acherusicum and Meridiolembos sp. (EB-2) were significantly more abundant at stations further away than closer to an outlet. These differences in abundance with distance from an outlet could be due to stormwater discharge. 
At both outlet and control sites differences occurred in the biological community, univariate indices and taxa abundance with direction. However, at each site the lack of a consistent direction pattern through all these measures precluded any definite statement on the direction of impact of stormwater discharge on the macrobiota. Any attempt to elucidate a direction effect in this study is exacerbated by a range of other factors i.e. the influence of wharf or marina structures, disturbance activities such as shipping and the spatial heterogeneity of the macrobiota.

The impact of stormwater discharge on the benthic macrobiota has been found in other studies to include: a small decrease in the mean number of individuals and a small increase in the mean number of species and Shannon-Weiner diversity with increasing distance from an outlet (Botherway and Gardner, 2002); low species diversity and a lower number of individuals in the vicinity of an outlet (ORC, 1998); and a depauperate biological community and the presence and abundance of the polychaete Capitella (designated as capitata) (Bioresearches, 1997). In this study partial dominance plots were used to ascertain if stormwater discharge resulted in disturbed biological communities while the ordination of the biological community provided the foundation for the interpretation of both the structure of the macrobiota in an area and biotic differences with distance and direction from the shore or an outlet. However, detailed statistical analyses of the Univariate indices which included the taxonomic groups - molluscs, arthropods and polychaetes, and individual taxa have been used to pinpoint the possible effects of stormwater discharge on the macrobiota. From the findings of this and the other studies it has been found that no one biological measure can be used to determine impact. A range of parameters (Univariate and Multivariate, biological community, biological indices and individual taxa) are required to assess the impact and the extent of impact of stormwater discharge on the benthic macrobiota. In addition, the biological impact of stormwater discharge is outlet specific.

In this study it was found that the outward extent of impact of stormwater discharge on the benthic macrobiota in Wellington Harbour was site-specific and of the order of tens of metres (Tables 5.18 and 5.19). These results support the findings from New Zealand studies in Porirua Inlet (Botherway and Gardner, 2002), Auckland Harbour (Bioresearches, 1997) and Otago Harbour (ORC, 1998). The discharge of stormwater from an outlet in Porirua Inlet was found to have impacted the intertidal benthic macrobiota at $5 \mathrm{~m}$ but not at $90 \mathrm{~m}$ away from the outlet (Botherway and Gardner, 2002). Stormwater discharge from two 
outlets in Auckland Harbour impacted subtidal communities to at least $30 \mathrm{~m}$ (the distance limit of sampling), while discharge from outlets in Otago Harbour impacted subtidal communities to at least $30 \mathrm{~m}$ at some outlets (ORC, 1998). The results from the present study and the studies mentioned above highlight the need for detailed sampling over a small spatial scale i.e. 5 to 10 's of metres, in order to quantify the extent of impact of stormwater discharge on the benthic macrobiota.

\subsection{CONCLUSIONS}

The data strongly suggest that stormwater discharge has resulted in:

- Disturbed biological communities

- Changes in the biotic community with increasing distance from an outlet

- A low number of taxa at some stations

- Lower values in one or more of the indices (total, molluse, arthropod and polychaete taxa and total, mollusc, arthropod and polychaete individuals and Shannon-Weiner diversity) at Q-1, Q-2, EB-1 and EB-2 stations compared with the associated control stations.

- Significant differences in one or more of the indices number of total, polychaete, arthropod and mollusc taxa, polychaete and mollusc individuals and diversity with distance from AQ-1, Q-2 and EB-2.

- Lower abundances of 18 taxa at some outlet than at associated control sites

- Higher abundances of 5 taxa at some outlet than at associated control sites

- Significant differences in the abundance of 12 taxa with distance from an outlet.

The impact of stormwater discharge on the benthic macrobiota is outlet specific.

The impact and extent of impact of stormwater discharge on the benthic macrobiota can change over time.

The outward extent of the impact of stormwater discharge on the benthic macrobiota has been ascertained at all outlets except OPT. The extent of impact ranged from $10-44$ ? $\mathrm{m}$.

No one biological measure can be used to assess the impact and extent of impact of stormwater discharge on the benthic macrobiota; rather a range of parameters (Univariate and Multivariate, biological community, biological indices and individual taxa) need to be measured. 


\section{Chapter 6}

\section{TEMPORAL VARIABILITY OF THE BENTHIC MACROBIOTA}

\subsection{INTRODUCTION}

In natural marine populations an organism's abundance is the function of a complex of physical and biological processes/disturbances acting on its natality, recruitment, mortality, immigration and emigration. Temporal differences in the presence and abundance of an organism results from variations in it's natality, recruitment, mortality, immigration and emigration, and variations in the complex of physical and biological processes/disturbances acting on these population attributes. The biological processes include competition, predation (Thrush, 1999) and disturbance, for example the digging and foraging activities of animals such as crabs and rays (Thrush, 1986; Thrush et al., 1991). Physical processes include the normal seasonal and annual fluctuations in temperature and weather in an area, changes in sediment type (Livingston, 1987; Nichols and Thompson, 1985), and storms (Dodds and Vozarik, 1983). Short and long term changes in abundance can also occur as a result of the tidal cycle (Morrisey et al., 1992) and phenomena such as El Niño (Lee and Pritchard, 1996; Stull et al., 1986) respectively. Hence temporal variations in the presence and abundance of an organism can occur at scales of days to months to years (Dauer and Alden, 1995; Morrisey et al., 1992; Stull et al., 1986).

In addition to the natural processes acting on the presence and abundance of the macrobiota, there is in the vicinity of stormwater outlets physical disturbance through temporally irregular flows of differing volumes of stormwater containing differing quantities of suspended solids and contaminants (Mosley et al., 1997). Therefore stormwater discharge, which is ongoing and consists of differing physical influences i.e. sediment deposition, contaminant deposition and flow, has the potential to be an important physical process affecting the temporal variability of the macrobiota in the vicinity of stormwater outlets.

The aim of this section of the study was to investigate the temporal variability of the macrobiota. Temporal differences in the presence and abundance of the macrobiota between outlet and control sites could be due to the effect of stormwater discharge. To this end the 
biological community, univariate indices and the presence and abundance of selected taxa at outlet and control sites over time were investigated.

\subsection{METHODS}

\subsubsection{Sample Collection}

Sampling was carried out at station S10 at AQ-2, AQ-C and station S24 at EB-2 and EB-C every month for a year (from August 1998 to July 1999) and then quarterly for 15 months (from August 1999 to November 2000) (File: Sampling dates, Appendix II).

At each station 7 randomly collected samples of $0.011 \mathrm{~m}^{2}$ were taken to a depth of $15 \mathrm{~cm}$ deep by a SCUBA diver using purpose-built stainless steel samplers. Six of these samples were processed, with the seventh available for use in case of accidental spillage or sample loss.

\subsubsection{Sample Processing}

Each sample was sieved through a $0.5 \mathrm{~mm}$ screen using a gentle flow of seawater.' The material retained on the screen was fixed and preserved in formol $(10 \%$ formalin in seawater) for at least $24 \mathrm{~h}$ and then rinsed with freshwater, stained with Rose Bengal, and stored in $70 \%$ isopropanol until further processing was undertaken. The organisms present in each sample were sorted from the sediment using a dissecting microscope and stored in $70 \%$ isopropanol for later identification and counting. Organisms were identified where possible to the species level using a wide range of reference literature (Monro, 1930, 1936; Knox, 1960; Jones, 1963; Day, 1967; Cooper, 1969; Pawson, 1970; Barnard, 1972; Knox and Green, 1972a, 1972b; Rainer, 1973; Melrose, 1975; Read, 1975; Day, 1977; Fauchald, 1977; Blake and Kudenov, 1978; Day and Hutchings, 1979; Powell, 1979; Blake, 1984; McLay 1988; Spencer and Willan, 1995; Glasby, 1984; Glasby and Read, 1998; Bradford-Grieve, 1999; Beesley et al., 2000; Read, 2000; Böggemann and Fiege, 2001; www. museum.vic.govt.au.; keys for New Zealand Lumbrinerid (Hilbig and Glasby), and Glyceridae (Glasby) polychaetes and keys to the polychaete families Cirratulidae and Paraonidae (provided by C. Glasby)). A reference collection was built up and identifications verified by: Dr. N. Bruce (Isopoda), S. Eagar (Ostracoda), Dr. G Fenwick (Amphipoda), Dr. C. Glasby (Polychaeta), and Dr. B Marshall (Mollusca). 


\subsubsection{Data Analyses}

Data were analysed using and following recommendations of the software package PRIMER (version 5) (Plymouth Routines in Multivariate Ecological Research, Clarke and Warwick, 1994). Other statistical tests were carried using either SYSTAT (version 6.1) or STATISTICA (version 5.5).

\subsection{3.a The Biological Community}

\subsection{3.a.1 Determining if the Biological Community is Disturbed}

Partial dominance curves were used to determine if:

1. The biological community at outlet and control stations was disturbed on each sampling occasion.

2. There was a change in disturbance of the biological community at outlet and control stations over time.

Using biological community abundance data a partial dominance curve was constructed for each station (6 replicates) at each site on each sampling occasion. Partial dominance curves were used because it is recognised that in disturbed environments, as is expected in the vicinity of stormwater outlets, they better represent disturbance effects than does a cumulative dominance curve (Clarke, 1990; Clarke and Warwick, 1994). Partial dominance curves plot the abundance of each species relative to the total abundance of itself and all other less abundant species i.e. the dominance of the first ranked species is relative to itself and all remaining species, the dominance of the second ranked species is relative to itself and all remaining species ignoring the abundance of the first ranked species, and so on (Clarke and Warwick, 1994). Thus if $a_{i}$ is the absolute abundance of the $i$ th species, when ranked in decreasing abundance order, the partial dominance curve is a plot of $\mathrm{p}_{i}$ against $\log i$ ( $i=1$, $2 \ldots \ldots \ldots$, S-1) where

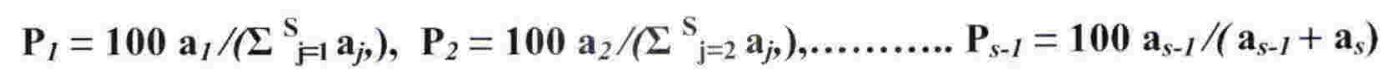

Consequently earlier values can never affect later points on the curve. For undisturbed communities the plot is "a rather smooth abundance curve, decreasing slightly in the initial stages and then remaining largely constant before the inevitable final rise, as the number of species making up the denominator term drops towards unity" (Clarke, 1990). By comparison the abundance curve for a disturbed community is "much more variable. This implies that pollution effects are not just seen in changes to a few dominant species but are a 
phenomenon which pervades the complete suite of species in the community" (Clarke and Warwick, 1994).

\subsection{3.a.2 Patterns of Community structure}

The null hypothesis to be tested is:

There is no difference in the temporal pattern of change of the biological community between that at an outlet site and that at the associated control site.

Multi Dimensional Scaling (MDS) plots were used to investigate the pattern of change in community structure at each station over time. The average abundance (from 6 replicates) of each taxa at each station was $\log (\mathrm{x}+1)$ transformed. From the transformed data a similarity matrix was generated using the Bray-Curtis similarity measure. Non-metric MDS was performed on the similarity matrix to produce a 2 dimensional ordination of stations. In the plots, sampling times have been linked in chronological order, which, according to Warwick and Clarke (1994) and Fromentin et al., (1997), is a means of showing the direction of temporal change.

\subsection{3.b Univariate Indices}

The univariate biological indices of total number of taxa (S) and individuals (N), ShannonWeiner diversity indice $\left(\mathrm{H}^{\prime}\right)$, number of taxa of molluses $\left(\mathrm{S}_{\mathrm{m}}\right)$, polychaetes $\left(\mathrm{S}_{\mathrm{p}}\right)$ and arthropods $\left(\mathrm{S}_{\mathrm{a}}\right)$ and number of individuals of molluscs $\left(\mathrm{N}_{\mathrm{m}}\right)$, polychaetes $\left(\mathrm{N}_{\mathrm{p}}\right)$ and arthropods $\left(\mathrm{N}_{\mathrm{a}}\right)$ were enumerated for the 6 samples at each station at each site on each sampling occasion.

The null hypotheses to be tested were:

There is no significant temporal difference in each index (i.e. $S, N, \mathbf{H}^{\prime}, S_{m}, S_{p}, S_{a}, N_{m}, N_{p}$, $\mathbf{N}_{\mathrm{a}}$ ) at each site.

There is no significant difference in each index (i.e. $\mathrm{S}, \mathbf{N}, \mathbf{H}^{\prime}, \mathrm{S}_{\mathrm{m}}, \mathrm{S}_{\mathrm{p}}, \mathrm{S}_{\mathrm{a}}, \mathbf{N}_{\mathrm{m}}, \mathbf{N}_{\mathrm{p}}, \mathbf{N}_{\mathrm{a}}$ ) between that at an outlet site station to that at the associated control site station, over time.

To test these hypotheses, a multifactorial GLM ANOVA of each index against the two factors of site and time was performed, resulting in the total model, the individual factors of site and time and the 2-way interaction of site $\mathrm{x}$ time. Site was a fixed factor while time was a random 
factor. Where significant effects occurred, a posteriori multiple comparisons were performed using the Student-Newmans-Keuls test. From the a posteriori comparisons any significant temporal differences in each index, within a site and between outlet and control sites, could be determined.

Cochran's test ( $\alpha=0.05$ ) for Homogeneity of Variance (Underwood, 1981) was carried out on the raw data and where variances were heterogeneous the data were transformed. For all indices the data remained heteroscedastic (Cochran's $C, \alpha=0.05$ ) following transformation (square root, $4^{\text {th }}$ root, $\log (x+1)$ transformations were all trialed). Multifactorial GLM ANOVA was still performed on the untransformed data however cautious interpretation of the results is required (Underwood, 1981).

\subsection{3.c Temporal Patterns of Taxon Abundance}

At each site the total number of individuals in each taxa, over all sampling occasions, was calculated. From these totals, comparisons, of the presence and abundance of taxa between outlet and control sites in each area i.e. between AQ-2 and AQ-C and between EB-2 and EB$\mathrm{C}$, were made. Taxa with a total of $\leq 20$ individuals (i.e. $\sim 1$ individual per sampling) have not been included in the comparisons because they are relatively uncommon and occurrence may be due to chance alone. Even for the taxa with $>20$ individuals differences in abundance between the outlet and associated control site may be due to chance.

At each site, SIMPER analysis of the biota $(\log (x+1)$ transformed data) between consecutive sampling occasions i.e. Time1-Time2, Time2-Time3 etc., was carried out and a table constructed of those species contributing $\geq 2.5 \%$ to the biotic dissimilarity. The total number of times each taxa contributed to $\geq 2.5 \%$ dissimilarity was then calculated and used to determine the taxa whose abundance changed the most over time.

For taxa with $\geq 100$ individuals at a site over time, plots of the average abundance over time were constructed. From the plots, temporal patterns in abundance of taxa were ascertained with the focus being on recruitment events. Recruitment is defined as the integrated settlement of larvae into the sediment, early post-settlement events and immigration of juveniles and adults from adjacent habitats (Renaud et al, 1999). In this study recruitment was inferred when there was a large increase in taxa abundance between consecutive sampling 
occasions. As the size of individuals was not measured, the increase in abundance could result from the immigration of individuals from elsewhere and/or from the settlement of juveniles.

\subsection{RESULTS}

Sampling was carried out on 18 occasions at AQ-2, AQ-C, EB-2 and EB-C. However, samples collected at EB-C in January 1999 were discarded as they were too poorly preserved to analyse, and samples collected at EB-2 in May 2000 were discarded because the samples collected were not in the vicinity of the site marker (the site marker was not found due to poor water visibility).

\subsubsection{The Biological Community}

220 taxa consisting of 46 molluscs, 68 arthropods, 94 polychaetes, 5 echinoderms and 7 others (oligochaeta, Nemertea, Coelenterata, Pycnogonida, Platyhelminthes and Phoronida) were identified (File: Species List in Appendix IV).

A total of 93,404 individuals were recorded from the samples collected over time. Of these individuals, $80.1 \%$ were polychaetes, $7.8 \%$ molluscs, $5.8 \%$ arthropods, $0.2 \%$ echinoderms and $6.4 \%$ other taxa. A summary of the composition of the macrobiota at each site is presented in Table 6.1.

Table 6.1: The macrobiota (taxa and individuals) present at each site over time

\begin{tabular}{|lllll|}
\hline & AQ-2 & AQ-C & EB-2 & EB-C \\
\cline { 2 - 5 } Total taxa & 113 & 116 & 137 & 154 \\
Total individuals & 24,153 & 15,749 & 21,780 & 33,247 \\
Mollusc taxa & 17 & 16 & 34 & 34 \\
Mollusc individuals & 672 & 460 & 1512 & 4622 \\
Polychaete taxa & 60 & 60 & 58 & 61 \\
Polychaete individuals & 23,063 & 14,951 & 17,410 & 22,351 \\
Arthropod taxa & 28 & 33 & 37 & 49 \\
Arthropod individuals & 209 & 280 & 1592 & 3330 \\
Echinoderm taxa & 2 & 1 & 3 & 5 \\
Echinoderm individuals & 2 & 1 & 68 & 119 \\
Other taxa & 5 & 5 & 5 & 5 \\
Other individuals & 207 & 57 & 1198 & 2825 \\
\end{tabular}




\subsection{1.a Temporal changes in biological community disturbance}

Partial dominance plots were constructed for each station at each site on each sampling occasion. All plots were analysed, however not all are presented with only 6 plots from the Aotea Quay and Evans Bay sites presented (Figs. 6.1 and 6.2).

The biological community at station S10 at both AQ-2 and AQ-C was disturbed while that at EB-2 was slightly disturbed on all sampling occasions (Figs. 6.1 and 6.2). At these sites the effect of disturbance on the biological community was different on different sampling occasions with differences occurring as changes in:

- the values for species of rank 1

- the shape of the curves

- the total number of species

Based on these differences, the biological community at AQ-2 was more disturbed in December 1998, January 1999, June 1999, November 1999 and November 2000, that at AQC was more disturbed in October 1998 and January 1999 and that at EB-2 more disturbed in October 1998, than on other sampling occasions.

At station S24 at EB-C there was little change in the shape of the partial dominance plots over time. An undisturbed biological community occurred at this station on all sampling occasions.

\subsection{1.b Temporal changes in the biological community}

Two-dimensional MDS plots $(\log (x+1)$ transformed data) were used to investigate patterns of biological community structure at outlet and control stations over time. In the plots sampling times have been linked in chronological order to show the direction of the temporal changes.

\section{Aotea Quay}

The biological community at AQ-2 in November 2000 (Sampling Time 18) was distinctly different from that present at AQ-2 and AQ-C on all other sampling occasions (insert of Fig. 6.3A). The MDS ordination of the biological community on all sampling occasions except at AQ-2 in November 2000, gives a clearer picture of changes in the biological community at each Aotea Quay site over time (Fig. 6.3A). On all sampling occasions, except August 2000, there was a separation of the biota at AQ-2 from that at AQ-C. At both sites the composition of the biological community was highly variable with the greatest temporal changes, as determined by the distance between sequential sampling periods, occurring at AQ-C. 


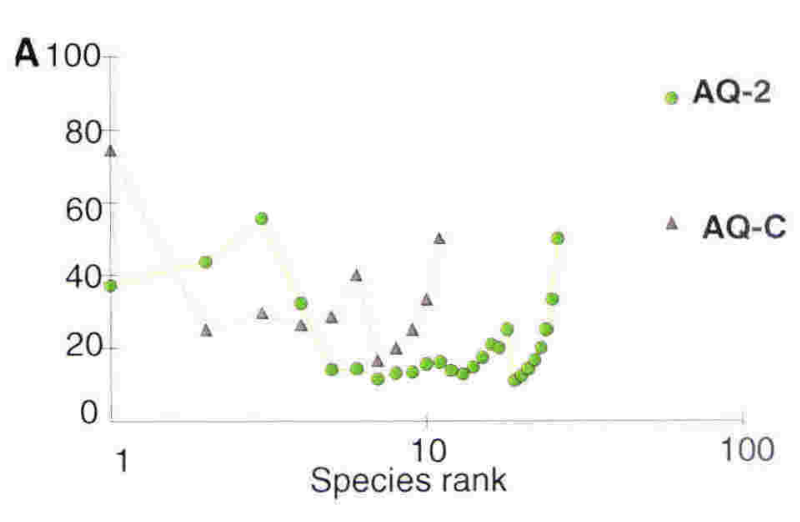

$\mathrm{B}_{100}$
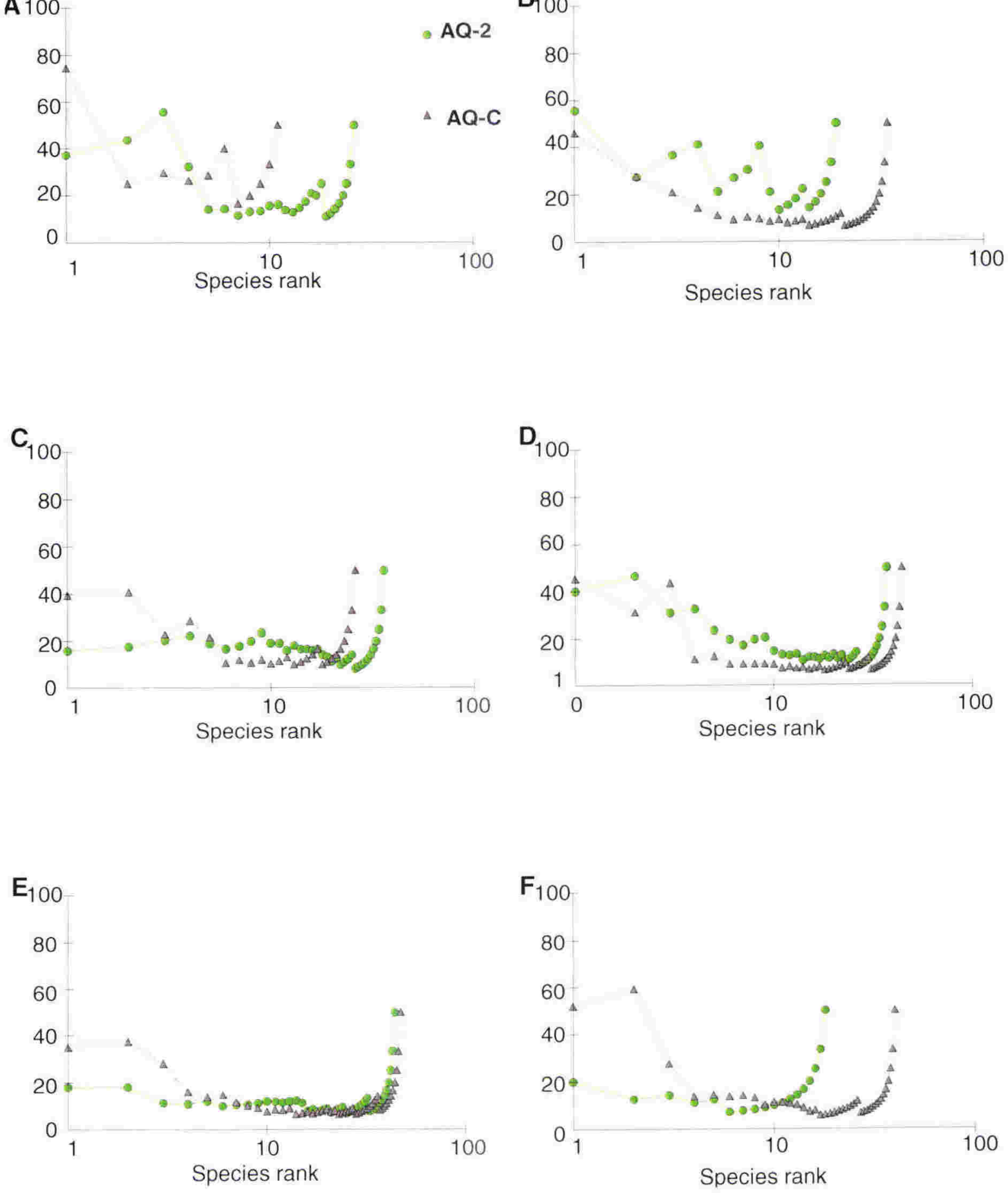

Figure 6.1: Partial Dominance Plots, at station S10 at the Aotea Quay outlet and control sites on six different sampling occasions.

$\mathrm{AQ}-2$ - Green circles $\quad \mathrm{AQ}-\mathrm{C}$ - Grey triangles

A - October 1998, B - December 1998, C - March 1999, D - August 1999,

E - May 2000, F - November 2000 

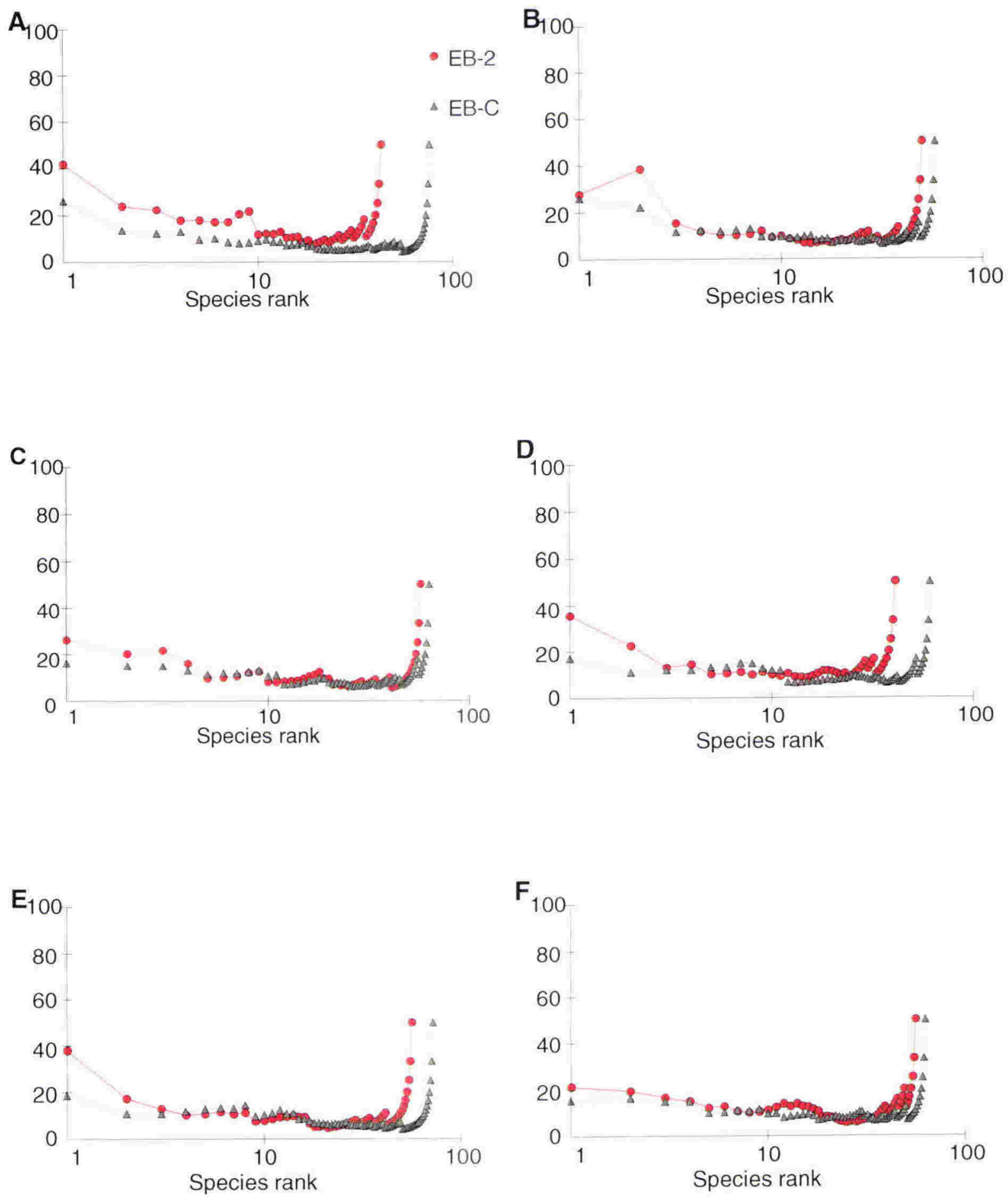

Figure 6.2: Partial Dominance Plots, at station S24 at the Evans Bay outlet and control sites on six different sampling occasions.

EB-2 - Red circle, EB-C - Grey triangle

A - October 1998, B - December 1998, C-March 1999, D - April 1999.

E-November 1999. F- February 2000. 
A

18
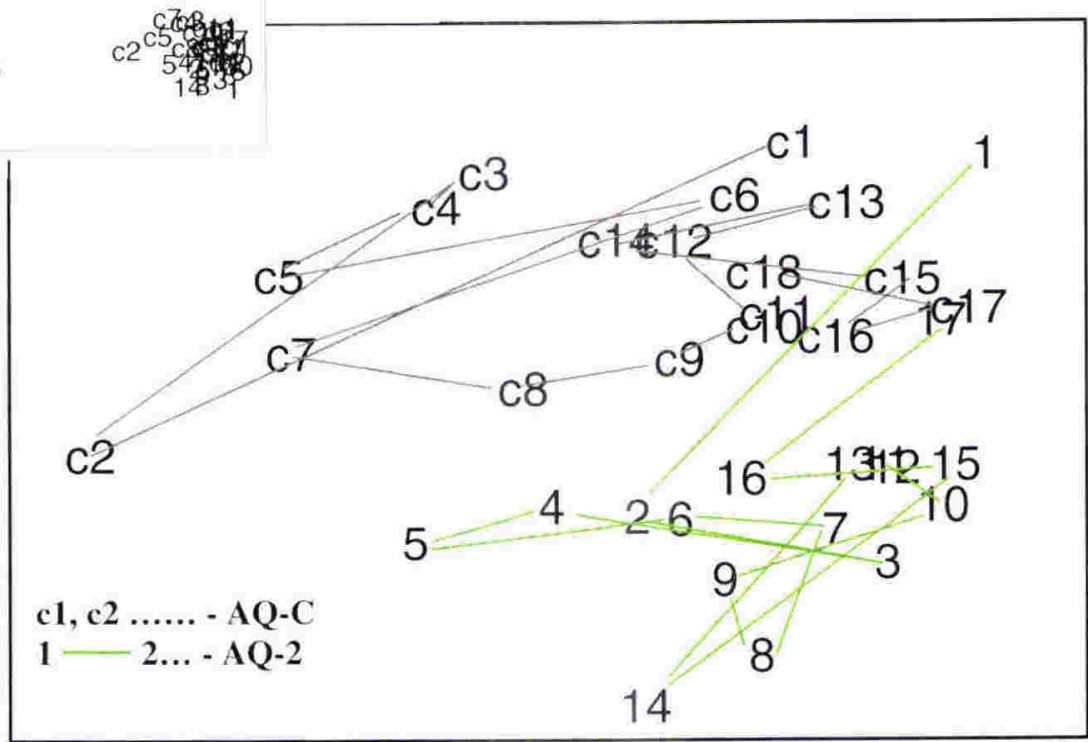

B

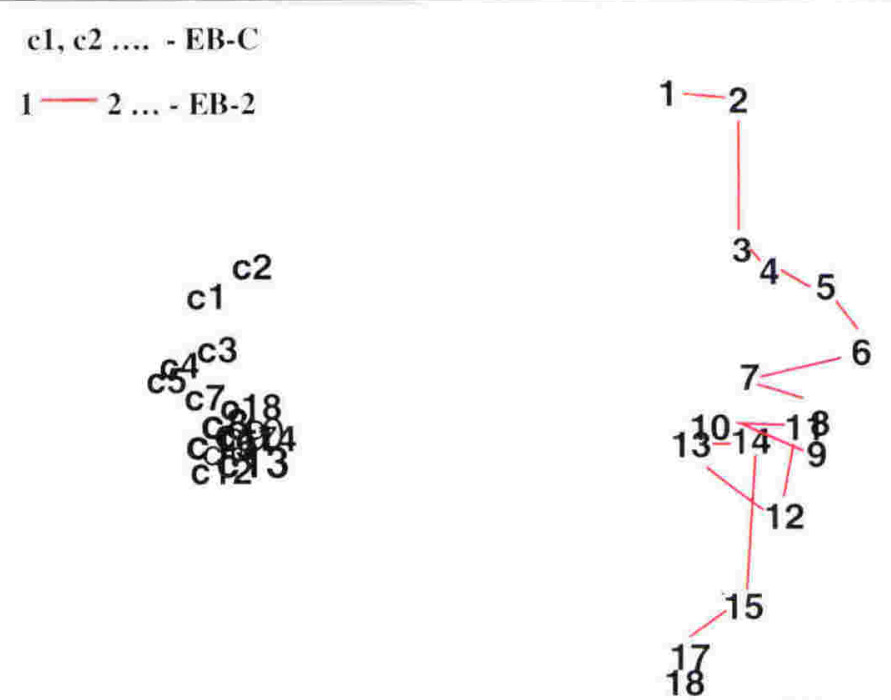

Figure 6.3: MDS of the biological community over time at outlet and control sites A - Aotea Quay- insert includes AQ-2 November 2000 (Time 18 (Stress=0.15), large plot includes all except AQ-2 November 2000 (Stress $=0.20$ )

B - Evans Bay (stress $=0.1$ )

Times : 1 - August 98, 2 - September 98,3-October 98, 4 - November 98 5 - December 98,6 - January 99, 7 - February 99, 8 - March 99 9 - April 99, 10 - May 99, 11 - June 99, 12 - July 99, 13 - August 99 14 - November 99, 15 - February 00, 16 - May 00, 17 - August 00 18 - November 00 
The direction of change in the biological community at AQ-2 was different to that at AQ-C. At both sites there was no apparent seasonal or annual pattern to the change in the biological community over time.

\section{Evans Bay}

The biological community at EB-2 was separated from that at EB-C on all sampling occasions (Fig. 6.3B). Over time small changes occurred in the biological community at EB-C, while at EB-2 the biological community changed continuously with the largest changes being between October-November 1998, February-March 1999 and November 1999-February 2000. There was no apparent seasonal or annual pattern to the change in the biological community at EB-2 over time.

The null hypothesis that there is no difference in the temporal pattern of change of the biological community between that at an outlet site and that associated control site is rejected. At both Aotea Quay and Evans Bay the temporal pattern of change of the biological community at the outlet site differed from that at the control site.

\subsubsection{Univariate Indices}

To determine if there were significant temporal differences in the total number of taxa $(\mathrm{S})$ and individuals $(\mathrm{N})$, Shannon-Weiner diversity indice $\left(\mathrm{H}^{\prime}\right)$, number of taxa of molluscs $\left(\mathrm{S}_{\mathrm{m}}\right)$, polychaetes $\left(\mathrm{S}_{\mathrm{p}}\right)$ and arthropods $\left(\mathrm{S}_{\mathrm{a}}\right)$ and number of individuals of molluses $\left(\mathrm{N}_{\mathrm{m}}\right)$, polychaetes $\left(\mathrm{N}_{\mathrm{p}}\right)$ and arthropods $\left(\mathrm{N}_{\mathrm{a}}\right)$, at each site and between outlet and associated control stations, a GLM ANOVA were performed on each index (Files: Indices Time and ANOVA Time in Appendix IV).

\subsection{2.a Aotea Quay}

For each index, except the number of polychaete individuals, the data has been plotted (Figs. 6.4-6.6). The polychaete individual data were not plotted because it is almost identical to that for the total number of individuals as the macrobiota at Aotea Quay was predominantly polychaetes i.e. low numbers of mollusc and arthropod individuals occurred.

\subsection{2.a.1 Comparison between the outlet and control site over time}

In November 2000 significantly fewer total taxa and polychaete taxa and in November 1999 fewer polychaete taxa occurred at AQ-2 than AQ-C. By comparison significantly more total 
and polychaete individuals occurred at AQ-2 than at AQ-C in November 1998, June 1999 and August 1999 with significantly more polychaete individuals also in April 1999. On 6 of the 18 sampling occasions significant differences occurred between the outlet and control site in the Shannon-Weiner diversity value, with diversity being higher at AQ-2 than at AQ-C on 4 of these occasions and higher at AQ-C than AQ-2 on the other 2 occasions. For the number of mollusc and arthropod taxa and individuals there was no significant difference between outlet and control site values on any sampling occasion.

\subsection{2.a.2 Temporal differences at each site}

Temporal differences for an index consisted of either significantly lower or higher values on one or more sampling occasions compared to other occasions (Table 6.2, Figs. 6.4 - 6.6). At AQ-2 and AQ-C there were significant differences in the number of total, mollusc and polychaete taxa, total and polychaete individuals and diversity but no significant differences in the number of arthropod taxa and individuals over time (File: ANOVA time in Appendix IV). At AQ-2 there were also significant differences in the number of mollusc individuals over time, but this was not so at AQ-C. The temporal difference in each index, except the number of mollusc taxa, was different at each site, an indication that the factors influencing the biota are site-specific. At AQ-2 there was no consistent temporal pattern among the indices, while at AQ-C a higher number of total and mollusc taxa and total and polychaete individual occurred in August 2000.

\subsection{2.b Evans Bay}

The data for each index at the Evans Bay sites has been plotted (Figs. 6.7-6.9).

\subsection{2.b.1 Comparison between the outlet and control site over time}

At EB-2 there were significantly fewer molluse taxa on all, fewer total taxa on 8, fewer molluse individuals on 10 , and lower Shannon-Weiner diversity on 4 , of the 16 (while sampling occurred on 18 occasions on only 16 of these were samples collected from both EB2 and EB-C) sampling occasions than at EB-C. For the number of arthropod taxa, values at EB-2 were significantly lower on 2 and significantly higher on 1 occasion and for the number of arthropod individuals significantly lower on 7 and significantly higher on 1 occasion, than at EB-C. Significantly more mollusc individuals occurred at EB-2 than EB-C in September 1998. For the number of polychaete taxa and total and polychaete individuals there was no significant difference between the outlet and control site values on any sampling occasion. 


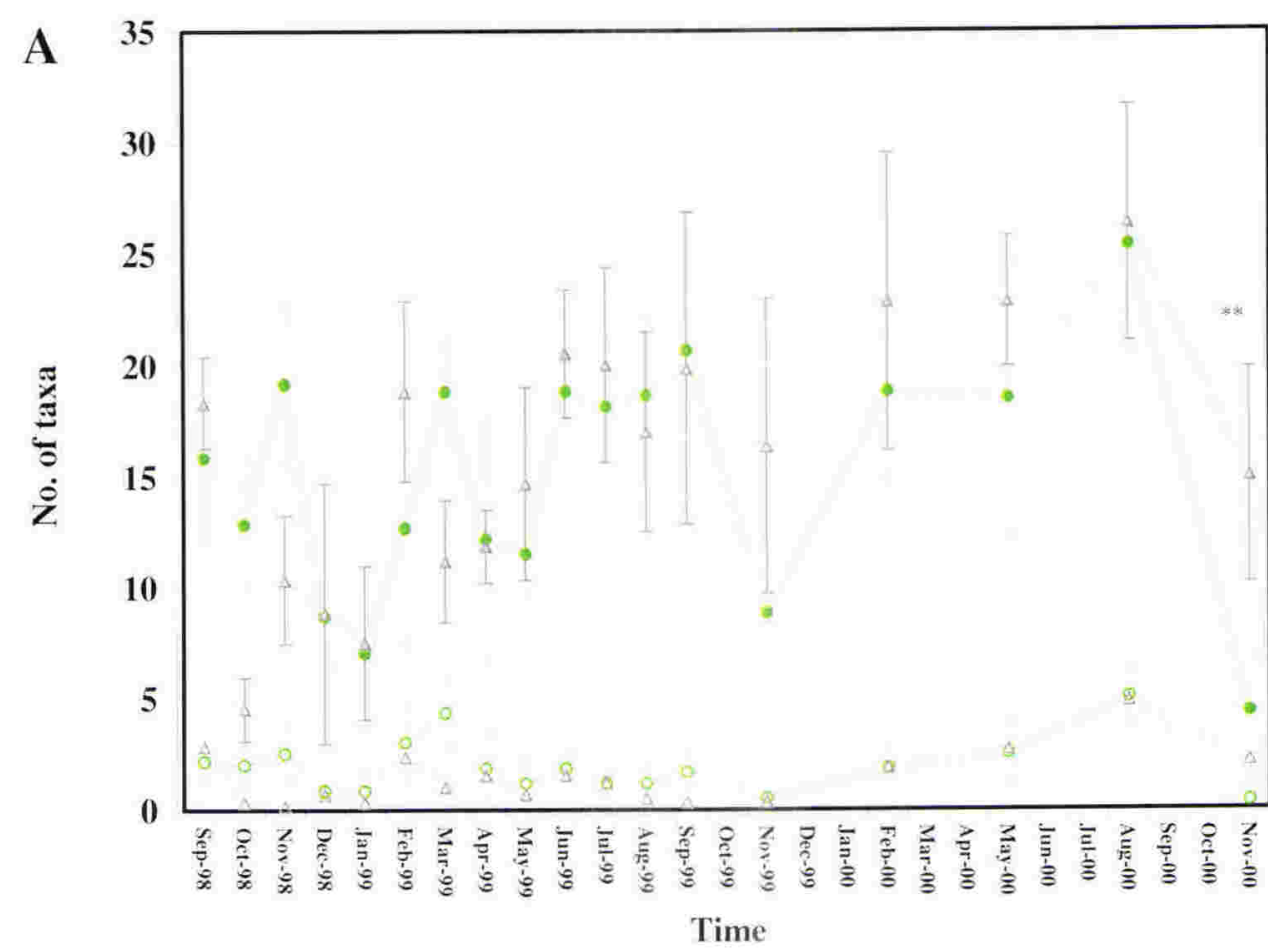
- AQ-2 Total
$\triangle$ AQ-C Total
AQ-2 Molluse
$\triangle$ AQ-C Mollusc

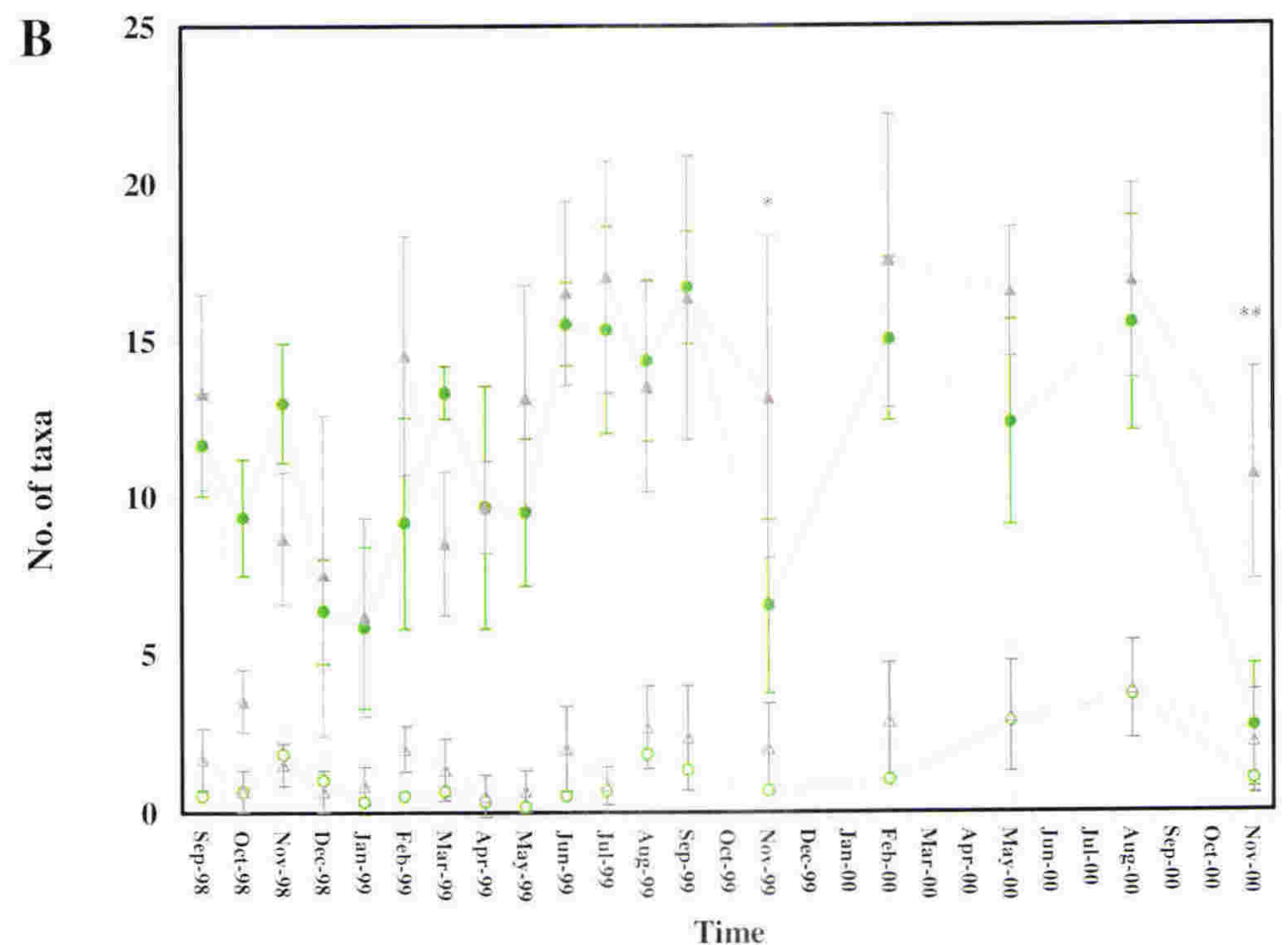

AQ-2 Polychaete
AQ-C Polychaete
AQ-2 Arthropod
AQ-C Arthropod

Figure 6.4: Number (mean $\pm 95 \% \mathrm{CI}$ ) of taxa at the Aotea Quay outlet and control site over time.

A: Number of total and molluse taxa

B: Number of polychaete and arthropod taxa

Significant differences between outlet and control values designated by $* \mathrm{p} \leq 0.05, * * \mathrm{p} \leq 0.01, * * * \mathrm{p} \leq 0.001$, otherwise no significant difference 

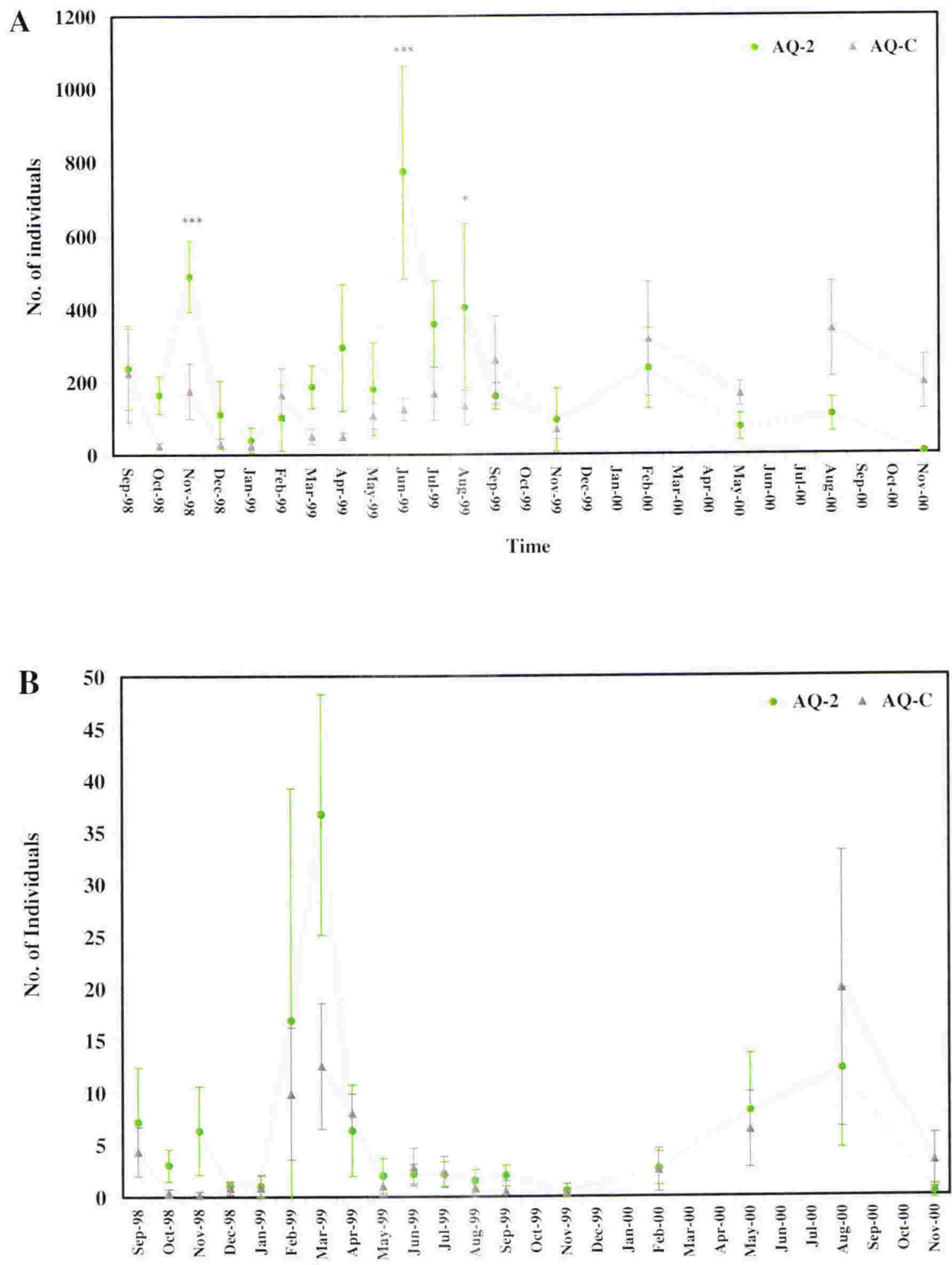

Time

Figure 6.5: Number (mean $\pm 95 \%$ CI) of individuals at the Aotea Quay outlet and control site over time. A: Number of total individuals

B: Number of mollusc individuals

Significant differences between outlet and control values designated by

$* \mathrm{p} \leq 0.05, * * \mathrm{p} \leq 0.01, * * * \mathrm{p} \leq 0.001$, otherwise no significant difference 


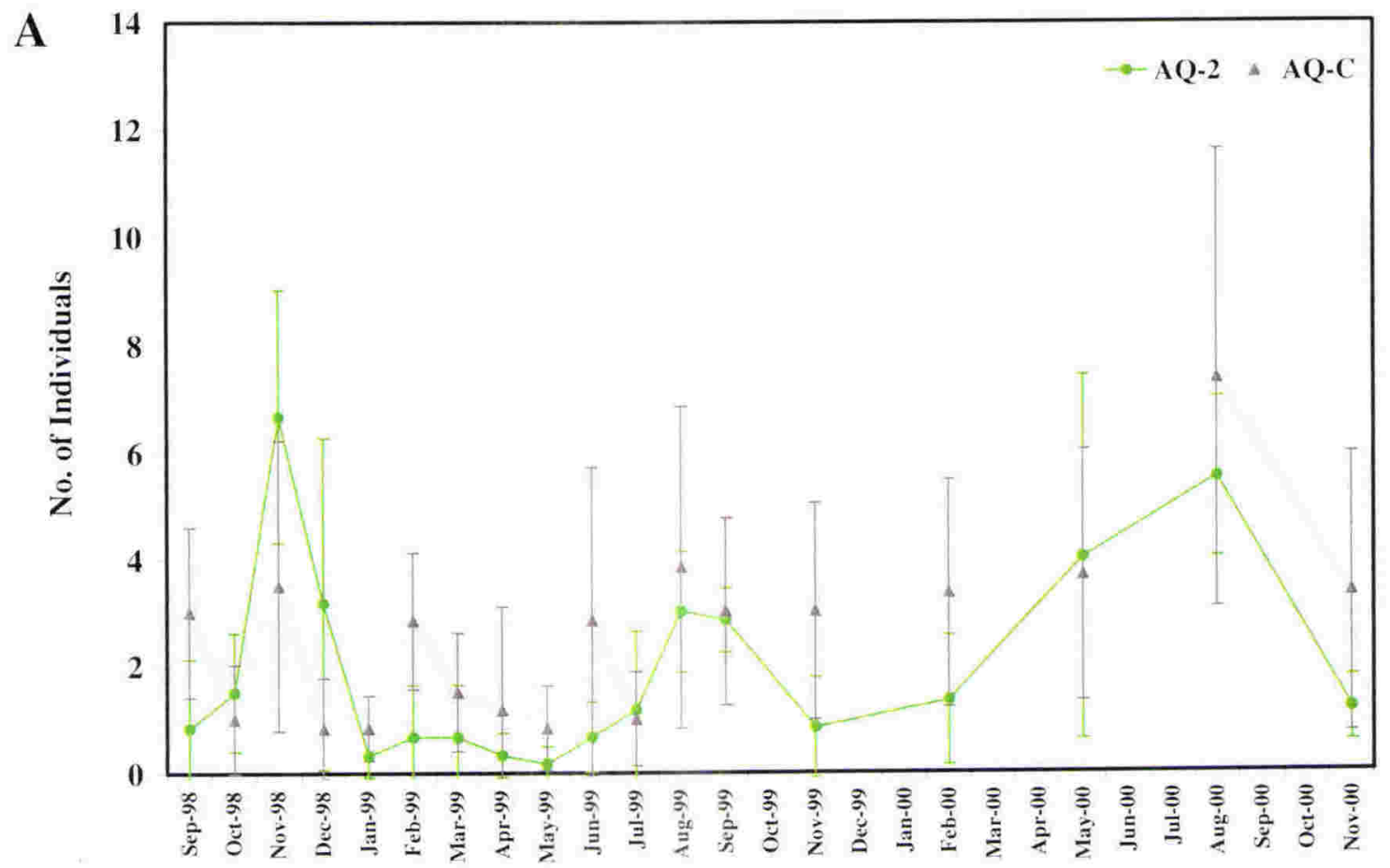

Time

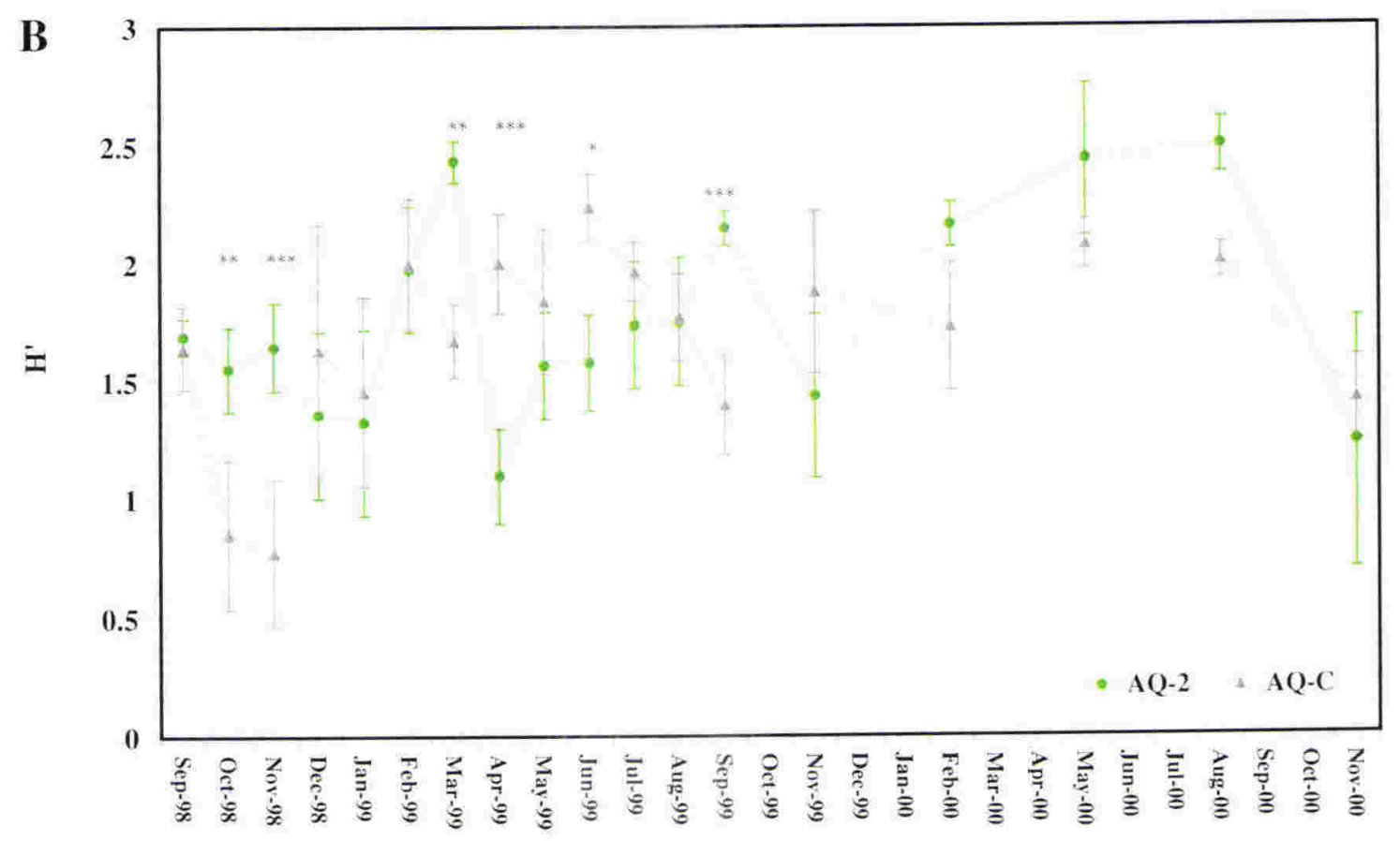

Figure 6.6: Number (mean $\pm 95 \% \mathrm{CI}$ ) of arthropod individuals and diversity at the Aotea Quay outlet and control site over time.

A: Number of arthropod individuals

B: Shannon-Weiner diversity

Significant differences between outlet and control values designated by

$* \mathrm{p}<0.05, * * \mathrm{p}<0.01$, *** $\mathrm{p}<0.001$, otherwise no significant difference 
Table 6.2: Summary of the significant temporal differences in each index at each site Lower - Significantly lower abundance than on other occasions at the site Higher - Significantly higher abundance than on other occasions at the site

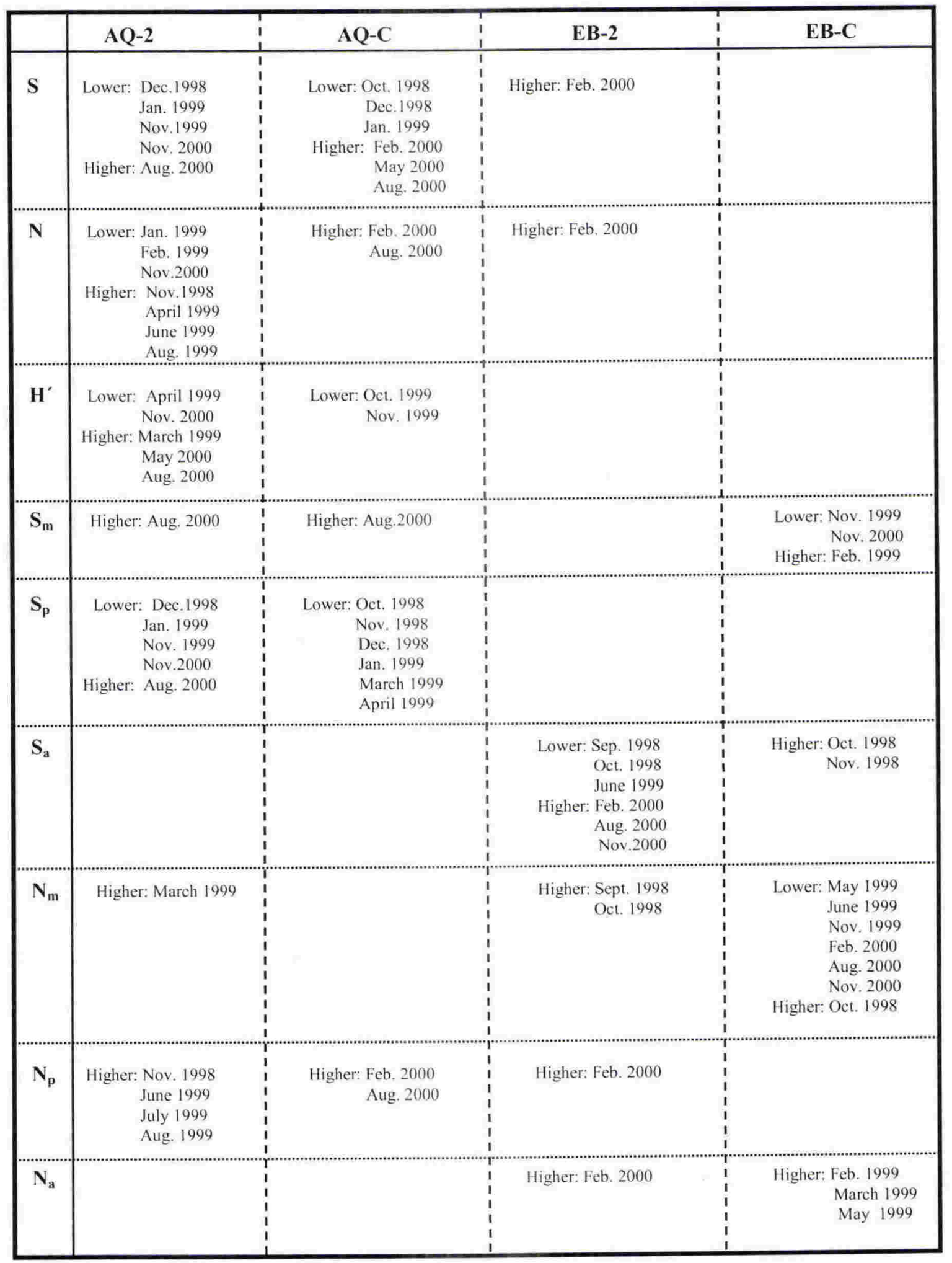




\subsection{2.b.2 Temporal differences at each site}

At EB-2 there was a significant temporal difference in the number of total and arthropod taxa and mollusc, polychaete and arthropod individuals but no significant temporal difference in diversity and the number of mollusc and polychaete taxa (File: ANOVA time in Appendix IV, Table 6.2). The significant difference in the number of total taxa and total, polychaete and arthropod individuals consisted of a higher number in February 2000 than on any other sampling occasion. At EB-C temporal differences consisted of higher numbers of arthropod taxa and individuals on 2 to 3 , and both higher and lower numbers of molluse taxa and individuals on one or more, of the 18 sampling occasions (Table 6.2, Figs. 6.7 and 6.8).

The temporal pattern of the number of total and mollusc taxa and total and polychaete individuals from March to September 1999, and the number of polychaete individuals from September to November 1998, was similar at EB-2 and EB-C (Figs 6.7 and 6.8). The March to September pattern consisted of a decrease in the number of total and mollusc taxa and fewer total and polychaete individuals between March and June, followed by a gradual increase in the number of taxa to August, and a large increase in individuals between July and August. The September to November 1998 pattern consisted of an increase in the number of polychaete individuals. Both of these temporal patterns, which are suggestive of a seasonal effect, did not occur in the other indices.

The null hypothesis that there is no significant temporal difference in each index (i.e. S, N, $\mathbf{H}^{\prime}, \mathbf{S}_{\mathrm{m}}, \mathbf{S}_{\mathbf{p}}, \mathbf{S}_{\mathrm{a}}, \mathbf{N}_{\mathrm{m}}, \mathbf{N}_{\mathbf{p}}, \mathbf{N}_{\mathrm{a}}$ ) at each site is rejected. Over all sites significant temporal differences occurred in all indices, however, significant temporal differences did not occur in all indices at any one site rather differences occurred in $4-7$ of the 9 indices at a site.

The null hypothesis that there is no significant difference in each index (i.e. $\mathbf{S}, \mathbf{N}, \mathbf{H}^{\prime}, \mathbf{S}_{\mathbf{m}}$, $S_{p}, S_{a}, N_{m}, N_{p}, N_{a}$ ) between that at an outlet site station to that at the associated control site station over time is rejected. In Evans Bay significant differences occurred in the number of total, mollusc and arthropod taxa, number of molluse and arthropod individuals and diversity between the outlet and the control site station on one or more occasions. At Aotea Quay significant differences occurred in the number of polychaete taxa, number of total and polychaete individuals and diversity between the outlet and the control site station on one or more occasions. 

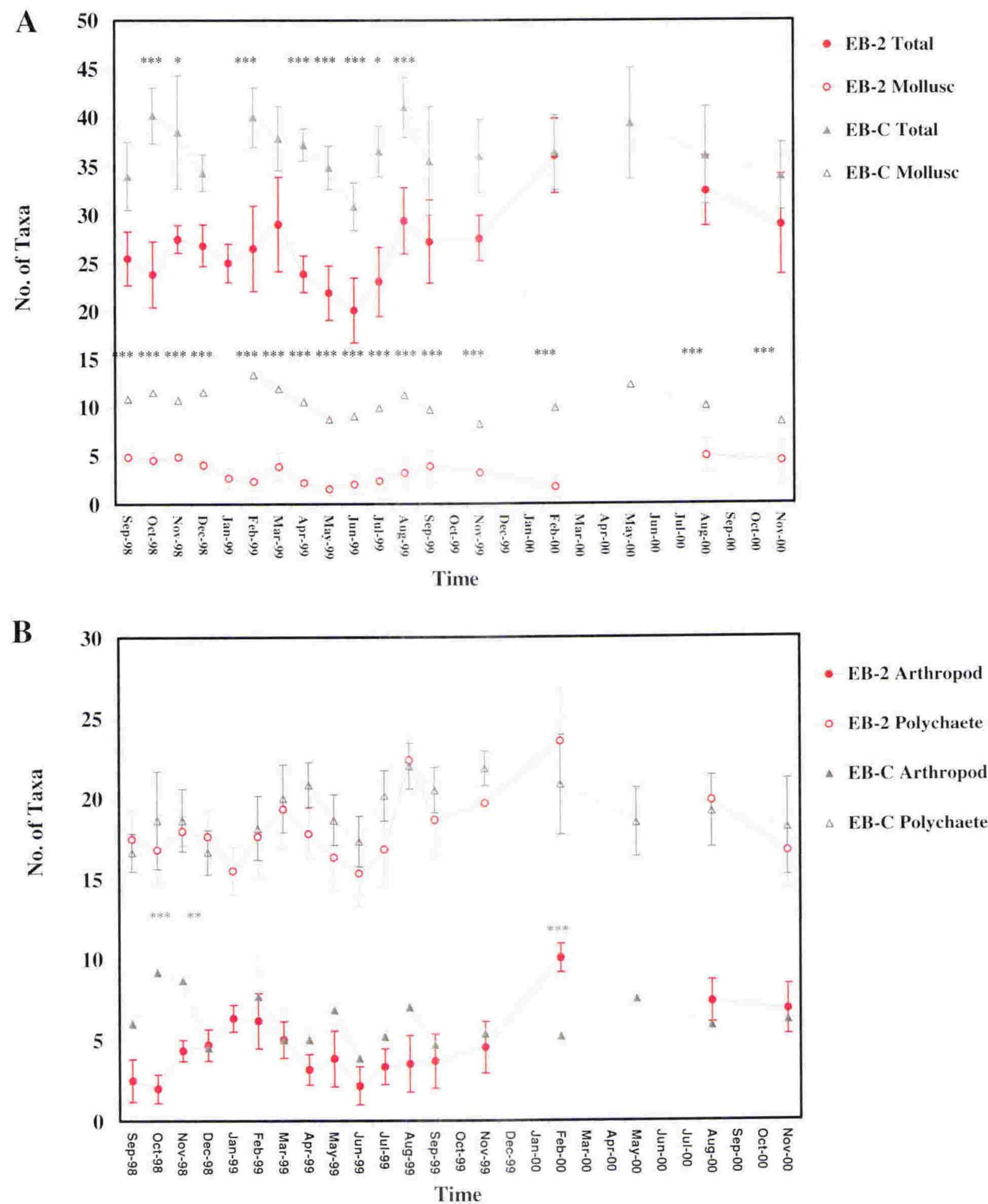

Figure 6.7: Number (mean $\pm 95 \% \mathrm{CI}$ ) of taxa at the Evans Bay outlet and control site over time. A: Number of total and mollusc taxa B: Number of arthropod and polychaete taxa Significant differences between outlet and control values designated by $* \mathrm{p} \leq 0.05, * * \mathrm{p} \leq 0.01, * * * \mathrm{p} \leq 0.001$, otherwise no significant difference 

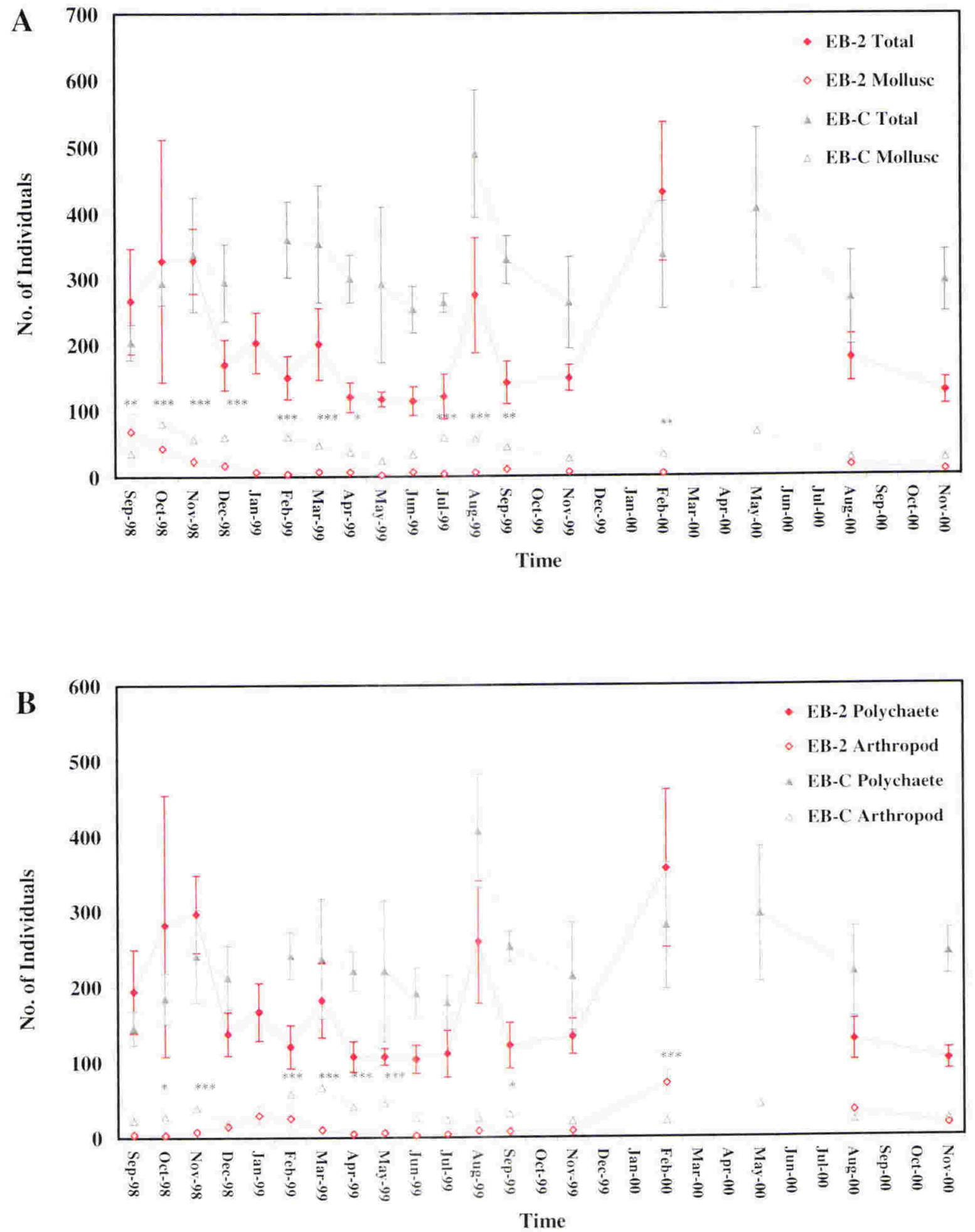

Figure 6.8: Number (mean $\pm 95 \% \mathrm{CI}$ ) of individuals at the Evans Bay outlet and control site over time.

A: Number of total and mollusc individuals

B: Number of arthropod and polychaete individuals

Significant differences between outlet and control values designated by

$* \mathrm{p} \leq 0.05, * * \mathrm{p} \leq 0.01, * * * \mathrm{p} \leq 0.001$, otherwise no significant difference 


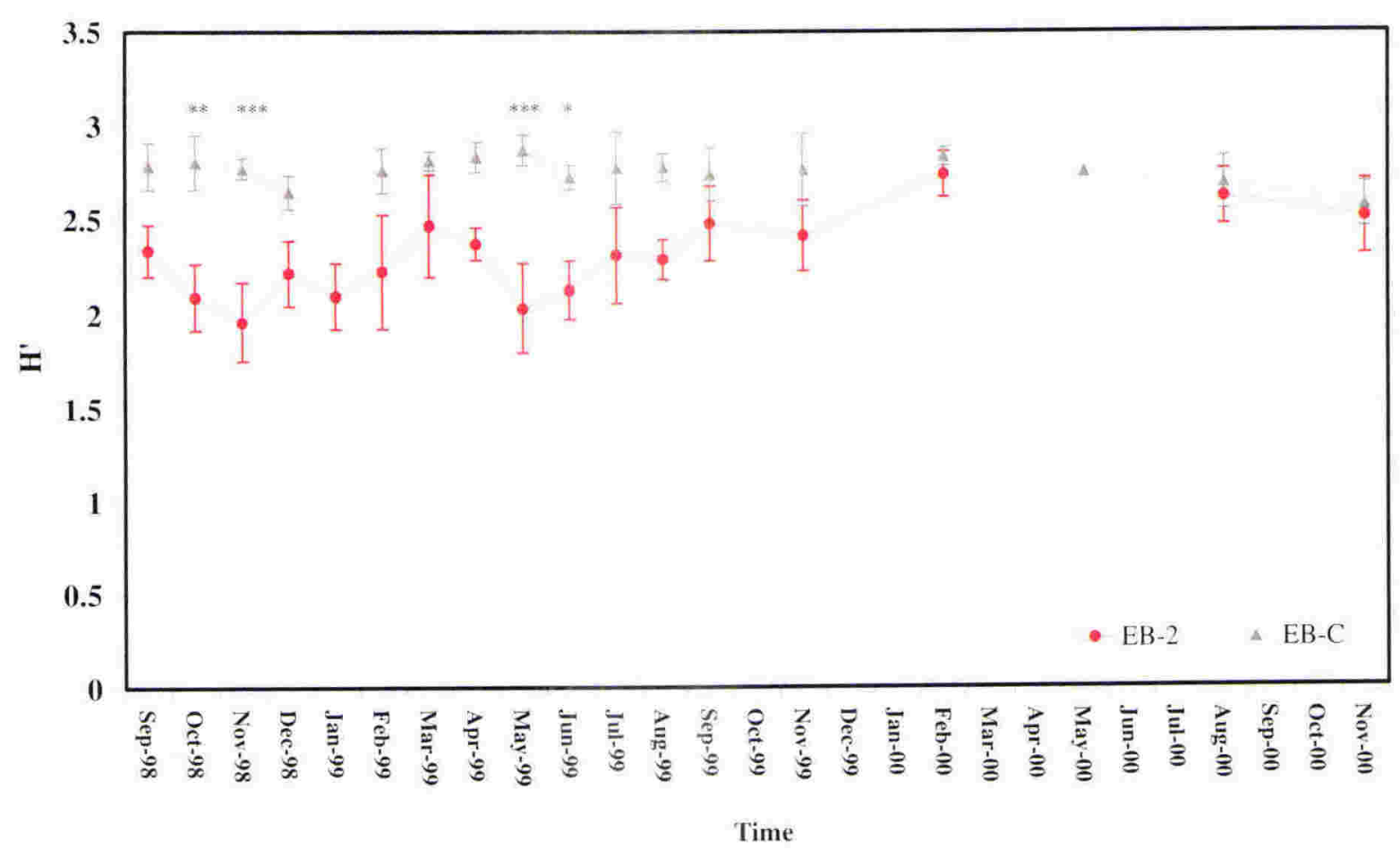

Figure 6.9: Diversity at the Evans Bay outlet and control site over time.

Significant differences between outlet and control sites designated by

$* \mathrm{p} \leq 0.05 ; * * \mathrm{p} \leq 0.01, * * * \mathrm{p} \leq 0.001$, otherwise no significant difference

\subsubsection{Temporal Patterns of Taxon Abundance}

\subsection{3.a Aotea Quay}

6.3.3.a.1 Total Abundance of Taxon as a function of time

Over the 28 months of sampling 113 taxa occurred at AQ-2 and 116 taxa occurred at AQ-C.

When the total number of individuals in each taxa, over all sampling occasions, was calculated it was found that at AQ-2 there were 28 taxa, and at AQ-C 36 taxa with a total abundance of more than 20 individuals. Taxa with more than 20 individuals were those considered in the comparison of taxon abundance between the outlet and control site.

27 taxa were at least twice as abundant at one Aotea Quay site than the other, with 12 taxa (2 bivalve molluses, 1 arthropod, 8 polychaetes and 1 other) more abundant at AQ-2 than AQ-C, and 15 taxa ( 3 arthropods and 12 polychaetes) more abundant at AQ-C than AQ-2 (Table 6.3). 
Table 6.3: Differences in the total abundance of taxa between the outlet (AQ-2) and control site (AQ-C) at Aotea Quay over time

Taxonomic Groups: $\mathrm{a}$ - arthropod, $\mathrm{b}$ - bivalve mollusc, $\mathrm{o}$ - other, $\mathrm{p}$ - polychaete

Taxon with an abundance an order of magnitude larger (abundance at site/ abundance at other site) at the site compared to the abundance at the other site

$\underline{\mathrm{AQ}-2}$

Capitella sp. $(6710 / 310)$

(p)

$\underline{\mathrm{AQ}-\mathrm{C}}$

Taxon at least 5 times more abundant at site than at other site (abundance at site/ abundance at other site)

$\underline{\mathrm{AQ}-2}$

Dosina zelandica $(74 / 14)$

Armandia maculata (2196/369) (b)

(p)

AQ-C

Tanaid sp. A (21/4)

Prionospio yuriel (79/14)

(a)

Exogone sp. B (47/8)

(p)

Genetyllis sp. $(56 / 3)$

Syllid sp.D (29/4)

Syllid sp.F $(32 / 6)$

Taxon at least twice as abundant at site than at other site (abundance at site/abundance at other

$\underline{\mathrm{AQ}-2}$

Arthritica bifurca (78/31)

Proharpinia spp. $(39 / 12)$

Barantolla sp. (626/302)

Boccardia syrtis $(25 / 6)$

Glycinde dorsalis (243/51)

Jasmineira sp. (24/6)

Notomastus sp. (41/13)

Pseudopolydora cf. paucibranchiata (215 / 54)

Nemertine spp. (172/39) (o)

(b)

(a)

(p)

(p)

(p)

(p)

(p)
$\underline{\mathrm{AQ}-\mathrm{C}}$

Halicarcinus cooki (24/10)

Oedicerotid sp.A (35/13)

Aphelochaeta sp. $(75 / 13)$

Caulleriella sp.. (49/21)

Chaetozone sp. $(20 / 5)$

Eulalia sp. B (23/8)

Exogone sp.A (181/44)

(p)

Prionospio spp. (1019/380)

Sphaerosyllis sp. B (79/32) (a)

(p)

(p)

(p)

(p)

(p)

(p)

Taxon without a large difference in abundance between $\mathrm{AQ}-2$ and $\mathrm{AQ}-\mathrm{C}$ (AQ-2 abundance/AQ-C abundance)

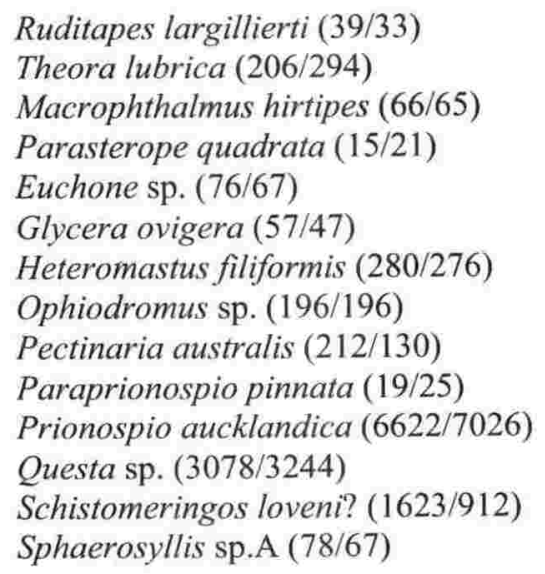

(b)

(p) 
There was a comparable abundance of 14 taxa ( 2 bivalve molluscs, 2 arthropods and 10 polychaetes) at AQ-2 and AQ-C (Table 6.3).

\subsection{3.a.2 Change in Abundance as a function of time}

At AQ-C 37 taxa contributed $\geq 2.5 \%$ each to the biotic dissimilarity over time (File AQ Time SIMPER, Appendix IV). Of the 37 taxa, the abundance of the polychaetes Schistomeringos loveni? (17 out the 17 time comparisons), Questa (17/17), Prionospio aucklandica (16/17), Ophiodromus sp. (15/17) and Heteromastus filiformis (14/17) changed the most over time.

At AQ-2 29 taxa contributed $\geq 2.5 \%$ each to the biotic dissimilarity over time (File AQ Time SIMPER, Appendix IV). Of the 29 taxa, the abundance of the polychaetes Schistomeringos loveni? (17/17), Questa sp. (17/17), Capitella sp. (17/17), Heteromastus filiformis (16/17), Armandia maculata (16/17) and Prionospio aucklandica (16/17) changed the most over time.

\subsection{3.a.3 Recruitment of individuals}

At Aotea Quay 15 taxa (those taxa with $\geq 100$ individuals at a site over time) were investigated with inferred recruitment occurring for 11 taxa (Table 6.4).

Table 6.4: Recruitment events of taxa at the Aotea Quay sites from September 1998 to November 2000 Taxonomic groups: $\mathrm{b}$ - bivalve mollusc, $\mathrm{p}$ - polychaete

Comparable recruitment events at the Outlet and the Control site
$\begin{array}{lll}\text { Theora lubrica } & \text { (b) } & \text { Jan-March 99, Feb-Aug } 00 \\ \text { Barantolla sp. } & \text { (p) } & \text { Nov 99-Feb 00 } \\ \text { Pseudopolydora } \text { cf.paucibranchiata } & \text { (p) } & \text { May-June } 99 \\ \text { Prionospio aucklandica } & \text { (p) } & \text { Oct-Nov } 98 \\ \text { Prionospio spp. } & \text { (p) } & \text { May-June } 99 \\ \text { Pectinaria australis } & \text { (p) } & \text { Nov 99-Feb 00 } \\ \text { Questa } \text { sp. } & \text { (p) } & \text { Jan-Feb 99, Nov 99-Feb } 00\end{array}$

Recruitment events at the control site but not at the outlet site

\begin{tabular}{|c|c|c|}
\hline Prionospio aucklandica & (p) & Aug-Sept 99, Nov 99-Feb 00, May-Aug 00 \\
\hline Prionospio spp. & (p) & June-July 99 \\
\hline Questa sp. & (p) & March-May 99, May-Aug 00 \\
\hline \multicolumn{3}{|c|}{ Recruitment events at the outlet site but not at the control site } \\
\hline Armandia maculata & $(\mathrm{p})$ & Oct-Nov 98 \\
\hline Ophiodromus sp. & (p) & Oct-Nov 98 \\
\hline Prionospio aucklandica & (p) & May-June 99 \\
\hline Questa sp. & (p) & May-June 99 \\
\hline Capitella spp. & (p) & Sept-Oct 98, March-April 99, May-June 99 \\
\hline Glycinde dorsalis & (p) & May-June 99, Aug- Sept 99 \\
\hline
\end{tabular}


Recruitment of 7 taxa occurred at the same time at AQ-2 and AQ-C. In addition 3 of the 7 taxa recruited at other times at AQ-C but not at AQ-2, and 2 of the 7 taxa recruited at other times at AQ-2 but not at AQ-C. AQ-2 specific recruitment occurred for 4 taxa, 3 of which were outlet abundant taxa (Table 6.3). Capitella sp., Glycinde dorsalis, Prionospio aucklandica and Questa sp. all had more than one recruitment event in a year.

\subsection{3.b Evans Bay}

\subsection{3.b.1 Total Abundance of Taxon as a function of time}

Over the 28 months of sampling 137 taxa occurred at EB-2 and 154 taxa occurred at AQ-C, with 50 taxa at EB-2 and 59 taxa at EB-C having a total abundance of more than 20 individuals over time. The taxa with more than 20 individuals were those considered in the comparison of taxa abundance between the outlet and control site (Table 6.5).

53 taxa were at least twice as abundant at one Evans Bay site than the other, with 19 taxa (1 bivalve mollusc, 1 gastropod mollusc, 7 arthropods, 8 polychaetes and 2 other) more abundant at EB-2 than EB-C, and 34 taxa (1 amphinueran mollusc, 6 bivalve molluscs, 4 gastropod molluscs, 9 arthropods, 1 echinoderm, 12 polychaetes and 1 other) more abundant at EB-C than EB-2. There was a comparable abundance of 19 taxa (3 bivalve molluscs, 3 arthropods, 1 echinoderm, 10 polychaetes and 2 others) at EB-2 and EB-C (Table 6.5).

\subsection{3.b.2 Change in Abundance as a function of time}

At EB-C 29 taxa contributed $\geq 2.5 \%$ each to the biotic dissimilarity over time (File: EB time SIMPER, Appendix IV). Of the 29 taxa, the abundance of the copepod Stephos spp. (9 out of 16 comparisons), the gastropod mollusc Notoacmea helmsi (7/16), and the polychaetes Hesionid sp. A (8/16) and Caraziella philipensis (7/16) changed the most over time.

At EB-2 39 taxa contributed $\geq 2.5 \%$ each to the biotic dissimilarity over time (File: EB time SIMPER, Appendix IV). Of the 39 taxa, the abundance of the polychaetes Hesionid sp. A (13/16), Prionospio yuriel (12/16), Heteromastus filiformis (11/16), Capitella spp. (10/16), Hemipodus simplex (10/16) and Pseudopolydora cf. paucibranchiata (9/16) and Oligochaetes $(11 / 16)$ changed the most over time.

\subsection{3.b.3 Recruitment of individuals}

In Evans Bay 44 taxa (those taxa with $\geq 100$ individuals at a site over time) were investigated with inferred recruitment occurring for 16 taxa (Table 6.6). 
Table 6.5: Differences in the total abundance of taxa between the outlet (EB-2) and control site (EB-C) in Evans Bay over time

Taxonomic Groups: a - arthropod, am - amphineuran mollusc, b - bivalve mollusc, e - echinoderm $\mathrm{g}$ - gastropod mollusc, $\mathrm{o}$ - other, $\mathrm{p}$ - polychaete

Taxon present at a site and absent or with one individual at other site (total number of individuals at site)
$\begin{array}{llll}\text { EB-2 } & \text { EB-C } \\ \text { Lumbriculus aoteoaroae (262) } & \text { (p) } & \text { Leptochiton inquinatus }(47) & (\text { am) } \\ \text { Callianassa filholi }(133) & \text { (a) } & \text { Paraphoxus australis }(28) & \text { (a) } \\ & & \text { Anthurid sp.A (36) } & \text { (a) } \\ & \text { Corbula zelandica }(50) & \text { (b) } \\ & \text { Caecum digitatum }(167) & \text { (b) }\end{array}$

Taxon with an abundance an order of magnitude larger (abundance at site/ abundance at other site) at the site compared to the abundance at the other site

\begin{tabular}{lc}
\hline EB-2 & \\
Cominella adspersa $(30 / 2)$ & (g) \\
Munna sp. $(84 / 4)$ & (a) \\
Ventojassa sp. $(324 / 13)$ & (a) \\
Boccardia syrtis $(48 / 2)$ & (p) \\
Capitella spp. $(1297 / 12)$ & (p) \\
Heteromastus filiformis $(528 / 16)$ & (p) \\
Paraprionospio pinnata (140/8) & (p) \\
Polydora sp. $(54 / 4)$ & (p) \\
Prionospio yuriel $(438 / 27)$ & (p)
\end{tabular}

EB-C

Stephos spp. (1956/190)

Gari stangeri $(854 / 9)$

Gumina dolochostoma (305/4)

Notoacmea helmsi (1037/98)

Nucula hartvigiana (291/17)

Trochus tiaratus (40/4)

Melita spp. $(658 / 12)$

Pagurus spp. (23/2)

Amphiura sp. (42/3)

Aphelochaeta sp. (211/19)

Carazziella philipensis (318/17)

Schistomeringos loveni (1722/62)

Sphaerosyllis sp.A (3375/87)

Sphaerosyllis sp. B (459/18)

Armandia maculata (1502/132)

Taxon at least 5 times more abundant at site than at other site (abundance at site/ abundance at other site)

EB-2

Corophium acherusicum (61/11)

Meridiolembos sp. $(271 / 35)$ (a)

(a)

\section{EB-C}

Arthritica bifurca $(323 / 53)$

Mysid sp. (25/4)

(b)

Scleroconcha sculpta (71/8)

Boccardia chiliensis $(41 / 8)$

Prionospio spp. (1976/305)

Scolelepis sp. $(89 / 9)$ (a)

(a)

(p)

Taxon at least twice as abundant at site than at other site (abundance at site/ abundance at other site)

\section{EB-2}

Macomona liliana $(436 / 213)$

Proharpina spp. (210/57)

Oedicerotid sp. (46/18)

Glycinde dorsalis $(788 / 227)$

Flatworm (25/7)

Scolanthus sp. $(271 / 61)$ (b)

(a)

(a)

(p)

(o)

(o)

\section{EB-C}

Leptomya retiaria $(342 / 78)$

Xymene plebeius $(85 / 35)$

Halicarcinus cooki (137/45)

Caulleriella sp. (38/16)

Pectinaria australis $(358 / 152)$

Hemipodus simplex (1557/647)

Oligochaete spp. (2399/938)

$\underline{\text { Taxon without a large difference in abundance between EB-2 and EB-C (EB-2 abundance/EB-C }}$ abundance)

Ruditapes largillierti (326/279) (b)
Tawera spissa $(241 / 303)$

Trochodota dendyi (54/67)

Diasterope grisea $(46 / 51)$

Exogone sp.A (75/127)

Glycera ovigera (71/54)

Notomastus sp. (128/187)

Owenia fusiformis (789/651)

(b)

(e)

(a)

(p)

(p)

(p)

(p)

Pseudopolydora cf. paucibranchiata(704/423) (p)

Phoronid sp. (70/45) (o)
Scintillona zelandica (112/192)

Cmbicopa hispida $(22 / 15)$

Parawaldeckia thomsoni (17/29)

Barantolla sp. (6229/6029)

Hesionid sp.A (664/440)

Ophiodromus sp. (124/108)

Platynereis australis (27/24)

Nemertine spp. $(104 / 103)$
Prionospio aucklandica (3253/2437) (p) 
Table 6.6: Recruitment events of taxa at the Evans Bay sites from September 1998 to November 2000. Taxonomic groups: $\mathrm{a}$ - arthropod, $\mathrm{b}$ - bivalve mollusc, $\mathrm{p}$ - polychaete

\begin{tabular}{|c|c|c|}
\hline \multicolumn{3}{|c|}{ Comparable recruitment events at the Outlet and the Control site } \\
\hline Leptomya retiaria & (b) & Oct-Nov 98 \\
\hline Barantolla sp. & (p) & July-Aug 99 \\
\hline Hemipodus simplex & (p) & Nov $99-$ Feb 00 \\
\hline Hesionid sp.A & (p) & Feb- March 99 \\
\hline Glycinde dorsalis & (p) & July-Aug 99 \\
\hline Pectinaria australis & (p) & Nov $99-$ Feb 00 \\
\hline Pseudopolydora cf. pauci & ranchiata $(\mathrm{p})$ & July-Aug 99, Nov 99 - Feb 00 \\
\hline Prionospio aucklandica & (p) & Sept-Nov 98 \\
\hline \multicolumn{3}{|c|}{ Recruitment events at the control site but not at the outlet site } \\
\hline Macomona liliana & (b) & Sept-Oct 98 \\
\hline Tawera spissa & (b) & Sept-Oct 98 \\
\hline Hesionid sp.A & (p) & April-May 99 \\
\hline Hemipodus simplex & (p) & July-Aug 99 \\
\hline Prionospio aucklandica & (p) & July-Aug 99 \\
\hline Prionospio spp. & (p) & Oct-Nov 98, July - Aug 99 \\
\hline \multicolumn{3}{|c|}{ Recruitment events at the outlet site but not at the control site } \\
\hline Meridiolembos sp. & (a) & Dec $98-J a n 99$, Nov 99- Feb 00 \\
\hline Ventojassa sp. & (a) & Nov $99-$ Feb 00 \\
\hline Barantolla sp. & (p) & Nov $99-$ Feb 00 \\
\hline Heteromastus filiformis & (p) & July-Aug 99, Nov 99-Feb 00 \\
\hline Owenia fusiformis & (p) & Feb-March 99, Nov 99-Feb 00 \\
\hline Paraprionospio pinnata & (p) & July-Aug 99 \\
\hline Prionospio spp. & (p) & Nov $99-$ Feb 00 \\
\hline
\end{tabular}

Recruitment of 8 taxa occurred at the same time at EB-2 and EB-C. In addition 3 of the 8 taxa recruited at other times at EB-C but not at EB-2, and 1 of the 8 taxa recruited at other times at EB-2 but not at EB-C. EB-C specific recruitment occurred for 4 taxa, EB-2 specific recruitment occurred for 5 taxa, and recruitment of the polychaete Prionospio spp. occurred at both sites but at different times.

The polychaetes Heteromastus filiformis and Pseudopolydora cf. paucibranchiata had more than one recruitment event in a year and annual recruitment possibly occurred for the arthropod Meridiolembos sp. and the polychaetes Owenia fusiformis and Prionospio spp..

\subsection{DISCUSSION}

Within the time frame of this study (August 1998 - November 2000) the results suggest that stormwater discharge has, apart from November 2000 at Aotea Quay, not resulted in severe changes in the macrobiota in the vicinity of outlets EB-2 and AQ-2. This could be because: 
- The sedimentological and chemical changes, which the data suggest (see Chapters 3 and 4) occurred over time at these outlets as a result of stormwater discharge, were not severe enough to result in a severe change in the macrobiota.

- Stormwater has been discharged from these outlets for many years prior to this study thus the macrobiota present could be composed of taxa tolerant to the amount of sedimentological and chemical change that occurred.

- Recovery of the macrobiota in the time between samplings events.

In considering the recovery of the macrobiota between sampling events it is relevant to note that the zone of effect of stormwater discharge around each outlet is comparatively small (see Chapter 5). Therefore following a possible stormwater discharge caused extreme macrobiota disturbance event, the recruitment (juveniles and adults) of taxa into the impacted area could occur through larval colonisation following reproduction of taxa in non-impacted areas and through adult migration from non-impacted areas of the harbour. Lateral adult migration has been found to play a large part in the rapid colonization of the infaunal community of an area subjected to small-scale disturbances (Levin, 1984, Zajac and Whitlatch, 1991). Such lateral migration, as investigated using trays of defaunated sediment, was found to have resulted in the abundance of the initial colonists in the trays reflecting the abundance of the biota in adjacent sediment within 20 days (Thrush and Roper, 1988). However larval colonisation into an area following a disturbance is dependent on the type of disturbance and the timing of the disturbance relative to the life-history attributes of each taxa (Grassle and Grassle, 1974; Levin, 1984; Zajac and Whitlatch, 1991). Contaminated sediment can also affect the recruitment of benthic invertebrates (Roach et al, 2001). Because stormwater discharge can cause changes in grain size, organic matter content and metal concentrations, the taxa recruited would in part be dependent on the sediment and contaminant conditions existing following the disturbance.

The data indicate that disturbed biological communities occurred at the Aotea Quay outlet and control site. At both sites there were large differences in the shape of the partial dominance curves and the number of taxa present over time, with little similarity between the outlet and control site curves on each sampling occasion. Frequent biological disturbance at both sites is also suggested by the:

1. Change in the number of total and polychaete taxa, total and polychaete individuals and diversity over time. 
2. Number of times the abundance of taxa changed over time (SIMPER analysis). At AQ-2 the abundance of 12 taxa and at AQ-C the abundance of 11 taxa changed between two consecutive sampling occasions on more than half of the sampling occasions.

At the Aotea Quay sites disturbance events appear to differ in their biological effect and be happening at different times. Disturbance of the macrobiota at AQ-C is likely to be as a result of sediment disturbance by ship propeller action while at AQ-2 it is not possible to distinguish between the disturbance effect of stormwater discharge and that of ship propeller action.

At AQ-2 the biological community changed over time, with the macrobiota present in November 2000 very different to that on all other sampling occasions (Fig. 6.3). In November 2000 , the biota was characterised by a low number of total taxa and individuals, which may be due to a toxic event resulting from stormwater discharge i.e. an extreme disturbance has occurred. Prior to November 2000 there was no clear pattern in the direction and amount of change in the biological community over time at AQ-2, however the biota in September 1998, January 1999 and May 2000 was comparable, as was that in May 1999, June 1999, July 1999, August 1999 and February 2000. The biological community at one or other or both these groups of times, may be the state the biota returns to after a disturbance event i.e. the biota recovered between stresses.

The biological community at AQ-2 remained distinct from that at AQ-C over all sampling occasions except August 2000, in August 2000 the biological community at both sites, as indicated by their very close proximity on the MDS plot (Fig. 6.3), was very similar. At both AQ-2 and AQ-C the biological community was highly variable over time with the direction and amount of change between sampling times different at each site. This indicates that the temporal variability was due to site-specific factors with these factors operating at different times at each site. At both sites there was no obvious seasonal and/or annual pattern in the biological community which could be an indication that disturbance events play a major role in determining the macrobenthic community dynamics in the Aotea Quay area.

Over the period of sampling there were more total and polychaete individuals at AQ-2 than at AQ-C. This difference was mostly due to the high abundance of the opportunistic polychaete Capitella spp. at AQ-2. The abundance of Capitella spp. at AQ-2 changed significantly over time with large increases in abundance as a result of the recruitment of juveniles on 3 
occasions. An increase in the abundance of Capitella (capitata), is a well documented response to environmental disturbance and organic matter (Chapman et al., 1996; Estacio et al., 1997; Gray, 1979; Pearson and Rosenberg, 1978; Simboura et al., 1995; Warren, 1977; Weston, 1990), with this species reproducing throughout the year (Tsutsumi and Kikuchi, 1984) and producing lecithotrophic larvae with a short planktonic stage (several hours to 1 day) (Grassle and Grassle, 1976; Tsutsumi and Kikuchi, 1984). The polychaete Armandia maculata also contributed to the difference in the number of total and polychaete individuals between sites, with more individuals at AQ-2 than at AQ-C. At AQ-2 a high number of $A$. maculata individuals were recruited to the population between October and November 1998, however the abundance of this species changed a lot at both AQ-2 (on 16 of 17 occasions) and AQ-C (on 13 of 17 occasions).

While the data indicates that different biological disturbance events occurred at different times at each of the Aotea Quay sites the overall difference in environmental conditions between AQ-2 and AQ-C is evidenced by:

1. The separation of the AQ-2 biota from the AQ-C biota (Fig 6.3).

2. The taxa present over time. 12 taxa ( 2 mollusc, 8 polychaete, 1 arthropod and 1 other taxa) were more abundant at AQ-2 than at AQ-C and 15 taxa (12 polychaete and 3 arthropod taxa) were more abundant at AQ-C than at AQ-2.

The differences in environmental conditions between AQ-2 and AQ-C are attributed not only to stormwater discharge but also to the other disturbances that occur at Aotea Quay.

In Evans Bay the macrobiota at the control site was not apparently disturbed while that at the outlet site was slightly disturbed on all sampling occasions (Fig. 6.2). The data indicate that biological disturbance at EB-2 is attributed to stormwater discharge although there were only small differences in the degree of disturbance over time, possibly because:

1. The station sampled was not close to the outlet but $24 \mathrm{~m}$ away, and stormwater discharge disturbance effects are possibly greater closer to, than further from the outlet.

2. Stormwater discharge from this outlet is not a large disturbance. or as a combination of these factors.

The biological community at EB-2 remained distinct from that at EB-C throughout the period of sampling (Fig 6.3) and overall there were a lower number of total and arthropod taxa and 
total, mollusc, polychaete, arthropod, echinoderm and other individuals at EB-2 than at EB-C. This large difference in the biological community between the outlet and control site is considered to result from the historic effect of stormwater discharge (over a long period of time), with the biological differences existing prior to the start of this study.

At EB-2 the biological community changed over time but there was little difference between the biota present in April, May and July 1999, and between that present in June, September and November 1999 while the largest difference occurred between November 1999 and February 2000. Over the total period of sampling there was an overall unidirectional change in the community at EB-2 while at EB-C there was a smaller but unidirectional change in the biological community from August 1998 and February 1999 only. In February and March 1998 a toxic bloom of the naked dinoflagellate Karenia brevisulcata occurred in Wellington Harbour and as a result there was a decrease in the total number of benthic species and individuals and species diversity in some areas of the harbour (Wear and Gardner, 2001). By March 1999 the benthic biota was recovering with a significant increase in the total number of benthic species and individuals, particularly polychaetes, and species diversity at sites severely impacted by the bloom (Gardner and Wear, in press). While the unidirectional change in the biological community at EB-2 and EB-C between August 1998 and February 1999 could represent recovery of the biological community from this toxic algae bloom, there was no significant overall increase in the number of total and polychaete taxa and individuals and species diversity at the two sites over this time period (Figs. 6.7-6.9). Over the same time period, unidirectional changes did not occur in the biological communities and there was no significant overall increase in the number of total and polychaete taxa and individuals and species diversity at the Aotea Quay sites. If recovery from the bloom resulted in changes in the biota over time, it is expected that recovery would be most apparent at the Aotea Quay sites which are in the northern half of the harbour where the effect of the toxic bloom was most severe. There was a significant decrease in the number of species and species diversity as a result of the toxic algae bloom at a site in close proximity to Aotea Quay. In addition, the Evans Bay sites were in 3-4 $\mathrm{m}$ of water at the head of a bay subjected to wind-induced turbulence from the predominant north-west wind, and it has been noted that this bloom did not have a deleterious effect on the biota at a site in the harbour where the depth and wind regime is comparable to that in Evans Bay (Wear and Gardner, 2001). Therefore the unidirectional changes in the biological communities at EB-2 and EB-C, between August 1998 and February 1999, are not considered to represent recovery from the toxic algae bloom. 
The unidirectional change in the biological community between August 1998 and February 1999 at EB-C is likely to be a natural temporal pattern, while the greater unidirectional changes at EB-2 may result from a combination of the natural temporal pattern and the effect of the stormwater discharged. The overall unidirectional pattern at EB-2 but not EB-C could indicate, that as a result of multiple disturbances through stormwater discharge the biological community at EB-2 does not recover to the same stable state between disturbances, rather it is continually changing and therefore different stable states may occur in the biological community over time. However, it is possible that because the biota at EB-2 was different to that at EB-C, the difference in the temporal pattern between sites was a function of the taxa present, their life history strategies and the natural biological and physical processes occurring at each site. After all 19 taxa ( 2 mollusc, 8 polychaete, 7 arthropod and 2 other taxa) were more abundant at EB-2 than at EB-C, and 34 taxa (11 mollusc, 12 polychaete, 9 arthropod, 1 echinoderm and 1 other taxa) were more abundant at EB-C than at EB-2 over time.

At EB-2 significant temporal differences occurred in the number of arthropod taxa and mollusc individuals, and there were a significantly higher number of total taxa and total, arthropod and polychaete individuals present in February 2000. Except for mollusc individuals, comparable temporal differences did not occur at EB-C. At EB-C the abundance of 29 taxa changed significantly over the 27 months of sampling, with these changes occurring at most on 9 of the 17 occasions but more typically on $\leq 3$ occasions i.e. changes in taxa abundance over time are probably natural patterns of recruitment. At EB-2 the abundance of 39 taxa changed significantly over time, with the abundance of 7 of these taxa, including the outlet abundant species Capitella spp., Heteromastus filiformis and Prionospio yuriel (Table 6.5), changing significantly on 9 or more of the 16 sampling occasions i.e. these changes in abundance could be due to disturbance events rather than natural patterns of recruitment. Thus temporal changes in univariate indices and taxa at EB-2 but not at EB-C could be as a result of the effect of stormwater discharge.

Recruitment is defined as the integrated settlement of larvae into the sediment, early postsettlement events and immigration of juveniles and adults from adjacent habitats (Renaud et al, 1999). In this study recruitment was inferred when there was a large increase in abundance between consecutive sampling occasions. Consequently recruitment could only be investigated for taxa with a large number of individuals over the period of sampling. 
Recruitment could well have occurred in taxa with an overall lower abundance but could not be determined using this method.

Seasonal recruitment, i.e. at a particular time of year and indicative of larval colonization, occurred for the amphipod Meridiolembos sp., the polychaete Owenia fusiformis and possibly the bivalves Leptomya retiaria, Macomona liliana, Tawera spissa and Theora lubrica, the amphipod Ventojassa sp. and the polychaetes Armandia maculata, Glycinde dorsalis, Hesionid sp.A., Ophiodromus sp., Pectinaria australis and Paraprionospio pinnata. Recruitment of some of these taxa at one or other of the outlet sites indicates that suitable environmental conditions existed at the time of recruitment. The seasonal recruitment of different taxa at the outlet and control site in an area could be a reflection of factors known to affect recruitment (Grassle and Grassle, 1974; Pearson and Rosenberg, 1978; Bonsdorff, 1989; Zajac et al., 1998, Lu and Wu, 2000), i.e.:

- Environmental differences between sites.

- The availability of space for recruits.

- Biological interactions with the existing biota e.g. predation, inter and intra-specific competition.

- Local hydrography which affects larval transport.

Irregular recruitment occurred for the capitellid polychaete species Capitella spp., Barantolla sp., and Heteromastus filiformis, the spionid polychaete species Prionospio aucklandica, Prionospio spp. and Pseudopolydora cf. paucibranchiata as well as the polychaete Questa sp. and possibly Hemipodus simplex. Capitellids and spionids are opportunistic polychaetes with the ability to respond quickly to disturbed conditions (Grassle and Grassle, 1974; Grall and Glémarec, 1997; Pearson and Rosenberg, 1978; Lu and Wu, 2000). Therefore the irregular recruitment of Capitella spp. and Heteromastus filiformis at AQ-2 and EB-2 respectively but not at the associated control sites is suggestive of a response to disturbance resulting from stormwater discharge. Irregular recruitment of Prionospio aucklandica and Questa sp. occurred at both AQ-2 and AQ-C, with recruitment being at different times at each site. This is suggestive of recruitment following a disturbance event at each site but with the disturbance occurring at different times at each site.

In this study the temporal patterns of the biological community, univariate indices and abundance of selected taxa at outlet and control sites were investigated in order to assess if 
and what effect stormwater discharge over time has on the on the temporal variability of the macrobiota. While the partial dominance plots revealed that the biological communities at AQ-2, EB-2 and AQ-C were disturbed and that the level and timing of disturbance varied, the univariate indices and selected taxa analyses were used to pinpoint the effect of stormwater discharge on the temporal variability of the macrobiota. In this study it was necessary to carry out analyses to the level of taxa because of:

- Differences in the biota between the outlet and control site in an area (possibly as a result of the effect of stormwater discharged over a long period of time prior to this study)

- The different types of disturbance that occur as a result of stormwater discharge

- The different types of disturbances happening in an area.

The data indicate that over the study period the stormwater discharged had:

- A small effect on the temporal variability of the macrobiota at EB-2

- A severe effect on the biota at AQ-2 in November 2000 and a moderate? (possibly due to stormwater discharge, however disturbance effects of ship propeller action cannot be discounted) effect on the macrobiota over the rest of the study period.

An assessment, of the factors which could account for the differences in the temporal variability of the macrobiota between an outlet and associated control site, whether it was the physical factors measured in this study i.e. grain size, organic matter content and metal concentrations or some other factor/s, is the subject of Chapter 7.

\subsection{CONCLUSIONS}

The data suggests that stormwater discharge at AQ-2 had a severe effect on the macrobiota between August and November 2000 with the macrobiota in November 2000 characterised by a low number of total taxa and individuals.

The data suggests that at AQ-2 disturbance events (possibly due to stormwater discharge however disturbance effects of ship propeller action cannot be discounted) had a moderate effect on the temporal variability of macrobiota between August 1998 and August 2000. These effects occurred as:

- Changes in the level of disturbance (partial dominance plots) of the biological community over time 
- More total and polychaete individuals over time than at AQ-C

- Significant temporal differences in Univariate indices

- Significant changes in the abundance of 12 taxa on over more than half of the sampling occasions.

- The high abundance and irregular recruitment of the opportunistic polychaete Capitella spp.

- Irregular recruitment of Prionospio auckandica and Questa sp.

The data suggests that at EB-2 stormwater discharge has had a small effect on the temporal variability of the macrobiota at EB-2. These effects were:

- A slightly disturbed (partial dominance plots) biological community on all sampling occasions

- Significant temporal difference in the number of arthropod taxa

- Significant changes in the abundance of 7 taxa on over more than half of the sampling occasions.

- Irregular recruitment of the opportunistic polychaete Heteromastus filiformis and the polychaetes Barantolla sp. and Prionospio spp.

No one biological measure can be used to assess the effect of stormwater discharge on the temporal variability of the macrobiota. A range of biological measures i.e. Univariate and Multivariate, community and individual taxa and in particular univariate and individual taxa analyses are required to assess the effect of stormwater discharge on the temporal variability of the macrobiota. 


\section{Chapter 7 \\ SYNTHESIS}

\subsection{INTRODUCTION}

Stormwater discharge from the outlets in inner Wellington Harbour has resulted in organic matter content, metal concentrations and aspects of the macrobiota (biological communities, taxonomic groups and taxa) at outlet sites differing from those at associated control sites (Chapters 3, 4, 5 and 6). Sediment grain size differences cannot be so clearly attributed to sediment discharged with stormwater. Even though stormwater can contain large quantities of suspended solids (Mosley et al., 1997; Morrisey 1997; Vincent and Thomas 1997) which drop to the seafloor beyond the outlet, and the stormwater flows, which at times consist of large volumes at high velocity, can also affect grain size characteristics by scouring and redistribution of the sediments in the vicinity of an outlet (Timperley and Kurschel, 2000).

The macrobiota can be directly affected by stormwater discharge through dislodgment as a result of high volume and velocity flows and burial by deposited sediment. However stormwater discharge can also indirectly affect macrobiota through changes in sediment grain size, organic matter content and metal concentrations. Sediment grain size characteristics, organic matter content, metal concentrations, water depth and other variables not measured in this study such as depth of the redox layer, salinity, hydrological conditions and contaminant load (toxic synthetic organics such as PAH's, PCB's, DDT, herbicides; nutrients) all influence the presence and abundance of macrobiota (Blackstock and FilionMyklebust, 1983; Gray, 1974; Long et al., 1995; Pearson and Rosenberg, 1978; Skei et al., 1996; Theede et al., 1969).

Establishing cause and effect relationships between biota and contaminants can be derived from 3 types of studies. The first is laboratory ecotoxicological studies in which the effect of contaminants on the biota can be determined using controlled experiments. There is considerable literature regarding such studies (e.g. Long et al., 1995; Marsden et al., 2000, Pandeswara and Yallapragada, 2000; ANZECC, 2000). The weakness of this approach is that in the laboratory it is not possible to reproduce the range of potentially relevant environmental factors present in the environment. To overcome this, comparable toxicity tests can be carried out in the laboratory and in the field (DeWitt et al., 1999). 
The second type of study involves manipulative field experiments using contaminant spiked sediment (Chiaroni, 1998; Fletcher et al., 2001; Morrisey et al., 1996; Watzin and Roscigno, 1997). In such experiments the concentration of a specific contaminant is manipulated while all other environmental variables remain unchanged.

In the third type of study, contaminant concentrations and the biota are measured in the field and the data are then used to investigate possible cause and effect by data correlation (Long et al., 1995; ANZECC, 2000). The weaknesses of this approach are:

1. the assumption of cause and effect is based on a correlation which at best can indicate a strong relationship between the biota and one or more contaminants

2. it is not possible to separate combined from single contaminant effects

3. large data sets are required

4. the possibility exists that biological effects are not due to any of the measured variables but to some other either unmeasured or unidentified variable(s)

(ANZECC, 2000; Inglis and Kross, 2000; Morrisey et al., 1996).

A more integrated assessment, the 'sediment quality triad' includes three separate measures, sediment chemistry, biological community structure and laboratory ecotoxicological analyses to provide a burden-of-evidence approach (Chapman et al., 1996). While this integrated approach is the ideal, it is prohibitively expensive and time consuming.

The aim of this chapter is to investigate whether the biological effects of stormwater discharge are linked to the sediment characteristics (grain size, sorting, organic matter content) and metal concentrations which occur in the vicinity of outlets. The third type of study discussed above is used with data (from outlet and control sites) presented in chapters 3, 4, 5 and 6 (spatial and temporal variability in the organic matter content, grain size, metal concentrations and macrobiota) incorporated into the analyses. From the analyses it may be possible to identify which of the measured sedimentological and/or metal variable(s) have an effect on the presence and abundance of macrobiota in the vicinity of stormwater outlets. Such information will be very useful to Local Authorities if they are intending to improve the 'health' of the nearshore benthic environment by removing or reducing contaminants (i.e. organic matter, metals, organic chemicals and sediment) in stormwater before it is discharged. 


\subsubsection{Sediment Characteristics}

\subsection{1. a Stormwater discharge and sediment characteristics (from Chapter 3)}

The data strongly suggests that stormwater discharge has resulted in the following effects on sediment characteristics in inner Wellington Harbour:

1. Organic matter enrichment of sediments in the vicinity of stormwater outlets. The coarse-grained sediments of the harbour contain $1.4-3 \%$ organic matter whereas the fine-grained sediments contain 3.5-7.7\% organic matter (Haddon and Wear, 1993; Goff et al., 1998; Wear and Anderlini, 1995). In the vicinity of the stormwater outlets the sediment organic matter content ranged from $1.0-43.7 \%$, indicating pronounced organic matter enrichment.

2. Altered grain size characteristics in the vicinity of stormwater outlets with:

- high percentages of gravel close to and extending to $\geq 10-15 \mathrm{~m}$ in front of some outlets

- elevated percentages of sand also occurred close to and out to $\geq 20-30 \mathrm{~m}$ at some outlets

3. Significant changes in organic matter content over time.

\subsection{1.b Sediment characteristics and the macrobiota}

The physical characteristics of soft sediment are a recognised influence on the composition of benthic faunal assemblages (Sanders, 1958, 1960; Gray, 1974). Organic matter content also has a large influence on the presence and abundance of macrobenthic species (Pearson and Rosenberg, 1978). Thus the altered sediment characteristics (grain size, sorting and organic matter content) likely resulting from stormwater discharge have the potential to affect the presence and abundance of the macrobiota.

\subsubsection{Metal Concentrations}

\subsection{2.a Stormwater discharge and metal concentrations (from Chapter 4)}

The data strongly suggest that stormwater discharge has resulted in the following effects on metal concentrations in inner Wellington Harbour:

- Elevated concentrations of $\mathrm{As}, \mathrm{Cr}, \mathrm{Cu}, \mathrm{Ni}, \mathrm{Pb}$ and $\mathrm{Zn}$ in the sediment in the vicinity of stormwater outlets.

- High variability in metal concentrations over time. 


\subsection{2.b Metal concentrations and the macrobiota}

The effects of stormwater discharge on the macrobiota could occur as a result of elevated concentrations of $\mathrm{As}, \mathrm{Cr}, \mathrm{Cu}, \mathrm{Ni}, \mathrm{Pb}$ and $\mathrm{Zn}$ because high metal concentrations have the potential for biological effects (Long et al., 1995; ANZECC, 2000). As a consequence, Sediment Quality Guidelines (SQG's) have been developed for the protection of aquatic life and for the protection of consumers of aquatic life (Smith et al. 1996). A wide range of sediment contaminants (e.g. metals, non-metallic inorganics, synthetic organics, etc), are listed in these guidelines, along with concentrations at which each may have a biological effect. Therefore, they can be used to identify areas where there is potential for adverse biological effects (Long et al. 1995) and trigger further action such as more detailed investigations and remedial action (O'Connor et al. 1998). Three SQG's will be considered with respect to the data collected in this study (Table 7.1).

Table 7.1: Sediment Quality Guideline Values (ppm) for six metals

\begin{tabular}{|c|c|c|c|c|c|c|}
\hline & TEL $^{a}$ & PEL $^{1 b c}$ & ER-L ${ }^{d}$ & ER-M ${ }^{2 e f}$ & ISQG-Low ${ }^{g}$ & ISQG-High $^{3 h i}$ \\
\hline As & 7.24 & 41.6 & 8.2 & 70 & 20 & 70 \\
\hline $\mathrm{Cr}$ & 52.3 & 160 & 81 & 370 & 80 & 370 \\
\hline $\mathrm{Cu}$ & 18.7 & 108 & 34 & 270 & 65 & 270 \\
\hline $\mathrm{Ni}$ & 15.9 & 42.8 & 21 & 52 & 21 & 52 \\
\hline $\mathrm{Pb}$ & 30.2 & 112 & 47 & 220 & 50 & 220 \\
\hline $\mathrm{Zn}$ & 124 & 271 & 150 & 410 & 200 & 410 \\
\hline $\begin{array}{l}1 . \\
2 . \\
3 .\end{array}$ & $\begin{array}{l}\text { From Smith et al. (1) } \\
\text { From Long et al. (19 } \\
\text { From ANZECC guid }\end{array}$ & $\begin{array}{l}\text { 96) } \\
\text { 95) } \\
\text { elines }(2000\end{array}$ & lapted fro & $\mathrm{m}$ Long et al. & (1995) & \\
\hline
\end{tabular}

${ }^{a}$ TEL: Threshold Effects Level - concentrations below which effects rarely occur.

${ }^{b}$ PEL: Probable Effects Level - concentrations above which effects predicted to occur.

${ }^{c}$ TEL - PEL: adverse effects occasionally occur.

${ }^{d}$ ER-L: Effects Range Low - Concentrations below which sediments unlikely to be toxic.

${ }^{e}$ ER-M: Effects Range Median - Concentrations above which toxicity is probable and effects frequently occur.

${ }^{f}$ ER-L - ER-M: Possible Effects range when effects occasionally occur. 
${ }^{g}$ ISQG-Low: Interim sediment guideline Low $\equiv$ ER-L.

${ }^{h}$ ISQG-High: Interim sediment guideline High $\equiv$ ER-M.

${ }^{i}$ ISQG-Low - ISQG-High: Range when effects occasionally occur.

The Effects Range values (ER-L and ER-M) and the ANZECC values (ISQG-Low and ISQG-High) are most accurate for $\mathrm{Cu}$ and $\mathrm{Pb}$ but are of low accuracy for $\mathrm{Ni}$ (Long et al. 1995). The PEL values for As and Ni have low accuracy (Smith et al. 1996). The SQG values in these guidelines are the total metal concentration for the whole sediment whereas in this study the values are the total metal concentration in the $<63 \mu \mathrm{m}$ sediment fraction.

\subsection{2.c Potential for adverse biological effects in Wellington Harbour}

\section{Quality of Wellington Harbour surface sediments}

For each metal the concentration in surface sediment exceeded at least one of the lower SQG values i.e. TEL, ER-L or ISQG-Low, but the higher SQG values i.e. PEL, ER-M and ISQGHigh, were not exceeded (Table 7.2)

Table 7.2: Concentration (ppm) of six metals (mean \pm 1. S.D.) in sediment from harbour cores and from each control site. Aotea Quay $\mathrm{N}=84$; Queens Wharf $\mathrm{N}=9$; Evans Bay $\mathrm{N}=83$.

\begin{tabular}{|c|c|c|c|c|}
\hline & Surface $^{*}$ & $\begin{array}{l}\text { Aotea } \\
\text { Quay } \\
\text { control }\end{array}$ & $\begin{array}{l}\text { Queens } \\
\text { Wharf } \\
\text { control }\end{array}$ & $\begin{array}{l}\text { Evans Bay } \\
\text { control }\end{array}$ \\
\hline As & 16 & $17 \pm 2 * *$ & $23 \pm 2 * *$ & $23 \pm 3 * *$ \\
\hline $\mathrm{Cr}$ & 72 & $69 \pm 3$ & $70 \pm 1$ & $74 \pm 3$ \\
\hline $\mathrm{Cu}$ & 73 & $71 \pm 12$ & $171 \pm 9$ & $65 \pm 11$ \\
\hline $\mathrm{Ni}$ & 29 & $23 \pm 2$ & $22 \pm 1$ & $24 \pm 3$ \\
\hline $\mathrm{Pb}$ & 104 & $100 \pm 13$ & $171 \pm 13$ & $127 \pm 9$ \\
\hline Zn & 221 & $224 \pm 22$ & $274 \pm 12$ & $232 \pm 10$ \\
\hline \multicolumn{5}{|c|}{$\begin{array}{l}\text { * - Harbour core. Averaged from sediment } 0-50 \mathrm{~cm} \text { from the sediment surface (Dunbar, 1994) } \\
\text { ** - These As values (XRF analysis) could be higher than the true value (see Table 4.1) }\end{array}$} \\
\hline
\end{tabular}




\section{Quality of control site sediments}

For each metal at each control site the concentration in the sediment exceeded at least one of the lower SQG values. At the Queens Wharf control site concentrations of $\mathrm{Cu}, \mathrm{Pb}$ and $\mathrm{Zn}$, and at the Evans Bay control site the concentration of $\mathrm{Pb}$ exceeded the PEL but not the ER$\mathrm{M}$ and ISQG-high values (Table 7.2).

\section{Quality of outlet site sediments}

Cr: The $\mathrm{Cr}$ concentration in all samples exceeded the TEL but not all exceeded the ER-L and ISQG-Low values. PEL, ER-M and ISQG-High values were not exceeded at any site.

Ni: The Ni concentration in all samples exceeded the TEL value but not all exceeded the ER-L and ISQG-Low values. The PEL, ER-M and ISQG-High values were exceeded at OPT station R15 and the PEL value was exceeded at EB-2 station S24 (in November 1998).

As, $\mathbf{C u}, \mathbf{P b}$ and $\mathbf{Z n}$ : The concentration of $\mathrm{Pb}$ in all samples exceeded the TEL, ER-L and ISQG-Low values while the concentration of $\mathrm{As}, \mathrm{Cu}$, and $\mathrm{Zn}$ in all samples exceeded the TEL and ER-L but not all exceeded the ISQG-Low values. The PEL, ER-M and ISQGHigh values for each metal were exceeded at stations at many of the outlet sites (Table 7.3). Where the PEL, ER-M and ISQG-High values were exceeded at the stations sampled over time (AQ-2, Q-2 and EB-2) this excess did not necessarily occur on every sampling occasion (Table 4.9, File: Time Summary in Appendix III).

Therefore $\mathrm{As}, \mathrm{Cr}, \mathrm{Cu}, \mathrm{Ni}, \mathrm{Pb}$ and $\mathrm{Zn}$ concentrations in sediments in the vicinity of stormwater outlets and at some control sites have the potential to cause adverse biological effects.

\subsubsection{The Macrobiota}

Of the taxa recorded in this study (File: Species List in Appendix IV) 127 were represented by more than 10 individuals throughout the study (spatial and temporal variability). Fiftythree of the 127 taxa were more abundant at control than outlet sites, 25 were more abundant at outlet than control sites with comparable abundance of 49 taxa at control and outlet sites (Table 7.4). Differences in the abundance of taxa between outlet and control sites are a reflection of differences in the sedimentological/chemical/biological conditions between the sites, and could result from differences in: 


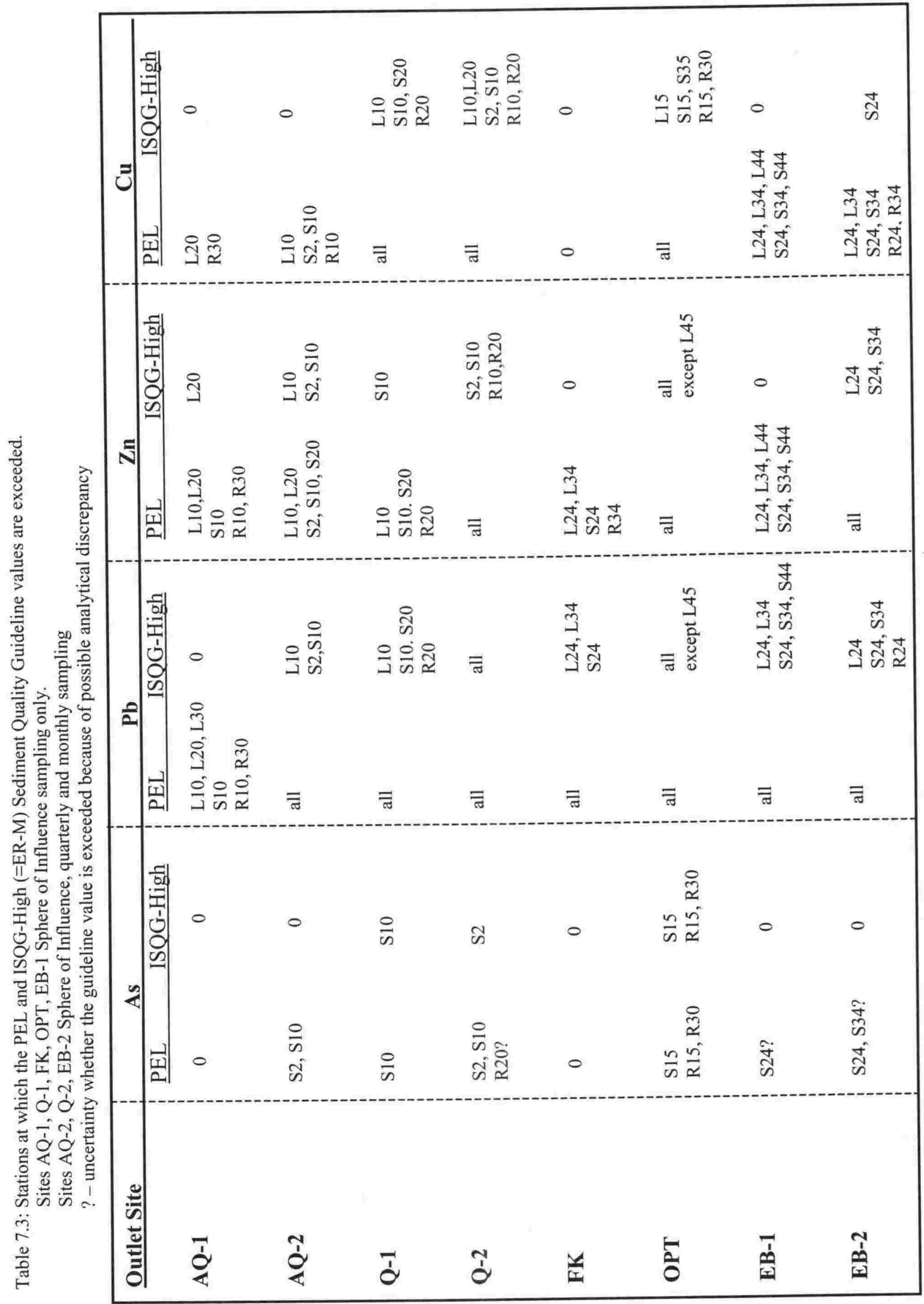


Table 7.4: Taxa with more than 10 individuals. Categories based on mean abundance per sample.

For outlets, mean abundance was calculated over all outlet samples; same applies for the control samples.

More abundant i.e. more than twice as abundant at one type (outlet or control) of site than the other.

Comparable abundance i.e. less than twice as abundant at one type of site than the other

Group: A - Arthropod, Am - Amphineuran mollusc, B - Bivalve mollusc, E - Echinoderm,

G - Gastropod mollusc , O - Other, P - Polychaete

\begin{tabular}{|c|c|c|c|c|c|}
\hline More abundant at Controls & 言 & Comparable abundances & 产 & More abundant at outlets & 言 \\
\hline Caecum digitatum & $\mathrm{B}$ & Arthritica bifurca & $\bar{B}$ & Cominella adspersa & B \\
\hline Calyptraea tenuis & $\mathrm{G}$ & Nozeba emarginata & B & Dosina zelandica & B \\
\hline Corbula zelandica & B & Ruditapes largillierti & B & Macomona liliana & B \\
\hline Gari stangeri & B & Scintillona zelandica & B & Paphies australis & B \\
\hline Gumina dolochiostoma & $\mathrm{G}$ & Tawera spissa & B & Philine auriformis & G \\
\hline Turbonilla sp. & G & Theora lubrica & B & Soletellina nitida & B \\
\hline Odostomia sp. & $\mathrm{G}$ & Patiriella regularis & $\mathrm{E}$ & Callianassa filholi & A \\
\hline Leptochiton inquinatus & $\mathrm{Am}$ & Echinocardium caudatum & E & Lysianassid sp. & A \\
\hline Leptomya retiaria & B & Halicarcinus cooki & A & Propharpinia spp. & A \\
\hline Micrelenchus artizona & $\mathrm{G}$ & Macrophthlamus hirtipes & A & Meridiolembos sp. & A \\
\hline Myadora striata & B & Pontophilus spp. & A & Corophium acherusicum & A \\
\hline Notoacmea helmsi & $\mathrm{G}$ & Parawaldeckia thomsoni & A & Aglaophamus macroura & $\mathrm{P}$ \\
\hline Nucula hartvigiana & $\mathrm{B}$ & Ventojassa $\mathrm{sp}$ & A & Aonides trifidus & $\mathrm{P}$ \\
\hline Pseudotonicia cuneata & $\mathrm{Am}$ & Amphipod sp.A & A & Axionice sp. & $\mathrm{P}$ \\
\hline Ischnochiton maoriamus & $\mathrm{Am}$ & Amphipod sp.C & A & Boccardia syrtis & $P$ \\
\hline Trochus tiaratus & $\mathrm{G}$ & Oedicerotid sp.A & A & Capitella spp. & $P$ \\
\hline Turbo smaragdus & G & Tanaid sp.A & A & Cossura consimilis & $\mathrm{P}$ \\
\hline Xymene plebeius & G & Munna sp. & A & Glycinde dorsalis & $\mathrm{P}$ \\
\hline Xymene pusillus & G & Diasterope grisea & A & Lumbricalus aotearoae & $\mathrm{P}$ \\
\hline Trochodota dendyi & E & Harbansus sp. & A & Magelona sp. & $\mathrm{P}$ \\
\hline Amphiura sp. & E & Cymbicopa hispida & A & Maldanid sp.A & $\mathrm{P}$ \\
\hline Stephos spp. & A & Parasterope quadrata & A & Owenid sp.B & $\mathrm{P}$ \\
\hline Mysid sp. & A & Armandia maculata & $\mathrm{P}$ & Perinereis? brevicirris & P \\
\hline Pagurid spp. & A & Barantolla sp. & $\mathrm{P}$ & Polydora hoplura & $\mathrm{P}$ \\
\hline Paraphoxus australis & A & Chrysopetalid sp. & $\mathrm{P}$ & Polydora sp. & $\mathrm{P}$ \\
\hline Iphinotus typicus & $\mathrm{A}$ & Euchone sp. & $\mathrm{P}$ & & \\
\hline Melita spp. & A & Eulalia sp.B & $\mathrm{P}$ & & \\
\hline Liljeborgia barhami & $\mathrm{A}$ & Genetyllis sp. & $P$ & & \\
\hline Anthurid sp.A & $\mathrm{A}$ & Glycera ovigera & $\mathrm{P}$ & & \\
\hline Scleroconcha sculpta & A & Hesionid sp.A & $P$ & & \\
\hline Aphelochaeta sp. & $\mathrm{P}$ & Heteromastus filiformis & $P$ & & \\
\hline Boccardia chiliensis & $\mathrm{P}$ & Notomastus sp. & $P$ & & \\
\hline Carazziella philipensis & $P$ & Ophiodromus sp. & $P$ & & \\
\hline Caulleriella sp. & $P$ & Owenia fusiformis & $P$ & & \\
\hline Chaetozone sp. & $P$ & Paradoneis sp. & $\mathrm{P}$ & & \\
\hline Eulalia sp.A & $\mathrm{P}$ & Paraprionospio pinnata & $P$ & & \\
\hline Goniadid sp. & $\mathrm{P}$ & Pectinaria australis & $\mathrm{P}$ & & \\
\hline Hemipodus simplex & $\mathrm{P}$ & Platynereis australis & $\mathrm{P}$ & & \\
\hline Jasmineira sp. & $\mathrm{P}$ & Pista sp. & $P$ & & \\
\hline Lepidonotus sp. & $\mathrm{P}$ & Prionospio aucklandica & $P$ & & \\
\hline Lumbrineris sp.1 & $\mathrm{P}$ & Prionospio yuriel & $\mathrm{P}$ & & \\
\hline Monticellina $\mathrm{sp}$. & $P$ & Pseudopolydora cf. paucibranchiata & $P$ & & \\
\hline Prionospio spp. & $P$ & Questa sp. & $\mathrm{P}$ & & \\
\hline Questa sp. & $\mathrm{P}$ & Schistomeringos loveni? & $P$ & & \\
\hline Scolelepis sp. & $\mathrm{P}$ & Sthenelais taurangaensis & $\mathrm{P}$ & & \\
\hline Exogone sp.A & $\mathrm{P}$ & Oligochaete spp. & $\mathrm{O}$ & & \\
\hline Exogone sp.B & $\mathrm{P}$ & Phoronid sp. & $\mathrm{O}$ & & \\
\hline Sphaerosyllis sp.A & $P$ & Platyhelminth spp. & $\mathrm{O}$ & & \\
\hline Sphaerosyllis sp. B & $\mathrm{P}$ & Nemertea spp. & $\mathrm{O}$ & & \\
\hline Syllid sp.A & $\mathrm{P}$ & & & & \\
\hline Syllid sp.D & $\mathrm{P}$ & & & & \\
\hline $\begin{array}{l}\text { Syllid sp.F } \\
\text { Scolanthus sp. }\end{array}$ & $\begin{array}{l}\mathrm{P} \\
\mathrm{O}\end{array}$ & & & & \\
\hline
\end{tabular}


- Sediment structure between sites either as a result of stormwater discharge or natural spatial heterogeneity or other disturbances.

- Organic matter content and metal concentrations as well as other unmeasured variables between sites as a result of stormwater discharge.

- Biological influences such as competition, predation and niche availability

There were 25 outlet abundant taxa of which three were site abundant (Aonides trifidus and Paphies australis at Q-1 and Perinereis ?brevicirris (juveniles) at OPT) and two occurred in low numbers but with peaks of abundance as a result of recruitment (Macomona liliana and Dosina zelandica). The polychaete Capitella spp., a well recognised, pollution tolerant taxa (Pearson and Rosenberg, 1978; Chapman et al., 1996; Estacio et al., 1997), was abundant in the vicinity of some of the stormwater outlets i.e. it thrives in conditions resulting from stormwater discharge, as may do some or all of the outlet abundant taxa. By comparison, it is probable that some of the 53 control abundant taxa are pollution intolerant or pollution sensitive.

\subsection{3.a Stormwater discharge and the macrobiota (From Chapters 5 and 6)}

The data strongly suggest that stormwater discharge has resulted in the following effects on the macrobiota in inner Wellington Harbour:

- Disturbed biological communities

- Changes in the composition of the biological community with increasing distance from an outlet

- A lower number of taxa at some outlet stations compared to the number of taxa at associated control stations

- Lower values in one or more of the biological indices (total, mollusc, arthropod and polychaete taxa and total, mollusc, arthropod and polychaete individuals and Shannon-Weiner diversity) at Q-1, Q-2, EB-1 and EB-2 stations compared to that at the associated control stations

- Significant differences in one or more of - the number of total, polychaete, arthropod and mollusc taxa, polychaete and mollusc individuals and diversity, with distance from AQ-1, Q-2 and EB-2

- Lower abundances of 18 taxa at some outlets than at the associated control site

- Higher abundances of 5 taxa at some outlets than at the associated control site 
- Significant differences in the abundance of the polychaetes Armandia maculata, Capitella spp., Exogone sp.A, Heteromastus filiformis, Hesionid sp.A, Ophiodromus sp., Owenia fusiformis, Prionospio aucklandica, Prionospio yuriel and Schistomeringos loveni?, and the amphipods Corophium acherusicum, Meridiolembos sp. and Proharpinia spp. with distance from an outlet

- Temporal differences in biological community disturbance

- The macrobiota at AQ-2 in November 2000 being very different from that on all other sampling occasions

- A moderate effect on the temporal variability of the macrobiota at AQ-2 between August 1998 and August 2000

- A small effect on the temporal variability of the macrobiota at EB-2

- More total and polychaete individuals (with a high abundance of the opportunistic polychaete Capitella spp.) over time at AQ-2 than at AQ-C

- Significant temporal differences in the number of total, mollusc, polychaete and arthropod taxa, total, polychaete and arthropod individuals and Shannon-Weiner diversity

- Significant temporal changes in the abundance of taxa

- Irregular recruitment of the polychaetes Capitella spp., Heteromastus filiformis, Barantolla sp., Prionospio auckandica, Prionospio spp. and Questa sp.

\subsection{METHODS}

\subsubsection{Sedimentological, chemical and biological variables used in the analyses}

To investigate if the biological effects which likely result from stormwater discharge are linked to the measured sedimentological and chemical variables which occured in the vicinity of outlets, the following variables were used (the biological variables were those found to be likely affected by stormwater discharge whereas all measured sedimentological and chemical variables have been included):

\section{Sedimentological variables}

- $\%$ gravel, $\%$ sand, $\%$ silt, $\%$ clay, $\%$ mud ( $=\%$ silt $+\%$ clay $), \%$ carbonate

- mean grain size

- sediment sorting

- $\%$ organic matter 
Chemical variables

- $\mathrm{As}, \mathrm{Cr}, \mathrm{Cu}, \mathrm{Ni}, \mathrm{Pb}$ and $\mathrm{Zn}$ concentrations (ppm)

Environmental variable

- Water depth (below chart datum)

Biological variables

- The biological community i.e. presence and abundance of all taxa

- Univariate indices - Number of total $(\mathrm{S})$, mollusc $\left(\mathrm{S}_{\mathrm{m}}\right)$ and arthropod $\left(\mathrm{S}_{\mathrm{a}}\right)$ taxa

- Number of total $(\mathrm{N})$, mollusc $\left(\mathrm{N}_{\mathrm{m}}\right)$, arthropod $\left(\mathrm{N}_{\mathrm{a}}\right)$ and polychaete $\left(\mathrm{N}_{\mathrm{p}}\right.$ individuals

- Shannon-Weiner diversity $\left(\mathrm{H}^{\prime}\right)$

- Abundance of the molluscs Gari stangeri, Gumina dolochostoma, Leptomya retiaria, Macomona liliana, Notoacmea helmsi, Nucula hartvigiana, the arthropods Corophium acherusicum, Meridiolembos sp., Proharpinia spp., Stephos spp. and Ventojassa sp., the polychaetes Aphelochaeta sp., Armandia maculata, Capitella spp., Caraziella phillipensis?, Glycera ovigera, Glycinde dorsalis, Hemipodus simplex, Hesionid sp.A, Heteromastus filiformis, Lumbriculus aotearoae, Ophiodromus sp., Owenia fusiformis, Paraprionospio pinnata, Pectinaria australis, Prionospio aucklandica, Prionospio yuriel, Prionospio spp., Schistomeringos loveni? and Syllid spp., the coelenterate Scolanthus sp. and Oligochaetes.

\subsubsection{Linking the biological community to environmental and chemical variables}

The Primer routine BIO-ENV was used to determine which combination of the measured sedimentological, environmental and chemical variables best explained the biological community structure at:

- Each site (spatial variability data)

- At each site sampled over time (temporal variability data). Restricted to the 7 (out of 18) sampling occasions when all sedimentological and chemical variables were measured

The underlying assumption of the BIO-ENV procedure is that a large data set composed of many measured variables (in this case 16-sedimentological, environmental and chemical) can be reduced to those variables that account for most of the variation in the biological data set (Clarke and Warwick, 1994). A Spearman Rank correlation coefficient $\left(\rho_{\mathrm{s}}\right)$ was used to ascertain the variable subset which maximised the correlation between biotic similarity and 
the sedimentological/environmental/chemical dissimilarity matrices. The dissimilarity matrix was calculated using the normalized Euclidian distance and transformed data. The transformations used were those used for statistical analyses in chapters $3,4,5$ and 6 , i.e. metal data - $\log _{10}$ transformation, organic matter data - square root transformation, biological data - $\log (\mathrm{x}+1)$ transformation. There is no a priori knowledge of which sedimentological/environmental/chemical variable or combination of variables is most likely to explain maximum variation in the biological data, hence all possible permutations (1 variable, 2 variables......16 variables) of the 16 (unless otherwise stated) sedimentological/environmental/chemical variables were tested against the biological data.

\subsubsection{Linking univariate indices to sedimentological and chemical variables}

Linear regression (SYSTAT vs. 6.1) was used to determine if a significant relationship existed between the univariate indices and the measured sedimentological and chemical variables.

\subsection{3.a Combined data analyses for each index}

The null hypothesis to be tested is:

There is no correlation between each index $\left(\mathrm{S}, \mathrm{N}, \mathbf{H}^{\prime}, \mathrm{S}_{\mathrm{m}}, \mathrm{S}_{\mathrm{a}}, \mathbf{N}_{\mathrm{m}}, \mathrm{N}_{\mathrm{p}}, \mathrm{N}_{\mathrm{a}}\right)$ and the measured sedimentological and chemical variables across all sites

All index data i.e. from spatial and temporal sampling at outlet and control stations where all sedimentological and chemical variables (15 variables) were measured were used in the analysis (91 data points) (Data in file: Univariate in Appendix V). The value for each index and organic matter content at each station is the mean ( 3 samples), whereas for all other sedimentological and chemical variables the one value obtained per station was used. The correlation of each index to each of the sedimentological and chemical variables was initially investigated by generation of a Pearson correlation matrix. Matrices were generated using both untransformed and $\log _{10}$ transformed data. Pearson correlation coefficients vary from -1 to +1 , with a value of 0 indicating that neither of the variables can be predicted from the other, while values of -1 to +1 indicate that one variable can be predicted perfectly from the other using a linear equation. An arbitrary correlation coefficient range of $\geq 0.65$ or $\leq$ 0.65 was set and correlations within this range were assessed by simple linear regression (GLM: Estimate model). The simple linear regression significance level was $\alpha=0.05$, with corrections made to $\alpha$ when multiple tests were performed (Rice, 1989). 


\subsection{3.b Site data analyses for each univariate index}

The null hypothesis to be tested is:

At each site there is no correlation between each index $\left(\mathrm{S}, \mathrm{N}, \mathrm{H}^{\prime}, \mathrm{S}_{\mathrm{m}}, \mathrm{S}_{\mathrm{a}}, \mathbf{N}_{\mathrm{m}}, \mathrm{N}_{\mathrm{p}}, \mathbf{N}_{\mathrm{a}}\right)$ and the measured sedimentological and chemical variables

Site analyses were carried out because of macrobiota differences between areas and sites (outlet and control). However sufficient biological, sedimentological and chemical data were only available for the Aotea Quay (AQ-2 and AQ-C) and Evans Bay (EB-2 and EB-C) sites where both spatial and temporal sampling was undertaken $(\mathrm{N}=14$ at Aotea Quay sites and $\mathrm{N}=13$ at Evans Bay sites). The statistical methods used for the analyses are outlined in section 7.2.3.a.

\subsubsection{Linking taxa to sedimentological and chemical variables}

Linear regression (SYSTAT vs. 6.1) was used to determine if a significant relationship existed between taxa and the measured sedimentological and chemical variables.

The null hypothesis to be tested is:

At each site there is no correlation between each taxa and the measured sedimentological and chemical variables

Analyses were only carried out on the Aotea Quay (AQ-2 and AQ-C) and Evans Bay (EB-2 and $\mathrm{EB}-\mathrm{C})$ data $(\mathrm{N}=14$ at Aotea Quay sites and $\mathrm{N}=13$ at Evans Bay sites). The taxa investigated were area specific, and for each area were those with:

- A significant difference in abundance with distance from an outlet

- A significant difference in abundance between an outlet and control station

- $\geq 200$ individuals at a site over time and at least twice as abundant at one site than the other in the area

The statistical methods used for the analyses are outlined in section 7.2.3.a.

\subsection{RESULTS}

\subsubsection{Linking the biological community to environmental and chemical variables}

To determine whether the biological community at each site correlate to the measured sedimentological, environmental and chemical variables the BIO-ENV analysis was applied 
to both the spatial and temporal data. BIO-ENV determines the combination of measured sedimentological, environmental and chemical variables that 'best' accounts for the variation in biological community structure. The results of these analyses are presented in File: BIOENV in Appendix V, with a summary in Table 7.5.

Table 7.5: The sedimentological, environmental and chemical variables giving the best match to the biological community at each site. The variables listed are those giving the highest value of

. s (Spearman rank correlation coefficient) at each site.

S: Results -Spatial Variability data.

T: Results -Temporal variability data

\begin{tabular}{|c|c|c|c|}
\hline \multirow{11}{*}{ S. } & SITE & $\rho_{s}$ & VARIABLES \\
\hline & $\mathrm{AQ}-\mathrm{C}$ & 0.88 & Mud, Silt, Sorting, Ni, Cu \\
\hline & $\mathrm{AQ}-1$ & 0.63 & Silt, Carbonate, $\mathrm{Cr}, \mathrm{Cu}, \%$ organic \\
\hline & AQ-2 & 0.84 & Mud, Mean grain size, $\mathrm{Ni}, \mathrm{As}, \%$ organic \\
\hline & Q-C & 0.98 & Silt, Carbonate, $\mathrm{Cr}, \mathrm{Cu}, \mathrm{As}$ \\
\hline & Q-1 & 0.72 & Depth, Clay, $\%$ organic \\
\hline & Q-2 & 0.95 & Depth, Sand, As, $\%$ organic \\
\hline & OPT & 0.79 & Silt, Clay, $\mathrm{Zn}, \%$ organic \\
\hline & EB-C & 0.84 & Gravel, Mean grain size, As \\
\hline & EB-1 & 0.69 & Carbonate, $\%$ organic \\
\hline & EB-2 & 0.51 & Clay, Mean grain size, $\mathrm{Cu}$ \\
\hline \multirow[t]{4}{*}{ T. } & $\mathrm{AQ}-\mathrm{C}$ & 0.68 & Sediment sorting, $\mathrm{Ni}$ \\
\hline & $\mathrm{AQ}-2$ & 0.81 & Clay, Mean grain size, $\mathrm{Cr}, \mathrm{Pb}$ \\
\hline & EB-C & 0.25 & $\mathrm{Cr}, \mathrm{Pb}, \mathrm{As}$ \\
\hline & EB-2 & 0.71 & $\mathrm{Ni}, \mathrm{Pb}$ \\
\hline
\end{tabular}

\subsection{1.a Control Sites}

\section{Spatial Variability}

At AQ-C, Q-C and EB-C there was a very high correlation $(0.84-0.98)$ of the biological community to a combination of sedimentological and chemical variables. The spatial variability of the biological community at control sites is correlated to sediment structure and the concentration of some metals (Table 7.5).

\section{Temporal variability}

The biological community at AQ-C had had a high correlation $\left(\rho_{\mathrm{s}}=0.68\right)$ to sediment sorting and $\mathrm{Ni}$ whereas the biological community at EB-C had a low correlation $\left(\rho_{\mathrm{s}}=0.25\right)$ to $\mathrm{As}, \mathrm{Cr}$ and $\mathrm{Pb}$ concentrations (Table 7.5). 


\subsection{1.b. Outlet Sites}

\section{Spatial variability}

At all outlet sites, except EB-2, organic matter content was one of the variables contributing to the highest correlation values with the biological community (Table 7.5). There was no consistent occurrence of any other variable, with outlet site biological communities correlated to depth, carbonate, grain size characteristics and metal concentrations and in particular, $\mathrm{Cr}$ and $\mathrm{Cu}$ at $\mathrm{AQ}-1, \mathrm{As}$ and $\mathrm{Ni}$ at AQ-2, As at Q-2, $\mathrm{Zn}$ at OPT and $\mathrm{Cu}$ at EB-2.

\section{Temporal Variability}

At AQ-2 the biological community had a high correlation $\left(\rho_{\mathrm{s}}=0.81\right)$ to the $\%$ clay, mean grain size and $\mathrm{Pb}$ and $\mathrm{Cr}$ concentrations.

At EB-2 the biological community had a high correlation $\left(\rho_{\mathrm{s}}=0.71\right)$ to $\mathrm{Ni}$ and $\mathrm{Pb}$ concentrations.

\subsubsection{Linking univariate indices to sedimentological and chemical variables}

\subsection{2.a Combined data analyses for each index}

Pearson correlation coefficient values of $\geq 0.65$ or $\leq-0.65$ occurred for the number of total (S) and arthropod $\left(\mathrm{S}_{\mathrm{a}}\right)$ taxa (File: Univariate correlations in Appendix V). For these correlations the relationships (details in File: Univariate Regress in Appendix V) are given by the following equations:

$$
\begin{aligned}
& \mathrm{S}=-16.142\left(\log _{10} \% \text { silt }\right)+39.086 \quad\left(\mathrm{r}^{2}=0.482, \mathrm{p}<0.001\right) \\
& \mathrm{S}=-15.141\left(\log _{10} \% \text { mud }\right)+42.202 \quad\left(\mathrm{r}^{2}=0.485, \mathrm{p}<0.001\right) \\
& \mathrm{S}=-26.446\left(\log _{10} \% \text { organic }\right)+43.202 \quad\left(\mathrm{r}^{2}=0.513, \mathrm{p}<0.001\right) \\
& \log _{10} \mathrm{~S}_{\mathrm{a}}=-0.37\left(\log _{10} \% \text { mud }\right)+1.038 \quad\left(\mathrm{r}^{2}=0.433, \mathrm{p}<0.001\right) \\
& \log _{10} \mathrm{~S}_{\mathrm{a}}=-0.646\left(\log _{10} \% \text { organic }\right)+1.067 \quad\left(\mathrm{r}^{2}=0.466, \mathrm{p}<0.001\right)
\end{aligned}
$$

With an increase in the organic matter (Figs. 7.1 and 7.2) and mud content there was a significant decrease in the number of total and arthropod taxa. Similarly, with an increase in silt content there was a significant decrease in the number of total taxa. However the $r^{2}$ values for all relationships were not high i.e. differences in the number of total and arthropod taxa are at best moderately correlated to the given variable. 


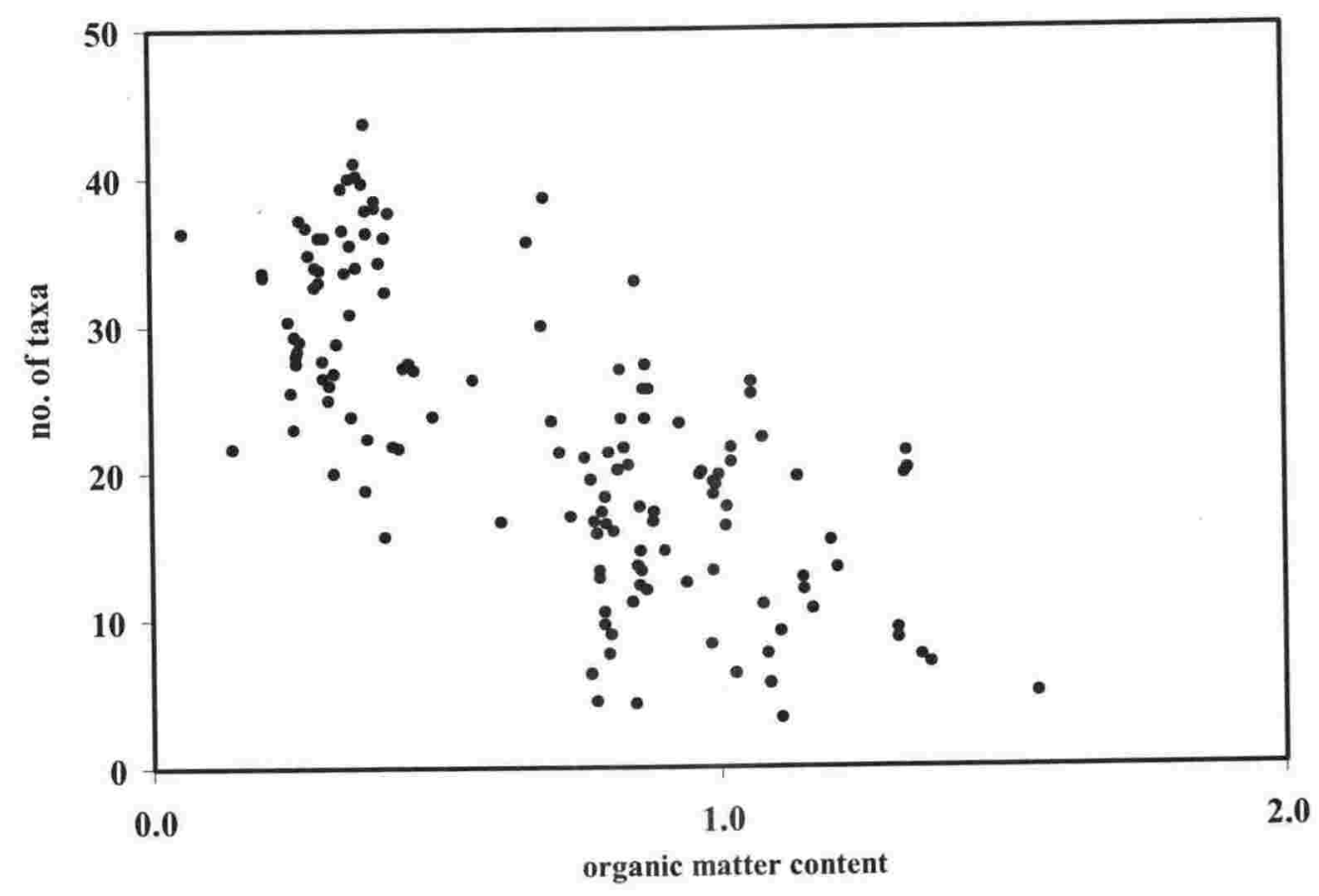

Figure 7.1: Mean number of total taxa versus organic matter content (Log10 transformed)

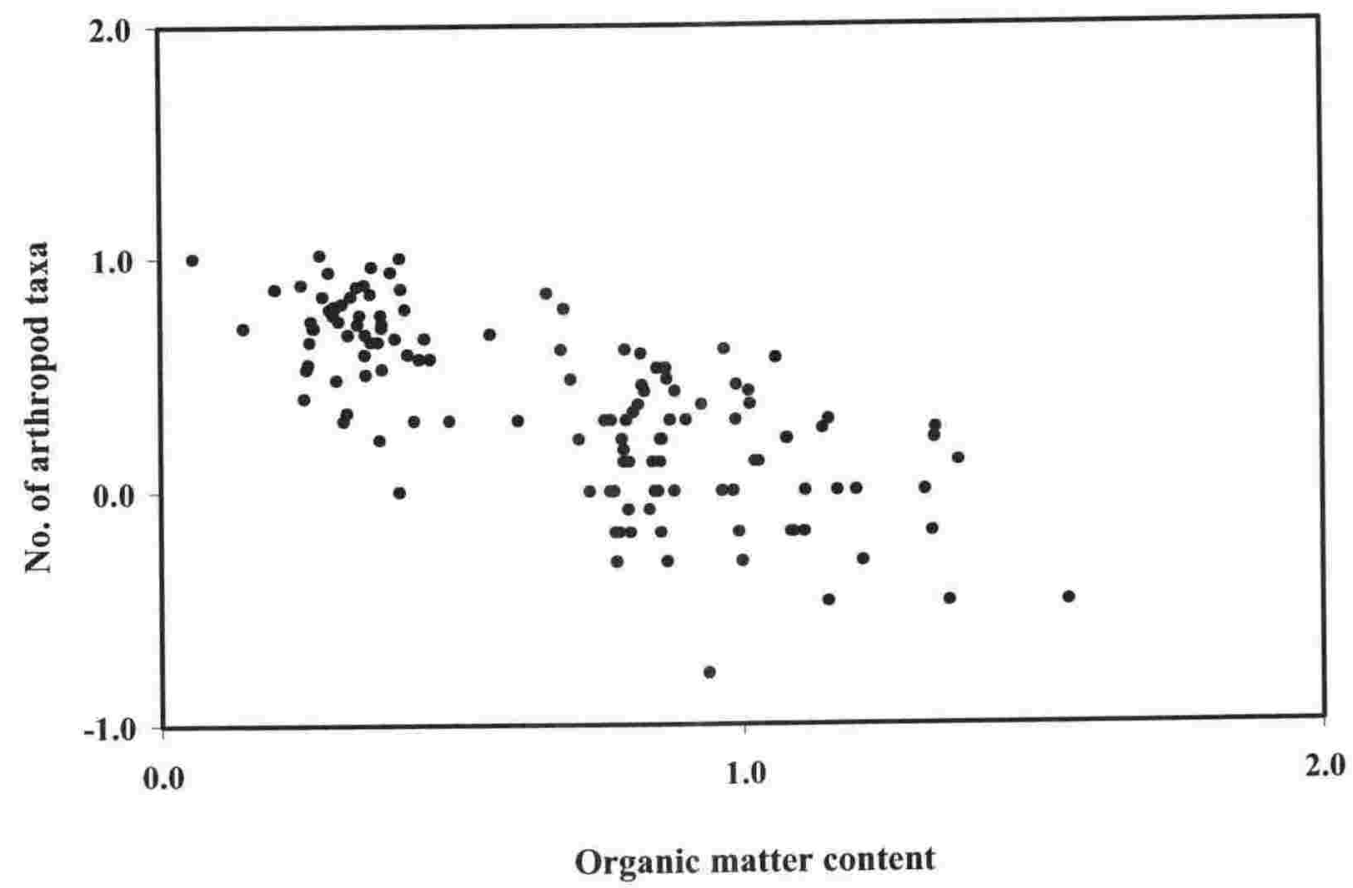

Figure 7.2: Mean number of arthropod taxa ( $\log 10$ transformed) versus organic matter content (Log10 transformed). $\mathrm{N}=91$ 
The null hypothesis that there is no correlation between each index $\left(\mathrm{S}, \mathrm{N}, \mathbf{H}^{\prime}, \mathrm{S}_{\mathrm{m}}, \mathbf{S}_{\mathrm{a}}, \mathbf{N}_{\mathrm{m}}\right.$, $N_{p}, N_{a}$ ) and the measured sedimentological and chemical variables across all sites is rejected for $\mathrm{S}$ and $\mathrm{S}_{\mathrm{a}}$ and accepted for $\mathrm{N}, \mathrm{H}^{\prime}, \mathrm{S}_{\mathrm{m}}, \mathrm{N}_{\mathrm{m}}, \mathrm{N}_{\mathrm{p}}, \mathrm{N}_{\mathrm{a}}$. There were significant relationships between $\mathrm{S}$ and $\%$ silt, $\%$ mud and \% organic and between $\mathrm{S}_{\mathrm{a}}$ and $\%$ mud and \% organic.

\subsection{2.b Site data analyses for each index}

\subsection{2.b.1 Aotea Quay}

\section{Outlet $A Q-2$}

Pearson correlation coefficient values of $\geq 0.65$ or $\leq-0.65$ only occurred for the number of total individuals $(\mathrm{N})$ (File: Univariate correlations in Appendix V). There was a significant decrease in the number of total individuals with an increase in the concentration of $\mathrm{Pb}$, however because the $r^{2}$ value is low the relationship is weak (Table 7.6, File: AQ univariate regress in Appendix V).

\section{Control $A Q-C$}

Pearson correlation coefficient values of $\geq 0.65$ or $\leq-0.65$ occurred for the number of total (S) and mollusc $\left(\mathrm{S}_{\mathrm{m}}\right)$ taxa and mollusc $\left(\mathrm{N}_{\mathrm{m}}\right)$ individuals (File: Univariate correlations in Appendix V). There was a significant increase in the number of total and mollusc taxa and mollusc individuals with an increase in the gravel content and a significant increase in the number of molluse individuals with a decrease in clay content and mean grain size $(\Phi)$ (Table 7.6, File: AQ univariate regress in Appendix V). The relationship between the number of mollusc taxa and \% gravel was high whereas the relationship between the number of mollusc individuals and $\%$ gravel, $\%$ clay and mean grain size was moderate and that between the number of total taxa and $\%$ gravel weak.

\subsection{2.b.2 Evans Bay}

\section{Outlet EB-2}

Pearson correlation coefficient values of $\geq 0.65$ or $\leq-0.65$ did not occur for any index at this site (File: Univariate correlations in Appendix V).

\section{Control EB-C}

Pearson correlation coefficient values of $\geq 0.65$ or $\leq-0.65$ occurred for the number of total $(\mathrm{N})$ and mollusc $\left(\mathrm{N}_{\mathrm{m}}\right)$ individuals, diversity $\left(\mathrm{H}^{\prime}\right)$ and number of mollusc $\left(\mathrm{S}_{\mathrm{m}}\right)$ taxa (File: 
Univariate correlations in Appendix V), but large leverage and outliers in some data ruled out valid linear regression for all indices except the number of total individuals (File: EB Univariate Regress in Appendix V). There was an increase in the number of total individuals with an increase in silt content however because the $\mathrm{r}^{2}$ value was low the relationship was weak (Table 7.6).

Table 7.6: Relationship of univariate indices to sedimentological and chemical variables at outlet and control sites at Aotea Quay and in Evans Bay.

Transformations: Univariate indices, sedimentological and chemical data all $\log _{10}$ except

Total taxa at Aotea Quay and Total individuals in Evans Bay

\section{Outlet AQ-2}

Simple Linear Regression

Total individuals $\mathrm{vs} \mathrm{Pb}$

$\mathbf{r}^{2} \quad$ constant

slope

$-570.32$ p

Control AQ-C

Simple Linear Regression

Total taxa vs $\%$ gravel

Mollusc taxa vs \% gravel

Mollusc individuals vs \% gravel

Mollusc individuals vs \% clay

Mollusc individuals vs mean g.s. 0.646

$\begin{array}{cccc}\mathbf{r}^{2} & \text { constant } & \text { slope } & \mathbf{p} \\ 0.438 & 8.971 & 9.828 & 0.01 \\ 0.812 & -0.033 & 0.439 & <0.001 \\ 0.597 & 0.626 & 0.032 & 0.002 \\ 0.616 & 2.111 & -1.128 & 0.001 \\ 0.646 & 0.962 & -0.772 & 0.001\end{array}$

\section{Control EB-C}

Simple Linear Regression

Total individuals vs $\%$ silt

$\begin{array}{cc}\mathbf{r}^{2} & \text { constant } \\ 0.435 & 66.207\end{array}$

slope

524.59 0.014

The null hypothesis that at each site there is no correlation between each index $\left(\mathrm{S}, \mathbf{N}, \mathrm{H}^{\prime}\right.$, $\mathrm{S}_{\mathrm{m}}, \mathrm{S}_{\mathrm{a}}, \mathrm{N}_{\mathrm{m}}, \mathrm{N}_{\mathrm{p}}, \mathrm{N}_{\mathrm{a}}$ ) and the measured sedimentological and chemical variables is rejected for sites AQ-2, AQ-C and EB-C but accepted for site EB-2. At AQ-2, AQ-C and EB-C at least one index was correlated to at least one of the measured sedimentological and/or chemical variables.

\subsubsection{Linking taxon to environmental and chemical variables}

\subsection{3.a Aotea Quay}

The correlation of 15 taxa i.e. the arthropod Macrophthalmus hirtipes, the polychaetes Armandia maculata, Barantolla sp., Capitella spp., Glycera ovigera, Glycinde dorsalis, Heteromastus filiformis, Ophiodromus sp., Paraprionospio pinnata, Pectinaria australis, 
Prionospio aucklandica, Prionospio spp., Pseudopolydora cf. paucibranchiata, Questa sp. and Schistomeringos loveni?, with sedimentological and chemical variables was investigated.

\section{Outlet $A Q-2$}

Correlation values of $\geq 0.65$ or $\leq-0.65$ occurred for the polychaetes Pectinaria australis and Questa sp. (File: Taxa correlations in Appendix V). There was a significant increase in the abundance of Pectinaria australis with an increase in \% sand, and a significant increase in the abundance of Questa sp. with an increase in \% mud and \% silt and a decrease in $\mathrm{Cr}$ concentration (Table 7.7; File: AQ Taxa Regress in Appendix V). The occurrence of data with large leverage and outliers ruled out valid linear regression for the remaining correlations with values $\geq 0.65$ or $\leq-0.65$.

Table 7.7: Relationship of taxa with sedimentological and chemical variables at the Aotea Quay sites. All data, except $\%$ sand were $\log _{10}$ transformed.

\begin{tabular}{lcccc} 
Outlet AQ-2 & & & & \\
Simple Linear Regression & $\mathbf{r}^{2}$ & constant & slope & p \\
\hline Pectinaria australis vs \% sand & 0.58 & -0.53 & 0.02 & 0.003 \\
Questa sp. vs Cr & 0.43 & 20.53 & -10.66 & 0.011 \\
Questa sp. vs \% mud & 0.61 & -2.686 & 2.168 & 0.001 \\
Questa sp. vs \% silt & 0.65 & -2.501 & 2.498 & 0.001
\end{tabular}

\section{Control AQ-C}

Simple Linear Regression Armandia maculata vs $\% \mathrm{Zn}$

Armandia maculata vs \% clay

Armandia maculata vs $\%$ mud

Armandia maculata vs mean g.s

Barantolla sp. vs \% carbonate

Barantolla sp. vs \% organic

Barantolla sp. vs \% gravel

Barantolla sp. vs \% mud

Glycera ovigera vs $\mathrm{Cu}$

Glycera ovigera vs \% carbonate

Heteromastus filiformis vs \% gravel

Heteromastus filiformis vs mean g.s

$\mathrm{r}^{2}$

$\begin{array}{ll}r^{2} & \text { constant }\end{array}$

slope

$\begin{array}{ll}7.662 & 0.012\end{array}$

0.49

$-0.852$

0.01

0.47

2.279

$-1.08$

0.007

0.47

0.876

0.73

2.313

$-0.681$

0.001

0.83

4.303

$-1.342$

$<0.001$

0.77

$-0.174$

$-4.605$

$<0.001$

0.83

5.119

1.068

$<0.001$

0.44

9.118

$-2.662$

0.72

1.230

$-4.843$

0.45

0.209

$-0.783$

$<0.001$

0.52

1.417

0.799

Heteromastus filiformis vs \% carbonate 0.64

2.491

$-1.006$

$<0.001$

Heteromastus filiformis vs \% organic 0.76

4.506

$-1.305$

1.013

$-4.594$

1.038

$-0.617$

$\begin{array}{lr}\text { Paraprionospio pinnata vs \% carbonate } & 0.58 \\ \text { Pectinaria australis vs \% silt } & 0.44\end{array}$

$-0.665$

0.008

Pectinaria australis vs \% gravel

0.62

$-0.023$

0.208

0.001

0.001

$<0.001$

0.004

0.014

0.003 


\section{Control $A Q-C$}

Correlation values of $\geq 0.65$ or $\leq-0.65$ occurred for the polychaetes Armandia maculata, Barantolla sp., Glycera ovigera, Heteromastus filiformis, Paraprionospio pinnata, Pectinaria australis and Prionospio spp. and Questa sp. (File: Taxa correlations in Appendix V). There was a significant increase in the abundance of Armandia maculata with a decrease in \% mud, \% clay and mean grain size and an increase in $\mathrm{Zn}$ concentration, a significant increase in the abundance of Barantolla sp. with a decrease in \% organic matter, $\%$ mud and \% carbonate and an increase in \% gravel, a significant increase in the abundance of Glycera ovigera with a decrease in \% carbonate and $\mathrm{Cu}$ concentration, a significant increase in the abundance of Heteromastus filiformis with a decrease in mean grain size, \% carbonate and \% organic matter and an increase in \% gravel, a significant increase in the abundance of Paraprionospio pinnata with a decrease in \% carbonate and a significant increase in the abundance of Pectinaria australis with a decrease in \% silt and an increase in $\%$ gravel (Table 7.7; File: AQ Taxa Regress in Appendix V). The occurrence of data with large leverage and outliers ruled out valid linear regression for the remaining correlations with values $\geq 0.65$ or $\leq-0.65$.

\subsection{3.b Evans Bay}

The correlation of 27 taxa i.e. the molluses Gari stangeri, Gumina dolochostoma, Leptomya retiaria, Macomona liliana, Notoacmea helmsi and Nucula hartvigiana, the arthropods Corophium acherusicum, Meridiolembos sp., Proharpinia spp., Stephos spp. and Ventojassa sp., the polychaetes Aphelochaeta sp., Armandia maculata, Capitella spp., Caraziella phillipensis?, Glycinde dorsalis, Hemipodus simplex, Hesionid sp.A, Heteromastus filiformis, Lumbriculus aotearoae, Owenia fusiformis, Pectinaria australis, Prionospio yuriel, Prionospio spp., Schistomeringos loveni? and syllid spp., the coelenterate Scolanthus sp. and Oligochaetes, with the sedimentological and chemical variables was investigated. All environmental, chemical and taxon data except $\mathrm{Ni}$ concentration were $\log _{10}$ transformed prior to analysis.

\section{Outlet EB-2}

Correlation values of $\geq 0.65$ or $\leq-0.65$ occurred for the polychaetes Capitella spp., Hesionid sp.A, Hemipodus simplex, Heteromastus filiformis, Owenia fusiformis, Schistomeringos loveni?, Syllid spp. and Oligochaetes (File: Taxa correlations in Appendix V). There was a significant increase in the abundance of Capitella spp. with an increase in the concentration 
of $\mathrm{As}, \mathrm{Cr}, \mathrm{Ni}, \mathrm{Pb}$ and $\mathrm{Zn}$, a significant increase in the abundance of Hesionid sp.A with an increase in the concentration of $\mathrm{Cr}, \mathrm{Cu}, \mathrm{Ni}, \mathrm{Pb}$ and $\mathrm{Zn}$, a significant increase in the abundance of Heteromastus filiformis with a decrease in the $\%$ carbonate, a significant increase in the abundance of Owenia fusiformis with a decrease in \% organic matter and the concentration of $\mathrm{Cr}, \mathrm{Cu}, \mathrm{Ni}$ and $\mathrm{Pb}$, a significant increase in the abundance of Schistomeringos loveni? with an increase in \% clay, a significant increase in the abundance of Syllid spp. with an increase in As concentration and a significant increase in the abundance of oligochaetes with an increase in \% organic matter and $\mathrm{Cu}, \mathrm{Pb}$ and $\mathrm{Zn}$ concentrations (Table 7.8; File EB taxa regress in Appendix V). The occurrence of data with large leverage and outliers ruled out valid linear regression for the remaining correlations with values $\geq 0.65$ or $\leq-0.65$.

\section{Control EB-C}

Correlation values of $\geq 0.65$ or $\leq-0.65$ occurred for Gumina dolochostoma, Leptomya retiaria, Nucula hartvigiana, Corophium acherusicum, Meridiolembos sp., Ventojassa sp., Aphelochaeta sp., Glycinde dorsalis, Hesionid sp.A, Owenia fusiformis, Schistomeringos loveni? and Syllid spp. (File: Taxa correlations in Appendix V). There was a significant increase in the abundance of Gumina dolochostoma with an increase in the \% carbonate, a significant increase in the abundance of Leptomya retiaria with a decrease in \% sand and an increase in $\%$ mud, \%silt, \% clay and sorting, a significant increase in the abundance of Nucula hartvigiana with an increase in \% clay, \% organic, \% carbonate and sorting, a significant increase in the abundance of Ventojassa sp. with a decrease in the \% clay, a significant increase in the abundance of Aphelochaeta sp. with an increase in the \% gravel, $\%$ clay \% carbonate and sorting, a significant increase in the abundance of Glycinde dorsalis with an increase in mean grain size, a significant increase in the abundance of Hesionid sp.A with an increase in the \% clay, a significant increase in the abundance of Owenia fusiformis

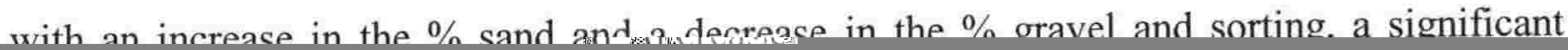


Table 7.8: Relationship between taxa and sedimentological and chemical variables at the Evans Bay sites All data, except $\mathrm{Ni}$ concentration were $\log _{10}$ transformed

\begin{tabular}{|c|c|c|c|c|}
\hline $\begin{array}{l}\text { Outlet EB-2 } \\
\text { Simple Linear Regression }\end{array}$ & $r^{2}$ & constant & slope & p \\
\hline Capitella spp. vs As & 0.465 & -3.191 & 2.622 & 0.01 \\
\hline Capitella spp. vs $\mathrm{Cr}$ & 0.526 & -11.989 & 6.438 & 0.005 \\
\hline Capitella spp. vs $\mathrm{Ni}$ & 0.62 & -1.564 & 0.07 & 0.001 \\
\hline Capitella spp. vs $\mathrm{Pb}$ & 0.810 & -5.443 & 2.537 & 0.000 \\
\hline Capitella spp. vs Zn & 0.623 & -6.205 & 2.608 & 0.001 \\
\hline Hesionid sp.A vs Cr & 0.447 & -10.051 & 5.325 & 0.012 \\
\hline Hesionid sp.A vs $\mathrm{Cu}$ & 0.495 & -3.435 & 1.771 & 0.007 \\
\hline Hesionid sp.A vs Ni & 0.77 & -1.671 & 0.067 & 0.000 \\
\hline Hesionid sp. A vs $\mathrm{Pb}$ & 0.56 & -4.626 & 2.057 & 0.003 \\
\hline Hesionid sp.A vs Zn & 0.600 & -5.637 & 2.296 & 0.002 \\
\hline Heteromastus filiformis vs $\%$ carbonate & 0.528 & 2.121 & -2.107 & 0.007 \\
\hline Owenia fusiformis vs $\mathrm{Cr}$ & 0.573 & 11.551 & -5.554 & 0.003 \\
\hline Owenia fusiformis vs $\mathrm{Cu}$ & 0.774 & 5.079 & -2.04 & 0.000 \\
\hline Owenia fusiformis vs $\mathrm{Ni}$ & 0.755 & 2.596 & -0.06 & 0.000 \\
\hline Owenia fusiformis vs $\mathrm{Pb}$ & 0.727 & 5.925 & -2.159 & 0.000 \\
\hline Owenia fusiformis vs $\%$ organic & 0.443 & 2.206 & -3.537 & 0.013 \\
\hline Schistomeringos loveni? vs \% clay & 0.430 & -0.112 & 0.243 & 0.029 \\
\hline Syllid spp. vs As & 0.563 & -1.811 & 1.488 & 0.003 \\
\hline Oligochaetes vs $\%$ organic & 0.478 & -0.808 & 2.832 & 0.009 \\
\hline Oligochaetes vs $\mathrm{Cu}$ & 0.713 & -2.409 & 1.338 & 0.001 \\
\hline Oligochaetes vs $\mathrm{Pb}$ & 0.725 & -3.114 & 1.477 & 0.000 \\
\hline Oligochaetes vs $\mathrm{Zn}$ & 0.644 & -3.438 & 1.496 & 0.002 \\
\hline $\begin{array}{l}\text { Control EB-C } \\
\text { Simple linear Regression }\end{array}$ & $r^{2}$ & constant & slope & p \\
\hline Gumina dolochostoma vs $\%$ carbonate & 0.663 & -3.496 & 2.57 & 0.002 \\
\hline Leptomya retiaria vs \% sand & 0.714 & 20.916 & -10.482 & 0.001 \\
\hline Leptomya retiaria vs $\%$ mud & 0.546 & -1.368 & 2.261 & 0.004 \\
\hline Leptomya retiaria vs \% silt & 0.838 & -1.425 & 4.239 & 0.000 \\
\hline Leptomya retiaria vs $\%$ clay & 0.470 & -1.008 & 2.152 & 0.01 \\
\hline Leptomya retiaria vs sorting & 0.488 & -0.827 & 2.984 & 0.008 \\
\hline Nucula harvigiana vs \% clay & 0.473 & -0.491 & 1.261 & 0.009 \\
\hline Nucula harvigiana vs sorting & 0.664 & -0.372 & 1.786 & 0.001 \\
\hline Nucula harvigiana vs \% carbonate & 0.662 & -2.526 & 1.883 & 0.001 \\
\hline Nucula harvigiana vs \% organic & 0.545 & -2.634 & 6.116 & 0.004 \\
\hline Ventojassa sp. vs \% clay & 0.699 & 2.352 & -2.947 & 0.000 \\
\hline Aphelochaeta sp. vs $\%$ gravel & 0.641 & -0.032 & 0.489 & 0.002 \\
\hline Aphelochaeta sp. vs \% clay & 0.418 & -0.509 & 1.164 & 0.017 \\
\hline Aphelochaeta sp. vs sorting & 0.557 & -0.509 & 1.826 & 0.003 \\
\hline Aphelochaeta sp. vs \% carbonate & 0.618 & -2.617 & 1.880 & 0.002 \\
\hline Glycinde dorsalis vs Mean grain size & 0.571 & -1.368 & 3.888 & 0.004 \\
\hline Hesionid sp.A vs \% clay & 0.667 & -0.956 & 2.095 & 0.001 \\
\hline Owenia fusiformis vs \% gravel & 0.496 & 1.22 & -0.439 & 0.007 \\
\hline Owenia fusiformis vs $\%$ sand & 0.674 & -11.224 & 6.217 & 0.001 \\
\hline Owenia fusiformis vs sorting & 0.466 & 1.595 & -1.595 & 0.01 \\
\hline Schistomeringos loveni? vs \% gravel & 0.768 & 0.010 & 0.926 & 0.006 \\
\hline Schistomeringos loveni? vs \% sand & 0.507 & 17.824 & -8.799 & 0.006 \\
\hline Schistomeringos loveni? vs \% mud & 0.605 & -1.100 & 2.205 & 0.002 \\
\hline Schistomeringos loveni? vs \% clay & 0.657 & -0.936 & 2.359 & 0.001 \\
\hline Schistomeringos loveni? vs sorting & 0.672 & -0.725 & 3.244 & 0.001 \\
\hline Syllid spp. vs \% gravel & 0.537 & 0.909 & 0.542 & 0.004 \\
\hline Syllid spp. \% sand & 0.364 & 11.476 & -5.222 & 0.029 \\
\hline Syllid spp. vs \% mud & 0.438 & 0.239 & 1.316 & 0.014 \\
\hline Syllid spp. vs $\%$ clay & 0.540 & 0.270 & 1.500 & 0.004 \\
\hline Syllid spp. vs sorting & 0.591 & 0.372 & 2.133 & 0.002 \\
\hline Syllid spp. vs \% carbonate & 0.442 & -1.407 & 1.766 & 0.018 \\
\hline
\end{tabular}


The null hypothesis that at each site there is no correlation between each taxa and the measured sedimentological and chemical variables is rejected. At outlet sites the abundance of Capitella spp., Hesionid sp.A, Heteromastus filiformis, Owenia fusiformis, Pectinaria australis, Questa sp., Schistomeringos loveni?, Syllid spp. and Oligochaetes was correlated to one or more sedimentological and chemical variables. At control sites the abundance of Aphelochaeta sp., Armandia maculata, Barantolla sp., Glycera ovigera, Glycinde dorsalis, Gumina dolochostoma, Hesionid sp.A, Heteromastus filiformis, Leptomya retiaria, Nucula hartvigiana, Owenia fusiformis, Paraprionospio pinnata, Pectinaria australis, Ventojassa sp., Schistomeringos loveni? and Syllid spp. was correlated to one or more sedimentological and chemical variables.

\subsection{DISCUSSION}

\subsubsection{Sediment Grain Size}

In Wellington Harbour the presence and abundance of taxa, the number of total taxa and individuals and diversity are influenced by sediment grain size (McKoy, 1970; Wear and Anderlini, 1995). This is also the case for the nearshore environment of Wellington Harbour with the number of total and mollusc taxa, total and mollusc individuals at the Aotea Quay and Evans Bay control sites moderate to highly correlated to one or more of the sedimentological variables of $\%$ gravel, $\%$ silt, $\%$ clay and mean grain size. The biological community present at each control site also had a high correlation to a combination of sediment grain size and chemical variables (Table 7.5, spatial variability data) and the abundance of the molluscs Leptomya retiaria and Nucula hartvigiana, the arthropods Ventojassa sp., the polychaetes Aphelochaeta sp., Armandia maculata, Barantolla sp., Glycinde dorsalis, Hesionid sp.A, Heteromastus filiformis, Owenia fusiformis, Pectinaria australis, Schistomeringos loveni? and Syllid spp. was moderate to highly correlated to one or more of the grain size variables. Thus, in the nearshore environment of inner Wellington Harbour, as in other marine sediments grain size is an important determinant of the presence and abundance of the macrobiota.

In the vicinity of some stormwater outlets the data suggests that sediment grain size was altered by stormwater discharge with high percentages of gravel close to and extending from the outlet to $\geq 10-15 \mathrm{~m}$, elevated percentages of sand, close to and out to $\geq 20-30 \mathrm{~m}$ and high 
percentages of mud at stations $\geq 20 \mathrm{~m}$. At each outlet site the biological community present had moderate to high correlation to a combination of sedimentological and chemical variables, however the actual sediment variable/s differed among sites (Table 7.5, spatial variability data). In addition, the abundance of the polychaetes Pectinaria australis and Questa sp. at outlet sites was moderate to highly correlated to one or more of the grain size variables. Differences in the presence and abundance of these taxa between outlet and control sites could, partly or totally be as a result of the grain size differences between sites. Therefore it is possible that altered sediment structure, as a result of stormwater discharge, has affected the biological community and abundance of taxa at outlet sites.

\subsubsection{Organic matter content}

As the organic matter content increases, sediment oxygen concentration (Bickford, 1996) and oxygen penetration into the sediment (oxic zone) decrease (van Duyl et al., 1992). Consequently, the Redox Potential Discontinuity (RDP) layer gets closer to the sediment surface and there is an intensification of reducing (anaerobic) conditions through the sediment column (Pearson and Stanley 1979). The microbial decomposition of this organic matter is principally via anaerobic pathways with aerobic decomposition usually accounting for 3-14\% (Mackin and Swider, 1989). Anaerobic decomposition primarily results in the formation of hydrogen sulphide $\left(\mathrm{H}_{2} \mathrm{~S}\right)$ due to the high availability of sulphates in seawater, but ammonia $\left(\mathrm{NH}_{3}\right)$, manganous ions $\left(\mathrm{Mn}^{2+}\right)$, ferrous ions $\left(\mathrm{Fe}^{2+}\right)$ and methane $\left(\mathrm{CH}_{4}\right)$ can also be produced (Mackin and Swider, 1989; Fenchel and Riedl 1970). $\mathrm{H}_{2} \mathrm{~S}$ and $\mathrm{NH}_{3}$ are toxic compounds. Hence, there are a number of different mechanisms by which sediment organic matter enrichment can affect the presence and abundance of the macrobiota.

The impact of organic matter enrichment on faunal composition and faunal community structure has been documented in detail (Pearson and Rosenberg, 1978). The macrobiota respond in a consistent pattern to changes in organic matter enrichment whether these changes occur over time or as a spatial gradient from a discharge point. From a discharge point the recognised spatial gradient of macrobiota response (Pearson and Rosenberg, 1978) consists of the following zones:

1. An abiotic zone.

2. An opportunistic zone with a few species each occurring in high number.

3. An 'ecotone' point of overlap between opportunistic and 'normal' species, characterised by a low abundance of a low number of species. 
4. A transition zone consisting of a large number of 'normal' species at 'non-normal' densities.

5. Non-impacted macrobiota i.e. 'normal'.

The organic matter content resulting in such effects is variable and site-specific. For benthic polychaetes Raman and Ganapati (1983) found an abiotic zone at 7.4\% (median: range 4.0$17.8 \%$ ), an opportunistic zone at $2.5 \%$ (median: range $0.9-4.7 \%$ ), a transitional zone at $2.1 \%$ (median: range $0.6-3.5 \%$ ) and a healthy zone at $0.93 \%$ (median: range $0.5-1.1 \%$ ) organic matter. By comparison, Blackstock et al. (1986) recorded a transitional macrofauna at $8.8 \%$, with a low number of species and individuals at $21.1-21.9 \%$ organic matter. In a sheltered harbour area with $2-13.2 \%$ organic matter, the biota was dominated by the opportunistic species Capitella capitata (Estacio et al., 1997).

In inner Wellington Harbour high sediment organic matter $(>22 \%)$ content has not resulted in an abiotic zone, but in an impoverished biota characterised by a low number of taxa and individuals. An opportunistic zone as defined by a specified range in organic matter content cannot be identified in the vicinity of the outlets. High densities of individuals i.e. $>500$ (mean number of individuals) per $0.011 \mathrm{~m}^{2}$ occurred at some stations and on some sampling occasions (Figs. 5.11, 6.5 and 6.8), however such abundances were not significantly correlated to organic matter content. At stations with less than $22 \%$ organic matter and particularly those with less than $10 \%$ organic matter content, the large range in the number of taxa and individuals for a given organic matter level is a reflection of the large number of other factors influencing the biota at these stations.

Organic matter content was one of the 2-5 variables correlated to the biological community at 6 of the 7 outlet sites, with the mean organic matter content at these sites ranging from $1.2-36.4 \%$. The biological community at control sites was not correlated to organic matter content. In sediment with $0.8-3.9 \%$ organic matter, this was one of four variables (Botherway and Gardner, 2002), while at 0.8-2.9\% Total Organic Carbon (TOC) was one of six variables (Nipper et al., 1998) and at 6.0-10.6\% TOC was also one of six variables (Oug, 1998) correlated to biological community structure.

With an increase in organic matter content there was a significant decrease in the number of total and arthropod taxa (Figs.7.1 and 7.2). Arthropods are known to be highly sensitive to 
organic matter enrichment and hypoxia (Diaz and Rosenberg, 1995; Estacio et al. 1997; Pearson and Rosenberg, 1978). The decrease in the number of total taxa cannot just be attributed to the decrease in arthropod taxa as arthropods only made up a ninth to a third of the total taxa. Therefore, taxa in other taxonomic groups must have also been impacted by an increase in organic matter content but the impact was taxon-specific rather than taxonomic group-specific because there was no significant relationship between organic matter and any of the other taxonomic groups.

In Evans Bay there was a significant increase in the abundance Oligochaetes, and a significant decrease in the abundance of the polychaete Owenia fusiformis with an increase in organic matter content (in the range 1.1-3.1\%) at outlet site and a significant increase in the abundance of the mollusc Nucula hartvigiana with an increase in organic matter content (in the range 1.6-2.5\%) at the control site. At the Aotea Quay control site there was a significant decrease in the abundance of the polychaetes Barantolla sp. and Heteromastus filiformis with an increase in organic matter content (in the range 2.3-7.2\%). However, the abundance of these five taxa was not just correlated to organic matter content. Therefore, the correlation between these taxa and organic matter can only be considered an indication of the effect of organic matter because of the likely interaction of organic matter with the other variables. Nonetheless, the significant difference in the abundance of the polychaete Owenia fusiformis with distance from an outlet is consistent with changes in organic matter content.

At present no sediment quality standards exist in New Zealand for organic matter levels in marine sediments. The establishment of sediment organic matter standards is therefore an area of future work.

In this study one or more of the following polychaetes Armandia maculata, Barantolla sp., Capitella spp., Heteromastus filiformis, Prionospio aucklandica and Schistomeringos loveni?, numerically dominated samples containing $\geq 500$ individuals per $0.011 \mathrm{~m}^{2}$. As such they may be characteristic of the opportunistic zone, or characteristic of the transition zone, responding to organic matter enrichment in inner Wellington Harbour.

Prionospio aucklandica, the most abundant taxon in this study, does not occur within the Harbour basin or Harbour entrance channel, but low numbers occur in the sediments of 
Oriental Bay (K. Kröger, pers.com.). Within the nearshore environment of the inner Harbour this species occurred in all sediment types and in sediments with a wide range of organic matter content and metal concentrations i.e. it is a very tolerant species. High numbers of $P$. aucklandica occurred at outlet and control sites, with the maximum density of 1193 per $0.011 \mathrm{~m}^{2}$ (OPT station $\mathrm{S} 15$, November 98 ). The abundance of $P$. aucklandica also changed over time at both control and outlet sites with frequent recruitment, i.e. $P$. aucklandica has the life-history characteristics of an opportunistic species. However even though the highest abundance of $P$. aucklandica was at an outlet site, the sediment at this site did not have a high organic matter content. Because this species was abundant and numerically variable over time at outlet and control sites with recruitment occurring at different times at control and outlet sites, the opportunistic response of this species is not considered to be to organic matter. Rather high and temporally variable abundances of $P$. aucklandica appear to be an opportunistic response to sediment disturbance and oxygenation through such events as propeller backwash, as occurs at Aotea Quay and Queens wharf and stormwater flow e.g. at the stations close to the OPT outlet. Thus P. aucklandica may be an anaerobic intolerant, oxygen requiring organism.

The second most abundant taxon in inner Wellington Harbour, the capitellid polychaete Barantolla sp. was present at all outlet and control sites, was more abundant in Evans Bay than at Aotea Quay and Queens Wharf, and had a maximum abundance of 157 per $0.011 \mathrm{~m}^{2}$ (EB-C, Station S30, November 98) with peaks in abundance as a result of recruitment. This species is considered to be common and widespread rather than an opportunist. In inner Wellington Harbour Barantolla sp. was found to occur in muddy sand containing less than 8 $\%$ organic matter i.e. this capitellid cannot be categorized as an 'organic loving/organic tolerant' species. Instead, by its presence or absence Barantolla sp could be used as an indicator of elevated sediment organic matter levels.

Capitella (capitata) which has the potential for rapid population growth (Chesney and Tenore, 1985) requires organically enriched but relatively oxic sediment (Tsutsumi, 1987, 1990) and has faster juvenile growth in organically enriched than non-organically enriched sediments (Bridges, 1996; Tsutsumi, 1987). It is considered an enrichment and opportunist species (e.g. Beukema, 1991; Grassle and Grassle, 1974; Gray, 1979; Pearson and Rosenberg, 1978). 
Capitella spp., which either occurred in low numbers or was absent at the control sites, occurred in the vicinity of all the outlets at densities typically less than 70 but up to 317 (AQ-2, S10 May 99) and 784 per $0.011 \mathrm{~m}^{2}$ (AQ-2, S10 June 99). At AQ-2 S10 in both May and June 99, Capitella spp. numerically dominated the macrobiota with their abundance characteristic of an opportunistic/enrichment species. The abundance of Capitella spp. decreased significantly with increasing distance from outlets AQ-1, AQ-2, Q-1 and EB-2, and changed over time. There was however no significant relationship between the abundance of Capitella spp. and organic matter content. Rather, Capitella spp. occurred over a wide range (1.1-36.4\%) of organic matter. However Capitella (capitata) is, rather than one species, a complex of sibling species with the species partitioning the environment temporally as a result of life history and dispersal differences (Grassle and Grassle, 1977). The occurrence of such a complex of sibling species in New Zealand has not been investigated, however if such a complex does exist in New Zealand it could account for the lack of a significant relationship between organic matter and the abundance of Capitella spp..

Heteromastus filiformis exhibits an opportunistic response to organic matter (Pearson and Rosenberg, 1978; Gray, 1979; Beukema, 1991; Knox and Fenwick, 1981), but it is more typical of less extreme pollution or as a secondary coloniser following pollution or enrichment abatement (Gray 1979; Pearson and Rosenberg, 1978). However, Heteromastus filiformis is also a widespread and abundant macrobenthic species in intertidal to deep trench unpolluted sediments (Knox et al., 1977; Knox et al., 1978; Rosenberg, 1995; Whitlatch, 1977).

In this study Heteromastus filiformis was more abundant at Aotea Quay and Queens Wharf than in Evans Bay, and more abundant at control than outlet sites, with a maximum of 429 per $0.011 \mathrm{~m}^{2}$ at AQ-C station S30 in November 98. This species occurred in a wide range of sediment types containing $<12 \%$ organic matter and at some sites its abundance decreased with increasing organic matter content (in combination with other variables). The response of Heteromastus filiformis to organic matter could, in part, account for the higher abundances at control than outlet stations, however there were also significantly more individuals at $44 \mathrm{~m}$ from outlet EB-2 than closer to the outlet (organic matter at all stations was $<12 \%$ ). This might suggest that the abundance of this species has been affected by other 
factors including, possibly metals and/or unmeasured contaminants resulting from stormwater discharge.

Armandia maculata was present at all sites and had a maximum abundance of 264 per $0.011 \mathrm{~m}^{2}$ at $\mathrm{AQ}-2$ station $\mathrm{S} 10$ in November 98 with peaks of abundance as a result of recruitment. This species was significantly more abundant at stations closer to rather than further away from outlet AQ-2 in November 1998. Over time there was a higher abundance of Armandia maculata at AQ-2 (sediment organic matter 4.5-37.1\%) than at AQ-C (sediment organic matter 2.0-8.2\%). This species appears to be tolerant to organic matter with its abundance enhanced by organic matter enrichment. It has been found that the abundance of Armandia brevis is enhanced by moderate organic matter enrichment (Weston, 1990).

The dorvilleid polychaete Schistomeringos loveni? occurred at all sites and attained a maximum abundance of 306 per $0.011 \mathrm{~m}^{2}$ (AQ-2, S10, June 99), with more than 100 individuals at OPT station S15, AQ-C station S10 (February, 99), and AQ-2 station S10 (April 99). This species was significantly more abundant at stations closer to rather than further away from outlet AQ-2. While some dorvilleids have an opportunistic response to high levels of organic matter (Pearson and Rosenberg, 1978), the high number of S. loveni? at both outlet and control sites indicates it could be an opportunist in response to factors other than organic matter. The opportunistic response to other factors appears to be similar to that of $P$. aucklandica i.e. to sediment disturbance through such events as propeller backwash and stormwater flow.

\subsubsection{Metals}

A metal is toxic to an organism when its excretory, metabolic, storage and detoxification mechanisms are no longer capable of matching metal uptake rate, with toxicity varying greatly between phyla, species, populations, individuals and even life history stage (Langston, 1990). The relative toxicity of metals to marine biota is given in the following series from the most to least toxic: $\mathrm{Cd}>\mathrm{Cu}>\mathrm{Zn}>\mathrm{Cr}>\mathrm{Ni}>\mathrm{Pb}$ and $\mathrm{As}$ (McClusky et al., 1986). However, in sediments where there is a mix of metals, they can act synergistically, additively or antagonistically in relation to the biota (Long et al., 1995). For example, $\mathrm{Cu}$ and $\mathrm{Zn}$ are more than additive in toxicity to a wide range of biota (Eisler, 1997), while Ahsanullah et al., (1988) found that a combination of $\mathrm{Zn}$ and $\mathrm{Cu}$ was less toxic than 
expected to the amphipod Allorchestes compressa i.e. they acted in an antagonistic manner, and for $\mathrm{Cd}$ and $\mathrm{Cu}$, the biota uptake of $\mathrm{Cd}$ is unaffected by the $\mathrm{Cu}$ concentration while $\mathrm{Cu}$ uptake is inhibited by the presence of Cd (Rule and Alden, 1996). The toxicity of lower ranked metals can also be overshadowed by the presence of more toxic metals (Chiaroni, 1998). High correlation between contaminants also makes it difficult to ascribe effects to any one contaminant. In field conditions examples of the deleterious effects of a specific metal on the macrobenthos are comparatively rare (Bryan and Langston, 1992).

As high metal concentrations in marine sediments have the potential for biological effects Sediment Quality Guidelines (SQG's) have been developed for the protection of aquatic life and for the protection of consumers of aquatic life (Smith et al. 1996). However it has been argued that no chemical measurement reliably predicts sediment toxicity and the use of chemical data to imply a biological effect should not be used except possibly in cases of extreme contamination (O'Connor and Paul, 2000). For example, Gray et al. (1988) could not separate the effects of pollution from those arising from a natural environmental gradient, despite a clearly defined contaminant gradient resulting from large chemical waste discharges. It has also been found that in field-based correlative studies it is often not possible to discriminate between the effects of moderate and low metal contamination and natural variability of abundance of the biota (Chapman et al, 1998; Nipper et al, 1998). Nonetheless, at stations where the sediment metal content exceeds guideline concentrations by this criterion there is potential for a biological effect (Long et al., 1995). Thus the As, $\mathrm{Cu}$, $\mathrm{Ni}, \mathrm{Pb}$ and $\mathrm{Zn}$ concentrations in the sediment in the vicinity of the stormwater outlets in this study have the potential to affect the macrobiota.

The macrobiota at AQ-2 station S10 in November 2000 was very different from that on all other sampling occasions (Fig. 6.3A) and was characterised by a low number of taxa and individuals. In August 2000 the $\mathrm{Cu}, \mathrm{Pb}$ and $\mathrm{Zn}$ concentrations were $253 \mathrm{ppm}, 435 \mathrm{ppm}$ and 713 ppm respectively, while in November 2000 they were 129 ppm, 366 ppm and 278 ppm respectively. The August concentration of each metal was $2-2.5$ times higher than those recorded on all previous sampling occasions but they were not the highest concentrations recorded in this study. However the $\mathrm{Cu}$ concentration was 2.5 times higher than the PEL value of $108 \mathrm{ppm}$, but lower than the ER-M/ISQG-High value of $370 \mathrm{ppm}$, the $\mathrm{Pb}$ concentration was 4 times higher than the PEL value of $112 \mathrm{ppm}$ and 1.6 times higher than the ER-M/ISQG-High value of $270 \mathrm{ppm}$ and the $\mathrm{Zn}$ concentration was 2.6 times higher than 
the PEL value of $271 \mathrm{ppm}$ and 1.7 times higher than the ER-M/ISQG-High value of 410 $\mathrm{ppm}$. Therefore it is possible that the high metal concentrations in August were toxic to most of the organisms present resulting in the mean number of taxa and individuals present in November 2000 being respectively 4.33 and 5, while on all other occasions the mean number of taxa and individuals respectively ranged from 8-26 and 40-773. The macrobiota present in August did not appear to be affected by these high metal concentrations, which suggests that metals may have been deposited at this station just prior to sampling. Such high concentrations of these metals at other outlet sites did not have a comparable impact on the biota as their concentrations at AQ-2. However at the other sites such as EB-2 and possibly Q-2 and OPT, higher concentrations persisted over time and hence acclimation of the macrobiota to the elevated concentrations cannot be discounted as biota can exhibit differing responses to contaminants depending on the frequency and severity of previous exposures (Lam and Gray, 2000). On the other hand the impoverished macrobiota at AQ-2 in November 2000 may have nothing to do with the concentration of metals.

The biological community at all sites was correlated to 2-5 sedimentological, environmental and chemical variables with at least one of the metals being in the list of variables of all control sites and of outlet sites AQ-1, AQ-2, Q-2, OPT and EB-2 but not Q-1 and EB-1. The actual metal in the list differed among sites i.e. they were site-specific and no one metal can be isolated as having the greatest influence on the biological communities in the nearshore environment of inner Wellington Harbour. This is hardly surprising given the variation among areas, high metal concentrations at some control sites and the differences in sedimentological/chemical conditions in the vicinity of the outlets. The distribution of the biological community with distance (alongshore and offshore) from an intertidal stormwater outlet in Porirua Inlet, north of Wellington was found to be best correlated to a combination of 4-5 variables including $\mathrm{Cu}, \mathrm{Pb}$ and $\mathrm{Zn}$ concentrations (Botherway and Gardner, 2002) while in an analysis of 'urban' (subjected to diffuse and point-source discharges) and 'nonurban' tropical estuaries, the difference among the biological communities was found to be best correlated to 3 variables i.e. $\mathrm{Cu}, \mathrm{Pb}$ and oil (Inglis and Kross, 2000). Therefore metal concentrations can have an effect on biological communities.

In this study the only significant correlation of a taxomomic index to a metal was the decrease in the number of total individuals with an increase in Pb concentration (at AQ-2), however the correlation was weak. While not detected at the taxonomic index level in this 
study, it has been found that crustacean arthropods are susceptible to elevated metal concentrations (Chiaroni, 1998, Long et al., 1995; Morrisey et al, 1996; O'Connor and Paul, 2000; Roach et al., 2001; Warwick, 2001; Warwick and Clarke, 1994). They can exhibit an avoidance response (Roper and Hickey, 1994), behavioural changes (Roast et al., 2000), life history responses (Marsden et al., 2000) and mortality (Marsden and Wong, 2001). Echinoderms are also susceptible to elevated metal concentrations with molluscs and polychaetes less so (Clarke and Warwick, 1994: Long and Chapman, 1985). For example, it has been found that in sediments with high concentrations of $\mathrm{Cu}$ (up to $581 \mathrm{ppm}$ ), $\mathrm{Pb}$ (up to $2109 \mathrm{ppm}$ ) and $\mathrm{Zn}$ (up to $1190 \mathrm{ppm}$ ) there were reduced numbers of echinoderms and crustaceans and a predominance of polychaetes and molluscs (Long and Chapman, 1985). However Ward and Hutchings (1996) found no taxonomic specificity in the effect of $\mathrm{Pb}, \mathrm{Zn}$ and $\mathrm{Cr}$ concentrations amongst 15 polychaete, 5 crustacean and 4 mollusc species which occurred at all sites except 'metal-polluted' sites where $\mathrm{Pb}$ concentrations were up to 5270 ppm and $\mathrm{Zn}$ concentrations up to $16700 \mathrm{ppm}$.

In Evans Bay, the molluscs Corbula zelandica, Caecum digitatum, Gari stangeri, Gumina dolochostoma, Notoacmea helmsi, Nucula hartvigiana, Leptochiton inquinatus, Tawera spissa, Trochus tiaratus, the arthropods Anthurid sp.A., Melita spp., Pagurus spp., Paraphoxus australis, Stephos spp., and Ventojassa sp., the echinoderms Amphiura sp. and Trochodota dendyi, and the polychaetes Aphelochaeta sp., Armandia maculata, Caraziella phillipensis, Goniadid sp., Hemipodus simplex, Prionospio spp., Schistomeringos loveni? and syllids, and the coelenterate Scolanthus sp. were either absent or relatively low in abundance at outlet site EB-2, but common to abundant at the control site. At Aotea Quay the arthropod Tanaid sp.A and the polychaetes Prionospio yuriel, Prionospio spp. and syllids were relatively low in abundance at outlet site AQ-2 but common to abundant at the control site AQ-C. The highest concentrations of $\mathrm{As}, \mathrm{Cu}, \mathrm{Ni}, \mathrm{Pb}$ and $\mathrm{Zn}$ were $59 \mathrm{ppm}, 238$ ppm, 44 ppm, 458 ppm and 702 ppm respectively at EB-2, 49 ppm, 60 ppm, 31 ppm, 205 ppm and 261 ppm respectively at EB-C, 73 ppm, 253 ppm, 30 ppm, 435 ppm and 713 ppm respectively at AQ-2 and $20 \mathrm{ppm}, 87 \mathrm{ppm}, 27 \mathrm{ppb}, 128 \mathrm{ppm}$ and $245 \mathrm{ppm}$ respectively at AQ-C. Thus, the absence or low abundance of taxa from both EB-2 and AQ-2 could be, either partly or totally, as a result of high metal concentrations. However, these effects cannot be attributed to one particular metal. The abundance of amphipods and syllid and spionid (examples of this group are Prionospio yuriel and Prionospio spp.) polychaetes has been found to decrease with an increase in the concentration of $\mathrm{Cu}$ (up to $1200 \mathrm{ppm}$ ) 
(Morrisey et al., 1996). Rygg (1985) found that some amphipods and bivalve molluscs were absent from sediment with a $\mathrm{Cu}$ concentration higher than 200 ppm, whereas Amphiura spp. which were common in non-polluted sediments were only occasionally found in sediment where the $\mathrm{Cu}$ concentrations were higher than $200 \mathrm{ppm}$. Low abundances of spionids, and lower settlement of spionids, capitellids (including Capitella spp.) and syllids have been found in $\mathrm{Zn}$ spiked sediments. Spionid recruitment was most affected at concentrations > $630 \mathrm{ppm}$, Capitellid recruitment was most affected at concentrations $>1,100 \mathrm{ppm}$ and syllid recruitment was most affected at 8,100 ppm of $\mathrm{Zn}$ (Watzin and Roscigno, 1997).

The abundance of Capitella spp., Hesionid sp.A, Owenia fusiformis, syllids and Oligochaetes at EB-2 and Questa sp. at AQ-2 was correlated to metal concentrations. While these correlations do not signify cause and effect they can be considered as a possible indication of the tolerance of these taxa to the metal concentrations present. There was a significant increase in abundance of Capitella spp. with an increase in concentration of As, $\mathrm{Cr}, \mathrm{Ni}, \mathrm{Pb}$ and $\mathrm{Zn}$ and a significant decrease in abundance of Capitella spp. with distance from outlet EB-2 in November 1998 i.e. these taxa which was more abundant at stations with the highest metal concentrations appear very tolerant to high metal concentrations. Capitella (capitata) has also been found to occur in organically enriched sediments with high concentrations of $\mathrm{Pb}$ (up to $5270 \mathrm{ppm}$ ) and $\mathrm{Zn}$ (up to $16700 \mathrm{ppm}$ ) (Ward and Hutchings, 1996) and to be a dominant species at a sewage sludge disposal site where the metal concentrations were up to 20 times higher than background levels i.e. $\mathrm{Cu}$ up to 200 ppm, $\mathrm{Zn}$ up to $600 \mathrm{ppm}$ and $\mathrm{Pb}$ up to $320 \mathrm{ppm}$ (Halcrow et al., 1973). There was also a significant increase in abundance of Hesionid sp. A with an increase in concentration of $\mathrm{Cr}$, $\mathrm{Cu}, \mathrm{Ni}, \mathrm{Pb}$ and $\mathrm{Zn}$ and a significant increase in the abundance of Oligochaetes with an increase in concentration of $\mathrm{Cu}, \mathrm{Pb}$ and $\mathrm{Zn}$ i.e. these taxa are also very tolerant to high metal concentrations. Also, Oligochaetes have been found to be more abundant in a metalcontaminated estuary than in other estuaries in south-west England (Warwick, 2001). There was a significant increase in the abundance of Questa sp. with a decrease in concentration of $\mathrm{Cr}$ at AQ-2. The $\mathrm{Cr}$ concentration at this site ranged from $62-84 \mathrm{ppm}$ i.e. there was only a small range in $\mathrm{Cr}$ concentration. Nonetheless, the highest concentration of $\mathrm{Cr}$ was above the TEL value of $52.3 \mathrm{ppm}$ and close to the ER-L value of $81 \mathrm{ppm}$ and the ISQG-Low value of $80 \mathrm{ppm}$ i.e. the concentration of $\mathrm{Cr}$ has the potential for a biological effect. The results are suggestive of Questa sp. being intolerant of the slightly elevated $\mathrm{Cr}$ concentrations as occurred at AQ-2. 
At EB-C the abundance of the tube building polychaete Owenia fusiformis was correlated to sediment variables (Table 7.8) with a positive correlation to the $\%$ sand and a negative correlation to \% gravel and sediment sorting, while at EB-2 the abundance of this species decreased with an increase in $\mathrm{Cr}, \mathrm{Cu}, \mathrm{Ni}$ and $\mathrm{Pb}$ concentration. There was also a significant increase in abundance of $O$. fusiformis with distance from the outlet with $44>34>24 \mathrm{~m}$ in November 1998 and $44>34=24 \mathrm{~m}$ in May 1999 and on both occasions there were significantly more $O$. fusiformis at the $24 \mathrm{~m}$ station at EB-C than EB-2. At the EB-2 24, 34 and $44 \mathrm{~m}$ stations respectively the concentrations in the $<63 \mu \mathrm{m}$ sediment fraction were $\mathrm{Cr}$ 109, 103, 82 ppm, Cu 238, 173, 94 ppm, Ni 44, 35.4, 28.5 ppm and $\mathrm{Pb} 458,341,186 \mathrm{ppm}$ in November 1998 and $\mathrm{Cr}$ 100, 86 and 81 ppm, Cu 202, 127, 96 ppm, Ni 33, 26, 26 ppm and $\mathrm{Pb} 379,251,198 \mathrm{ppm}$ in May 1999. Pb ER-M and ISQG-High values were exceeded at the 24 and $34 \mathrm{~m}$ but not the $44 \mathrm{~m}$ stations in both November 1998 and May 1999. PEL values were exceeded for $\mathrm{Cu}$ at the 24 and $34 \mathrm{~m}$ but not the $44 \mathrm{~m}$ stations in both November 1998 and May 1999 and for $\mathrm{Ni}$ at the $24 \mathrm{~m}$ station in November 1998. These results suggest that the spatial distribution of $O$. fusiformis at EB-2 could result from the intolerance of this taxa to high concentrations of one or a combination of $\mathrm{Cr}, \mathrm{Cu}, \mathrm{Ni}$ and $\mathrm{Pb}$, with this intolerance being to concentrations of $\mathrm{Pb}$ at or above ER-M/ISQG-High values and concentrations of $\mathrm{Cu}$ and $\mathrm{Ni}$ at or above PEL values. As such $O$. fusiformis could be an indicator species for sediment contamination with these metals. However, further investigations are required.

\subsubsection{Unmeasured Variables}

In this study not all of the documented macrobenthic impacts were correlated to the measured environmental variables. For the indices and taxa with no significant correlation to any of the measured environmental variables it is possible that either unmeasured environmental variables resulting from stormwater discharge (e.g. other metals such as $\mathrm{Cd}$ and Hg, PAH's, PCB's, other synthetic organic contaminants, altered salinity, water flow) or natural processes including biological factors/interactions (predation, competition, bioturbation, recruitment, random fluctuations) are impacting on them.

\subsection{CONCLUSIONS}

Correlations were used to investigate whether the data indicated biological effects of stormwater discharge (Chapters 5 and 6) can be linked to sediment characteristics (Chapter 3 ) and metal concentrations (Chapter 4) which likely result from stormwater discharge. 
While correlations do not signify cause and effect they can be considered as an indication of the relationship between the macrobiota and a given variable.

Sediment grain size: At each outlet site the biological community present had moderate to high correlation to a combination of variables including sediment grain size variable/s and the abundance of 3 taxa at outlet sites was moderate to highly correlated to one or more of the grain size variables. Thus it is likely that the presence and abundance of the biological community and in particular specific taxa are linked to sediment grain size characteristics which result from stormwater discharge.

Organic matter content: At stations where the organic matter content was $>22 \%$ there was an impoverished biota characterised by a low number of taxa and individuals. With an increase in organic matter content there was a significant decrease in the number of total and arthropod taxa. Organic matter content was one of the 2-5 environmental/chemical variables correlated to the biological community at 6 of the 7 outlet sites while the biological community at control sites was not correlated to organic matter content. There was a significant difference in the abundance of oligochaetes and the polychaete Owenia fusiformis with an increase in organic matter content.

As, $\mathbf{C r}, \mathbf{C u}, \mathbf{N i}, \mathbf{P b}$ and $\mathrm{Zn}$ concentrations: It is possible that high metal concentrations at AQ-2 in August 2000 resulted in a low number of taxa and individuals in November 2000. The biological community at all control and 5 outlet sites was correlated to 2-5 environmental/chemical variables with at least one metal being in the list of variables but the actual metal/s were site specific and no one metal can be isolated as having the greatest influence on the biological communities. At outlet AQ-2 there was a weak correlation of a decrease in the number of total individuals with an increase in $\mathrm{Pb}$ concentration. 28 taxa were either absent or relatively low in abundance at an outlet site but common to abundant at the associated control site which could be, either partly or totally, as a result of high metal concentrations. The abundance of Capitella spp., Hesionid sp.A, Owenia fusiformis, Prionspio aucklandica, Questa sp and Oligochaetes was correlated to metal concentrations. These correlations can be considered as a possible indication of the tolerance of these taxa to the metal concentrations present. The spatial distribution of $O$. fusiformis at EB-2 could result from the intolerance of this taxa to high concentrations of one or a combination of $\mathrm{Cr}$, $\mathrm{Cu}, \mathrm{Ni}$ and $\mathrm{Pb}$. 


\section{Chapter 8 \\ OVERVIEW}

The aim of this study was to investigate the spatial and temporal effect of stormwater discharge on the nearshore benthic environment of inner Wellington Harbour. To achieve this aim the spatial and temporal sedimentological (sediment structure i.e. grain size and organic matter content), chemical (As and the metals - $\mathrm{Cr}, \mathrm{Cu}, \mathrm{Ni}, \mathrm{Pb}$ and $\mathrm{Zn}$ ) and biological (macrobiota) characteristics of the nearshore benthic environment at control and stormwater outlet sites were investigated. In addition univariate and multivariate methods were used to investigate the links between the biological and the sedimentological and chemical variables.

\subsection{Spatial effect of stormwater discharge}

By sampling at stations located along three transects and with these stations positioned at increasing distance from each of eight stormwater outlets and from a point on the shore at each of three control sites, it was possible to determine the spatial extent of the influence of stormwater discharge on the nearshore benthic environment.

The data indicates that stormwater discharge has resulted in organic and metal enrichment of the sediment in the vicinity of the outlets. In general, the highest level of enrichment occurs close to, and decreases with increasing distance from an outlet. The estimated outward extent of enrichment from an outlet is both outlet and contaminant specific (Table 8.1 i.e. Tables 3.6, 4.7 and 5.18 combined). For organic matter and metals, the outlets have been ranked according to the degree of contamination of the sediment i.e. from the most to the least contaminated. The ranking of outlets for organic matter is given in Fig. 8.1 and for metals in Fig 8.2. In addition, the 'level' of contamination at each site is given by the colour coding of site names in these two figures. 


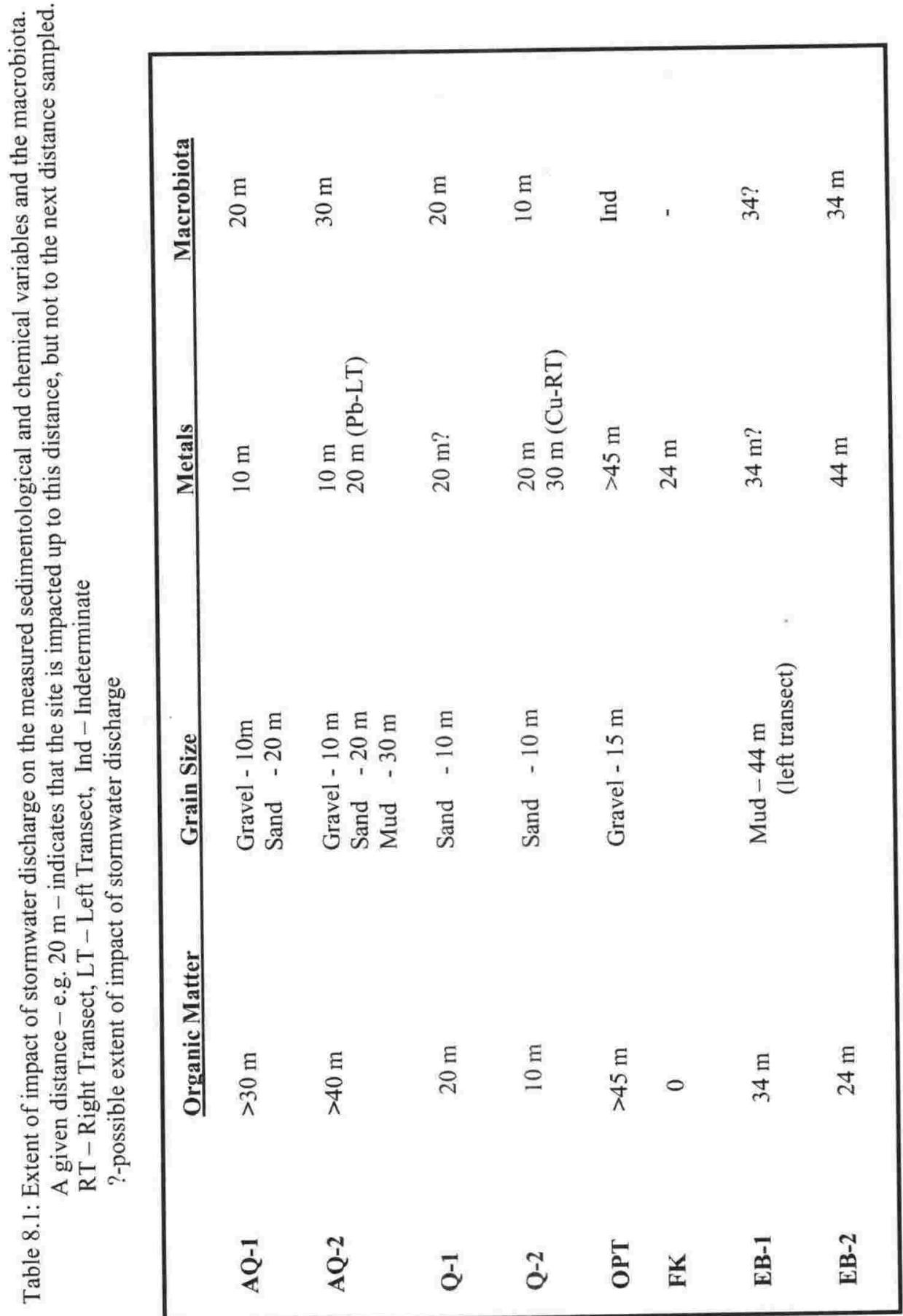




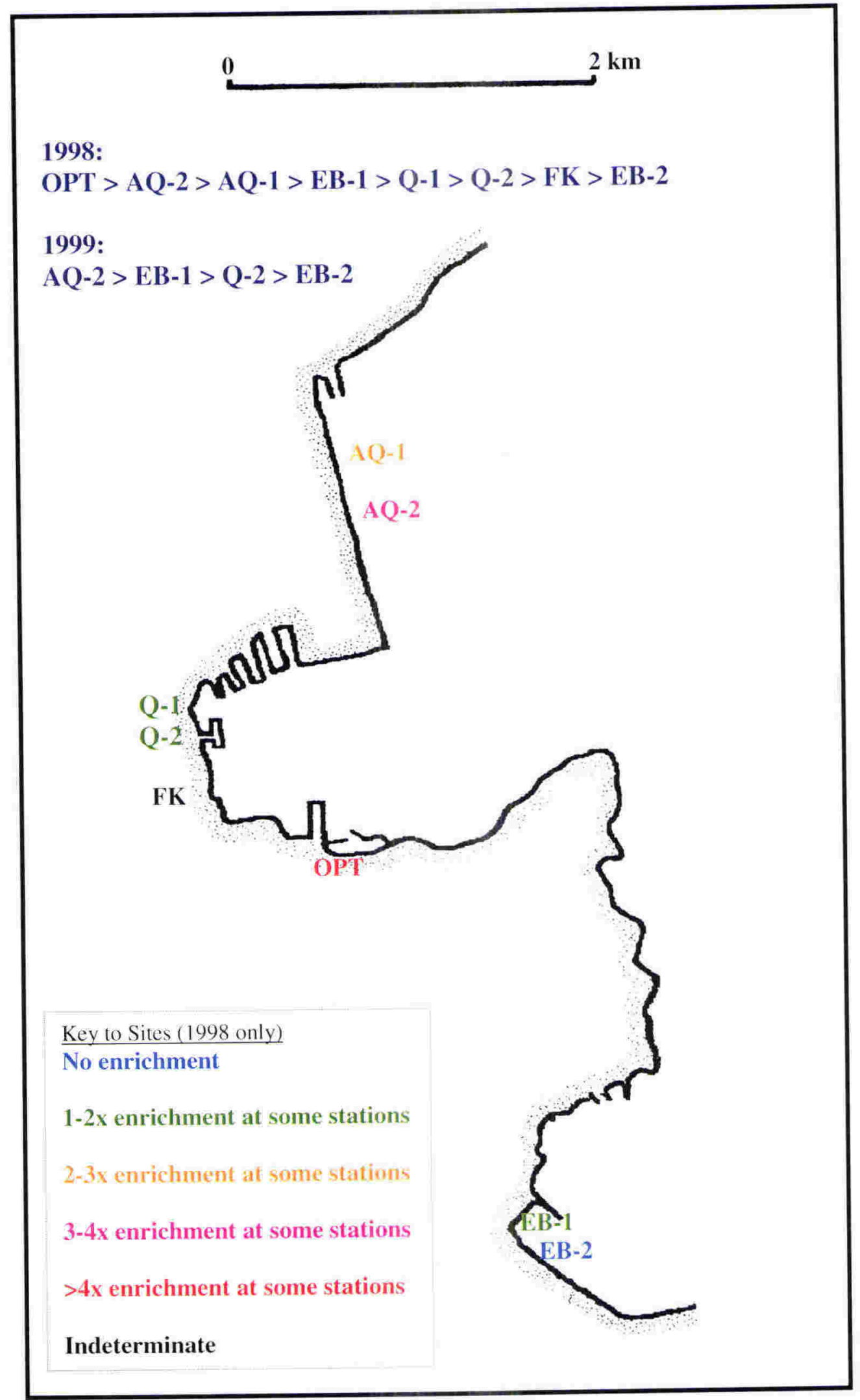

Figure 8.1: Ranking of outlet sites from the most to the least contaminated with organic matter 


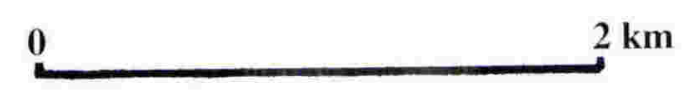

1998:

OPT $>$ EB-2 $>$ EB-1 $>$ Q-2 $>$ Q-1 $>$ AQ-2 $>$ AQ-1

1999:

EB-2 $>$ EB-1 $>$ Q-2 $>$ AQ-2

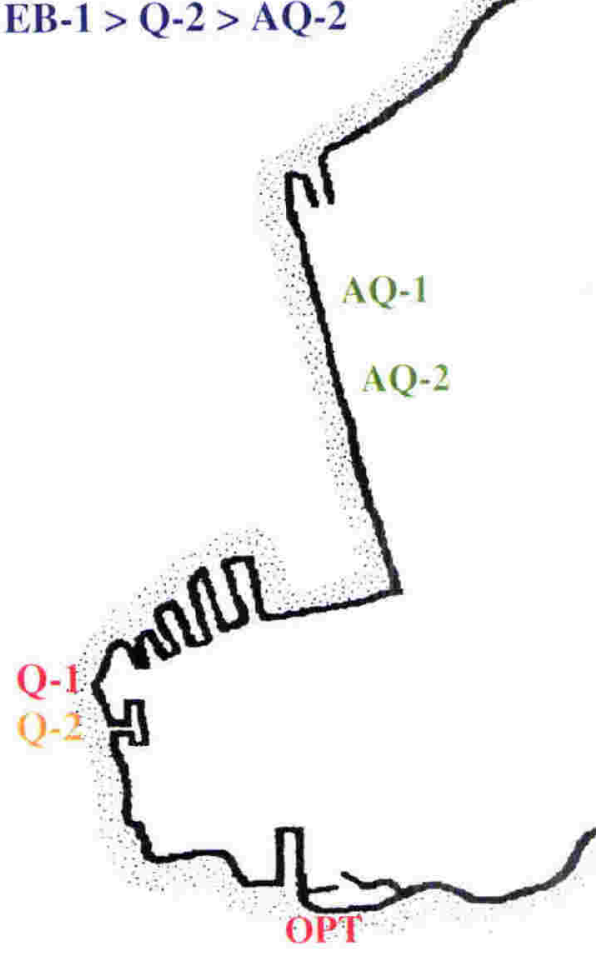

Key to Sites (1998 only)

EF of $1.4-2$ at some stations

EF of $2-3$ at some stations

EF of $3-4$ at some stations

EF of $>4$ at some stations

Figure 8.2: Ranking of outlet sites from the most to the least contaminated with metals. Outlet FK excluded due to discrepancies in the calculation of EF values 
The data indicates that stormwater discharge has resulted in elevated levels of gravel, sand and mud at some outlets with differences in the amount of each with respect to distance from the outlet. The estimated outward extent of the influence of stormwater discharge on grain size (Table 8.1) can only be thought of as a minimum estimate because the fine sediment discharged from an outlet can be carried well beyond the outlet in times of high rainfall.

The data indicates that as a result of stormwater discharge the biological community in the vicinity of all outlets was disturbed and changed with increasing distance from an outlet. Significant differences occurred in the number of total, mollusc and arthropod taxa, total, mollusc, arthropod and polychaete individuals, and Shannon-Weiner diversity, either with distance from some outlets and/or between control and outlet sites. Significant differences occurred in the abundance of the polychaetes Armandia maculata, Capitella spp., Exogone sp.A, Glycera ovigera, Heteromastus filiformis, Hemipodus simplex, Hesionid sp.A, Owenia fusiformis, Paraprionospio pinnata, Prionospio spp, Prionospio yuriel, Pseudopolydora cf. paucibranchiata, Questa sp. and Schistomeringos loveni?, the bivalve molluscs Arthritica bifurca, Dosina zelandica, Gari stangeri and Theora lubrica, the amphipods Proharpinia spp., and the echinoderm Amphiura sp. between outlet and control sites. And significant differences occurred in the abundance of the polychaetes Armandia maculata, Capitella spp., Heteromastus filiformis, Hesionid sp.A, Ophiodromus sp., Owenia fusiformis, Prionospio aucklandica, Prionospio yuriel and Schistomeringos loveni?, Oligochaetes, the bivalve Dosina zelandica and the amphipods Corophium acherusicum, Meridiolembos sp. and Proharpinia spp. with distance from one or more of the outlets. The estimated outward extent of the influence of stormwater discharge on the macrobiota is given in Table 8.1. This estimated extent of effect is based on the presence and abundance of the macrobiota. However, a greater extent of influence, on unmeasured biological parameters such as stress, behaviour, physiology and life history has not been determined and cannot be discounted. This is a possibility, especially at those outlets where the outward extent of organic matter and metal impact was greater than the estimated outward extent of impact for the macrobiota. 


\subsection{Temporal effect of stormwater discharge}

Routine sampling at two outlet and two control sites was used to quantify changes in the sedimentological, chemical and macrobiota variables as a result of stormwater discharge over time.

Over the 28 months of this study, the data indicates that changes occurred in organic matter content, the quantities of gravel and sand, metal concentrations, the biological community, the number of total, polychaete, mollusc and arthropod taxa, the number of total, polychaete, mollusc and arthropod individuals and Shannon-Weiner diversity and the abundance of numerous taxa as a result of stormwater discharge. There was no correlation of the temporal changes in organic matter content and metal concentrations to hydrological and meteorological conditions.

\subsection{Links between the biological and the sedimentological and chemical variables}

At some outlet stations, sediment grain size was altered and/or there were high levels of organic matter and/or the concentration of some metals exceeded values at which biological effects were likely to result. As a consequence, an assessment of the relationship between the macrobiota and the sedimentological and chemical variables was investigated. As this is a field based study such relationships are correlations only, i.e. cause and effect links cannot be established (Chapman et al., 1998; Morrisey, 1996).

The biological community at outlet and control sites was best correlated to combinations of 2-5 of the sedimentological/chemical variables. Of these 2-5 variables, organic matter content was the only commonly occurring variable at outlet sites (except at outlet EB-2) and did not occur as one of the variables at the control sites. At all control and 5 outlet sites at least one metal was one of the $2-5$ variables, but the actual metal/s was sitespecific and no one metal can be isolated as having the greatest influence on the biological communities of inner Wellington Harbour. 
At stations where the organic matter content was $>22 \%$ there was an impoverished macrobiota characterised by a low number of taxa and individuals. And with an increase in organic matter content there was a significant decrease in the number of total and arthropod taxa. At AQ-2 the number of total individuals was weakly correlated to $\mathrm{Pb}$ concentration and the low number of taxa and individuals at AQ-2 in November 2000 could possibly be as a result of high $\mathrm{Cu}, \mathrm{Pb}$ and $\mathrm{Zn}$ concentrations at this site in August 2000.

At outlet sites the abundance of:

- Pectinaria australis, Questa sp. and Schistomeringos loveni? was moderate to highly correlated to one or more of the grain size variables.

- Owenia fusiformis and oligochaetes was correlated to organic matter content, however, the abundance of each of these taxa was also correlated to other sedimentological and chemical variables.

- Capitella spp., Hesionid sp.A, Owenia fusiformis, Prionspio aucklandica, Questa $\mathrm{sp}$ and Oligochaetes was correlated to the concentration of one or more metals. And the spatial distribution of $O$. fusiformis at EB-2 could result from the intolerance of this taxa to high concentrations of one or a combination of $\mathrm{Cr}, \mathrm{Cu}$, $\mathrm{Ni}$ and $\mathrm{Pb}$.

At control sites the abundance of:

- Aphelochaeta sp., Armandia maculata, Barantolla sp., Glycinde dorsalis, Hesionid sp.A, Heteromastus filiformis, Leptomya retiaria, Nucula hartvigiana, Owenia fusiformis, Pectinaria australis, Schistomeringos loveni?, Syllid spp. and Ventojassa sp., was moderate to highly correlated to one or more of the grain size variables.

- Barantolla sp., Heteromastus filiformis and Nucula hartvigiana was moderate to highly correlated to organic matter content.

28 taxa were relatively low in abundance at outlet sites but common to abundant at control sites, which could, either partly or totally be as a result of high metal concentrations at outlet sites. 


\subsection{INFORMATION FOR DECISION MAKERS}

This study provides data which Regulatory Authorities can use to carry out their obligations under the Resource Management Act (1991) with regard to discharges into receiving waters. Such authorities require "the adoption of the best practicable option to prevent or minimise any actual or likely adverse effect on the environment of any discharge of a contaminant'. In this study it has been found that contaminants discharged in stormwater do accumulate in the sediments in proximity to stormwater outlets and that the macrobiota in the vicinity of stormwater outlets is impacted by stormwater discharge.

\subsubsection{Monitoring the 'health' of the nearshore benthic environment}

It has been found that the effect of stormwater discharge on the nearshore benthic environment is outlet-specific i.e. the sedimentological, chemical and macrobiota effects were different at each outlet. This makes it difficult to identify one or a small number of parameters that could be used as future 'cost-effective' measures to ascertain and monitor the 'health' of the nearshore benthic environment of Wellington Harbour. However, of the sedimentological, chemical and macrobiota measures used in this study, it is suggested that the following would be the most 'cost-effective' measures that could be used to monitor the 'health' of the nearshore benthic environment of Wellington Harbour:

1. Sediment organic matter content

2. Concentration of $\mathrm{Cu}, \mathrm{Pb}$ and $\mathrm{Zn}$

3. Macrobiota:

- Number of total, mollusc, arthropod and polychaete taxa

- Number of total, mollusc, arthropod, polychaete and echinoderm individuals

- Shannon-Weiner diversity

- Abundance of Barantolla sp., Capitella spp. and Owenia fusiformis (sandy sediment areas only) 


\subsubsection{Remediation}

The ideal long term solution to ensure the nearshore benthic environment of inner Wellington Harbour is 'healthy' i.e. 'Safeguarding the life-supporting capacity of .... ecosystems' and 'Avoiding, remedying, or mitigating any adverse effects of activities on the environment' (Section 5, Resource Management Act, 1991), would be to remove organic matter and contaminants (polycyclic aromatic hydrocarbons (PAH's), organochlorines, dioxins, nutrients, metals - in particular $\mathrm{Cr}, \mathrm{Cu}, \mathrm{Pb}$ and $\mathrm{Zn}$ ) from the stormwater before it is discharged into the harbour. Of most concern are the contaminants of anthropogenic origin because they can accumulate in marine sediments and many are toxic to a wide range of terrestrial and marine organisms. However organic matter, which in the Wellington region is primarily natural in origin, is also a problem because it accumulates beyond the outlet and does have a considerable impact on the health of the benthic environment.

A reasonable solution to improve the 'health' of the nearshore benthic environment would be to reduce the concentrations of organic matter and metals, in particular $\mathrm{Cr}, \mathrm{Cu}$, $\mathrm{Pb}$ and $\mathrm{Zn}$ in stormwater before it is discharged. The downside of this is that a reduction of organic matter content in the vicinity of stormwater outlets could result in an increase in the bioavailability of any metals still discharged in stormwater. Organic matter and its breakdown products (humic and fulvic acids) have a high affinity for metals (Gerringa and Cambon, 1991; Skei et al., 1996) thus binding metals into a non-bioavailable form.

As the highest concentrations of metals and organic matter in the sediment occur close to an outlet and decrease with increasing distance seaward, local authorities may be of the opinion that the implementation of a mixing zone around each outlet is a solution to their statutory requirements under the Resource Management Act (1991) with regard to the impact of stormwater discharge on the receiving environment. 'Mixing zones are often defined as an explicit area around an effluent discharge where the Management Goals of the ambient waters do not need to be achieved and hence the designated Environmental Values may not be protected' (ANZECC Guidelines, 2000). While under the definitions 
provided in the guidelines the mixing zones are for 'areas of water' they could equally be applied to 'areas of seabed' in front of stormwater outlets in Wellington because there is a defined zone of influence around an outlet. However the establishment of mixing zones around the stormwater outlets of Wellington Harbour is inappropriate because:

1. In some areas there is the potential for redistribution of organic matter and contaminant enriched sediment by propeller action.

2. Not all contaminants are deposited in the immediate vicinity of an outlet as contaminants and organic matter are likely to be carried some distance from an outlet during periods of high stormwater flow.

Elevated metal concentrations already occur in the inner harbour due to human activities (wharf facilities, shipping activities, urban runoff, stormwater discharge and periodic emergency sewage overflows (Stoffers et al., 1986; Smith 1986; Wright and Glasby, 1992) over a period of time in this area of restricted water circulation (Booth, 1975; Heath, 1977). The continued input of contaminants via stormwater discharge in combination with the 2 factors outlined above will only increase metal concentrations in the sediment of all of inner Wellington Harbour over time.

\subsection{Areas of Future Research}

1. Detailed life history studies of:

- abundant and widespread nearshore macrobenthic taxa

- those taxa impacted by stormwater discharge

- taxa present at control sites but absent or low in abundance at outlet sites

This information would aid in the determination of the effects of moderate and low levels of contamination on the presence and abundance of taxa and the factors determining the presence and abundance of control site abundant taxa. It is only when seasonal and natural variability and the ecological requirements of organisms are well understood that changes due to moderate and low levels of contamination can be adequately interpreted (Nipper et al., 1998). 
2. Manipulative field experiments in both sandy and muddy sediments.

The information obtained would allow for a better understanding of the relationship of the benthic macrobiota to the quantity of organic matter and selected metals in the sediment as cause and effect relationships could be established. The results obtained can be used for in the development of Sediment Quality Values for organic matter and for metals in the Harbour environment of New Zealand.

3. Assessment of the concentration of other contaminants (e.g. PAH's, PCB's, and other organic contaminants) in the sediments in the vicinity of stormwater outlets.

4. Investigative work on organic matter levels in marine sediments with the goal of establishing sediment quality standards for organic matter content. 


\section{REFERENCES}

Adams, W.J., Kimerle, R.A. and Barnett, Jr. J.W. 1992. Sediment quality and aquatic life assessment. Environmental Science and Technology 26: 1864-1875.

Ahsanullah, M., Mobley, M.C. and Rankin, P. 1988. Individuals and combined effects of zinc, cadmium and copper on the marine amphipod Allorchestes compressa. Australian Journal of Marine and Freshwater Research 39:33-37.

Aloupi, M. and Angelidis, M.O. 2001. Geochemistry of natural and anthropogenic metals in the sediments of the island of Lesvos, Aegean Sea. Environmental Pollution 113: 211-219.

Anderlini, V.C. and Wear, R.G. 1995. Ecological survey of proposed dredge sites at Queens Wharf Wellington Harbour. Island Bay Marine Laboratory, Victoria University of Wellington. 22pp.

Angelidis, M. O. and Aloupi, M. 2000. Geochemical study of coastal sediments influenced by river-transported pollution: Southern Evoikos Gulf, Greece. Marine Pollution Bulletin 40(1): 77-82

Ankley, G.T. 1996. Evaluation of metal/acid-volatile sulfide relationships in the prediction of metal bioaccumulation by benthic macroinvertebrates. Environmental Toxicolology and Chemistry 15(12):2138-2146.

Ankley, G.T., Di Toro, D.M., Hansen, D.J. and Berry, W.J. 1996. Technical basis and proposal for deriving sediment quality criteria for metals. Environmental Toxicology and Chemistry 15(12):2056-2066.

Ansari, Z. A., Ingole, B.S. and Parulekar, A.H. 1986. Effect of high organic enrichment of benthic polychaete population in an estuary. Marine Pollution Bulletin 17(8): 361-365.

Australian and New Zealand Environment and Conservation Council (ANZECC), 2000. Australian and New Zealand guidelines for fresh and marine water quality. Volume 2. (Chapter 8)

Balls, P.W., Hull, S., Miller, B.S., Pirie, J.M. and Proctor. W. 1997. Trace metal in Scottish estuarine and coastal sediments. Marine Pollution Bulletin 34(1): 42-50.

Barnard, J.L. 1972. The Marine Fauna of New Zealand: Algae-living Littoral Gammaridea (Crustacea, Amphipoda). New Zealand Oceanographic Institute Memoir 62: 1-216

Barrett, P.J. and Brooker, M.R. 1989. Grain size analysis at VUW. Research School of Earth Sciences, Victoria University of Wellington, Wellington, New Zealand.

Bay, S., Jones, B. H. and Schiff, K. 1999. Study of the impact of stormwater discharge on Santa Monica Bay. Report for the Los Angeles County Department of Public Works, Alhambra, California. 16pp.

Beatson, D. 1985. The New Zealand Weather Book. Whitcoulls Pulishers, Christchurch, New Zealand. 87pp. 
Beesley, P.L., Ross, G.J.B. and Glasby, C.J. (eds) 2000. Polychaetes and allies: The Southern Synthesis. Fauna of Australia. Vol. 4A Polychaeta, Myzostomida, Pogonophora, Echiura, Sipunculida. CSIRO Publishing: Melbourne xii 465 pp.

Bell, R.G., Hume, T.M., Dolphin, T.J., Green, M.O. and Walters, R.A. 1997. Characterisation of physical environmental factors on an intertidal sandflat, Manukau Harbour, New Zealand. Journal of Experimental Marine Biology and Ecology 216:11-31.

Berry, W.J., Hansen, D.J., Mahony, J.D., Robson,D.L., Di Toro, D.M., Shipley, B.P., Rogers, B., Corbin, J.M. and Boothman, W.S. 1996. Predicting the toxicity of metal-spiked sediments using acid-volatile sulfide and interstitial water normalizations. Environmental Toxicology and Chemistry 15(12):2067-2079.

Beukema, J.J. 1991. Changes in composition of bottom fauna of a tidal-flat area during a period of eutrophication. Marine Biology 111:293-301.

Bickford, G.P. 1996. The effects of sewage organic matter on biogeochemical processes within mid-shelf sediments offshore Sydney, Australia. Marine Pollution Bulletin 33(712):168-181.

Bilyard, G.R. 1987. The value of benthic infauna in marine pollution monitoring studies. Marine Pollution Bulletin 11:581-585.

Bioresearches, 1997. Harbour Edge Stormwater Appraisal. Report for City Design, Auckland. 52pp.

Blackstock, 1984. Biochemical metabolic regulatory responses of marine invertebrates to natural environmental change and marine pollution. Oceanography and Marine Biology: an Annual Review 22:263-313.

Blackstock, J. and Filion-Myklebust, C. 1983. Environmental and biochemical investigation of some effects of organic pollution in inner Oslofjord, Norway. Marine Biology 73:155163.

Blackstock, J., Johannessen, P.J. and Pearson, T.H. 1986. Use of a sensitive indicator species in the assessment of biological effects of sewage disposal in fjords near Bergen, Norway. Marine Biology 93: 315-322.

Blake, J.A. 1984. Four new species of Spionidae (Polychaeta) from New Zealand, with comments on a syntype of Spio aequalis Ehlers from Chatham Island. Proceedings of the Biological Society of Washington 97(1): 148-159.

Blake, J.A. and Kudenov, J.D. 1978. The Spionidae (Polychaeta) from southeastern Australia and adjacent areas with a revision of the genera. Memoirs of the National Museum of Victoria 39:171-280.

Böggemann, M. and Fiege, D. 2001. Description of seven new species of the genus Glycera Saigny, 1818 (Annelida: Polychaeta: Glyceridae). Ophelia 54(1):29-49. 
Bonsdorff, E. 1989. Infaunal colonization and its dependence on environmental variationexperimental evidence from the northern Baltic Sea. pp 349-356 in Ryland, J. S. and Tyler, P.A.(eds) Reproduction, Genetics and Distributions of Marine Organisms. 23rd European Marine Biology Symposium Conference. University of Wales, Swansea. Olsen\&Olsen.

Booth, J.D. 1975. Seasonal and tidal variations in the hydrology of Wellington Harbour. New Zealand Journal of Marine and Freshwater Research 9(3): 333-354.

Botherway, K.J. and Gardner, J.P.A. 2002. Effect of storm drain discharge on the soft shore ecology of Porirua Inlet, New Zealand. New Zealand Journal of Marine and Freshwater Research 36: 241-255.

Bradford-Grieve, J.M. 1999. New species of benthopelagic copepods of the genus Stephos (Calanoida:Stephidae) from Wellington Harbour, New Zealand. New Zealand Journal of Marine and Freshwater Research 33:13-27.

Bridges, T.S. 1996. Effects of organic additions to sediment, and maternal age and size, on patterns of offspring investment and performance in two opportunistic deposit-feeding polychaetes. Marine Biology 125:345-357.

Brodie, J.W. 1958. A note on tidal circulation in Port Nicholson, New Zealand. New Zealand Journal of Geology and Geophysics 1:684-702.

Bryan, G.W. and Langston, W.J. 1992. Bioavailability, accumulation and effects of heavy metals in sediments with special reference to the United Kingdom estuaries: A review. Environmental Pollution 76: 89-131.

Burton, G.A. and MacPherson, C. 1995. Sediment toxicity testing issues and methods. Pp 70-103 in D. J. Hoffman, Rattner, B.A., Burton, Jr. G.A. Cairns Jr., J., (eds). Handbook of Ecotoxicology. Lewis Publishers.

Chapman, P.M., Paine, M.D., Arthur, A.D. and Taylor, L.A. 1996. A triad study of sediment quality associated with a major, relatively untreated marine sewage discharge. Marine Pollution Bulletin 32(1): 47-64.

Chapman, P.M., Wang, F., Jansse, C., Persoone, G. and Allen, H.E. 1998. Ecotoxicology of metals in aquatic sediment: binding and release, bioavailability, risk assessment and remediation. Canadian Journal of Fisheries and Aquatic Science 55: 2221-2243

Chen, M. and Wu, H. 1995. Copper, Cadmium and Lead in sediments from the Kaohsiung River and its harbour area, Taiwan. Marine Pollution Bulletin 30(12):879-884.

Chesney, E.J. Jr. and Tenore, K.R. 1985. Oscillations of laboratory populations of the polychaete Capitella capitata (Type I): their cause and implications for natural populations. Marine Ecology Progress Series 20:289-296.

Chiaroni, L. 1998. Manipulative field experiment to study the effect of elevated levels of zinc on benthic macrofauna in Tauranga Harbour. M.Sc. Thesis, University of Waikato. 78pp. 
Clarke, K.R. 1990. Comparisons of dominance curves. Journal of Experimental Marine Biology and Ecology 138:143-157.

Clarke, K.R. and Warwick, R.M. 1994. Change in marine communities: an approach to statistical analysis and interpretation. Natural Environment Research Council, UK, 144pp.

Cook, J.M., Gardner, M.J., Griffiths, A.H., Jessep, M.A., Ravenscroft, J.E. and Yates, R. 1997. The comparability of sample digestion techniques for the determination of metals in sediments. Marine Pollution Bulletin 34(8): 637-644.

Cooper, R.D. 1969. The systematics and ecology of the sub-order Gammaridea (Amphipoda). Families Lysianassidae, Phoxoxocephalidae and Haustoriidae obtained from Wellington Harbour. M.Sc. Thesis, Victoria University of Wellington, New Zealand. 164pp.

Dahlbäck, B. and Gunnarsson, L.A..H. 1981. Sedimentation and sulfate reduction under a mussel culture. Marine Biology 63: 269-275.

Dassenakis, M.I., Kloukiniotou, M.A., and Pavlidou, A.S. 1996. The influence of long existing pollution on trace metal levels in a small tidal Mediterranean bay. Marine Pollution Bulletin 32(3): 275-282.

Davis, J.C. 1986. Statistics and Data Analysis in Geology. 2nd Edition. John Wiley, New York.

Dauer, D.M., Luckenbach, N.W. and Rodi (Jr), A.J. 1993. Abundance biomass comparison (ABC method): effects of an estuarine gradient, anoxic/hypoxic events and contaminated sediments. Marine Biology 116: 507-516.

Dauer, D.M. and Alden, R.W. III 1995. Long-term trends in the macrobenthos and water quality of the lower Chesapeake Bay (1985-1991). Marine Pollution Bulletin 30(12): 840850 .

Day, J.H. 1967. A monograph on the Polychaeta of southern Africa. British Museum of Natural History Publication 656. Trustees of the British Museum (Natural History): London. Part 1 Errantia pp 1-458; Part 2, Sedentaria pp 459-878.

Day, J.H. 1977. A review of the Australian and New Zeland Orbiniidae (Annelida: Polychaeta). Pp. 217-246 in Reish, D.J. and Fauchald, K. (eds) Essays on Polychaetous Annelids in Memory of Dr. Olga Hartman. Allan Hancock Press: Los Angeles, 604pp.

Day, J.H. and Hutchings, P.A. 1979. An annotated check-list of Australian and New Zealand Polychaeta, Archiannelida and Myzostomida. Records of the Australian Museum 32 (3): 80161.

DeWitt, T.H., Hickey, C.W., Morrisey, D.J., Nipper, M.G., Roper, D.S., Williamson, R.B., Van Dam, L. and Williams, E.K. 1999. Do amphipods have the same concentration-response to contaminated sediment in situ as in vitro? Environmental Toxicity and Chemistry 18(5):1026-1037. 
Diaz, R.J. and Rosenberg, R. 1995. Marine benthic hypoxia: A review of its ecological effects and the behavioural responses of benthic macrofauna. Oceanography and Marine Biology: an Annual Review 33: 245-303.

Dickinson, W.W., Dunbar, G.B. and McLeod, H. 1996. Heavy metal history from cores in Wellington Harbour, New Zealand. Environmental Geology 27: 59-69.

Dobson, J. 2000. Long term trends in trace metals in biota in the Forth Estuary, Scotland, 1981-1999. Marine Pollution Bulletin 40(12): 1214-1220.

Dodds, F.C. and Vozarik, J.M. 1983. Immediate effects of a storm on coastal infauna. Marine Ecology Progress Series 11:273-279.

Dunbar, G.B. 1994. Seismic and cultural influences on the sedimentary record, Wellington Harbour, New Zealand. Unpublished M.Sc. Thesis. Wellington: Geology Department, Victoria University of Wellington. 155pp.

Eisler, R. 1997. Copper hazards to fish, wildlife, and invertebrates: A synoptic review. U.S. Geological Survey, Biological Resources Division, Biological Science Report USGS/BRD/BSR-1997-0002. 98pp.

Ellis, J.B. 1976. Sediments and water quality of urban stormwater. Water Services 80: 730734.

ESR Ltd, 1997. Analysis of chemical contamination and toxicity of sediments adjacent to the dry dock at the Port of Lyttelton. A report for OCEL Consultants Limited Christchurch, New Zealand. 18pp + appendices.

Estacio, F.J., Garcia-Adiego, E.M., Fa, D.A., Garcia-Gómez, J.C., Daza, J.L., Hortas, F. and Gómez-Ariza, J.L. 1997. Ecological analysis in a polluted area of Algeciras Bay (Southern Spain): External 'versus' Internal outfalls and environmental implications. Marine Pollution Bulletin 34(10): 780-793.

Everaarts, J.M. and Fischer, C.V. 1992. The distribution of heavy metals (Cu, Zn, Cd, Pb) in the fine fraction of surface sediments of the North Sea. Netherlands Journal of Sea Research 29(4): 323-331.

Fauchald, K. 1977. The Polychaete Worms. Definitions and Keys to the Orders, Families and Genera. Natural History Museum of Los Angeles County, Science Series 28: 1-188.

Fenchel, T.M. and Riedl, R.J. 1970. The sulfide system: a new biotic community underneath the oxidised layer of marine sand bottoms. Marine Biology 7: 255-268.

Ferreira, M. F., Chiu, W.S., Cheok, H.K., Cheang, F and Sun, W. 1996. Accumulation of nutrients and heavy metals in surface sediments near Macao. Marine Pollution Bulletin 32(5):420-425

Fletcher, R., Reynoldson, T.B. and Taylor, W.D. 2001. The use of benthic mesocosms for the assessment of sediment contamination. Environmental Pollution 115:173-182. 
Folk, R.L. 1980. Petrology of Sedimentary Rocks. Hemphill Publishing Company. Austin, Texas. 182pp.

Folk, R.L. and Ward, W.C. 1957. Brazos river bar: A study in the significance of grain size parameters. Journal of Sedimentology and Petrology 27(1): 3-26.

Förstner, U. 1987. Sediment-associated contaminants - an overview of scientific bases for developing remedial options. Hydrobiologia 149: 221-246.

Förstner, U and Wittmann, G. 1983. Metal Pollution in the Aquatic Environment. 2nd ed. Springer. Berlin Heidelberg, New York. 486pp.

Fromentin, J.M., Ibanez, F., Dauvin, J.C., Dewarumez, J.M. and Elkaim, B. 1997. Longterm changes of four macrobenthic assemblages from 1978 to 1992. Journal of the Marine Biological Association of the United Kingdom 77: 287-310.

Gardner, J.P.A. and Wear, R.G. in press. Subtidal macro-invertebrate community recovery in Wellington Harbour (New Zealand) after a large-scale natural die-off. Marine Ecology Progress Series.

Gerino, M. 1990. The effect of bioturbation on particle redistribution in Mediterranean coastal sediment. Preliminary results. Hydrobiologia 207:215-258.

Gerringa, L.J.A. and Cambon, J.-P. 1991. The extractability of $\mathrm{Cu}$ from marine sediment as a function of degradation of organic matter. Netherlands Journal of Sea Research 27(2):157163.

Gibbs, R.J. 1993. Metals of the bottom muds in Townsville Harbor, Australia. Environmental Pollution: 297-300.

Glasby, C.J. 1984. A review of Dorvillea and Schistomeringos (Annelida: Polychaeta) chiefly from southern and eastern Australia with a description of a new species of Schistomeringos. Pp 98-111 in Hutchings, P.A. (ed.) Proceedings of the First International Polychaete Conference, Sydney, Australia. Linnean Society of New South Wales: Sydney $483 \mathrm{pp}$.

Glasby, C.J. and Read, G.B. 1998. A chronological review of polychaete taxonomy in New Zealand. Journal of the Royal Society of New Zealand 28(3): 347-374.

Glasby, G.P., Stoffers, P., Walter, P., Davis, K.R. and Renner, R.M. 1988. Heavy-metal pollution in Manukau and Waitemata Harbours, New Zealand. New Zealand Journal of Marine and Freshwater Research 22: 595-611.

Goff, J.R., Dunbar, G.B., and Barrett, P.J. 1998. Monthly to decadal sediment accumulation rates in a semi-enclosed embayment. Journal of Coastal Research 14(2): 461-471.

Grall, J. and Glémarec, M. 1997. Using biotic indices to estimate macrobenthic community perturbations in the Bay of Brest. Estuarine, coastal and Shelf Science (Supplement A) 44: 43-53. 
Grant, A. and Middleton, R. 1990. An assessment of metal contamination of sediments in the Humber Estuary, U.K. Estuarine, Coastal and Shelf Science 31: 71-85.

Grassle, J.F. and Grassle, J.P. 1974. Opportunistic life histories and genetic systems in marine benthic polychaetes. Journal of Marine Research 32: 253-284.

Grassle, J.F. and Grassle, J.P. 1976. Sibling species in the marine pollution indicator Capitella (Polychaeta). Science 192:567-569.

Grassle, J.F. and Grassle, J.P. 1977. Temporal adaptations in sibling species of Capitella. Pp.177-189. in Coull,B.C.(ed.) Ecology of Marine Benthos. University of South Carolina Press.

Gray, J.S. 1974. Animal-sediment relationships. Oceanography and Marine Biology: an Annual Review 12: 223-261.

Gray, J.S. 1979. Pollution-induced changes in populations. Philosophical Transactions of the Royal Society of London (Series B) 286: 545-561.

Gray, J.S. 1980. Why do ecological monitoring? Marine Pollution Bulletin 11:62-65.

Gray, J.S., Aschan, M., Carr, M.R., Clarke, K.R., Green, R.H., Pearson, T.H., Rosenberg, R. and Warwick, R.M. 1988. Analysis of community attributes of the benthic macrofauna of Frierfjord/Langesundfjord and in a mesocosm experiment. Marine Ecology Progress Series 46: 151-165.

Green, R.H. 1979. Sampling design and statistical methods for environmental biologists. John Wiley and Sons, New York, New York, USA.

Haddon, M. and Wear, R.G. 1993. Ecological survey of proposed dredge sites in Wellington Harbour. Coastal Marine Research Unit, Victoria University of Wellington, New Zealand. Report No 22. 90pp.

Halcrow, W., Mackay, D.W. and Thornton, I. 1973. The distribution of trace metals and fauna in the Firth of Clyde in relation to the disposal of sewage sludge. Journal of the Marine Biological Association of the United Kingdom 53:721-739.

Hansen, D.J., Berry, W.J., Mahony, J.D., Boothman, W.S., Di Toro, D.M., Robson, D.L., Ankley, G.T., Ma, D. and Pesch, C.E. 1996. Predicting the toxicity of metal-contaminated field sediments using interstitial concentrations of metals and acid-volatile sulfide normalizations. Environmental Toxicolology and Chemistry 15(12):2080-2094.

Heath, R.A. 1977. Circulation and hydrology of Wellington Harbour. NZOI Oceanographic summary. No 12: $21 \mathrm{pp}$.

Hewitt, J.E., Thrush, S.F., Cummings, V.J. and Pridmore, R.D. 1996. Matching patterns with processes: predicting the effect of size and mobility on the spatial distributions of the bivalves Macomona liliana and Austrovenus stutchburyi. Marine Ecology Progress Series 135:57-67. 
Hewitt, J.E., Legendre, P., McArdle, B.H., Thrush, S.F., Bellehumeur, C. and Lawrie, S.M. 1997. Identifying relationships between adult and juvenile bivalves at different spatial scales. Journal of Experimental Marine Biology and Ecology 216:77-98.

Inglis,G.J. and Kross, J.E. 2000. Evidence for systematic changes in the benthic fauna of tropical estuaries as a result of urbanization. Marine Pollution Bulletin 41(7-12):367-376.

Johnson, D. 1990. Wellington by the Sea: 100 years of work and play. David Bateman Ltd, Auckland, N.Z.

Jones, N.S. 1963. The Marine Fauna of New Zealand: Crustaceans of the Order Cumacea. New Zealand Oceanographic Institute Memoir 23:1-80

Kennedy, P. 1981. Water quality survey of the Wellington Harbour. Part 2. Heavy Metals in Wellington Harbour. Unpublished Report.

Knox, G.A. 1960. The polychaetous annelids of New Zealand. Part I. Glyceridae. Records of the Canterbury Museum 7: 219-231.

Knox, G.A. and Green, K.M. 1972a. The polychaetous annelids of New Zealand. Part 2: Lumbrineridae. Journal of the Royal Society of New Zealand 2(1): 69-81.

Knox, G.A. and Green, K.M. 1972b.The polychaetous annelids of New Zealand. Part 4. Eunicidae. Journal of the Royal Society of New Zealand 2(4): 459-470.

Knox, G.A., Bolton, L.A. and Hackwell, K.1977. Report on the ecology of Parapara Inlet, Golden Bay. Estuarine Research Unit Report No 11. 70pp.

Knox, G.A., Fenwick, G and Bolton, L.A.1978. A preliminary quantitative study of the benthic fauna off Spencerville Pegasus Bay. Estuarine Research Unit Report No 17. 42pp.

Knox, G.A. and Fenwick, G.D. 1981. Zonation of inshore benthos off a sewage outfall in Hawke Bay, New Zealand. New Zealand Journal of Marine and Freshwater Research 15: 417-435.

Kristensen, E. and Blackburn, T.H. 1987. The fate of organic carbon and nitrogen in experimental marine sediment systems: Influence of bioturbation and anoxia. Journal of Marine Research 45:231-257.

Lam, P.K.S. and Gray, J.S. 2001. Predicting effects of toxic chemicals in the marine environment. Marine Pollution Bulletin 42(3):169-173.

Langston, W.J. 1990. Toxic effects of metals and the incidence of metal pollution in marine ecosystems. pp 101-122 in Furness, R.W. and Rainbow, P.S. (eds). Heavy metals in the marine environment. CRC Press, Inc., Boca Raton, Florida. 243 pp.

Lee, R.S. and Pritchard, T.R. 1996. How do long-term patterns affect time-limited environmental monitoring programmes? Marine Pollution Bulletin 33(7-12):260-268.

Lee, C.-L., Fang, M.-D. and Hsieh, M.-T. 1998. Characterization and distribution of metals in surficial sediments in southwestern Taiwan. Marine Pollution Bulletin 36(6): 464-471. 
Legendre, P., Thrush, S.F., Cummings, V.J., Dayton, P.K., Grant, J., Hewitt, J.E., Hines, A.H., McArdle, B.H., Pridmore, R.D., Schneider, D.C., Turner, S.J., Whitlatch, R.B. and Wilkinson, M.R. 1997. Spatial structure of bivalves in a sandflat: Scale and generating processes. Journal of Experimental Marine Biology and Ecology 216:99-128.

Levin, L.A. 1984. Life history and dispersal patterns in a dense infaunal polychaete assemblage: community structure and response to disturbance. Ecology 65(4):1185-1200.

Livingston, R.J. 1987. Field sampling in estuaries: the relationship of scale to variability. Estuaries 10:194-207.

Long, E.R. and Chapman, P.M. 1985. A sediment quality triad: measurements of sediment contamination, toxicity and faunal community composition in Puget Sound. Marine Pollution Bulletin 16:405-420.

Long, E.R., MacDonald, D.D., Smith, S.L. and Calder, F.D. 1995. Incidence of adverse biological effects within ranges of chemical concentrations in marine and estuarine sediments. Environmental Management 19(1): 81-97.

Loring, D.H. 1991. Normalization of heavy-metal data from estuarine and coastal sediments. Journal of Marine Science 48: 101-115.

Lu, L. and Wu, R.S.S. 2000. An experimental study on recolonization and succession of marine macrobenthos in defaunated sediment. Marine Biology 136: 291-302.

Luoma, S.N. 1989. Can we determine the biological availability of sediment-bound trace elements? Hydrobiologia176/177:379-396.

Luoma, S.N. 1990. Processes affecting metal concentrations in estuarine and coastal marine sediments. in Furness, R.W. and Rainbow, P.S. (eds). Heavy Metals in the Marine Environment. CRC Press, Boca Raton, Florida. 243pp.

Mackin, J.E. and Swider, K.T. 1989. Organic matter decomposition pathways and oxygen consumption in coastal marine sediments. Journal of Marine Research 47: 681-716.

Maloney, J. 1996. Influence of organic enrichment on the partitioning and bioavailability of cadmium in a microcosm study. Marine Ecology Progress Series 144:147-161.

Marsden, I.D., Wong, C.H.T. and Al-Mudaffar, N. 2000. Assessment of an estuarine amphipod (Paracorophium excavatum) as a bioindicator of contaminated sediment. Australasian Journal of Ecotoxicology 6:21-30.

Marsden, I.D. and Wong, C.H.T. 2001. Effects of sediment copper on a tube-dwelling estuarine amphipod, Paracorophium excavatum. New Zealand Journal of Marine and Freshwater Research 52:1007-1014.

Maxwell, B.E. 1956. Hydrobiological observations for Wellington Harbour. Transactions of the Royal Society of New Zealand 83: 493-503. 
Melrose, M.J. 1975. The Marine Fauna of New Zealand: Family Hymenosomatidae (Crustacea, Decapoda, Brachyura). New Zealand Oceanographic Institute Memoir 34: 1-111

McKoy, J.L. 1970. Animal-sediment relationships in Wellington Harbour. Bulletin of Natural Sciences, Victoria University of Wellington 1: 5-20.

McLay, C.L. 1988. Brachyura and crab-like Anomura of New Zealand. Leigh Laboratory Bulletin 22. 350pp.

McLusky, D.S., Bryant, V. and Campbell, R. 1986. The effects of temperature and salinity on the toxicity of heavy metals to marine and estuarine invertebrates. Oceanography and Marine Biology: An Annual Review 24:481-520.

Meyer, R.L. 1978. The pollutional load of stormwater runoff. A report submitted in partial fulfillment of the requirements for the degree of Master of Engineering at the University of Canterbury, Christchurch, New Zealand. 92pp.

Monro, C.C.A. 1930. Polychaete worms. Discovery reports 2:1-222.

Monro, C.C.A. 1936. Polychaete worms II. Discovery reports 12:59-198.

Morrisey, D. 1997. The Muck Stops Here. New Zealand Science Monthly March 1997:6-8.

Morrisey, D., Howitt, L., Underwood, A.J. and Stark, J.S. 1992. Spatial variation in softsediment benthos. Marine Ecology Progress Series 81:197-204.

Morrisey, D., Underwood, A.J., Howitt, L. and Stark, J.S. 1992. Temporal variation in softsediment benthos. Journal of Experimental Marine Biology and Ecology 164: 233-245.

Morrisey, D.J., Underwood, A.J. and Howitt, L. 1996. Effects of copper on the faunas of marine soft-sediments: an experimental field study. Marine Biology 125:199-213.

Morrisey, D.J., Williamson, R.B., Van Dam, L. and Lee, D.J. 2000. Stormwater contamination of urban estuaries. 2. Testing a predictive model of the build-up of heavy metals in sediments. Estuaries 23(1):67-79.

Morrisey, D.J., Turner, S.J., Mills, G.N., Williamson, R.B. and Wise, B.E. 2003. Factors affecting the distribution of benthic macrofuana in estuaries contaminated by urban runoff. Marine Environmental Research 55:113-136.

Mortimer, R.J.G. and Rae, J.E. 2000. Metal speciation (Cu, Zn, Pb, Cd) and organic matter in oxic to suboxic salt marsh sediments, Severn Estuary, Southwest Britain. Marine Pollution Bulletin 40(5):377-386.

Mosley, L., Ho, F., Peake, B.M. and Corson, J. 1997. A Characterisation of the runoff in the Kaikorai catchment, Dunedin. Report prepared for the Dunedin City Council, New Zealand. 53pp.

New Zealand Dive and Salvage (NZDS) 1999. video footage: Stormwater pipe structural survey. 
Nichols. F.H. and Thompson, J.K. 1985. Persistence of an introduced mudflat community in south San Francisco Bay, California. Marine Ecology Progress Series 24:83-97.

Nipper, M.G., Roper, D.S., Williams, E.K., Martin, M.L., Van Dam, L.F. and Mills, G.N. 1998. Sediment toxicity and benthic communities in mildly contaminated mudflats. Environmental Toxicology and Chemistry 17(3): 502-510.

O’Connor, T.P., Daskalakis, K.D., Hyland, J.L., Paul, J.F. and Summers, J.K. 1998. Comparisons of sediment toxicity with predictions based on chemical guidelines. Environmental Toxicology and Chemistry 17(3): 468-471.

O'Connor, T.P. and Paul, J.F. 2000. Misfit between sediment toxicity and chemistry. Marine Pollution Bulletin 40(1):59-64.

Otago Regional Council (ORC) 1998. Otago Harbour. An investigation of sediment in the upper harbour basin and Andersons Bay Inlet. Otago Regional Council, Dunedin, New Zealand. 137pp.

Oug, E. 1998. Relating species patterns and environmental variables by canonical ordination: An analysis of soft-bottom macrofauna in the region of Tromsø, Northern Norway. Marine Environmental Research 45(1):29-45.

Palmer, K. 1990. XRF analysis of granitoids and associated rocks St. Johns Range, South Victoria Land, Antarctica. Research School of Earth Science, Geology Board of Studies Publication 5. Victoria University of Wellington, New Zealand. 23pp.

Pandeswara, S.L. and Yallapragada, 2000. Tolerance, accumulation and depuration in an intertidal gastropod, Turbo intercostalis, exposed to cadmium. Marine Environmental Research 50:

Pawson, D.L. 1970. The Marine Fauna of New Zealand: Sea Cucumbers (Echinodermata: Holothuroidea). New Zealand Oceanographic Institute Memoir 52:1-69.

Pearson, T.H. 1982. The Loch Eil Project: Assessment and synthesis with a discussion on certain biological questions arising from a study of the organic pollution of sediments. Journal of Experimental Marine Biology and Ecology 57:93-124.

Pearson, T.H. and Rosenberg, R. 1978. Macrobenthic succession in relation to organic enrichment and pollution of the marine environment. Oceanography and Marine Biology: An Annual Review 16: 229-331.

Pearson, T.H. and Stanley, S.O. 1979. Comparative measurement of the redox potential of marine sediments as a rapid means of assessing the effects of organic pollution. Marine Biology 53:371-379.

Pilotto, P. 1995. Metal Pollution in the Wellington Harbour. Unpublished M.Sc. thesis in Chemistry, Victoria University of Wellington. New Zealand. 102pp.

Pilotto, P.J., Goff, J.R. and Weatherburn, D.C. 1998. A contemporary contamination record of stormdrain and harbour sediments, Wellington, New Zealand. Environmental Geology 36 (1-2): 159-166. 
Pilotto, P.J., Goff, J.R. and Weatherburn, D.C. 1999. Acid leached analyses of stormdrain and harbour sediments, New Zealand. Environmental Geology 37: 145-152.

Pledger, S. 1998. Design and Analysis of experiments. Stat 291 Lecture notes 1998. School of Mathematical and Computing Sciences, Victoria University of Wellington.

Powell, A.W.B. 1979. New Zealand Mollusca. Collins. Auckland. 500pp.

Puig, P., Palanques, A., Sanchez-Cabeza, J.A. and Masqué, P. 1999. Heavy metals in particulate matter and sediments in the southern Barcelona sedimentation system (Northwestern Mediterranean). Marine Chemistry 63: 311-329.

Rainer, S. 1973. Polydora and related genera (Polychaeta:Spionidae) from Otago waters. Journal of the Royal Society of New Zealand 3(4): 545-564.

Raman, A.V. and Ganapati, P.N. 1983. Pollution effects on ecobiology of benthic polychaetes in Visakhapatnam Harbour (Bay of Bengal). Marine Pollution Bulletin 14(2): 46-52.

Read, G. B. 1975. Systematics and biology of polydorid species (Polychaeta: Spionidae) from Wellington Harbour. Journal of the Royal Society of New Zealand 5(4): 395-419.

Read, G.B. 2000. Taxonomy and distribution of a new Cossura species (Annelida: Polychaeta: Cossuridae) from New Zealand. Proceeedings of the Biological Society of Washington 113(4):1096-1110.

Renaud, P.E., Syster, D.A., Ambrose, W.G. Jr. 1999. Recruitment patterns of continental shelf benthos off North Carolina USA: effects of sediment enrichment and impact on community structure. Journal of Experimental Marine Biology and Ecology 237: 89-106.

Rice, W.R. 1989. Analysing tables of statistical tests. Evolution 43(1):223-225.

Roach, A.C., Jones, A.R. and Murray, A. 2001. Using benthic recruitment to assess the significance of contaminated sediments: the influence of taxonomic resolution. Environmental Pollution 112: 131-143.

Roast, S.D., Widdows, J. and Jones, M.B. 2000. Mysids and trace metals: disruption of swimming as a behavioural indicator of environmental contamination. Marine Environmental Research 50:107-112.

Robertson, B., Gillespie, P., Asher, R., Frisk, S., Keeley, N., Hopkins, G., Thompson, S. and Tuckey, B. 2002. Estuarine Environmental Assessment and Monitoring: A National Protocol. Part C: Application of the Estuarine Monitoring Protocol. Prepared for supporting Councils and the Ministry for the Environment, Sustainable Management Fund Contract No. 5096. 40pp plus field sheets.

Roper, D.S. and Hickey, C.W. 1994. Behavioural responses of the marine bivalve Macomona liliana exposed to copper- and chlordane-dosed sediments. Marine Biology 118:673-680. 
Roper, D.S., Nipper, M.G., Hickey, C.W., Martin, M.L. and Weatherhead, M.A. 1995. Burial, crawling and drifting behaviour of the bivalve Macomona liliana in response to common sediment contaminants. Marine Pollution Bulletin 31(4-12): 471-478.

Rosenberg, R. 1995. Benthic marine fauna structured by hydrodynamic processes and food availability. Netherlands Journal of Sea Research 34(4): 303-317.

Roser, B.P. 1983. Comparative studies of copper and manganese mineralisation in the Torlesse, Waipawa and Haast Schist Terranes, New Zealand. Unpublished Ph.D. thesis, Victoria University of Wellington. 491pp.

Rubio, B., Nombela, M. A. and Vilas, F. 2000. Geochemistry of major and trace elements in sediments of the Ria de Vigo (NW Spain): an assessment of metal pollution. Marine Pollution Bulletin 40(11): 968-980

Rule, J.H. and Alden R.W. 1996. Interactions of $\mathrm{Cd}$ and $\mathrm{Cu}$ in anaerobic estuarine sediments. I. Partitioning in geochemical fractions of sediments. Environmental Toxicology and Chemistry 15(4):460-465.

Rygg, B. 1985. Effects of sediment copper on benthic fauna. Marine Ecology Progress Series 25:83-89.

Sanders, H.L. 1958. Benthic studies in Buzzards Bay. I. Animal-sediment relationships. Limnology and Oceanography 3(3): 245-258.

Sanders, H.L. 1960. Benthic studies in Buzzards Bay. III. The structure of the soft-bottom community. Limnology and Oceanography 5:138-153.

Service, M., Mitchell, S.H. and Oliver, W.T. 1996. Heavy metals in the superficial sediments of the N-W Irish Sea. Marine Pollution Bulletin 32(11):828-830.

Simboura, N., Zenetos, A., Panayotidis, P and Makra, A. 1995. Changes in benthic community structure along an environmental pollution gradient. Marine Pollution Bulletin 30(7): 470-474.

Simpson, S.T., Apte, S.C. and Batley, G.E. 1998. Effects of short-term resuspension events on the trace metal speciation in polluted anoxic sediment. Environmental Science and Technology 32: 620-625.

Skei, J., Hylland, K., Schanning, M.T., Berge, J.A., Gunnarsson, J.S. Sköld, M. and Eriksen, D.Ø. 1996. Interactions between eutrophication and contaminants. I. Principles, experimental design and synthesis. Marine Pollution Bulletin 33(1-6):64-70.

Smith, D.G. 1986. Heavy metals in the New Zealand Aquatic Environment: A Review. Water and Soil Miscellaneous Publication 100. 108pp.

Smith, S.L., MacDonald, D.D., Keenleyside, K.A. and Gaudet, C.L. 1996. The development and implementation of Canadian sediment quality guidelines. In Development and progress in sediment quality assessment: rationale, challenges, techniques and strategies. Edited by M. Munawar and G. Dave. Ecovision World Monograph Series, SPB Academic Publishing, Amsterdam, The Netherlands. pp. 233-249. 
Snelder, T. and Williamson, B. 1997. Urban stormwater quality problems recognised Water and Atmosphere. 5 (1): 8-10.

Spencer, H.G. and Willan, R.C. 1995. The marine fauna of New Zealand: Index to the fauna: 3. Mollusca. New Zealand Oceanographic Institute Memoir 105:1-125

Stoffers, P., Glasby, G.P., Wilson, C.J., Davis, K.R. and Walter, P. 1986. Heavy metal pollution in Wellington Harbour. New Zealand Journal of Marine and Freshwater Research 20: 495-512.

Stull, K., Haydock, C.I., Smith, R.W. and Montagne, D.E. 1986. Long-term changes in the benthic community on the coastal shelf of Palos Verdes, Southern California. Marine Biology 91:539-551.

Tessier, A., Campbell, P.G.C., Auclair, J.C. and Bisson, M. 1984. Relationships between the partitioning of trace metals in sediments and their accumulation in the tissues of the freshwater mollusk Elliptio complanata in a mining area. Canadian Journal of Fisheries and Aquatic Science 41:1463-1472.

Theede, H., Ponat, A., Hiroki, K. and Schlieper, C. 1969. Studies on the resistance of marine bottom invertebrates to oxygen-deficiency and hydrogen sulphide. Marine Biology 2:325337.

Thrush, S.F. 1986. Spatial heterogeneity in subtidal gravel generated by the pit-digging activity of Cancer pagurus. Marine Ecology Progress Series 30: 221-227.

Thrush, S.F., 1999. Complex role of predators in structuring soft-sediment macrobenthic communities: Implications of changes in spatial scale for experimental studies. Australian Journal of Ecology 24:344-354.

Thrush, S.F. and Roper, D.S. 1988. Merits of macrofaunal colonization of intertidal mudflats for pollution monitoring: preliminary study. Journal of Experimental Marine Biology and Ecology 116:219-233.

Thrush, S.F., Hewitt, J.E. and Pridmore, R.D. 1989. Patterns in the spatial arrangements of polychaetes and bivalves in intertidal sandflats. Marine Biology 102:529-535.

Thrush, S.F., Pridmore, R.D., Hewitt, J.E. and Cummings, V.J. 1991. Impact of ray feeding on sandflat macrobenthos: Do communities dominated by polychaetes or shellfish respond differently? Marine Ecology Progress Series 69:245-252.

Timperley, M. and Kuschel, G. 2000. What's in the Water? New Zealand Science Monthly. March 2000:6-8.

Tsutsumi, H. 1987. Population dynamics of Capitella capitata (Polychaeta: Capitellidae) in an organically polluted cove. Marine Ecology Progress Series 36:139-149.

Tsutsumi, H. 1990. Population persistence of Capitella sp. (Polychaeta: Capitellidae) on a mud flat subject to environmental disturbance by organic enrichment. Marine Ecology Progress Series 63:147-156. 
Tsutsumi, H. and Kikuchi, T. 1984. Study of the life history of Capitella capitata (Polychaeta: Capitellidae) in Amakusa, South Japan including a comparison with other geographic regions. Marine Biology 80:315-321.

Timperley, M. and Kuschel. G. 2000. What's in the Water? New Zealand Science Monthly March 2000:6-8.

Underwood, A.J. 1981. Techniques of analysis of variance in experimental marine biology and ecology. Oceanography and Marine Biology: An Annual Review 19:513-605.

Underwood, A.J. 1992. Beyond BACI: the detection of environmental impact on populations in the real, but variable world. Journal of Experimental Marine Biology and Ecology 161:145-178.

Underwood, A.J. 1993. The mechanics of spatially replicates sampling programs to detect environmental impacts in a variable world. Australian Journal of Ecology (18):99-116.

van der Linden, W.J.M. 1967. A textural analysis of Wellington Harbour sediments. New Zealand Journal of Marine and Freshwater Research 1:26-37

Van Duyl, F.C., Kop, A.J., Kok, A. and Sandee, A.J.J. 1992. The impact of organic matter and macrozoobenthos on bacterial and oxygen variables in marine sediment boxcosms. Netherlands Journal of Sea Research 29(4):343-355.

Vincent, V.C. and Thomas, M.P. 1997. Urban runoff pollution: An overview. Journal of Environmental Education and Information 16(2):185-196

Ward, N.I., Brooks, R.R., Roberts, E. and Boswell, C.R. 1977. Heavy metal pollution from automotive emissions and its effects on roadside soils and pasture spaces in New Zealand. Environmental Science and Technology 11(9): 917.

Ward, T.J. and Hutchings, P.A. 1996. Effects of trace metals on infaunal species composition in polluted intertidal and subtidal marine sediments near a lead smelter, Spencer Gulf, South Australia. Marine Ecology Progress Series 135:123-135.

Warren, L.M. 1977. The Ecology of Capitella capitata in British waters. Journal of the Marine Biological Association of the U.K. 57: 51-159.

Warwick, R.M. 1993. Environmental impact studies on marine communities: pragmatical considerations. Australian Journal of Ecology 18:63-80.

Warwick, R.M. 2001. Evidence for the effects of metal contamination on the intertidal macrobenthic assemblages of the Fal Estuary. Marine Pollution Bulletin 42(2): 145-148.

Warwick, R.M., Platt, H.M., Clarke, K.R., Agard, J. and Gobin, J. 1990. Analysis of macrobenthic and meiobenthic community structure in relation to pollution and disturbance in Hamilton Harbour, Bermuda. Journal of Experimental Marine Biology and Ecology 138:119-142. 
Warwick R.M. and Clarke, K.R. 1994. Relearning the ABC: taxonomic changes and abundance/biomass relationships in disturbed benthic communities. Marine Biology 118: 739-744.

Watzin, M.C. and Roscigno, P.R. 1997. The effects of zinc contamination on the recruitment and early survival of benthic invertebrates in an estuary. Marine Pollution Bulletin 34(6):443-455.

Wear, R.G. and Anderlini, V.C. 1995. Ecological survey of proposed and previous sediment relocation sites in Wellington Harbour. Victoria University of Wellington. Coastal Marine Research Unit. Report No 26. 25pp.

Wear, R.G. and Gardner, J.P.A. 2001. Biological effects of the toxic algal bloom of February and March 1998 on the benthos of Wellington Harbour, New Zealand. Marine Ecology Progress Series 218:63-76.

Westerlund, S.F.G., Anderson, L.G., Hall, P.O.J., Iverfeldt, A., Rutgers, M.M., van der Loeff, R. and Sundby, B. 1986. Benthic fluxes of copper, nickel, zinc and lead in the coastal environment. Geochimica et Cosmochimica Acta 50:1289-1296

Weston, D.P. 1990. Quantitative examination of macrobenthic community changes along an organic enrichment gradient. Marine Ecology Progress Series 61:233-244.

Whitlatch, R.B. 1977. Seasonal changes in the community structure of the macrobenthos inhabiting the intertidal sand and mud flats of Barnstable Harbor, Massachusetts. Biological Bulletin 152:275-294.

Whitlatch, R.B., Hines, A.H., Thrush, S.F., Hewitt, J.E. and Cummings, V. 1997. Benthic faunal responses to variations in patch density and patch size of a suspension-feeding bivalve. Journal of Experimental Marine Biology and Ecology 216:171-189.

Williams, T.M., Rees, J.G., Ferguson, A., Herd, R.A., Kairu, K.K. and Yobe, A.C. 1997. Metals, petroleum hydrocarbons and organochlorines in inshore sediments and waters of Mombasa, Kenya. Marine Pollution Bulletin 34(7): 570-577.

Williams, M.R., Millward, G.E., Nimmo, M., and Fones, G. 1998. Fluxes of Cu, Pb and Mn to the North-Eastern Irish Sea: the importance of sedimental and atmospheric inputs. Marine Pollution Bulletin 36(5): 366-375.

Williamson, R.B. 1986. Urban stormwater quality II. Comparison of three New Zealand catchments. New Zealand Journal of Marine and Freshwater Research 20:315-328.

Williamson, R.B. 1993. Urban runoff data book. Water Quality Centre Publication No. 20. National Institute of Water and Atmospheric Research Ltd., Hamilton, New Zealand. 51pp.

Williamson, R.B., Mol-Krijnen, J., and Van Dam, L. 1995. Trace metal partitioning in bioturbated, contaminated, surficial sediments from Mangere Inlet, New Zealand. New Zealand Journal of Marine and Freshwater Research 29:117-130. 
Williamson, R.B., Van Dam, L.F., Bell, R.G., Green M.O. and Kim, J.P. 1996. Heavy metal and suspended sediment fluxes from a contaminated, intertidal inlet (Manukau Harbour, New Zealand). Marine Pollution Bulletin 32(11): 812-822.

Williamson, R.B. and Morrisey, D.J. 2000. Stormwater contamination of urban estuaries. 1. Predicting the build-up of heavy metals in sediments. Estuaries 23(1):56-66.

Wright, I.C. and Glasby, G.P. 1992. Sediments and sediment quality of proposed dredge sites at Aotea-Thorndon and Overseas Passenger Terminal Wharves, Wellington Harbour, Wellington. NZOI report for Truebridge, Callender and Beach, Wellington, New Zealand. 40pp.

Zago, C., Giblin, A.E. and Bergamasco, A. 2001. Changes in the metal content of surficial sediments of Boston Harbour since the cessation of sludge discharge. Marine Environmental Research 51:389-415

Zajac, R.N., Whitlatch, R.B. 1991. Demographic aspects of marine, soft sediment patch dynamics. American Zoologist 31:808-820.

Zajac, R.N., Whitlatch, R.B. and Thrush, S.F. 1998. Recolonization and succession in softsediment infaunal communities: the spatial scale of controlling factors. Hydrobiologia 375/376:227-240.

www.marlin.ac.uk

www.museum.vic.gov.au/poly/capitems.html. 